\title{
Investigation of Combustion Characteristics of a Heavy-Duty Diesel Engine Retrofitted to Natural Gas Spark Ignition Operation
}

Jinlong Liu

West Virginia University, jlliu@mix.wvu.edu

Follow this and additional works at: https://researchrepository.wvu.edu/etd

Part of the Automotive Engineering Commons, Chemical Engineering Commons, Energy Systems

Commons, and the Heat Transfer, Combustion Commons

\section{Recommended Citation}

Liu, Jinlong, "Investigation of Combustion Characteristics of a Heavy-Duty Diesel Engine Retrofitted to Natural Gas Spark Ignition Operation" (2018). Graduate Theses, Dissertations, and Problem Reports.

3713.

https://researchrepository.wvu.edu/etd/3713

This Dissertation is protected by copyright and/or related rights. It has been brought to you by the The Research Repository @ WVU with permission from the rights-holder(s). You are free to use this Dissertation in any way that is permitted by the copyright and related rights legislation that applies to your use. For other uses you must obtain permission from the rights-holder(s) directly, unless additional rights are indicated by a Creative Commons license in the record and/ or on the work itself. This Dissertation has been accepted for inclusion in WVU Graduate Theses, Dissertations, and Problem Reports collection by an authorized administrator of The Research Repository @ WVU.

For more information, please contact researchrepository@mail.wvu.edu. 


\title{
Investigation of Combustion Characteristics of a Heavy-Duty Diesel Engine Retrofitted to Natural Gas Spark Ignition Operation
}

\author{
Jinlong Liu \\ Dissertation submitted to the \\ Benjamin M. Statler College of Engineering and Mineral Resources \\ at West Virginia University \\ in partial fulfillment of the requirements for the degree of
}

Doctor of Philosophy

in

Mechanical Engineering

Cosmin E. Dumitrescu, Ph.D., Chair

Nigel N. Clark, Ph.D.

Hailin Li, Ph.D.

V'yacheslav Akkerman, Ph.D.

Guodong Guo, Ph.D.

Department of Mechanical and Aerospace Engineering

Morgantown, West Virginia

2018

Keywords: Natural gas; Compression ignition engine; Spark ignition operation; Piston shape effects; Bowl-in-piston combustion chamber.

Copyright 2018 Jinlong Liu 


\title{
Abstract \\ Investigation of Combustion Characteristics of a Heavy-Duty Diesel Engine Retrofitted to Natural Gas Spark Ignition
}

\author{
Jinlong Liu
}

The conversion of existing diesel engines to natural-gas spark ignition operation by adding a gas injector in the intake manifold for fuel delivery and replacing the diesel fuel injector with a spark plug to initiate and control the combustion process can reduce U.S. dependence on petroleum imports and curtail engine-out emissions. As the conventional diesel combustion chamber (i.e., flat head and bowl-in-piston) creates high turbulence, the engine can operate leaner, which would increase its efficiency and reduce emissions. However, natural gas combustion in such retrofitted engines presents differences compared to that in conventional spark ignited engines. Subsequently, the main goal of this study was to investigate the characteristics of natural gas combustion inside a diesel-like, fast-burn combustion chamber using a unique array of experimental and numerical tools. The experimental platform consisted of a heavy-duty single-cylinder diesel engine converted to natural-gas spark ignition and operated at a low-speed, lean equivalence ratio, and medium-load condition. The engine can also operate in an optical configuration (i.e., the stock piston and cylinder block can be replaced with a see-through piston and an extended cylinder block), which was used to visualize flame behavior. The optical data indicated a thick and fast-propagated flame in the piston bowl but slower flame propagation inside the 
squish region. In addition, a 3D numerical model of the optical engine was built to better explain the geometry effects. The simulation results suggested that while the region around the spark plug location experienced a moderate turbulence that helped with the ignition process, the interaction of squish, piston motion, and intake swirl created a highly-turbulent environment that favored the fast burn inside the bowl and stabilized the combustion process. However, the squish region experienced a much lower turbulence, which, combined with the reduced temperature and pressure during the expansion stroke and its higher surface-to-volume ratio, reduced the burning velocity and the flame propagation, but also avoided knocking. Consequently, the bowl-in-piston geometry separated the leanburn natural gas combustion into two distinct events. To extend the optical findings, the metal engine configuration was used to investigate the effects of gas composition, spark timing, equivalence ratio, and engine speed on the two-stage combustion. The results suggested that operating conditions controlled the magnitude and phasing of the two combustion events. Moreover, 3D CFD simulations of the metal engine configuration showed that the squish region contained an important mixture fraction that would burn much slower and can increase the phasing separation between the two combustion events to a point that a second peak would appear in the heat release rate. Moreover, the rapidburn event in such an engine was much shorter compared to its traditional definition (i.e., the time in crank angle degrees between the $10 \%$ and $90 \%$ energy-release fractions). A better solution was to use the inflection points in the apparent heat release to locate the fast burning stage. Specifically, the second inflection point of heat release rate can be regarded 
as the end of the fast inside-the-bowl burning. Furthermore, the operating conditions controlled the fuel fraction that burned in the squish region before the fuel inside the bowl completely burned, hence the phasing of the late combustion stage. This suggests that squish added to the combustion complexities of such retrofitted engines and that the combustion strategy should optimize the mass of fuel that burns inside the squish region. In addition, the results indicated that the coefficient of variation and standard deviation of peak cylinder pressure are better metrics to evaluate the cycle-to-cycle variations than variations in the indicated mean effective pressure because they were less affected by the combustion event inside the squish region. Overall, the reliable ignition, stable combustion, and the lack of knocking in this 13.3 compression-ratio diesel chamber showed promise for heavy-duty compression ignition engines converted to spark ignition natural gas operation under lean conditions, which would accelerate the introduction of heavy-duty natural gas vehicles in the U.S.A. 


\section{Acknowledgement}

The path towards completing this dissertation was strenuous but full of satisfactions.

This journey would have not been possible without the support from my parents (Mr. Lianqi Liu and Mrs. Guirong $\mathrm{Xu}$ ) during my whole life. There are not enough words to express my gratitude towards my parents.

Next, I want to thank my advisor, Dr. Cosmin Dumitrescu. I was Dr. Dumitrescu's first $\mathrm{PhD}$ student, which made our relationship special. In addition to helping me become proficient in experimental and numerical work related to internal combustion engines, he taught me how to be a good person, a good colleague, and a valuable researcher. He did everything to ensure that my time at WVU was one of the best parts in my life. He was always available to discuss both personal and professional issues and treated me as a part of his family.

I want to thank my committee members, Drs. Nigel Clark, Hailin Li, V'yacheslav Akkerman, and Guodong Guo. The suggestions I received were extremely valuable. Dr. Clark is famous in the IC-engine field and a founder of WVU's Center for Alternative Fuels Engines and Emissions (CAFEE), one of the top automotive laboratories in the world. In addition to professional help, Dr. Li helped me to start my life in USA as an international student. In addition to learning a lot about combustion fundamentals from Dr. Akkerman, 
he helped me to attend Princeton-Combustion Institute Summer School, which provided combustion trainings at the highest level from famous researchers worldwide. Dr. Guo taught me how to better analyze combustion images from optical measurement or how to better post-process images from CFD simulation.

I gratefully acknowledge all the people from CAFEE, CIGRU, MAE department and the university who helped our team during experiments: Mr. Daniel Carder, Dr. Ross Ryskamp, Mr. Zack Luzader, Mr. Bradley Ralston, Mr. Adam Phillips, Mr. Kelsey Crawford, Mr. Dylan Connelly, Mr. Jason England, and Mr. Richard Atkinson. Mr. Phil Korpeck taught me MIG and TIG welding, how to operate a bandsaw, a metal lathe, a grinder, and other pieces-off equipment. I also want to thank Mr. Rasik Pondicherry, Mr. Hemanth Bommisetty, Mr. Vishnu Padmanaban, Mr. Rahul Kooragayala, Mr. Ali Can Sivri, Ms. Sarah Ann Mills and Ms. Iolanda Stocchi for assisting me in performing experiments or in setting up the engine lab. Dr. Andrew Nix, Dr. Marc C. Besch, Dr. Arvind Thiruvengadam, Dr. Greg Thompson, Dr. Derek Johnson, Dr. Scott W. Wayne, Dr. Mridul Gautam, and Dr. Nigel N. Clark also provided valuable suggestions on how to design an engine laboratory. But the most I learned on how to build an engine lab came from Dr. Dumitrescu, including how to design the intake, exhaust, cooling and lubrication systems, engine control and data acquisition, combustion and emission test, optical measurements, dyno control and safety design, etc. 
I also wish to thank the people that helped me on my journey from a CFD rookie to a more experienced one: Dr. Albio Gutierrez, former PostDoc at CAFEE, who taught me how to build a diesel engine model simulation in ANSYS/Fluent; Mr. William Kuykendall, a former expert working at ANSYS, who shared with me a lot of CFD "secrets" that were extremely valuable in building and calibrating the CFD models; Mr. Bruce Crawford, a WVU alumnus now at ANSYS, who taught me how to use CFD-Post in analyzing the results from ANSYS/Forte and how the parallel computing works; Mr. Nathan Gregg and Dr. Guillermo Avendaño-Franco from WVU High Performance Computing team, who taught me how to run engine simulations in Linux and in the cluster; Dr. James P. Szybist from Oak Ridge National Laboratory, who provided me with the opportunity to simulate GDI engines; Dr. Chitral Naik, ANSYS lead software developer, and K. Dean Edwards from Oak Ridge National Laboratory, who helped me understand the limitations of the combustion sub-models; Dr. Michele Battistoni and Dr. Carlo Nazareno Grimaldi from University of Perugia, who taught me the grid-size trade-off effects; Dr. Rolf D. Reitz from University of Wisconsin-Madison, who taught me about the effects of simplified engine geometry, sub-model transitions, rules in setting initial and boundary conditions, etc. The most important of all, Dr. Dumitrescu always challenged me to better understand the how CFD simulations work such as mesh refinement, simulation time step compared to chemical reaction time, assumption of chemical reactions, and CFD limitations.

I want to thank all my friends at WVU that made my life in Morgantown, WV so special. 
However, I am not mentioning their names for security reasons.

This material is based upon work funded by ORAU's Ralph E. Powe Junior Faculty Enhancement Award under grant number Ck \# 43006, WVU Energy Institute's O’Brien Energy Research Fund Round One under grant number Foundation 2R393 RC, and WV Higher Education Policy Commission under grant number HEPC.dsr.18.7. WVU and WV Higher Education Policy Commission Award \#1007604R also financially supported this work. The research was conducted at the WVU's Advanced Combustion Laboratory in Morgantown, WV, supported by WVU's CIGRU, CAFEE, and MAE department. The simulations were performed on the Super Computing System (Mountaineer) at WVU, which is funded in part by the National Science Foundation EPSCoR Research Infrastructure Improvement Cooperative Agreement \#1003907, the state of West Virginia (WVEPSCoR via the Higher Education Policy Commission) and WVU.

Finally, I am extremely proud about my Ph.D. degree from West Virginia University, a flagship R1 Doctoral University in the USA. I am proud to be a part of the automotive research done in WVU's College of Engineering, one of top engineering schools in the world. Moreover, I am proud to be an alumnus of the Mechanical and Aerospace Engineering department, one of the top engineering programs in the USA. 


\section{Table of Contents}

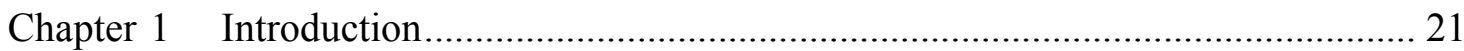

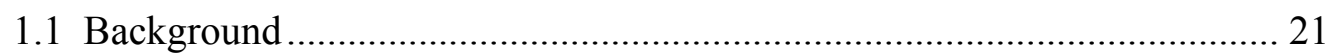

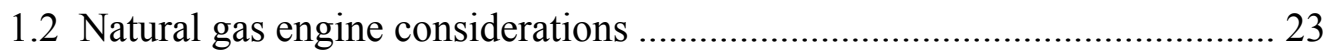

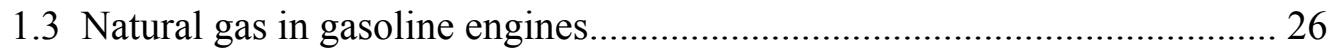

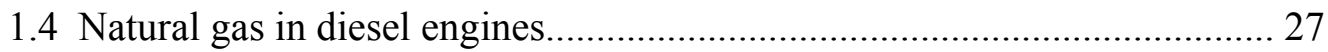

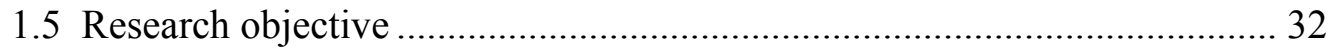

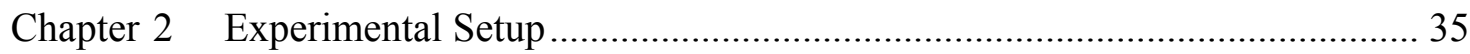

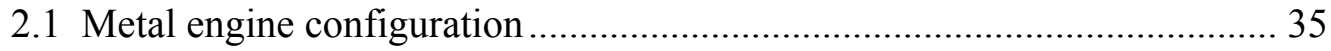

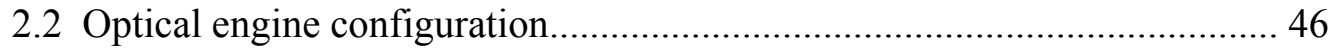

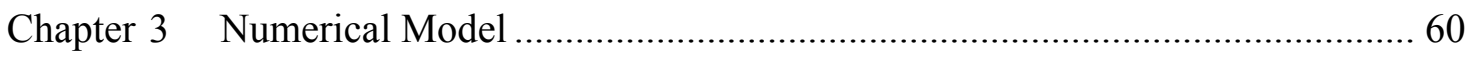

3.1 3D CFD model for the metal engine configuration .................................. 60

3.2 3D CFD model for the optical engine configuration ................................ 71

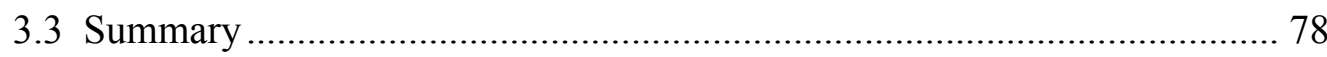

Chapter 4 Characteristics of Natural Gas Spark Ignition Combustion inside a Bowl-in-

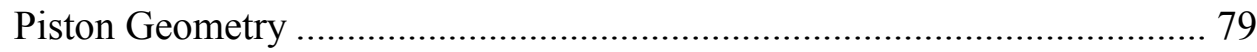

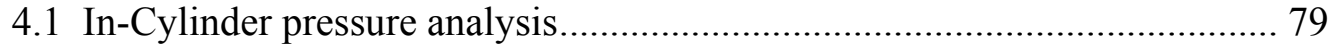

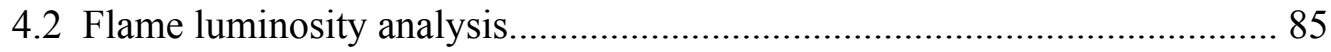

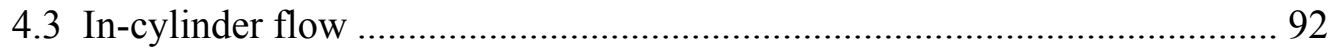

4.4 Local and time separation of the combustion process .............................. 98

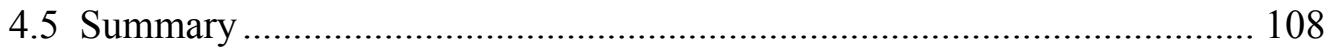

Chapter 5 Operating Condition Effects ........................................................... 110

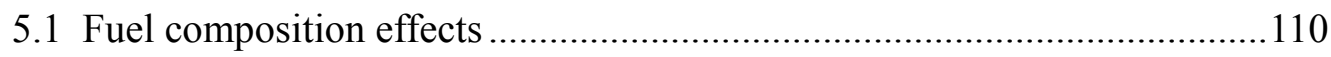

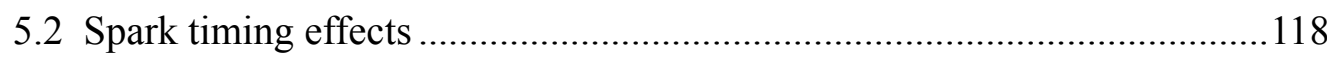




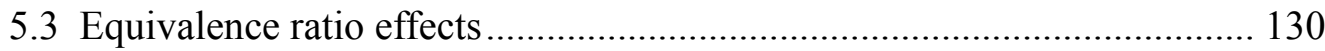

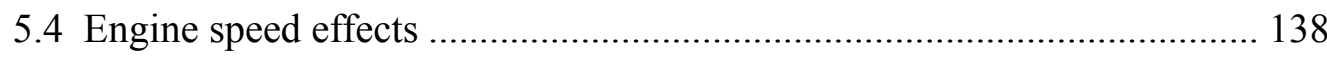

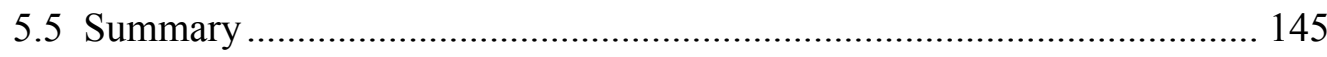

Chapter 6 Characterization of Energy Released Throughout the Combustion Period ..... 148

6.1 The separation of the combustion phenomena....................................... 148

6.2 Fuel composition effects on combustion stages..................................... 156

6.3 Spark timing effects on combustion stages........................................... 159

6.4 Equivalence ratio effects on combustion stages ................................... 164

6.5 Engine speed effects on combustion stages ......................................... 169

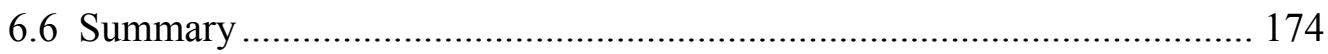

Chapter 7 Effect of Diesel Geometry on Cycle-to-Cycle Variation ............................ 176

7.1 Sources of cycle-to-cycle variation......................................................... 176

7.2 Effect of operating condition on cycle-to-cycle variation ....................... 189

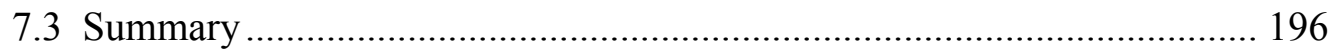

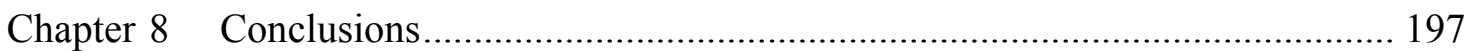

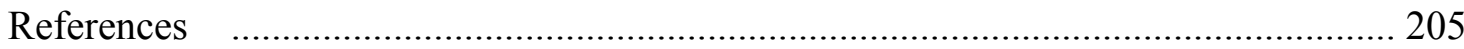




\section{List of Figures}

Figure 1.1 Rate of heat release of a typical diesel engine retrofitted to natural gas spark ignition operation plotted as the superposition of two bell-shaped curves that describe the inside- and outside-the-bowl combustion 31

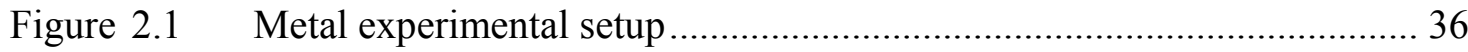

Figure 2.2 Combustion chamber in the metal engine configuration ......................... 38

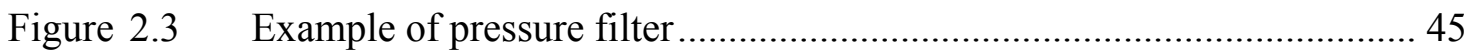

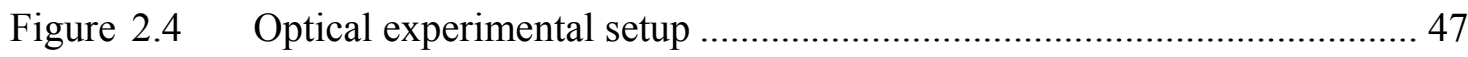

Figure 2.5 Combustion chamber in the optical engine configuration ...................... 47

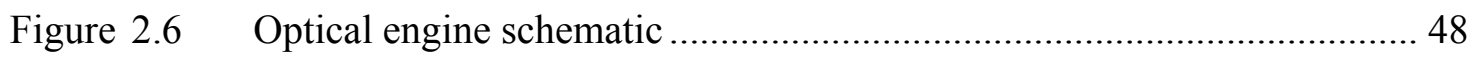

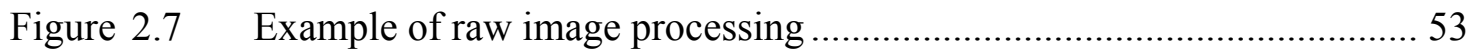

Figure 2.8 Comparison of detected flame with different threshold in image processing 55

Figure 2.9 The approach of calculating the flame images for average cycle based on individual cycles ............................................................................... 56

Figure 3.1 Nomenclature of the metal engine combustion chamber and its corresponding computational grid ..................................................... 61

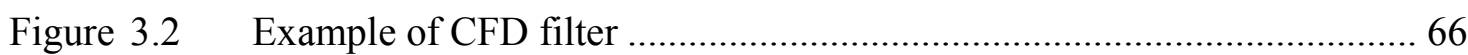

Figure 3.3 Experimental versus metal engine model simulated in-cylinder pressure and heat release rate. 68

Figure 3.4 Nomenclature of the optical engine combustion chamber and its corresponding computational grid ..................................................... 72

Figure 3.5 Experimental versus optical engine model simulated in-cylinder pressure

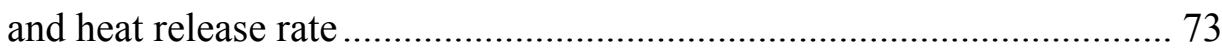

Figure 3.6 Experimental versus optical engine model simulated in-cylinder radial flame information 74 
Figure 3.7 Comparison of in-cylinder radial flame development ........................... 75

Figure $3.8 \quad$ Flame contour analysis in piston bowl from bottom view...................... 77

Figure 4.1 Pressure-based analysis for metal and optical engines at baseline condition 80

Figure 4.2 Apparent rate of heat release of several individual engine cycles for metal and optical engines at baseline condition 82

Figure 4.3 Engine performance for metal and optical engines at baseline condition ....

Figure 4.4 Combustion phasing for metal and optical engines at baseline condition....

Figure 4.5 Cycle-averaged flame luminosity from the spark until the end of

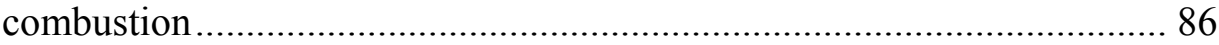

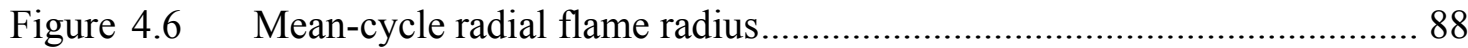

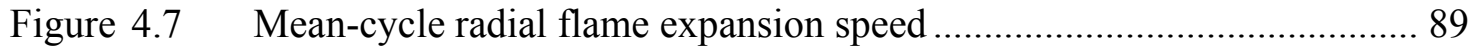

Figure 4.8 Flame intensity throughout the combustion process for the mean cycle.. 91

Figure $4.9 \quad$ Spatially-averaged in-cylinder turbulence ......................................... 92

Figure 4.10 Spatially-resolved in-cylinder gas motion during compression and expansion strokes ......................................................................... 94

Figure 4.11 Enlarged spatially-resolved in-cylinder gas motion during motoring cycle at several CAD of interest..................................................................... 95

Figure 4.12 Spatially-resolved turbulent kinetic energy at several CAD of interest ... 96

Figure 4.13 Spatially-averaged flame information for metal and optical engines ....... 98

Figure 4.14 Spatially-distributed turbulent flame speed at the flame front at several CAD of interest for metal and optical engines. 99

Figure 4.15 Spatially-distributed in-cylinder temperature at several CAD of interest for metal and optical engines 102

Figure 4.16 Spatially-distributed fuel mass fraction at several CAD of interest for metal 
and optical engines 103

Figure 4.17 Spatially-distributed chemical heat release rate at several CAD of interest for metal and optical engines 105

Figure 4.18 Flame propagation contour viewed from the piston bottom and side..... 106

Figure 5.1 Effect of NG composition on pressure-based analysis .111

Figure 5.2 Effect of NG composition on the apparent rate of heat release of individual engine cycles .112

Figure 5.3 Effect of NG composition on the engine performance 113

Figure 5.4 Effect of NG composition on the combustion phasing .114

Figure 5.5 Effect of NG composition on spatially-averaged flame information. 116

Figure 5.6 Effect of NG composition on spatially-distributed chemical heat release rate at several CAD of interest after SOC.

Figure 5.7 Effect of spark timing on pressure-based analysis .118

Figure 5.8 Effect of spark timing on the apparent rate of heat release of individual engine cycles 120

Figure 5.9 Effect of spark timing on the engine performance. 121

Figure 5.10 Effect of spark timing on the combustion phasing 123

Figure 5.11 Effect of spark timing on the CFD predicted mass fraction burned ....... 124

Figure 5.12 Effect of spark timing on the spatially-averaged flame information ...... 125

Figure 5.13 Effect of spark timing on the distribution of turbulent flame speed at the flame front at several CAD of interest after SOC. 126

Figure 5.14 Effect of spark timing on spatially-distributed chemical heat release rate at several CAD of interest after SOC

Figure 5.15 Effect of equivalence ratio on pressure-based analysis 131

Figure 5.16 Effect of equivalence ratio on the apparent rate of heat release of individual engine cycles 132 
Figure 5.17 Effect of equivalence ratio on the engine performance

Figure 5.18 Effect of equivalence ratio on the combustion phasing. 134

Figure 5.19 Effect of equivalence ratio on spatially-averaged flame information. 135

Figure 5.20 Effect of equivalence ratio on spatially-distributed chemical heat release rate at several CAD of interest after SOC. 136

Figure 5.21 Effect of engine speed on pressure-based analysis 139

Figure 5.22 Effect of engine speed on the apparent rate of heat release of individual engine cycles 140

Figure 5.23 Effect of engine speed on the engine performance 141

Figure 5.24 Effect of engine speed on the combustion phasing. 142

Figure 5.25 Effect of engine speed on spatially-averaged flame information 143

Figure 5.26 Effect of engine speed on spatially-distributed chemical heat release rate at several CAD of interest after SOC. 144

Figure 6.1 Rapid-burning period characterized by the duration between CA10 and CA90 on the rate of heat release and mass fraction burned for both metal and optical engines at baseline condition 149

Figure 6.2 CAD simulation predicted flame front location at CA10 and CA90 for both metal and optical engines at baseline condition 150

Figure 6.3 Rapid-burning period characterized by the duration between ROHR inflection points on the rate of heat release and mass fraction burned for both metal and optical engines at baseline condition 151

Figure 6.4 CAD simulation predicted flame front location at ROHR inflection points for both metal and optical engines at baseline condition 152

Figure 6.5 Burning duration, mass fraction burned, and average burning rate of early flame development, fast-burn, late-burn, and inside-the-bowl burn stages, for both metal and optical engines at baseline condition 154

Figure 6.6 Rapid-burning period characterized by the duration between CA10 and CA90 on the rate of heat release and mass fraction burned for different gas 
Figure 6.7 Rapid-burning period characterized by the duration between ROHR inflection points on the rate of heat release and mass fraction burned for different gas composition operations 157

Figure 6.8 CAD simulation predicted flame front location at ROHR inflection points for different gas composition operations

Figure 6.9 Burning duration, mass fraction burned, and average burning rate of early flame development, fast-burn, late-burn, and inside-the-bowl burn stages, for different gas composition operations 158

Figure 6.10 Rapid-burning period characterized by the duration between CA10 and CA90 on the rate of heat release and mass fraction burned for different spark timing operations 160

Figure 6.11 Rapid-burning period characterized by the duration between ROHR inflection points on the rate of heat release and mass fraction burned for different spark timing operations 161

Figure 6.12 CAD simulation predicted flame front location at ROHR inflection points for different spark timing operations 162

Figure 6.13 Burning duration, mass fraction burned, and average burning rate of early flame development, fast-burn, late-burn, and inside-the-bowl burn stages, for different spark timing operations. 163

Figure 6.14 Rapid-burning period characterized by the duration between CA10 and CA90 on the rate of heat release and mass fraction burned for different equivalence ratio operations 165

Figure 6.15 Rapid-burning period characterized by the duration between ROHR inflection points on the rate of heat release and mass fraction burned for different equivalence ratio operations 166

Figure 6.16 CAD simulation predicted flame front location at ROHR inflection points for different equivalence ratio operations 167

Figure 6.17 Burning duration, mass fraction burned, and average burning rate of early flame development, fast-burn, late-burn, and inside-the-bowl burn stages, 
Figure 6.18 Rapid-burning period characterized by the duration between CA10 and CA90 on the rate of heat release and mass fraction burned for different engine speed operations 170

Figure 6.19 Rapid-burning period characterized by the duration between ROHR inflection points on the rate of heat release and mass fraction burned for different engine speed operations 171

Figure 6.20 CAD simulation predicted flame front location at ROHR inflection points for different engine speed operations 172

Figure 6.21 Burning duration, mass fraction burned, and average burning rate of early flame development, fast-burn, late-burn, and inside-the-bowl burn stages, for different engine speed operations 173

Figure 7.1 Pressure-based data from optical engine experiments at baseline condition 177

Figure 7.2 Spark intensity and arc location variations during spark inception period 178

Figure 7.3 Flame propagation variations during fast burning period 181

Figure 7.4 Flame development variations during flame development in piston bowl 182

Figure 7.5 Late combustion and oxidation variations during late combusting period 183

Figure 7.6 Radial flame front propagation contours in piston bowl for selected individual and average cycles 184

Figure 7.7 Radial flame development based on the equivalent flame radius in piston bowl for selected individual and average cycles. 186

Figure 7.8 Flame center displacement for selected individual and average cycles.. 187

Figure 7.9 Effect of gas composition on cycle-to-cycle variation.......................... 190

Figure 7.10 Effect of spark timing on cycle-to-cycle variation 191 
Figure 7.11 Effect of equivalence ratio on cycle-to-cycle variation ........................ 193

Figure 7.12 Effect of engine speed on cycle-to-cycle variation ............................... 194 


\section{List of Tables}

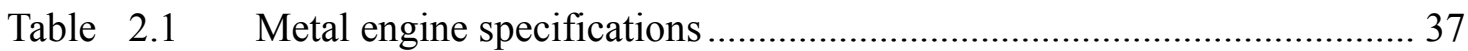

Table 2.2 Composition and selected properties of test gases .................................. 43

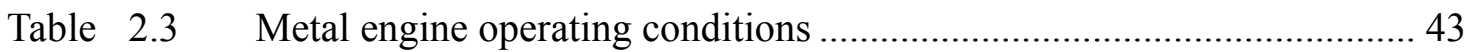

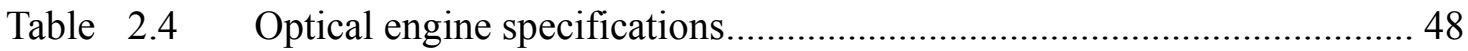

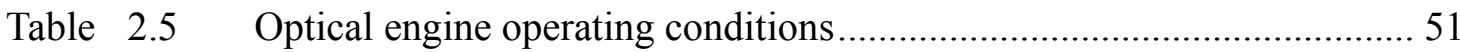




\section{Nomenclature}

\begin{tabular}{|c|c|}
\hline$\phi$ & Equivalence Ratio \\
\hline $2 \mathrm{D}$ & Two Dimensional \\
\hline $3 \mathrm{D}$ & Three Dimensional \\
\hline ATDC & After Top Dead Center \\
\hline BTDC & Before Top Dead Center \\
\hline CAx & CAD Corresponding to $\mathrm{x} \%$ Mass Fraction Burned \\
\hline CAD & Crank Angle Degree \\
\hline $\mathrm{CCV}$ & Cycle-to-Cycle Variation \\
\hline CFD & Computational Fluid Dynamics \\
\hline CMOS & Complementary Metal Oxide Semiconductor \\
\hline $\mathrm{COV}$ & Coefficient of Variation \\
\hline CR & Compression Ratio \\
\hline DOC & Combustion Duration \\
\hline EOC & End of Combustion \\
\hline FL & Flame Luminosity \\
\hline $\mathrm{IC}$ & Internal Combustion \\
\hline IMEP & Indicated Mean Effective Pressure \\
\hline LPP & Location of Peak Cylinder Pressure \\
\hline MFB & Mass Fraction Burned \\
\hline $\mathrm{MN}$ & Methane Number \\
\hline PCP & Peak Cylinder Pressure \\
\hline PRR & Rate of Pressure Rise \\
\hline RANS & Reynolds Averaged Navier-Stokes \\
\hline ROHR & Rate of Heat Release \\
\hline SI & Spark Ignition \\
\hline SOC & Start of Combustion \\
\hline ST & Spark Timing \\
\hline STD & Standard Deviation \\
\hline
\end{tabular}


TDC

WI
Top Dead Center

Wobbe Index 


\section{Chapter 1 Introduction}

Chapter 1 presents the benefits and challenges of natural gas (NG) utilization in internal combustion (IC) engines. It also discusses the current level of understanding and state of the art of NG utilization in heavy-duty diesel engines. Moreover, it presents the goal and objectives of this work. Finally, the content of the various chapters is summarized.

\subsection{Background}

On- and off-road IC engines played and continue to play an important economic and social role in the modern society. It is predicted that the IC engine will still be the main power source used in transportation for the foreseeable future [1]. As new regulations are targeting these engines in terms of thermal efficiency and emissions, a considerable amount of research was and is dedicated to increasing the use of alternative fuels and novel aftertreatment devices for controlling emissions [2]. Alternative gaseous fuels such as NG received additional attention [3] because they can reduce U.S. dependence on imported oil and enhance national energy security [4]. The large interest in NG relates to recent advancements in extracting technologies, which increased its availability and lower its cost $[5,6]$. Compared to gasoline or diesel, NG is a naturally-occurring fuel that requires little or no treatment prior to use [7]. Furthermore, the current fuel taxation system in the U.S. appears to favor gaseous fuels, particularly NG.

$\mathrm{NG}$ is also a cleaner combustion fuel $[8,9]$. The higher $\mathrm{H} / \mathrm{C}$ ratio of $\mathrm{NG}$ lowers engine-out carbon dioxide $\left(\mathrm{CO}_{2}\right)$ emissions (i.e., greenhouse gas) per unit power compared to gasoline 
or diesel engines [10]. In addition, NG engines emit less carbon monoxide (CO) emissions compared with those fueled with conventional petroleum fuels, which indirectly affect the concentrations of other greenhouse gases such as methane, tropospheric ozone, and carbon dioxide [11]. For example, $\mathrm{CO}$ depletes the concentration of hydroxyl $(\mathrm{OH})$ radicals in the atmosphere. But the $\mathrm{OH}$ radical plays an important role in methane removal from the atmosphere [11], so lower $\mathrm{CO}$ concentrations can help to increase the global rate of methane decomposition. More, nitrogen oxides $\left(\mathrm{NO}_{\mathrm{x}}\right)$ emissions are lower under a leancombustion regime [12], which can reducing their ambient levels and also the nitrate particles. NG will also lower soot emissions by avoiding the creation of fuel-rich regions inside the cylinder [1]. NG's low sulfur content decreases sulfur oxides and sulfate particle levels in the atmosphere, while lower $\mathrm{CO}$ emissions indirectly reduce the rate of conversion of sulfur dioxide $\left(\mathrm{SO}_{2}\right)$ to sulfuric acid as well, as the production of hydrogen peroxide (which plays an important role in $\mathrm{SO}_{2}$ conversion process) requires $\mathrm{CO}$ [11]. In addition to the lower acid levels, methane is the largest components of the unburned hydrocarbon (HC) emissions in $\mathrm{NG}$ engines. As methane is less reactive compared to other $\mathrm{HC}$ emissions, its influence on ozone formation is negligible and thus it is not regulated [13]. However, while methane is a more effective greenhouse gas compared to $\mathrm{CO}_{2}$ [14], it was estimated that the reduction in $\mathrm{CO}_{2}$ emissions due to the higher $\mathrm{H} / \mathrm{C}$ ratio of $\mathrm{NG}$ usually offsets the methane emissions [13].

Overall, NG is a promising alternative fuel for IC engines in the U.S. Further, despite some skepticism shown by the U.S. customers in regard to gas-fueled vehicles, NG engines are very popular in numerous countries all over the world, especially in countries that lack crude oil reserves [15]. The mature NG markets in these countries, which are supported by 
engine and vehicle manufactures, gas stations, after-sales services, and loyal customers, demonstrate the feasibility and potential of NG engine applications in U.S.

\subsection{Natural gas engine considerations}

Natural gas is an attractive fuel for IC engines because of its cleaner combustion, smaller carbon footprint, increased availability, and low cost. However, engine designers must also consider other parameters than just the fuel. For example, Equation 1.1 shows the theoretical engine efficiency $\left(\eta_{t h}\right)$ for a spark-ignition engine:

$$
\eta_{t h}=1-\frac{1}{r_{c}^{\gamma-1}}
$$

where $\gamma$ is the gas specific heat ratio and $r_{c}$ is the engine compression ratio (CR). The efficiency of the Otto cycle shown in Equation 1.1 is higher than the efficiency of a diesel cycle at the same compression ratio. But diesel engines have a higher efficiency than gasoline engines due to their higher $\mathrm{CR}$, as the compression ratio of a spark ignition (SI) engine is limited by knocking. However, NG is more resistant to auto-ignition than most liquid hydrocarbons (i.e., NG has a higher octane number) [16], which allows the use of a higher CR to increase efficiency in SI engine applications. In addition, a higher CR reduce in-cylinder residual gas fraction, which increases the flame speeds and burned-gas expansion rates, hence a better use of the expansion stroke and lower exhaust temperatures [17]. But the higher octane number also increases the difficulty in initiating and controlling the combustion process in compression ignition (CI) engine applications without the use 
of an additional ignition source [1].

Additionally, compared to gasoline, NG has wider flammability limits [18], which allow NG engines to operate at leaner equivalence ratios $[19,20]$. In theory, lean burn can increase $\gamma$, which can further increase $\eta_{t h}$, as shown in Equation 1.1. Lean mixtures also permit the use of high CR without knock [21]. Therefore, the higher CR, combined with lean operation, permits a more effective utilization of the available fuel energy. Also, lean-burn operation is a cost-effective way to control engine-out emissions in modern SI engines $[22,23]$. While a three-way catalyst is effective to simultaneously reduce $\mathrm{NO}_{\mathrm{x}}, \mathrm{CO}$, and $\mathrm{HC}$ emissions, it is relatively expensive and requires strict fuel-air control at or near stoichiometric equivalence ratio to work properly [24]. By comparison, lean burn operation can lower the emissions formation [22], even though some NG engines may need an oxidation catalyst to reduce nonmethane hydrocarbon (NMHC) or formaldehyde $\left(\mathrm{CH}_{2} \mathrm{O}\right)$ emissions [25]. But the high activation energy of NG lowers its laminar flame speed compared to other hydrocarbons, which challenges the use of a lean mixture in NG engines [11]. Specifically, the laminar flame speed of typical hydrocarbons is a strong function of the equivalence ratio, dropping sharply as the equivalence ratio is leaned from stoichiometry [26]. If the flame speed is too low such as in extreme lean-burn applications, knocking is very probable [27]. As the flame front compresses the unburned gases ahead of it, it also increases their temperature by compression heating. Under these conditions, the unburned mixture may begin to undergo pre-flame reactions and, with sufficient time, 
it may self-ignite explosively ahead of the flame front, generating shock waves and highpressure spikes [28]. The shock waves will disrupt the cold boundary layer next to the combustion chamber walls, increasing heat transfer to the wall and possibly causing overheating, hence engine damage [14]. In addition, NG's lower flame speed increases combustion duration, which can affect $\eta_{t h}$ [26]. While advanced spark timing can reduce combustion duration, it would also increase knocking tendency, especially under low-speed conditions. In addition, extreme lean-burn operation decreases combustion quality, which in turn lowers engine efficiency and increases $\mathrm{HC}$ and $\mathrm{CO}$ emissions [12]. A solution is to use a high CR and a combustion chamber that can also generate high turbulence [12], thereby increasing the turbulent flame speed and reducing cycle-to-cycle variations.

From a chemical perspective, natural gas is a mixture of various hydrocarbon molecules, with concentrations generally ranging from $75 \%$ to $98 \%$ for methane $\left(\mathrm{CH}_{4}\right), 0.5 \%$ to $13 \%$ for ethane $\left(\mathrm{C}_{2} \mathrm{H}_{6}\right)$, and $0 \%$ to $2.6 \%$ for propane $\left(\mathrm{C}_{3} \mathrm{H}_{8}\right)$ [29]. For peak shaving practices with added propane, composition variations are even more extreme with methane ranging from $55.8 \%$ to $98.1 \%$, ethane from $0.5 \%$ to $13.3 \%$, and propane from $0 \%$ to $23.7 \%[29,30]$. Albeit NG is predominantly methane, another concern is that the heavier hydrocarbons (ethane, propane, butane $\left(\mathrm{C}_{4} \mathrm{H}_{10}\right)$, etc.) and inert diluents $\left(\mathrm{N}_{2}\right.$ or $\left.\mathrm{CO}_{2}\right)$ can affect engine performance and emissions [31]. As a result, NG composition standards aligned with engine requirements must be introduced. Methane number (MN) and Wobbe index (WI)/Wobbe number $(\mathrm{WN})$ are two main parameters that characterize natural gas 
composition. Reference [32] used the motor octane number (MON) and the reactive hydrogen/carbon ratio to introduce a particular formula for calculating $\mathrm{MN}$ and described the NG's knock resistance because the octane scale was considered inappropriate for NGs with higher octane numbers [33]. The WI/WN describes the fuel's energy calculated by dividing the heating value of the gas [in $\mathrm{Btu} / \mathrm{SCF}$ ] to the square root of its specific gravity with respect to air [34]. While NG composition changes with geographical source, time of year, treatments applied during production and/or transportation, etc., [35], numerous studies showed relatively minor effects of the NG composition on engine performance [36]. It is believed that for reasonable fuel compositions, NG engines can operate reliably over a wide range of conditions if the engine control hardware and software are appropriately calibrated or the composition of the fuel is carefully controlled [31,37].

Overall, all the possible effects of the fuel physical and chemical properties need to be carefully weighted when designing a NG engine. The goal of a good NG engine design is to take full advantages of NG benefits and avoid its issues as much as possible.

\subsection{Natural gas in gasoline engines}

Ideally, NG would replace conventional petroleum-based fuels without the need of major engine modifications [38]. Gasoline engines are more easily to be modified to NG operation because the original spark plug can also ignite the NG/air mixture [39]. But the low compression ratio of the gasoline engine does not make full use of NG's property of 
higher resistance to knock. In addition, the low density of NG even under stoichiometric operation results in a penalty in engine power output $[40,41]$. Turbocharging can help compensate the power loss [42]. However, every improvement in specific power is counteracted by an increase in the production of specific $\mathrm{NO}_{\mathrm{x}}$ emissions [20,43]. Leanburn operation can decrease $\mathrm{NO}_{\mathrm{x}}$ emissions significantly [8] but has issues with reliable ignition and stable combustion [43]. For example, Polcyn et al. [44] noticed that stoichiometric operation had a more complete combustion than lean burn operation based on engine-out $\mathrm{CO}_{2}$ emissions. This can be explained by the decreased laminar flame speed that dropped sharply as the equivalence ratio was leaned from stoichiometry, which increased ignition lag and combustion duration [45]. Weaver et al. [11] reported that the roof-type head geometry in conventional SI engines is not optimal for lean combustion due to combustion instabilities and increased cycle-to-cycle variations. Consequently, gasoline engines with a roof-type head are more likely to be modified to NG stoichiometric operation $[46,47]$. In other words, the slow-burn geometry of conventional gasoline engines and NG's low laminar flame speed at lower equivalence ratio are not ideal to converting SI engines to NG lean burn operation. Therefore, some researchers focused on adding hydrogen to increase the laminar flame speed in such engines $[48,49]$.

\subsection{Natural gas in diesel engines}

As previously mentioned, gasoline engines modified to NG operation have difficulties in 
taking full advantage of NG's lean burn and high-CR capabilities. Therefore the conversion of existing diesel engines to NG operation is more attractive [50].

NG's higher resistance to auto-ignition increases the difficulties of firing the fuel in compression-ignition applications [51]. Solutions to ignite NG in diesel engines include homogeneous charge compression ignition (HCCI) [16], hot surface ignition [52,53], prechamber ignition [54,55], pilot ignition [56,57] and spark ignition [1,58]. In addition to load limitations caused by the excessive cylinder pressure, combustion stability and complex control are barriers for HCCI NG applications [16]. Hot surface ignition uses a high surface temperature (normally $1200-1400 \mathrm{~K}$ ) to ignite direct injected NG passing near it. However, in addition to control complexities, this method has difficulties in ensuring a repeatable ignition, which affects combustion stability. More, there are issues related to the longevity/reliability of the hot-surface material [16]. Another solution for lean burn operation is the use of pre-chambers to initiate the combustion process in gas engines. The pre-chamber acts like an amplifier in which the relatively-weak spark energy creates a flame jet that can initiate combustion even in an extremely lean mixture inside the main combustion chamber [54]. However, the lack of access for suitable instrumentation, combined with the difficulty of isolating the individual variables that affect ignition performance, has limited the research of stratified charge systems using pre-chambers [55]. More, the pre-chamber combustion creates a high thermal loading in the pre-chamber region, which results in difficulties in achieving good combustion and stability over a wide 
load and speed range [59]. Compared to the three ignition methods previously discussed, pilot-ignition and spark ignition are the two most-popular solutions to ignite the fuel/air mixture in CI engines converted to NG [60]. Pilot ignition uses a more-reactive fuel (e.g., diesel fuel) to initiate NG combustion. This increases engine cost and control complexities as it requires two fuel tanks, two separate fuel supply systems, and other engine and control modifications $[61,62]$. On the other hand, the economics and control complexities of the NG ignition system are also of particular concern in a cost-oriented market, as the capital costs need to be carefully weighed against long-term maintenance [63]. By contrast, the use of high-energy NG spark plugs is a more economical solution to convert existing diesel engines to NG SI operation with the least amount of engine and control modifications $[58,64]$. In addition, high-energy NG spark plugs can ensure repeatable and reliable ignition $[65,66]$. As a result, the spark plug is the predominant method to ignite the air-fuel mixture in NG engines [67].

As in most applications the spark plug is mounted in place of the fuel injector, NG is usually injected upstream of the intake valves and brought into the combustion chamber with the intake air [68,69]. Actually, NG fumigation inside the intake manifold has a number of benefits such as the use of a lower fuel pressure, which decreases the parasitic compressor work [31]. The intake and compression strokes also allow more time for NG to mix with the intake air, resulting in a more homogeneous fuel-air mixture in the combustion chamber [31]. 
Consequently, an economical method to achieve the conversion of heavy-duty diesel engines to NG SI operation is by replacing the fuel injector with a spark plug and using low-pressure port-fuel injection for NG delivery [70]. Several studies that investigated the combustion chamber effects on flame propagation [71,72] found that the original diesel combustion chamber (i.e., bowl-in-piston and flat head) increased flame speed (good for lean-burn operation) because the squish generated very high turbulence levels near topdead-center (TDC) compared to conventional SI chambers [11,73]. As mentioned before, a higher CR of diesel engine can also help increase the fuel conversion efficiency. More, the spark plug in retrofitted diesel engines is placed to a more central location compared to the spark plug position in some SI engines [12], which can avoid exposing the NG to conditions that favor knocking. Consequently, lean-burn high CR heavy-duty NG engines are capable of close-to-diesel efficiencies but with lower emission levels compared to a conventional stoichiometric spark ignition engine [11,74].

For conventional spark ignited engines, the rate at which fuel-air mixture burns is a singlestage combustion that increases from a low value immediately following the spark discharge to a maximum about halfway through the burning process and then decreases to close to zero as the combustion process ends [12]. However, natural gas combustion in diesel-retrofitted engines presents differences compared to that in conventional spark ignited engines. Figure 1.1 shows two cases of heat release rate from a typical diesel engine retrofitted to NG SI operation (the data comes from the individual engine cycles acquired 


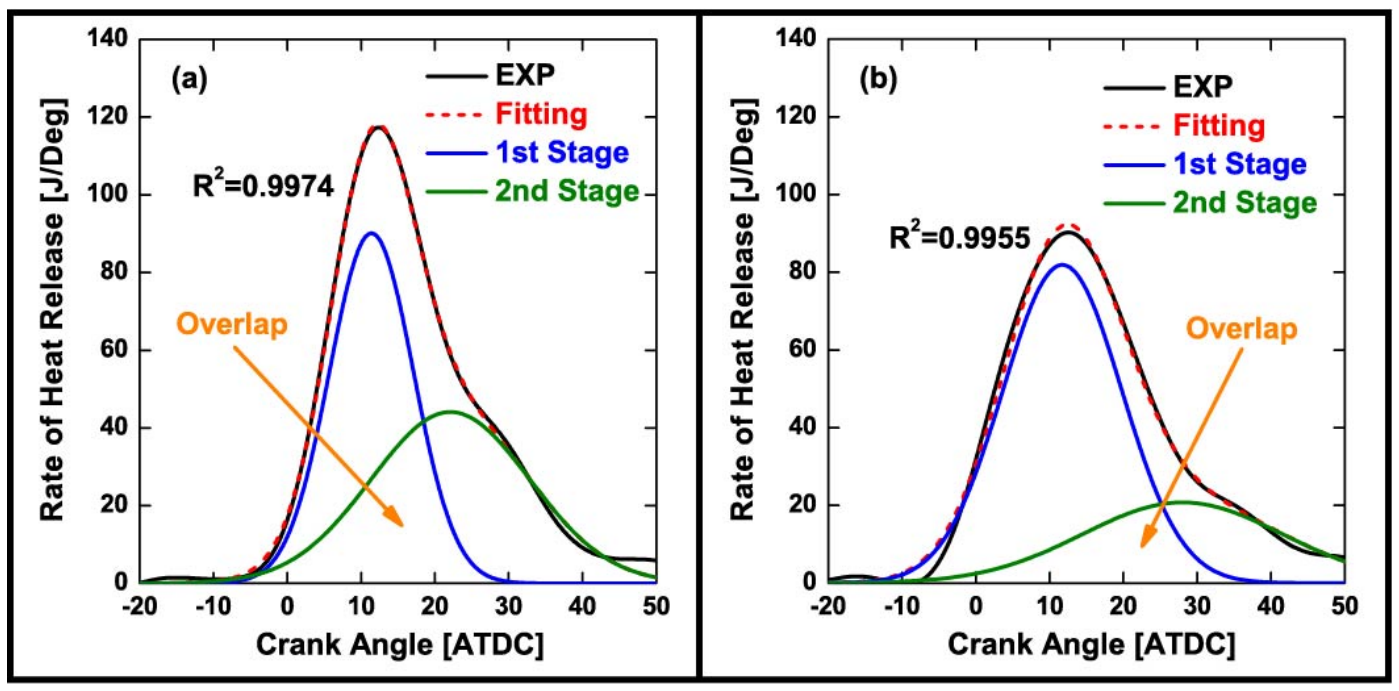

Figure 1.1 Rate of heat release of a typical diesel engine retrofitted to natural gas spark ignition operation plotted as the superposition of two bell-shaped curves that describe the inside- and outside-the-bowl combustion.

during experiments that will be presented later in this work). Similar to reference [70],

Figure 1.1 indicates that the apparent rate of heat release for NG SI combustion inside a bowl-in-piston geometry has a long tail compared to the combustion inside a conventional SI geometry. Figure 1.1 proposed a mathematical method to analyze the phenomena here. Specifically, each of two distinct combustion events can be described by a bell-shaped curve, with the apparent heat release rate for such retrofitted engines being the superposition of these two bell-shaped curves. While this curve-fitting methodology have its limitations in describing the physics of NG flame propagation in a bowl-in-piston geometry, it would be better than the current theory used for conventional SI engines. In addition, Meyer et al. [75] found that $\mathrm{NO}_{\mathrm{x}}$ emissions reduced in retrofitted diesel engines with low-swirl, but no swirl influence on HC emissions. As the combustion chamber geometry influence the flow patterns and turbulence intensity during the engine cycle, it 
also influences the turbulent flame propagation [24]. Consequently, the combustion chamber effects on the burning event are evident in both the rate of combustion and emissions formation and destruction [24]. However, almost all the fundamental studies in the literature offer only limited explanations on the combustion behavior inside diesel engines retrofitted to NG SI operation.

\subsection{Research objective}

A recent assessment by the U.S. Department of Energy (DOE) suggested that the number of natural gas vehicles can increase up to $20 \%$ of new heavy-duty vehicles by 2025 [76]. This is in addition to existing heavy-duty diesel engines that can be converted to NG leanburn SI operation. However, as mentioned before, the combustion characteristics of such retrofitted engines are not representative of the convectional spark ignition engines. The limited information in the literature can delay the introduction of new heavy-duty NG vehicles or the conversion of existing diesel engines to NG operation. Consequently, there is a need for fundamental and applied research that can help improve the understanding of the physical processes that occur in these engines. The main goal of this dissertation was to provide additional information on the NG flame behaviors inside a diesel-like, fast-burn combustion chamber. A unique array of experimental and numerical tools including a research engine that can operate in both conventional (i.e., all metal) and opticallyaccessible engine configuration and 3D CFD models were used to achieve the goal of this 
dissertation. In detail, the CFD model can provide in-cylinder turbulence distribution and flame propagation details. While the optical engine helped visualize just the inside-thebowl flame propagation, it can used as an additional tool to experimentally validate the numerical model predictions. Steady-state experiments inside the metal engine configuration investigated the effects of fuel composition, spark timing, equivalence ratio, and engine speed on the lean-combustion characteristics. The CFD model complemented the flame propagation information that the metal engine cannot provide. As the whole combustion event can be characterized by three stages (i.e., flame inception, the rapid burning, and the late combustion), the duration of and the burn rate during each stage were also investigated. More, the cycle-to-cycle variation was used to observe the stability of the lean-burn operation. Overall, the results can guide and/or complement the design and optimization directions for lean-burn high-CR NG SI engines, which would enhance the U.S. energy security and accelerate the introduction of heavy-duty NG engines in the U.S.A.

Following is a description of the content presented in the next chapters. Chapter 2 describes the engine setup for both metal and optically-accessible engine configurations. Chapter 3 introduces the 3D CFD models used to provide additional information that cannot be obtained from the experimental data. Chapter 4 focuses on the NG combustion behavior inside the bowl-in-piston geometry while trying to explain the two distinct combustion events shown in Figure 1.1. Optical measurements help to visualize flame propagation perpendicular on the engine axis. CFD simulations complement the optical data by 
providing the flow patterns and turbulence distribution inside the combustion chamber. More, the CFD model will be used to predict the flame propagation inside and outside the bowl from a side view. Chapter 5 presents the results of a parametric study using the metal engine configuration that changed the fuel composition, spark timing, mixture equivalence ratio, and engine speed. In addition, the CFD models provide the flame propagation information at each operating condition, which would be helpful in further investigating the influence of chamber geometry. The objective is to analyze the operating condition effects on the combustion features discussed in Chapter 4, especially the effects on the overlapping of the two distinct combustion events shown in Figure 1.1. Chapter 6 uses the energy released during the engine cycle to characterize the different stages of NG SI combustion inside a bowl-in-piston geometry. This chapter introduces a novel method to identify the rapid burning period, compared to the traditional method. Chapter 7 will observe the cycle-to-cycle variation in such retrofitted engines, particularly the cyclic differences in flame propagation as seen during flame visualization in the optical engine configuration. The information can be used for the development and validation of combustion models that simulate the physics of turbulent flames. 


\section{Chapter 2 Experimental Setup}

Experiments were performed at West Virginia University (WVU)'s Advanced Combustion Laboratory. The experimental platform consisted of a single-cylinder four-stroke heavyduty CI research engine (Ricardo/Cussons, U.K., Model Proteus), converted to NG SI operation. The engine can be operated in two different configurations: a conventional CI configuration (referred to as the metal engine configuration in the rest of the text) and an optically-accessible configuration that allows the combustion chamber visualization (referred to as the optical engine configuration in the rest of the text). This chapter will describe in detail both configurations. In addition, this chapter will discuss other experimental details such as engine operating conditions, fuel composition, and image processing algorithms for the optical measurements.

\subsection{Metal engine configuration}

The metal engine configuration was used to investigate the effects of fuel composition, spark timing, mixture equivalence ratio, and engine speed on the NG SI combustion phenomena inside a bowl-in-piston geometry. The major components of the metal configuration setup are presented next. In addition, the methods used to analyze the experimental data are also described.

\subsubsection{Test engine and dynamometer}


Figures 2.1 shows the experimental setup for the metal engine. The reported maximum

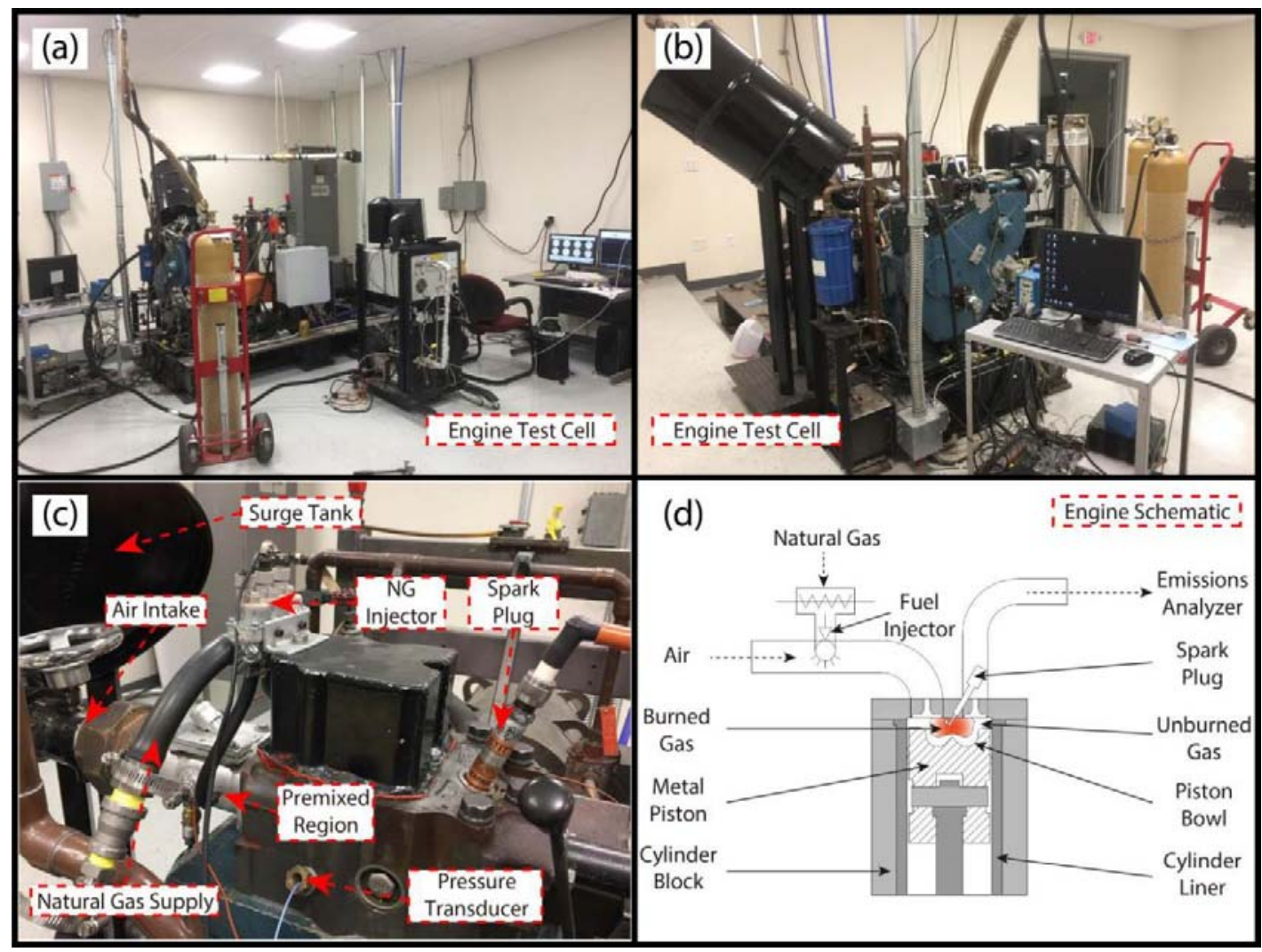

Figure 2.1 Metal experimental setup: $(a, b)$ engine test cell, (c) top engine view, and (d) engine schematic.

intermittent power of the engine in its original CI configuration is $55 \mathrm{~kW}$ at $2,200 \mathrm{rpm}$, using a boost ratio of 3.0 and an inlet air temperature $65^{\circ} \mathrm{C}$ [77]. Table 2.1 shows the engine specifications. This single-cylinder engine is mounted on an integral base frame with control instrumentation on a remote console, which are shown in Figures 2.1a and 2.1b. The original supercharged, direct-injection engine configuration (Volvo, Model TD 120) was converted to NG SI operation by replacing the main injector with a NG spark plug (Stitt, U.S., Model SRSGN40XLBEX8.4-2) and using a low-pressure gas injector to 
fumigate NG inside the intake manifold, as shown in Figures 2.1c and 2.1d.

Table 2.1 Metal engine specifications

\begin{tabular}{cc}
\hline Engine model & Ricardo/Cussons, Proteus \\
Research engine type & Single-cylinder \\
Cycle & 4 -stroke SI Premixed \\
Valves per cylinder & 2 \\
Bore $[\mathrm{mm}]$ & 130.2 \\
Stroke $[\mathrm{mm}]$ & 150 \\
Displacement [liters] & 1.997 \\
Intake valve open & 12 CAD BTDC exhaust \\
Intake valve close & 140 CAD BTDC compression \\
Exhaust valve open & 126 CAD ATDC compression \\
Exhaust valve close & 10 CAD ATDC exhaust \\
Connecting rod length [mm] & 275 \\
Squish height [mm] & 2 \\
Geometric compression ratio & $13.3: 1$ \\
Dynamic compression ratio & $12.9: 1$ \\
Combustion chamber & Mexican-hat bowl and flat head \\
\hline
\end{tabular}

No other modifications were made to the original combustion chamber, which consisted of a two-valve flat engine head, a Mexican-hat bowl-in piston, and a swirl-generating intake port, as shown in Figure 2.2. The swirl created a counterclockwise (seen from below) rotational motion of the air-fuel mixture in the cylinder. The spark plug was located on the same axis with the center of the bowl, but Figure $2.2 \mathrm{~b}$ shows that the bowl was located off the combustion chamber central axis. 


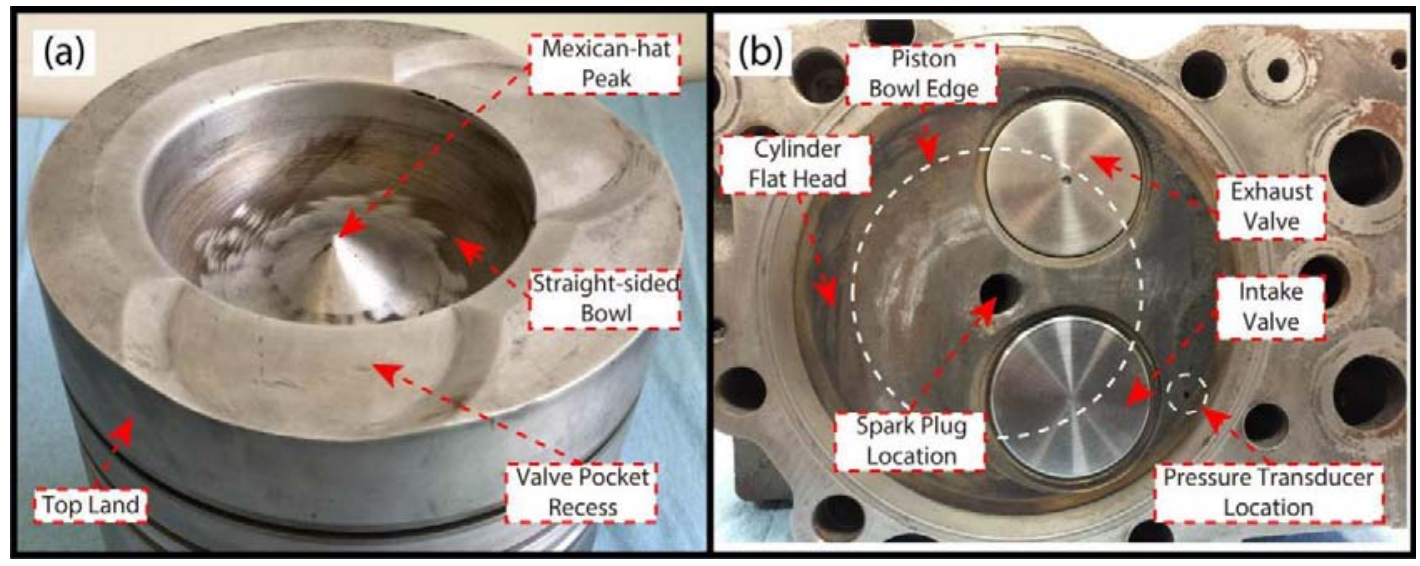

Figure 2.2 Combustion chamber in the metal engine configuration: (a) piston with the Mexican-hat bowl and (b) engine head with swirl-generating intake port.

A 75-kW DC electrical dynamometer (McClure, Model 4999, Trunnion type), rated at 420

V and 160 A, operated through a thyristor bank (KTK, Model 6P4Q75) controlled the engine speed regardless of the engine load. A 100-kg load cell (Tedea-Huntleigh, US, Model 104H) measured the torque applied on the dynamometer using a Wheatstone bridge.

\subsubsection{Air intake and gaseous fuel system}

Filtered intake air passed through a laminar flow element (LFE; Meriam, U.S., Model Z50MC2-2). A thermocouple was mounted upstream of the LFE to correct for variations in air density. A 30-gallon intake air surge tank and pressure snubbers, shown in Figure $2.1 \mathrm{~b}$, were installed after the LFE to dampen the pressure pulsations caused by the singlecylinder cyclic intake-valve opening and closing. This arrangement proved effective in dampening the intake air pressure fluctuations up to $83 \%$. 
The fuel supply system, shown in Figures 2.1a and 2.1c, consisted of a gas cylinder, a pressure regulator, and gas fuel injectors (Rail Spa, Italy, Model IG7 Navajo). The lowpressure gas injectors, operated at 35psi, delivered NG inside the intake manifold immediately after the intake valve opening. As a result, NG mixed with air inside the inlet manifold, resulting in a high level of premixing [70]. As the throttle position was maintained constant during the experiments, the mixture equivalence ratio and/or load were controlled by varying the injector pulse width.

\subsubsection{Cooling and lubrication system}

The engine platform was equipped with heaters, heat exchangers, and temperature controllers. This helped to maintain constant coolant and oil temperatures during optical experiments as the coolant and lubrication oil during skip-fire operation in the optical engine configuration was lower compared to the heat rejection from the combustion chamber in a continuously fired mode in the metal engine configuration. The temperatures of engine coolant, engine oil, intake air, and exhaust gases were measured with K-type thermocouples.

Engine cooling was achieved by a closed system consisting of a pressurized header tank, coolant pump (Boss, Model BK2507/10B), flow meter, electrical heater (6 kW), coolant filter, and heat exchangers. The coolant flow rate was 20 gallons per minute (gpm). The coolant was a 50/50 mixture by volume of demineralized water and commercial anti-freeze. 
The coolant was drawn from the bottom of the header tank and pumped by an electricallydriven pump through the heat exchanger before entering the engine cylinder jacket. A sensor inside the tank connected by a capillary actuator to an in-line valve controlled the raw water flow through the coolant heat exchanger, which in turn controlled the coolant temperature.

Engine oil lubrication was realized through a separate temperature and pressure control loop. The system consisted of an oil sump/reservoir, heater, pump (Brook Crompton Parkinson Motors), oil filter, and heat exchangers. An electrically-driven pump pumped the lubricating oil from the engine oil sump through the heat exchanger, oil filter, and temperature sensor before delivering it to the oil distribution manifold that supplied oil to the main bearings, big end bearing, camshaft bearings, and cylinder head at the entrance of the engine. A valve at the oil distribution manifold maintained the oil rail pressure at 4 bar by sending the excess oil back to the engine sump. A pressure switch at the oil distribution manifold sent a signal to the safety shutdown unit (SSU) if the minimum oil pressure was below 2 bar. The oil temperature was controlled by a sensor connected by a capillary actuator to an inline valve controlling the raw water flow through the oil heat exchanger. The oil sump also contained two $1.5 \mathrm{~kW}$ electrical heaters that warmed up the oil to working temperature prior to the start of the optical experiments.

\subsubsection{Engine control and data acquisition}


An aftermarket Engine Control Unit (Megasquirt, Model V3.0 mainboard with MS3X expansion) controlled the spark timing, mass of fuel injected, and several other engine parameters, based on inputs like the position of crankshaft and camshaft, amount of intake air, intake air temperature, coolant/oil temperature, and throttle position. Specialized software (TunerStudio, Version 3.0.28) applied built-in algorithms to determine the correct operating parameters such as spark timing, injection duration, dwell time for spark, etc. A variable reluctance (VR) transducer was mounted on a bracket off the crankcase to read 100 equidistant teeth distributed around the flywheel and determine the angular position of the crankshaft.

A pressure transducer (Kistler, Model 6011), mounted in the original position of the glow plug using a special outer sleeve as shown in Figure 2.1c, collected in-cylinder pressure data. A charger amplifier (Kistler, Model 5010) amplified the pressure transducer signal (0-10V signal calibrated to bars/volts) and then transmitted it to a data acquisition (DAQ) card (National Instruments, Model SCB-68A). An incremental rotary shaft encoder (BEI sensors, Model H25D, resolution 1800 counts per turn) was used to measure engine speed and determine the crankshaft position at any instant. In addition to pressure and speed signals, intake and exhaust temperatures were also collected by the DAQ card, which was connected to an I/O device (NI PCIe-6351) on the pressure analysis cart to provide usable combustion information such as the rate of pressure rise, apparent heat release rate, etc. Outputs from the load cell and LFE's pressure transducers (differential pressure transducer 
(Ashcroft, Model XLdc) and absolute pressure transducer (GP 50, Model: 211)), and various K-type thermocouples were connected to Ethernet measurement devices (LabJack, Model UE9, and ICP DAS, Model PET7019Z). An in-house built data acquisition system, SCIMITAR (developed on a Python software platform and installed on a Windows PC), was used for the monitoring and time series logging of the essential engine parameters such as in-cylinder pressure data, air flow rate, coolant and oil temperatures, engine torque, engine speed, etc. from these two Ethernet measurement devices. Moreover, the pressure collection and data analysis system used motored pressure to synchronize the crankshaft encoder data with the engine position. Specifically, the peak pressure in the motored pressure trace was used to determine the difference between the encoder z-pulse and the engine top dead center. The procedure was repeated at the beginning, during, and at the end of experiments to ensure that no encoder slippage affecting in-cylinder pressure measurements.

\subsubsection{Engine operating conditions}

A steady-state parametric study investigated the engine performance and combustion behavior at several operating conditions that changed fuel composition, spark timing (ST), equivalence ratio, and engine speed. The investigated fuels were methane $\left(\mathrm{CH}_{4}\right)$ and a $\mathrm{Cl}$ $\mathrm{C} 4$ alkane blend (hereafter referred to as NG), with compositions given in Table 2.2. The underlined parameters in bold italics in Table 2.3 were for the baseline condition and each 
test varied one parameter while holding constant the rest.

Table 2.2 Composition and selected properties of test gases

\begin{tabular}{ccc}
\hline Fuel Type & Methane & Natural Gas \\
\hline $\mathrm{CH}_{4}[\mathrm{vol} \%]$ & $99.5 \%$ & Balance \\
$\mathrm{C}_{2} \mathrm{H}_{6}[\mathrm{vol} \%]$ & $<1000 \mathrm{ppm}$ & $5.81 \%$ \\
$\mathrm{C}_{3} \mathrm{H}_{8}[\mathrm{vol} \%]$ & - & $2.39 \%$ \\
$\mathrm{n}-\mathrm{C}_{4} \mathrm{H}_{10}[\mathrm{vol} \%]$ & - & $0.45 \%$ \\
iso-C $4 \mathrm{H}_{10}[\mathrm{vol} \%]$ & - & $0.421 \%$ \\
$\mathrm{~N}_{2}[\mathrm{vol} \%]$ & $<4000 \mathrm{ppm}$ & $0.02 \%$ \\
$\mathrm{O}_{2}[\mathrm{vol} \%]$ & $<50 \mathrm{ppm}$ & - \\
$\mathrm{H}_{2} \mathrm{O}[\mathrm{vol} \%]$ & $<10 \mathrm{ppm}$ & - \\
$\mathrm{H} / \mathrm{C} \mathrm{ratio}$ & 4.0 & 3.77 \\
$\mathrm{LHV}\left[\mathrm{MJ} / \mathrm{m}^{3}\right]$ & 35.88 & 41.79 \\
Density $\left[\mathrm{kg} / \mathrm{m}^{3}\right]$ & 0.6682 & 0.7471 \\
$\mathrm{MON}[-]$ & 140.1 & 123.1 \\
Methane Number $[-]$ & 108.4 & 80.8 \\
Wobbe Index [kg/m $\left.{ }^{3}\right]$ & 48.2 & 53.1 \\
\hline
\end{tabular}

Table 2.3 Metal engine operating conditions

\begin{tabular}{ccc}
\hline Fuel Type & $\underline{\text { Methane }}$ & Natural Gas \\
\hline Spark Timing [CAD ATDC] & $-30,-25,-20,-15, \underline{\mathbf{- 1 0}}$ & -10 \\
Equivalence Ratio [-] & $0.71, \underline{\mathbf{0 . 7 3}}, 0.76,0.80$ & 0.71 \\
Engine Speed [rpm] & $\underline{\mathbf{9 0 0}}, 1000,1100,1200,1300$ & 900 \\
\hline
\end{tabular}

A controller malfunction during the spark time sweep was discovered during data analysis. As a result, the spark time sweep for methane was repeated. More, this test condition used 
in the spark timing sweeping has identical operating conditions with the baseline. The repeated test showed almost the same results compared with the baseline condition. During the experimental data analysis in the next chapters, the repeated tests were used to investigate the effects of spark timing and the original tests at the baseline condition were used to investigate the effects of the other engine parameters such as NG blends, equivalence ratio or engine speed. In addition, the higher molecular weight of NG and the increased viscosity of higher alkanes presented in NG would slightly reduce the NG flow through the gas injectors. As the mass of fuel injected was also proportional to the fuel density, there was a slight difference in the equivalence ratios of $\mathrm{CH}_{4}$ and $\mathrm{NG}$ under similar injection duration, as seen in Table 2.3.

The engine was warmed up before testing and oil/coolant temperatures were maintained constant to eliminate the effects of different boundary conditions on the combustion process. The throttle position in the experiments was fixed. 400 engine cycles at each operating condition were collected and used for the analysis in the next chapters.

\subsubsection{In-cylinder pressure analysis}

In-cylinder pressure data was analyzed using a single zone 0D heat-release model [12], under the assumptions of uniform in-cylinder pressure and temperature. Using the ideal gas law, the apparent rate of heat release (ROHR) can be calculated using below equation: 


$$
\left[\frac{d Q}{d \theta}\right]_{\text {gross }}=\left(\frac{\gamma}{\gamma-1}\right) \times P \times \frac{d V}{d \theta}+\left(\frac{1}{\gamma-1}\right) \times V \times \frac{d P}{d \theta}+\left[\frac{d Q}{d \theta}\right]_{h t}
$$

where, $\left[\frac{d Q}{d \theta}\right]_{\text {gross }}$ is the gross heat release rate, $P$ is the in-cylinder pressure, $V$ is the incylinder volume, $\gamma$ is the specific heat ratio (calculated based on the composition and temperature of the bulk mixture), $\theta$ is crank angle degree, and $\left[\frac{d Q}{d \theta}\right]_{h t}$ is the heat transfer to the boundaries (calculated, for example, with Woschni's equation [78]). Only the apparent rate of heat release was investigated in this work (i.e., $\left[\frac{d Q}{d \theta}\right]_{\text {gross }}-\left[\frac{d Q}{d \theta}\right]_{h t}$ ), using a constant specific heat ratio $(\gamma=1.35)$ and a dynamic compression ratio for the metal engine configuration of 12.9. Personal analysis codes were developed in a MATLAB ${ }^{\circ}$ environment.
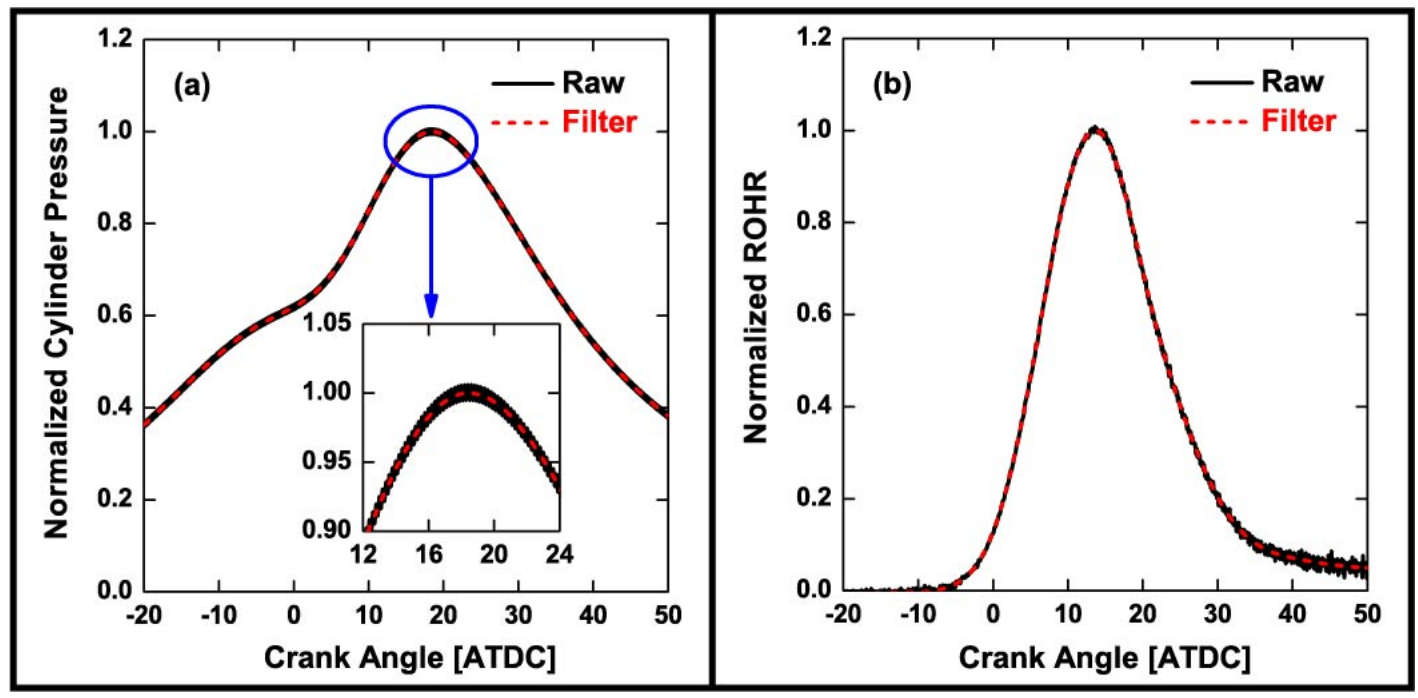

Figure 2.3 Example of pressure filter: (a) raw and filtered in-cylinder pressure, (b) rate of heat release calculated from raw and filtered pressure trace.

As the piezoelectric pressure transducer measured the pressure difference rather than the absolute pressure, the pressure signal was "pegged" (i.e., referenced) to the manifold intake 
pressure. The non-flush mounting of the pressure transducer inside the combustion chamber created standing/resonant waves in the access passage, which introducing undesired noise in the recorded pressure trace. Additional noise in the pressure trace was produced by mechanical vibrations, electric interference, thermal drift, etc. As a result, the raw in-cylinder pressure was filtered using a Savitzky-Golay FIR (finite impulse response) smoothing filter. The procedure was done in a MATLAB $®$ environment using the sgolayfilt (x, order, framelem) function. Figure 2.3 shows an example of raw (unfiltered) and filtered pressure trace, and the corresponding ROHR derived from it.

\subsection{Optical engine configuration}

The base research engine can be modified for optical investigations by replacing the cylinder block and piston. This section details the engine modifications, the control strategies, the optical equipment used to record the combustion event, and the methodology used for image processing.

\subsubsection{Optical piston}

Figures 2.4, 2.5 and 2.6 show the test cell, combustion chamber, and engine schematic, respectively, for the optical engine experiments. The original cylinder block was replaced with an extended version that allows the installation of the special piston with optical access. The "Bowditch" piston allowed the visualization of the combustion chamber from 


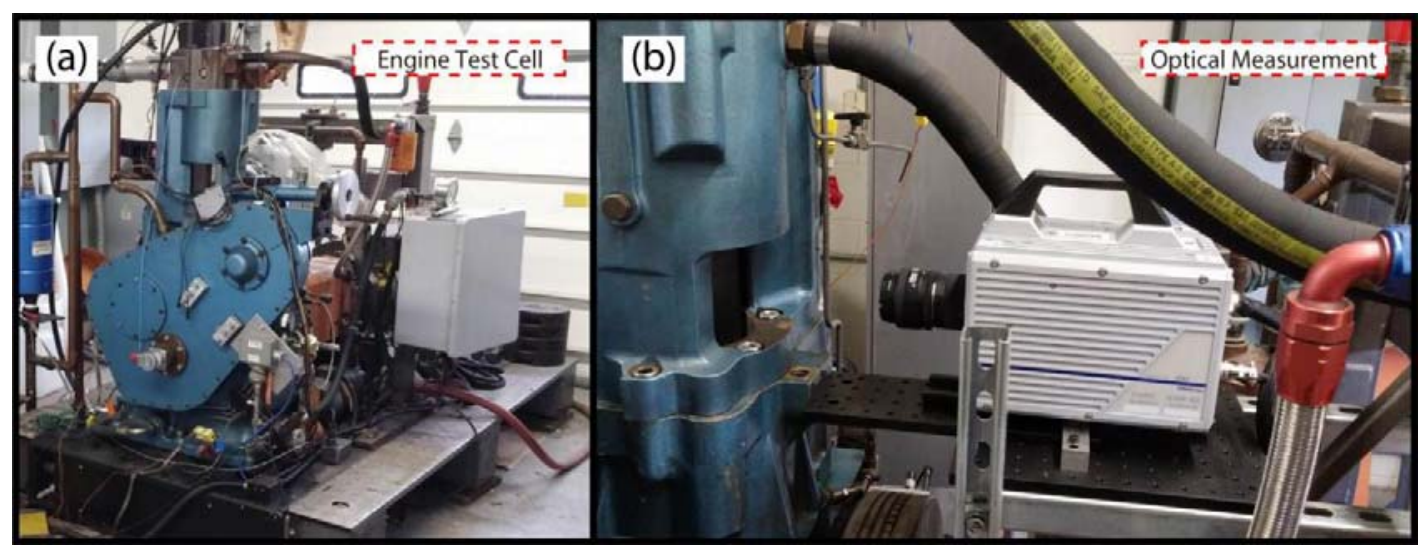

Figure 2.4 Optical experimental setup: (a) engine test cell and (b) optical measurement.

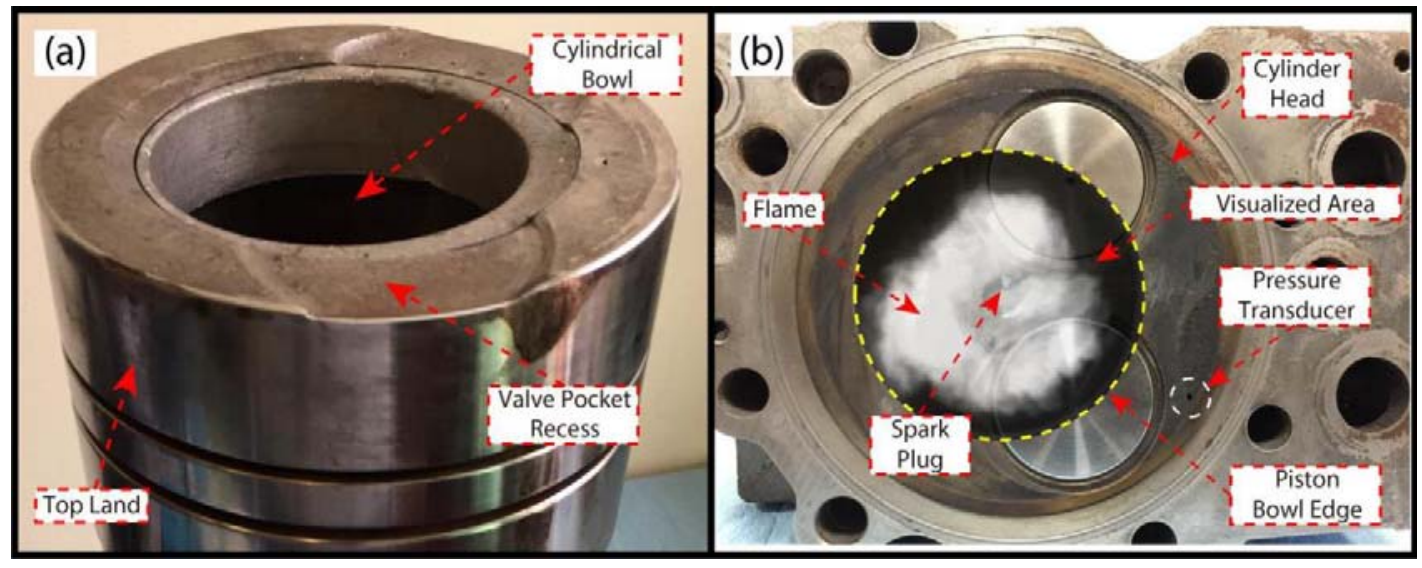

Figure 2.5 Combustion chamber in the optical engine configuration: (a) "Bowditch" piston bowl and (b) engine head. The white pixels inside the visualized area indicates an example of the flame captured by the CMOS camera.

below, as shown in Figure 2.4b. Compared to the original toroidal bowl-in-piston in the metal engine, the "Bowditch" piston had a bowl with a flat bottom and vertical walls (i.e., a cylindrical bowl), as seen in Figure 2.5a. This design is a compromise between minimizing the window cost, maximizing the field of view, and minimizing the optical distortions that would be introduced by a curved window [79]. In addition, the optical liner 


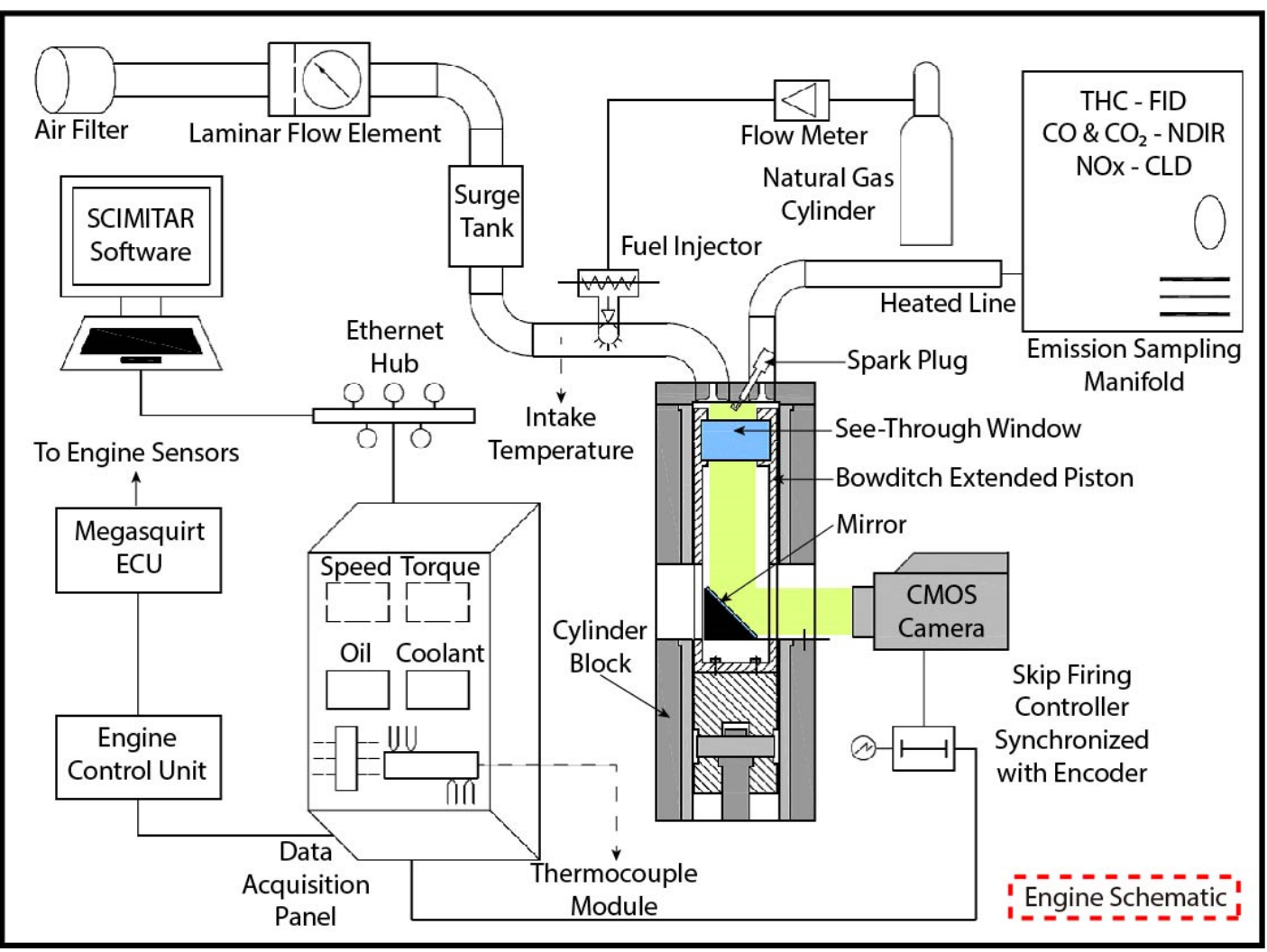

Figure 2.6 Optical engine schematic.

Table 2.4 Optical engine specifications

Dynamic compression ratio

Piston bowl diameter [mm]

Piston-bowl depth [mm]

Combustion chamber
11.0

77

25

Flat bowl-in-piston and flat head

had a greater clearance (i.e., a larger top ring-land volume, shown in Figure 2.5a) than the metal engine configuration, resulting in a greater blow-by [80]. These geometric differences, together with reduced heat transfer (lower thermal conductivity) [81], lowered the dynamic compression ratio to $11: 1$ in the optical configuration compared with the dynamic $\mathrm{CR}$ of 12.9:1 for the metal engine. Table 2.4 shows the optical engine 
specifications that are different from those of the metal engine in Table 2.1.

\subsubsection{Engine control strategy in the optical configuration}

The engine can be run only a few minutes at a time because the optical configuration did not include regular oil-feed channels. The solution is the application of a small amount of molybdenum disulphide anti-scuffing paste to the liner walls and piston rings. As the application of a larger volume of this lubricating paste would lead to the fouling of the optical window and hence would distort the quality of the recorded images, this solution created enough lubrication between the metal components for just a few minutes of engine operation. In addition, there were no cooling passages for the optical piston due to the restriction needed for window installation. To reduce the combustion heat transferred to the window and allow the window to cool down before reaching a damaging temperature, the engine was operated in a skip-fire mode [80] (i.e., a fired cycle was followed by five motored cycles).

A skip-firing controller based on the Arduino Nano prototyping platform together with a solid-state relay (SSR) was installed between the ECU and the fuel injector to skip the desired number of engine cycles. Specifically, the electronic module monitored and counted the camshaft sensor signals then closed the SSR at a specific timing and for a predetermined duration only once every five engine cycles. As the fuel injector would receive the ECU command only if the SSR was closed, it resulted in only one fired cycle 
once every five engine cycles.

\subsubsection{Optical measurements}

Combustion images were recorded using a high-speed CMOS camera (Photron, USA, Model Fastcam SA5) fitted with a 50-mm Nikon lens. The camera was mounted on a translational stage that both minimized vibration during engine operation and helped with focusing the camera on the area of interest inside the combustion chamber. Figures $2.4 \mathrm{~b}$ and 2.6 show that the high-speed camera visualized the combustion chamber from below through the fused-silica piston window using a $45^{\circ}$ mirror. The camera acquired flame luminosity (FL) in the visible range during fired operation only. The skip-firing controller both triggered the camera and synchronized image acquisition with the spark command. The start of image acquisition was synchronized with the engine spark timing to ensure that recorded data contained all the flame stages from inception to the end of combustion. The camera was operated at 15,000 frame-per-second, which corresponded to 2.77 frames per crank-angle degree (CAD), or one frame every 0.36 CAD at the engine speed used in this study. The maximum image resolution was 512 x 512 pixels, which resulted in a 113 $\mathrm{mm} \times 113 \mathrm{~mm}$ imaged area. The camera exposure time was set to $1 / 17,000 \mathrm{~s}(58.82 \mu \mathrm{s})$ to maximize the acquired signal, which ensured the detection of early weak flames. As FL increased several orders of magnitude throughout combustion and the exposure time cannot be modified during image acquisition, this approach resulted in saturated pixels for fullydeveloped turbulent flame images. However, it did not affect the flame propagation 
analysis presented in this work.

\subsubsection{Operating conditions}

Experiments were performed at lean-mixture conditions and medium engine load. Same operating conditions were used for both optical and metal configurations (baseline condition). The fuel burned in optical engine was the same with the baseline condition of metal configuration. The detailed fuel composition and properties were shown in Table 2.2.

Table 2.5 Optical engine operating conditions

\begin{tabular}{cc}
\hline Parameter & Value \\
\hline Spark Timing [CAD ATDC] & -10 \\
Equivalence ratio [-] & 0.66 \\
Engine speed [rpm] & 900 \\
Spark duration [ms] & 1 \\
Start of injection & 12 CAD BTDC exhaust \\
Intake manifold pressure [kPa] & 84 \\
Intake air temperature [K] & 300 \\
\hline
\end{tabular}

Table 2.5 summarizes the engine operating conditions. A spark timing of -10 CAD ATDC resulted in knock-free operation for both engine configurations. The different residual gas composition (air for the optical engine configuration and combustion products for the metal engine configuration), together with the different effective $\mathrm{CR}$, led to a leaner mixture for the optical engine. 
The thermal conductivity of quartz was much lower than the one of the original metal piston, which can promote the formation of hot spots. More, the optical piston used only two of the three piston rings, which necessitated manual lubrication of the liner and piston rings at very frequent intervals during testing. Despite skip-firing, the combustion event can still foul the optical window. Consequently, the cylinder head needed to be removed each time the window needed cleaning during experiments, which reduced the number of operating conditions and engine cycles that could be recorded at each operating condition before the image quality was affected. As a result, the analysis presented in this study was based on combustion visualization of only a reduced number of visualized cycles engine cycles (twenty-one), recorded at the baseline condition shown in Table 2.5. More, CFD simulations of the optical engine were used to obtain additional information of more flame behavior.

\subsubsection{Image processing}

Photron PFV Version 3.6.4 software controlled camera operation (i.e., frame rate, active pixel array size, shutter speed, and camera triggering). The images were exported as *.avi movie files and subsequently compiled into a series of still images (*.jpg) for image processing. Despite the image coding process [82] would loss some pixel information during video to image transition, image quality was high enough for analysis.

Recorded combustion images (still images) were also processed and analyzed in a 

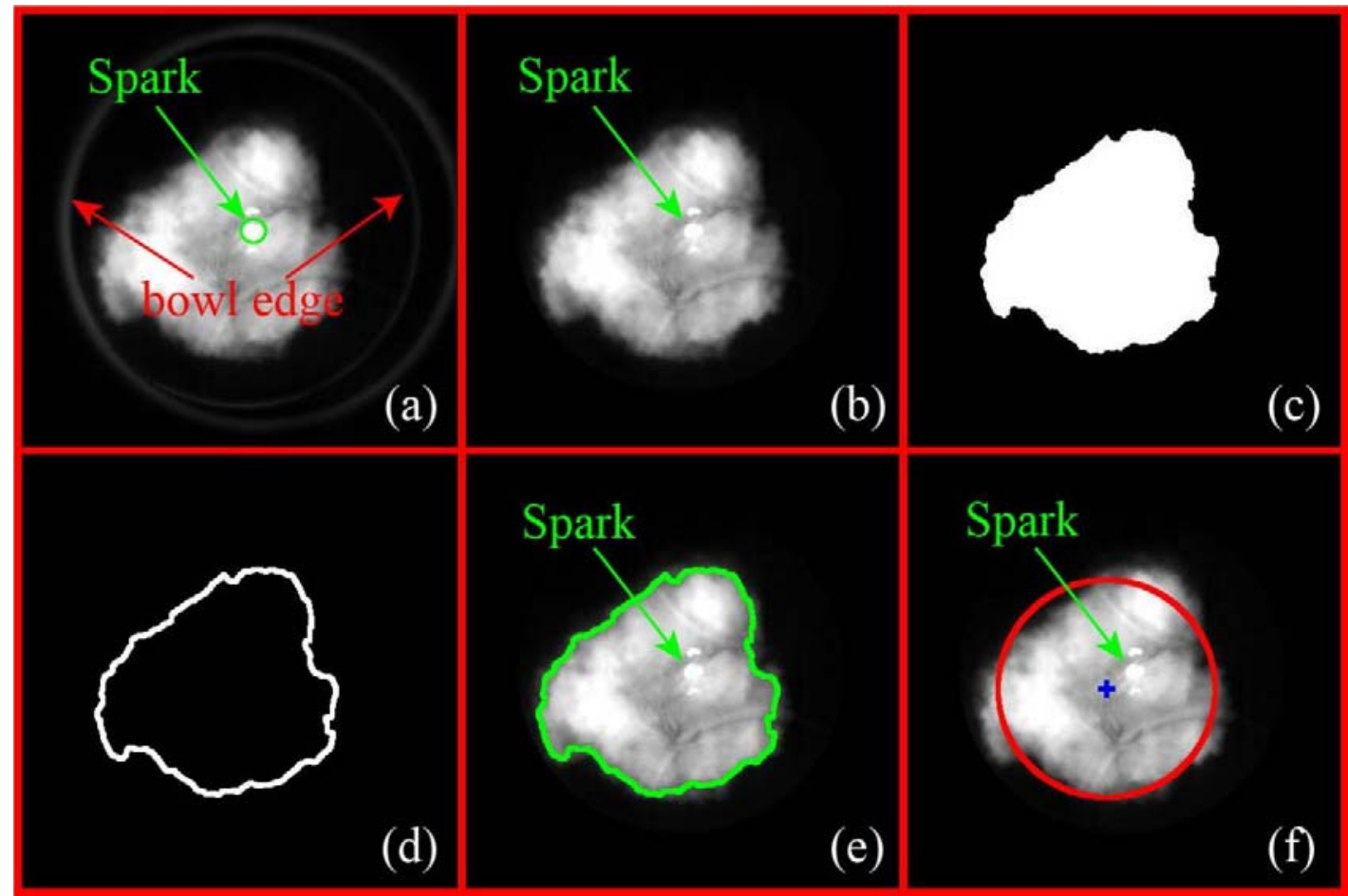

Figure 2.7 Example of raw image processing: (a) the raw image, (b) the image after the background noise was extracted, (c) the image after the binary conversion, (d) the flame edge after the binary conversion, (e) flame edge superimposed on the flame image, and (f) equivalent circular-flame area superimposed on the flame image; the small cross indicates the flame center. Re-entrant bowl edge and the spark plug are visible in (a).

MATLAB ${ }^{\circledR}$ environment using toolbox. Figure 2.7 shows an example of raw image processing for an image collected 22.7 CAD after the spark command (Frame \#64) in engine cycle \#8. Figure 2.7a, shows two circles that surrounded the flame area. The inner and outer circles indicate the bowl and the optical glass edge, respectively. The first step in image processing, shown in Figure 2.7b, was to remove both the camera background noise and these two circles form the raw image, while using the bowl edge as the limit for further image analysis. MATLAB ${ }^{\circledR}$ image processing using Otsu's method [83] converted the gray scale image in Figure $2.7 \mathrm{~b}$ to the binary image in Figure 2.7c. 
Compared to other SI optical studies, the flat-bowl piston geometry of the engine used here better supported the usual assumption of a flame front propagating isotropically from the spark location. As a result, the ideal flame shape would be circular when seen through the Bowditch piston. After the summation of all the white pixels from the 2D binary image, this assumption allowed the calculation of an equivalent flame radius:

$$
r=\sqrt{A / \pi}
$$

where $r$ is the equivalent flame radius and $A$ is the 2D flame area in the binary image. Figure $2.7 \mathrm{~d}$ shows the flame edge detected using the Sobel edge detection [84]. Figure $2.7 \mathrm{e}$ shows the flame with the superimposed edge. Finally, the Levenberg-Marquardt algorithm [85] determined the flame center, using Equation 2.3:

$$
\operatorname{error}_{i, j}=\sum_{x, y}\left(\sqrt{\left(r_{i}-r_{x}\right)^{2}+\left(c_{j}-c_{y}\right)^{2}}-r\right)^{2}
$$

where $\left(r_{i}, c_{j}\right)$ is the assumed 2D flame center location, $\left(r_{x}, c_{y}\right)$ is the assumed 2D flame center location, and error $_{i, j}$ is the cumulative error. Equation 2.3 was applied to each pixel in the processed image and a matrix of cumulative errors corresponding to each temporary center was created. The $2 \mathrm{D}$ flame center was the pixel with the minimum cumulative error. The flame center and equivalent circular-flame area are shown in Figure $2.7 f$. 


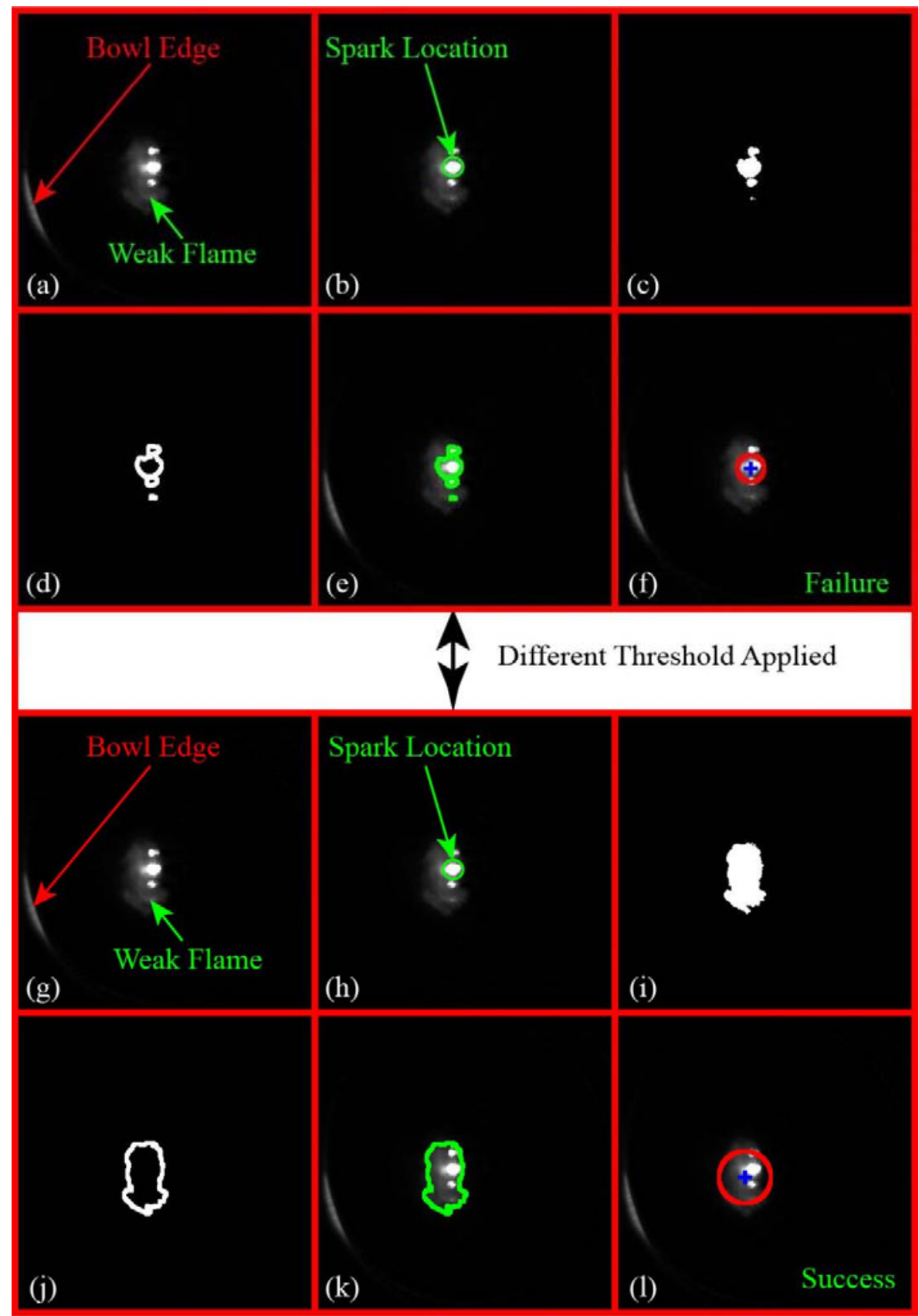

Figure 2.8 Comparison of detected flame with different threshold in image processing: $(a, g)$ the raw image, $(b, h)$ the image after the background noise was extracted, $(c, i)$ the image after the binary conversion, $(d, j)$ the flame edge after the edge detection, (e,k) flame edge superimposed on the flame image, and (f,l) equivalent circular-flame area superimposed on the flame image; the small cross indicates the flame center. The comparison between (c-f) and (i-I) show the results after using two different thresholds (see the text for details). 


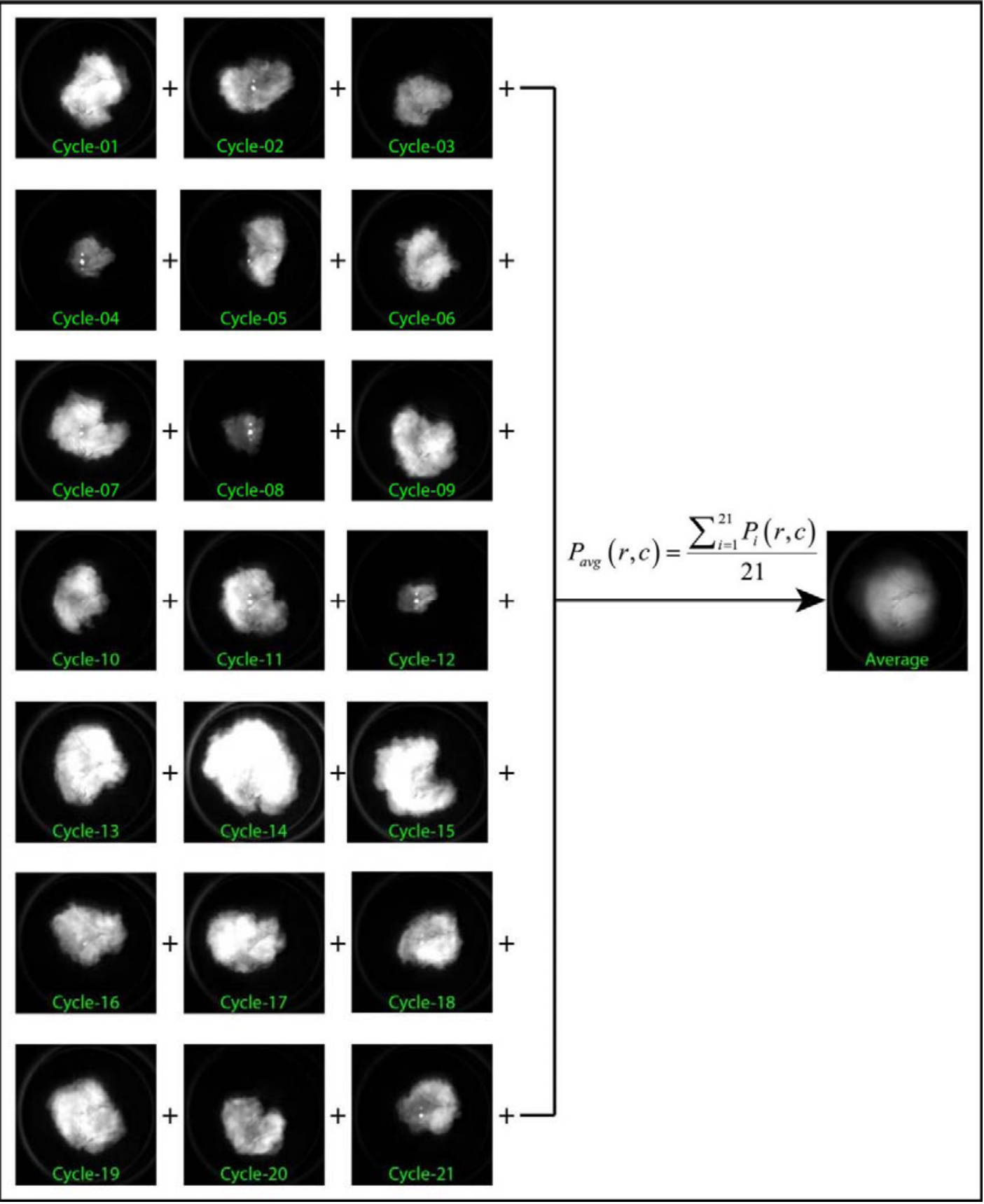

Figure 2.9 The approach of calculating the flame images for average cycle based on individual cycles.

The mean expansion speed of the burned gas is assumed to be the rate of change of the radial flame radius: 


$$
u_{b}=\frac{d r}{d t}
$$

where $u_{b}$ is the sum of flame burning speed and the mean gas speed just ahead of the flame front.

A larger camera exposure time ensured that flame was detected in its early stages. However, the Otsu threshold cannot guarantee the accurate capturing of the weak FL for all frames during the early flame development, such as the example shown in Figure 2.8a-f (engine cycle \#20, frame \#29, 10.1 CAD after ST). Spark reflections probably contributed to an improper Otsu threshold [86], which failed to describe the already-developed weak flame. The solution was to apply a lower threshold, as shown in Figure 2.8g-1. For such instances where the Otsu method failed, the threshold recalculation was repeated until the weaksignal enflamed area was accurately detected, especially during the spark inception period.

The average cylinder pressure was the mean value of pressure traces for all individual engine cycles. FL frames that corresponding to the mean pressure was referred as cycleaveraged flame images in this work. The value of each pixel in the cycle-averaged flame images was obtained by adding the intensities of the same pixel in all individual cycles, then dividing the result to the number of visualized cycles, as shown in Figure 2.9 (frame \#44, 15.5 CAD after ST). The same image processing steps as the ones described above were applied to the cycle-averaged FL images. 


\subsubsection{Heat transfer to the boundaries}

Heat transfer in the optical studies would be used to analyze the cycle-to-cycle variation in this study. The convection heat transfer rate to the boundaries was calculated with Equation

$$
\dot{Q_{h t}}=A \cdot h_{c} \cdot\left(T_{b}-T_{w}\right)
$$

where $\dot{Q}_{h t}$ is the convection heat transfer rate, $A$ is the instantaneous surface area of the combustion chamber walls, $h_{c}$ is the heat transfer coefficient, $T_{b}$ is the in-cylinder bulk temperature, and $T_{w}$ is the wall temperature. In-cylinder bulk temperature was higher in the optical configuration due to the differences in heat capacity between quartz and steel [87]. However, the skip-firing control strategy used for the optical experiments reduced the temperature differences between the optical and metal configurations [87]. As a result, a constant mean temperature of $420 \mathrm{~K}$ for the combustion chamber walls was used for heat transfer calculations. In-cylinder bulk temperature was calculated using the ideal gas law:

$$
T_{b}=\frac{P V}{m R}
$$

where $P$ is the instantaneous in-cylinder pressure, $V$ is the instantaneous cylinder volume, $R$ is the gas constant, and $m$ is the mixture mass, which was assumed to be constant between the closing of the intake valve and the opening of the exhaust valve (i.e., no blow-by). As the air is the main component of the lean combustible mixture and the molecular weight of the combustion products is usually close to the one of reactants in 
methane combustion, the air gas constant was used in the bulk temperature calculations.

The heat transfer coefficient $h_{c}$ in Equation 2.5 was calculated using the Woschni's correlation [78]:

$$
h_{c}\left(W / m^{2} \cdot K\right)=3.26 B(m)^{-0.2} P(k P a)^{0.8} T_{b}(K)^{-0.55} w(m / s)^{0.8}
$$

where $B$ is the cylinder bore of the engine and $w$ is the average in-cylinder gas velocity. The average in-cylinder gas velocity for this low swirl CI engine is:

$$
w=\left[C_{1} \bar{S}_{p}+C_{2} \frac{V_{d} T_{r}}{P_{r} V_{r}}\left(P-P_{m}\right)\right]
$$

where $\bar{S}_{p}$ is mean piston speed, $V_{d}$ is the displaced volume, $P_{r}, V_{r}, T_{r}$ are the workingfluid pressure, volume, and temperature at the reference state, $C_{1}$ equals 2.28 during compression, combustion and expansion period, $C_{2}$ is zero during compression period but equals $3.24 \times 10^{-3}$ during combustion and expansion period. In this study, the reference state was the inlet valve closing condition. In addition, $P_{m}$ is motored cylinder pressure at the same crank angle as $P$.

The mean piston speed used in Equation (2.7) can be calculated by the following equation:

$$
\bar{S}_{p}=2 \cdot s \cdot R P M / 600
$$

where $s$ is engine stroke and $R P M$ is engine speed. 


\section{Chapter 3 Numerical Model}

3D CFD software (ANSYS Forte, Version 17.2), specially designed for IC engines, was used to simulate the operation of the CI engine converted to SI. The G-equation-based model (which included spark inception and the fully-developed turbulent flame propagation) and the $\mathrm{k}-\varepsilon$ turbulence model simulated the combustion process and flow motion, respectively. A unique set of model tuning parameters in the combustion and turbulence models was applied to the numerical model when investigated the effects of changing the mixture composition, spark timing, equivalence ratio, engine load, engine speed, and combustion chamber (metal configuration versus optical configuration). This chapter details the numerical models and model validations for both metal and optical engine configurations.

\subsection{D CFD model for the metal engine configuration}

This section describes 3D CFD model for the metal engine configuration including model geometry, mesh control, sub-models, chemistry, initial and boundary conditions, and simulation controls. It also discusses model validation against the average experimental data.

\subsubsection{Model setup}

SolidWorks ${ }^{\circledR}$ was used to build in-cylinder geometry. After ANSYS ${ }^{\circledR}$ Workbench 
(ANSYS $₫$ Fluent) generated the mesh based on the SolidWorks ${ }^{\circledR}$ model, ANSYS $®$ Forte identified the model surfaces during the nomination process. However, Forte rebuilt the

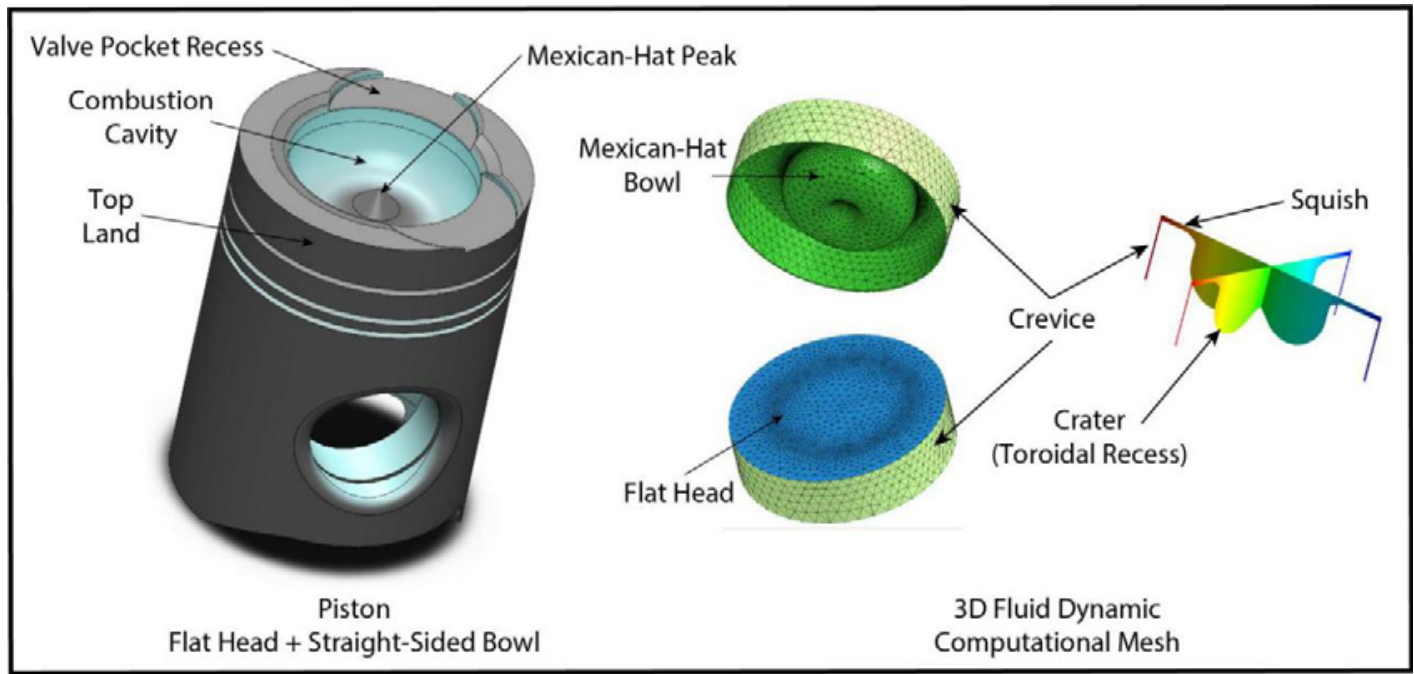

Figure 3.1 Nomenclature of the metal engine combustion chamber and its corresponding computational grid.

mesh control using different settings than Workbench. Figure 3.1 shows the imported metal engine model and the mesh at TDC. NG and air mixed in the experiments inside the inlet manifold, so the level of premixing was already high when the mixture entered the cylinder [70]. As a result, the 3D model did not simulate the intake and exhaust flows. A $360^{\circ}$ mesh was used because the piston bowl was off-center relative to the combustion chamber axis. However, as mentioned before, the spark plug was located on the bowl's center axis. A crevice volume (the narrow volume between the piston, piston rings, and cylinder wall) hanged off the side of the piston. The size of this crevice was adjusted to match the geometric compression ratio because other small feature regions such as the valve crevices, valve recesses, etc. were neglected. The clearance height was kept close to the one in the 
real engine to reasonably-match in-cylinder flow phenomena.

The chemistry is based on the built-in NG mechanism that consists of 39 species and 268 reactions. This mechanism was reduced from a detailed kinetics mechanism consisting of $\sim 4000$ species and validated over a range of equivalence ratios (0.4-2), pressure (1-100 bar), temperatures (1200K and higher), and EGR (0-20\%) [88]. As this mechanism does not include low-temperature reaction pathways, it cannot be used to directly predict knocking [88]. However, there was no evidence of knocking in the experiments at the investigated conditions. The $\mathrm{n}$ - and iso-butane shown as NG components in Table 2.2 were not included in the CFD gas composition because the reduced NG chemistry did not include these two components. In addition, their concentration was negligible compared to the other NG components.

A level-set method approach (G-equation) [89,90] predicted flame development. A major benefit of using this model was that the flame front position (i.e., the location of $G=0$ in the model)) could be validated against the FL data from the optical experiments. The discrete particle ignition kernel (DPIK) model [91,92] predicted the flame inception in a Lagrangian approach, and then transited to Eulerian initializing the flame surface, considering a kernel flame smaller than the grid size. If the spark kernel radius exceeded the characteristic flow length scale, the G-equation combustion model $[93,94]$ tracked the development of the turbulent flame front location. For a smooth mathematical transition 
between the two models, the flame front was assumed to be the same throughout the transition period. The combustion models used a local laminar flame speed that was extrapolated from software's built-in library of laminar flame speeds for methane, ethane, and propane. Specifically, the software calculated the laminar flame speed under premixed adiabatic conditions over a range of equivalence ratios (0.3-2), pressures (10-90 bar), unburned gas temperatures $(500-1000 \mathrm{~K})$, and EGR rates $(0-40 \%)$ using detailed (hightemperature) kinetics $[88,95]$. The data was parsed into a local flame speed library. The laminar flame speed for actual conditions was extrapolated by sampling points within the flame speed library using a linear-least-square fit [96] of a power law/Gulder equation [97]. The chemistry, decoupled from the turbulent flame propagation, was calculated outside of the flame, in the unburned and burned regions [98]. A re-normalized group (RNG) k- $\varepsilon$ model [99,100] (Reynolds-Averaged Navier Stokes (RANS) approach), specifically designed for IC engines, simulated in-cylinder turbulent compressible flows. The timefiltered RANS simulation captured physical quantities such as the geometric features [101], a main focus of this study. The CFD simulation used the default parameter settings in the turbulence model. Turbulence-enhancing effects on the flame propagation speed in SI engines are essential because the auto-ignition chemistry alone is not sufficient to properly model the flame propagation [102]. As a result, the G-equation, the RANS equations, and the RNG k-E model constituted a closed set of equations that completely described the turbulent flame propagation $[103,104]$. The resulting flame front information was then used to calculate in-cylinder heat release, end gas kinetics, and emissions formation. Specifically, 
the species conversion and heat release were modeled as chemical-kinetics-controlled processes (i.e., controlled by the reaction pathways defined by the chemical kinetic mechanisms) inside the regions outside the turbulent flame brush such as the post-flame zones and the end-gas zones [98]. Other main sub-models included the flame quenching model, wall heat transfer model, etc. The flame quenching model [98] examined whether the local flame crossed the border between the thin reaction-zone regime and the broken reaction-zone regime [105]. As the gas-phase convective heat transfer is the dominant heat transfer mechanism in engine applications, the near-wall shear stress and heat transfer were calculated using velocity and temperature wall functions, and energy conservation $[106,107]$

The simulation used automatic mesh-generation at each piston position based on defined mesh-size criteria and specified mesh refinement controls. Specifically, the global Cartesian grid size was $2.5 \mathrm{~mm}$. The spark plug location was refined by creating an $8-\mathrm{mm}$ ball around the spark plug using a grid size one quarter of the global grid size. Mesh refinement (half of global grid size) was also applied to the cell layers around the surfaces to preserve the small-scale features which otherwise risked being filtered out during the small feature deactivation process. These resulted in up to 253,000 and 230,000 computational cells for flow and chemistry calculations, respectively, with their number depending on the operating condition and gas composition. While a grid-convergence test indicated that the grid size would affect predicted results at this level of discretization, the 
use of a finer grid would also have been computationally-expensive in terms of running time, storage, and post-processing for the large number of operating conditions investigated here (it was observed during the grid-size analysis that the simulation would actually "freeze" when a smaller mesh size was used, most probably due to the internal memory limitations). However, a proper choice of tuning parameters in the combustion model allowed the under-resolved model to predict engine performance properly without the need to modify the tuning values for each set of operating conditions [51]. More details will be shown later in the model validation section.

The simulation started from intake valve closing (IVC) and completed at exhaust valve opening (EVO), assuming a homogeneous mixture of methane, air, and residual gas ( $2 \%$ of the exhaust mass). An initial swirl motion was added at IVC to simulate the intakegenerated swirl in the real engine. In addition, the boundaries had a uniformly-distributed and constant temperature during simulation. The model applied advanced adaptive timestep control to allow the most efficient solution while maintaining the accuracy during dynamic simulations where sharp gradients in the solution variables may occur. The initial and maximum simulation time steps were $5.0 \mathrm{e}-7 \mathrm{~s}$ and $5.0 \mathrm{e}-6 \mathrm{~s}$, respectively. The spark event activated the chemistry solver, which was applied independently of the fluid cells in the computational domain. In addition, adaptive mechanism clustering was applied to further save computer time by grouping thermodynamically-similar cells and reduce the calling frequency. For the output control, the spatially resolved and averaged data were 
saved every 1.0 and $0.2 \mathrm{CAD}$, respectively.

Time-filtered RANS simulation only resolved large-scale eddies and modeled the remaining scales. The RANS approach is grid-independent because filters in RANS simulations are in general directly coupled to the grid size and the magnitude of the eddy viscosity. However, the global grid size and mesh control strategy can be regarded as

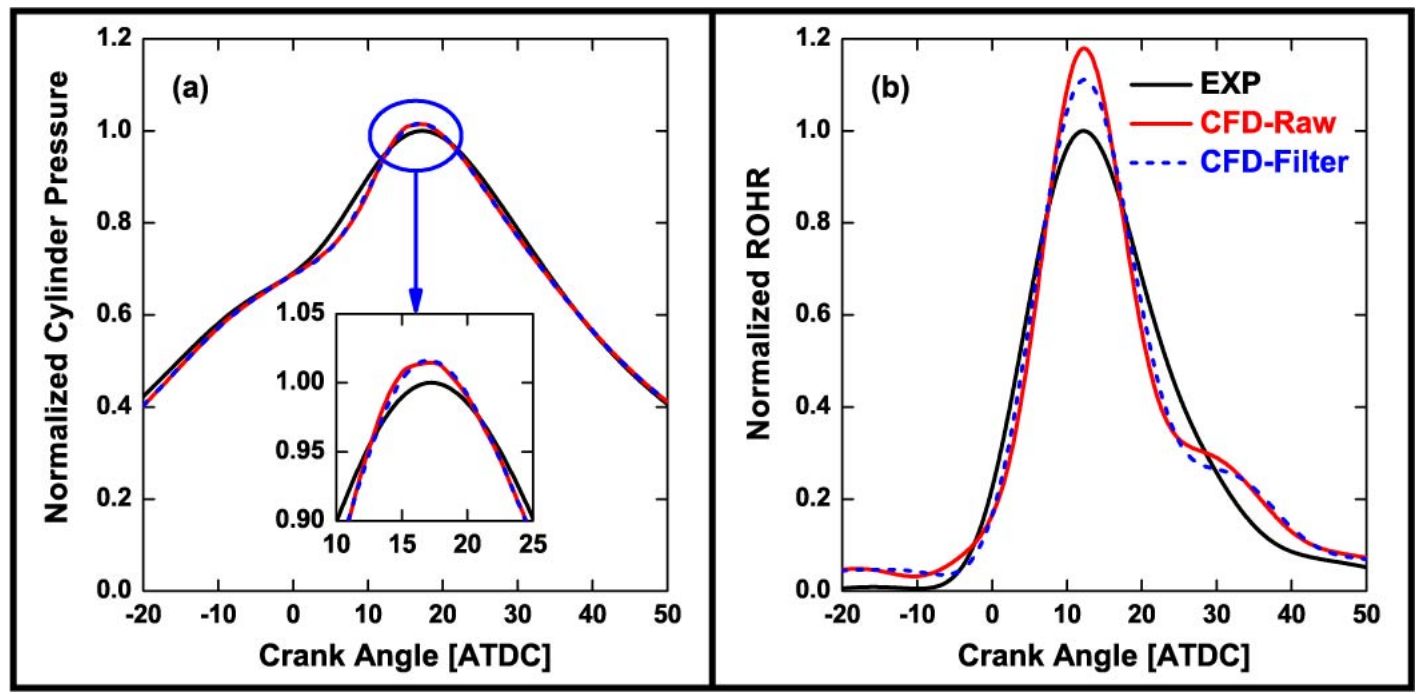

Figure 3.2 Example of CFD filter: (a) experimental pressure, raw and filtered CFD pressure, (b) experimental ROHR, raw and filtered ROHR calculated from filtered CFD pressure trace.

another tuning parameter in the grid-dependent combustion model, in addition to the ones in the combustion models. More, the discrete output points also added noises. As a result, the large cells discretized from the continuous domain required the use of additional filtering on the simulation output [69]. Specifically, a Butterworth zero-phase digital filtering was applied in post-processing to the predicted in-cylinder pressure, heat release 
rate, turbulence kinetic energy, turbulent flame speed and thickness, etc. Figure 3.2 shows an example of the filtered pressure and ROHR. The zero-phase digital filtering shown in Figure $3.2 \mathrm{~b}$ maintained the phasing of the heat release rate, which otherwise can affect engine performance and emissions. As the predicted in-cylinder pressure was validated against the experimental data, the filtered pressure data must avoid any changes in amplitude (i.e., preserve the peak cylinder pressure). Figure 3.2a shows that the filter smoothed the pressure trace, but kept all the small features.

\subsubsection{Model validation}

A robust engine simulation should not require extensive tuning when the operating condition or gas composition is changed [108]. To test this hypothesis for the numerical simulation used in this study, the tuning parameters that affects the combustion model were kept constant, regardless of the simulated gas composition and/or operating condition. The choice of model's CR, in-cylinder gas mixture composition, initial and boundary conditions, and sub-models (e.g., the heat transfer model) affect the predicted in-cylinder pressure trace for a motoring cycle [69]. The choice of tuning parameters for the spark kernel model, turbulent combustion model, and other sub-models (e.g., the turbulence model) affect in-cylinder pressure and ROHR phasing for a fired cycle [69].

The metal engine model was validated for all operating conditions shown in Table 2.3. The average experimental data at each operating condition were selected to validate the model. 
Figure 3.3a shows that the predicted in-cylinder pressure agreed well with the experimental

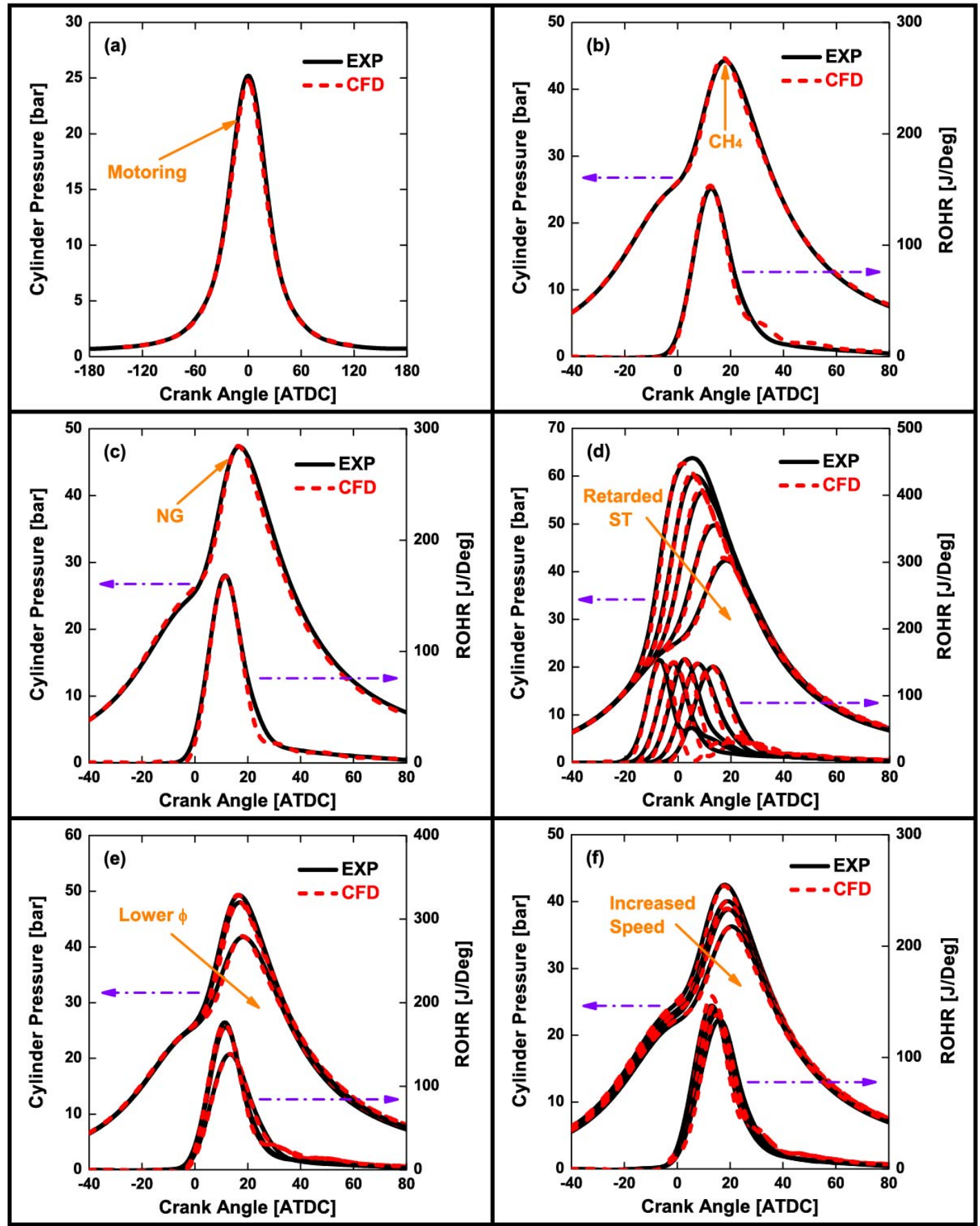

Figure 3.3 Experimental versus metal engine model simulated in-cylinder pressure and heat release rate, for (a) motored cycle (pressure only), (b) fired cycle, (c) different fuel composition, (d) different spark timing, (e) different equivalence ratio and (f) different engine speed. 
data. Therefore, the model under motoring conditions could be used to reasonably predict the in-cylinder turbulence created by charge motion, piston moving and combustion chamber added effects (such as squish band).

Figures $3.3 \mathrm{~b}$ and $3.3 \mathrm{c}$ show that the simulation results agreed well with the average experimental data for fired cycles regardless of the NG composition (see Table 2.3 for details), using a set of unique parameters for the combustion model. In addition, the numerical results predicted a slightly different magnitude of the late burn (i.e., the bump in the ROHR after its peak value towards the end of combustion). Individual engine cycles showed that the magnitude and phasing of the late burn varied cycle-to-cycle, as described later in this work. As a result, the model under firing conditions was able to reasonably predict the NG composition effects on the engine performance.

Figure $3.3 \mathrm{~d}$ shows that the predicted in-cylinder pressure and ROHR agreed well with the experimental data when spark timing changed (see Table 2.3 for details). The larger difference appeared at most advanced spark timings. For example, simulations for a -30 CAD ATDC ST predicted an advanced and lower peak pressure compared to the average experimental data. This difference was probably caused by the delayed and lower second peak of ROHR in the simulations, as shown in Figure 3.3d. In addition, the experimental ROHRs at -25 and -20 CAD ATDC ST show evident late burn towards the end of combustion, which suggests that an important fraction of the fuel burned late. However, 
the numerical model predicted a separated, dual-peak ROHR. More, the simulations show a $2^{\text {nd }}$ ROHR peak for all spark timings except for the -10 CAD ATDC ST. As it will be shown in the following chapters, several experimental cycles had significant late combustion even at -10 CAD ATDC ST and dual-peak ROHR for advanced STs. Consequently, although this late burn characteristic was hidden in the average ROHR data, the CFD model was able to capture it. More, it suggested that this model was able to reasonably predict the average NG lean-burn combustion phenomena inside a bowl-inpiston combustion chamber. Figures $3.3 \mathrm{e}$ and $3.3 \mathrm{f}$ show that the CFD model also predicted well the changes in the equivalence ratio and engine speed (see Table 2.3 for details). Again, the differences in late combustion were reasonable. More, as the actual flow around the intake valve was not modeled, the simulation could not properly capture the changes in volumetric efficiency with engine speed, hence the slightly lower intake pressure at IVC in in the higher-speed simulations shown in Figure 3.3f.

The rest of the differences between simulated results and average experimental data were probably due to the simplified geometry (i.e., small differences in crevice or squish region), the uniform-distributed and constant initial and boundary conditions (temperature and turbulence), the reduced fuel chemistry used to model fuel oxidation, the homogeneous mixture assumption, and uncertainties/simplifications in the various sub-models used.

The combustion phasing and duration influence engine performance and emissions through 
their effect on the in-cylinder heat release rate [12]. Consequently, it is reasonable to assume that predicted emissions would have a similar trend with the experiments if there was a good agreement between in-cylinder pressure and ROHR. The reason is that the built-in sub-models were proved to perform qualitatively well in SI CFD models [51]. However, a separate validation of the emissions trend is required for more complex effects such as the different diesel-NG ratio in dual fuel combustion [9]. This is needed not only to prove that the parameters used in the combustion model were correct, but also to prove the choice of chemical kinetics. Therefore, this study did not validate emissions as the emissions were not the focus here.

Overall, the CFD model agreed reasonably well with the experiments at all investigated conditions, which supported its use for analyzing the flame behavior under lean-burn conditions in this study.

\subsection{D CFD model for the optical engine configuration}

This section describes the numerical optical engine model but focuses only on the differences between this model and the metal engine model. Again, the average experimental data was used to validate the model.

\subsubsection{Model setup}


The optical engine model applied the same chemical mechanism and sub-models as the metal engine model. Figure 3.4 shows that model geometry was the major difference.

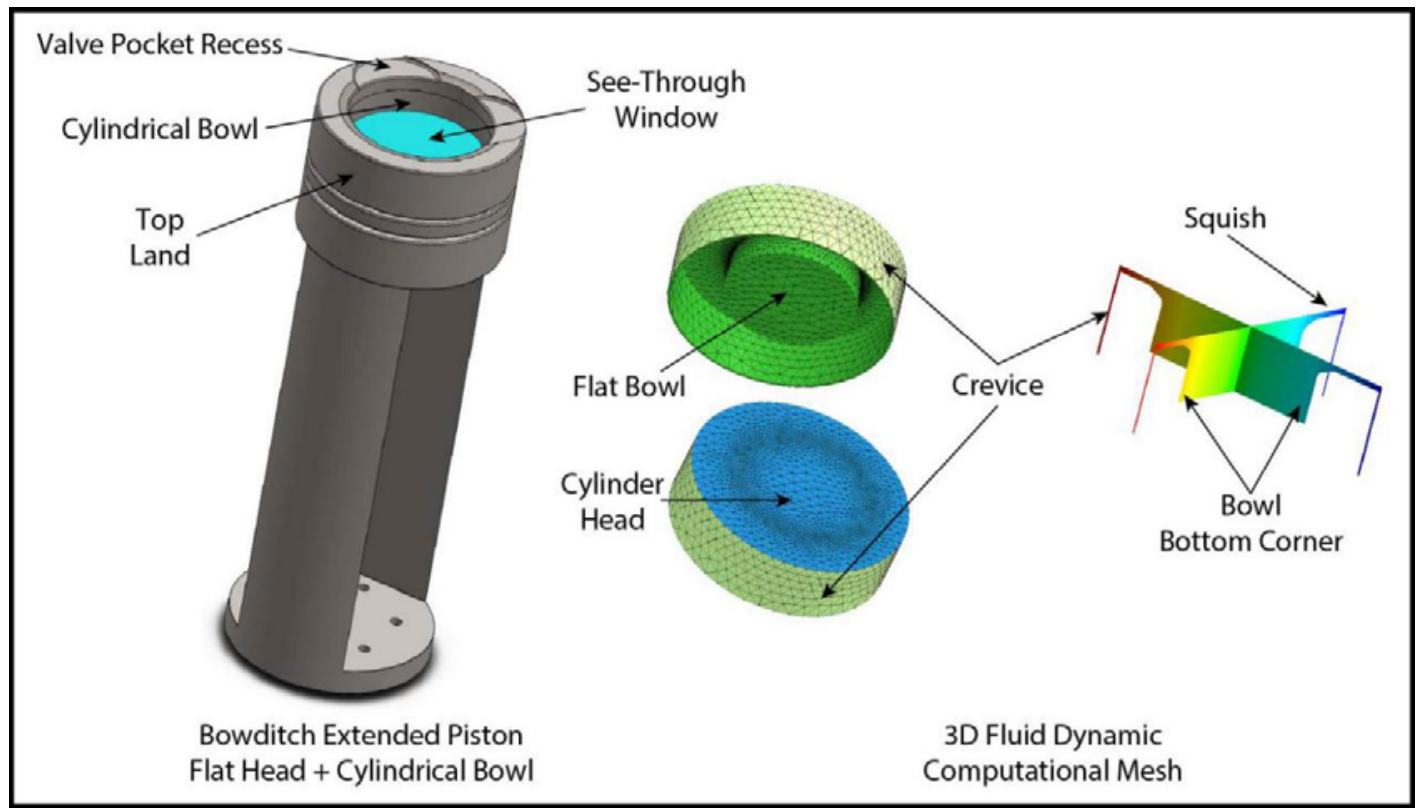

Figure 3.4 Nomenclature of the optical engine combustion chamber and its corresponding computational grid.

Specifically, the optical engine had a cylindrical bowl instead of the toroidal bowl in the metal engine. In addition, the bottom corner region shaped by the vertical wall and flat bottom in the optical piston bowl was different from the toroidal recess in the metal piston bowl. More, the top land volume was larger for the optical engine model. As a result, a crevice volume of a larger size hanged off the piston in the optical model shown in Figure 3.4 .

In addition to the different piston geometry, the skip-fire control strategy resulted in the residual gas in the optical engine being air not the combustion products. The rest of the 
model settings such as the mesh controls, the initial and boundary conditions, etc. were kept the same in both engine models.

\subsubsection{Model validation}

As mentioned in the Chapter 2, the number of acquired cycles during the optical experiments was low due to the complex engine operation. As a result, the average data of twenty-one engine cycles were used to validate the optical model.

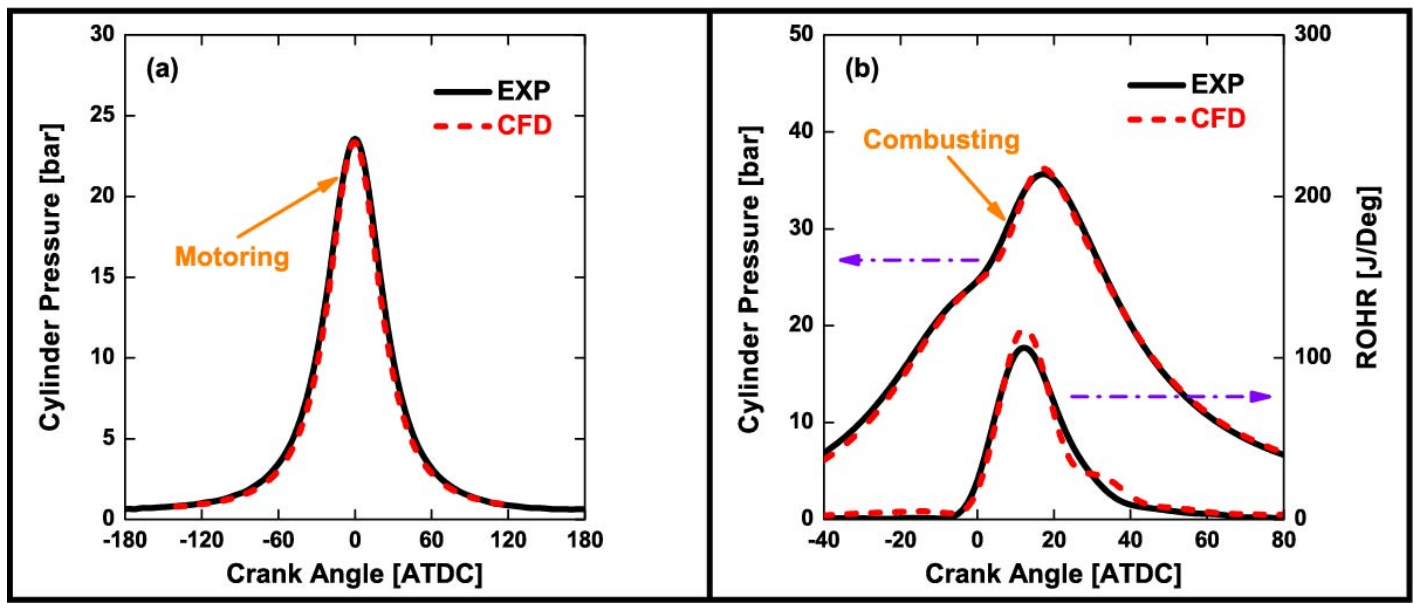

Figure 3.5 Experimental versus optical engine model simulated in-cylinder pressure and heat release rate, for (a) motored cycle (pressure only) and (b) fired cycle.

Figure 3.5 shows predicted and experimental data for both motored and fired cycles. The matched motoring pressure shown in Figure 3.5a validated the compression ratio, initial conditions, boundary conditions, and sub-models (e.g., turbulence model, wall heat transfer model, etc.) used in the simulation. The matched pressure and ROHR shown in Figure $3.5 \mathrm{~b}$ validated the choice of parameters used in the spark kernel model, turbulent combustion 
model, and other sub-models. In addition, it indicated that the G-equation-based RANS simulation agreed well with both metal and optical experiments using a unique set of model tuning parameters. The reader is directed to the explanation in the metal engine model section regarding the differences between the predicted and experimental data.

The flame propagation data inside the bowl region in the optical experiments was used for

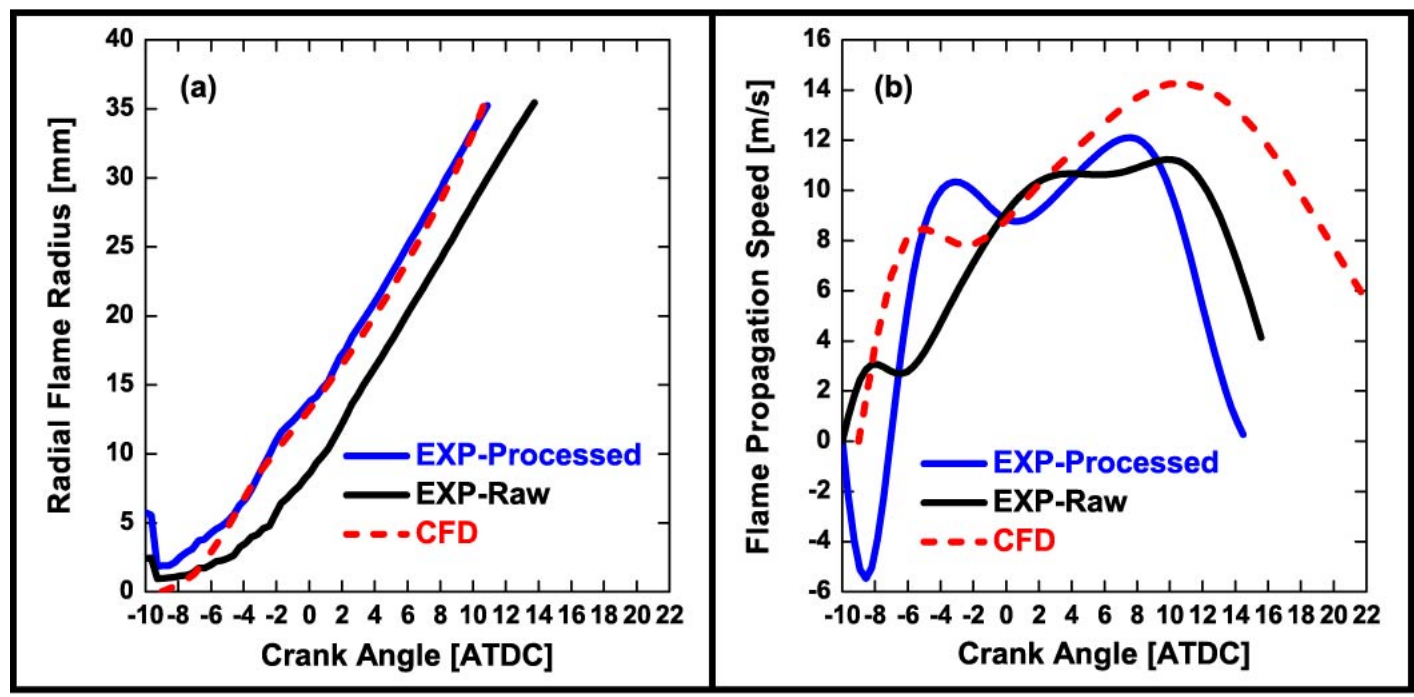

Figure 3.6 Experimental versus optical engine model simulated in-cylinder radial flame information, for (a) radial flame radius and (b) radial flame expansion speed.

further model validation that conventional metal engine data cannot provide. A comparison between the predicted and measured flame propagation inside the bowl is shown in Figure 3.6 . 


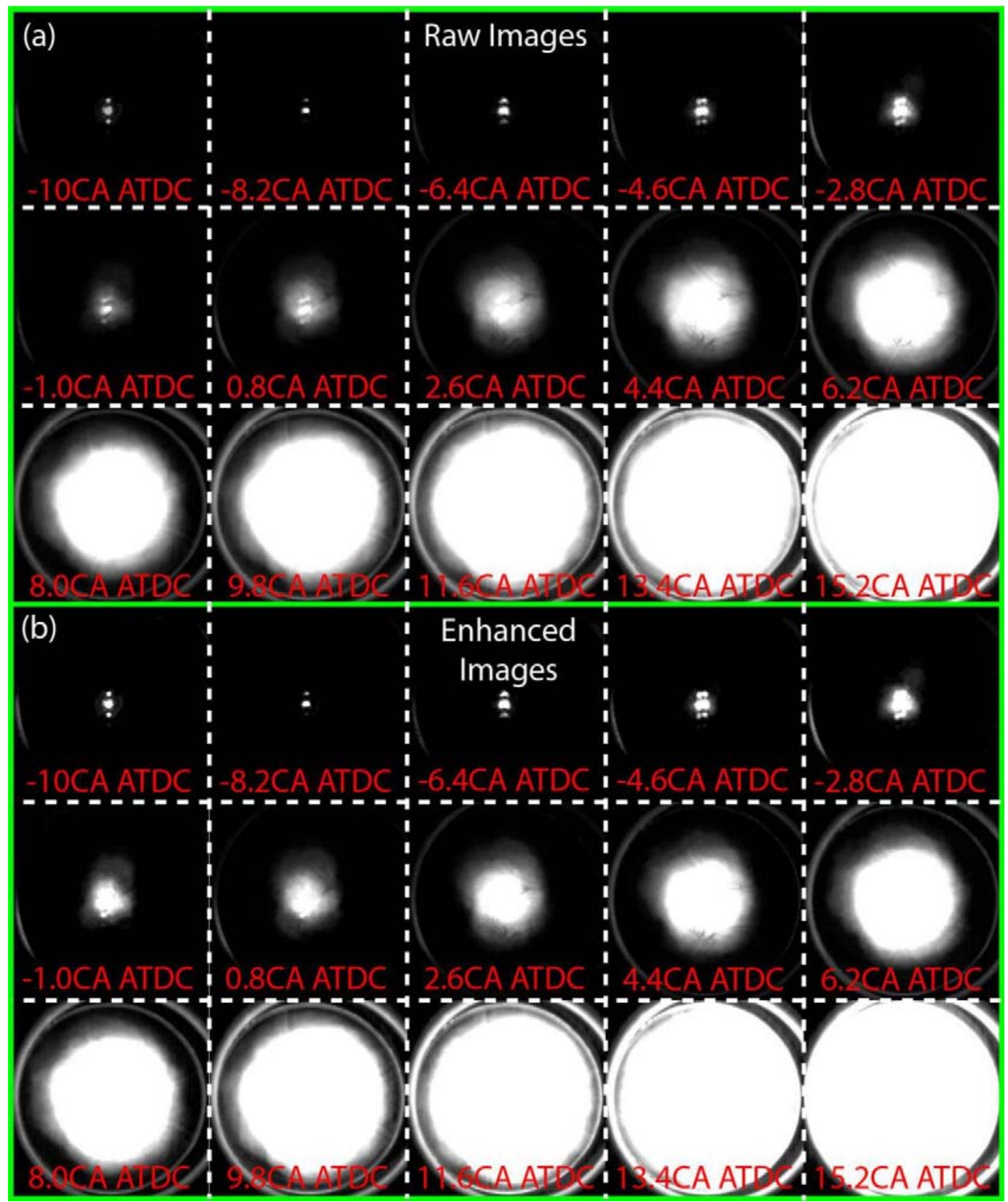

Figure 3.7 Comparison of in-cylinder radial flame development between (a) raw images and (b) enhanced images for average cycle at several CAD of interest.

Figure 3.7a shows the FL images for the average cycle at several CAD of interest before flame reaching the bowl edge based on the approach descried in Figure 2.9. The black line 
in Figure 3.6a shows the flame radius calculated with Equation 2.2 based on the optical measurements in Figure 3.7a. The flame front in the numerical simulation was defined as the location of $\mathrm{G}=0$ in the $\mathrm{G}$-equation turbulent combustion model [98]. The flame radius in the radial direction in the numerical simulations (shown in Figure 3.6a) was also calculated using the Equation 2.2. Even though the numerical simulation predicted that radial flame radius was away from the optical measurement, the gradient of the line was the same. As the edge of visible flame seen through the Bowditch piston was not the actual flame front, parallel relation between predicted and measured flame radius proved that the CFD can reasonably predict the flame propagation in cylinder. In addition, CFD results can help find the optimal thresholds in image binarization for flame detection described in Figures 2.7 and 2.8. However, non-optimal results (such as Figure 3.7a) from optical measurements will be used for discussions in the following chapters due to the lack of LES simulations to help individual cycles to find proper thresholds and due to the negligible effects on combustion characteristics analysis. Figure $3.7 \mathrm{~b}$ shows lower threshold effects when the flame was detected using the image-enhancement algorithm, indicating that an optimal threshold will better capture the enflamed region. The blue line shown in Figure 3.6a shows the measured radial flame radius after the optimal threshold was chosen. It is evident that the predicted flame proceeding process agreed well with the optical measurement from flame inception to the moment when the flame reached the walls of the piston bowl. The differences from -10 to -4 CAD ATDC were due to differences between the real and the simulated 1-ms-long ignition event. The high-intensity spark (as shown in 
Figure 3.7a) probably enlarged the real enflamed area and thus over-predicted the flame radius during spark inception period shown in Figure 3.6a. Figure 3.6b shows the comparison of mean expansion speed of the burned gas between simulation and experiments, calculated by Equation 2.4. The negative values for the optical measurements at the beginning of the analysis process were also due to the effects of the high-intensity spark event. Figure $3.6 \mathrm{~b}$ shows that the numerical simulations captured the flame propagation characteristics.

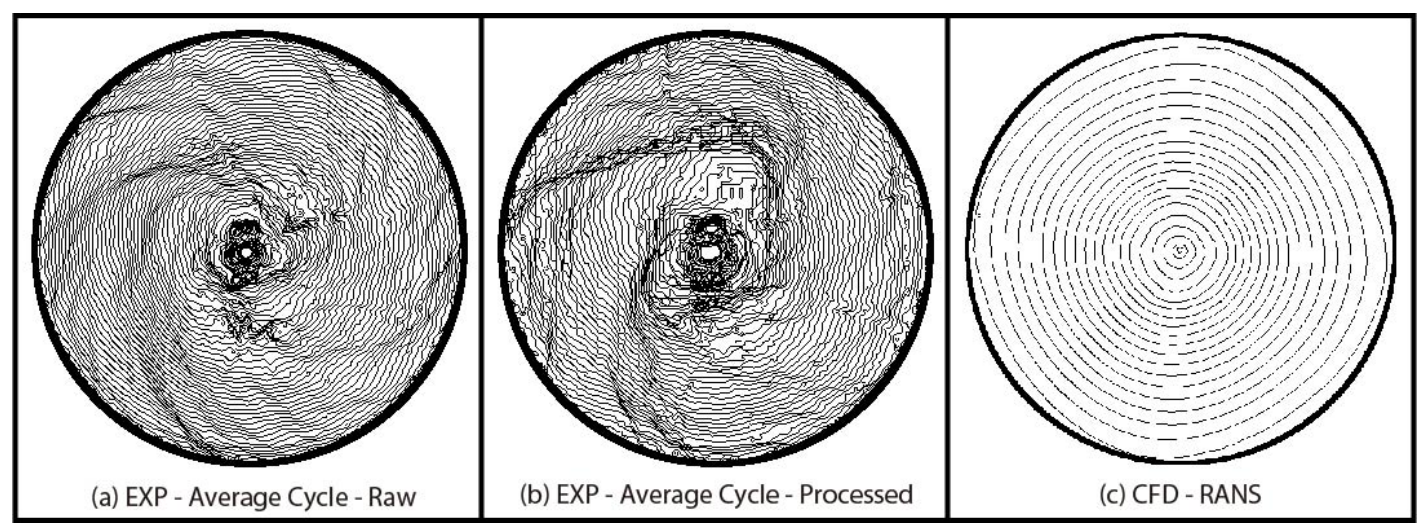

Figure 3.8 Flame contour analysis in piston bowl from bottom view on $(a, b)$ averaged cycle in the optical engine and (c) CFD simulation.

Figures $3.8 \mathrm{a}$ and $3.8 \mathrm{~b}$ present the contours of the flame front inferred from the FL images, for raw and enhanced images respectively. As a reminder, FL images were recorded every 0.36 CAD from the spark command. Figure 3.8c presents the contours of the flame front in the numerical simulation (i.e., the location of $\mathrm{G}=0$ ) every $1 \mathrm{CAD}$, using a similar viewing angle as in the experiment. The flame contours comparison indicates that the RANS simulation captured the flame propagation seen in the cycle-averaged FL data. The counter 
clock rotation seen in the experimental data validated the swirl motion settings in the CFD model. But this phenomenon was not evident in the predicted flame-front contours, probably because the time-filtered RANS simulation only resolved large-scale eddies while modeling the remaining scales [101]. However, it did not influenced the predicted results. In addition, Figures 3.8 validated the assumption of a spherical ignition kernel in DPIK model.

Overall, the model not only matched well the experimental in-cylinder pressure and ROHR but also captured the flame behavior of the average cycle. Consequently, the numerical simulations were deemed capable to reasonably predict in-cylinder turbulence and flame propagation behavior.

\subsection{Summary}

This chapter presented the 3D CFD model used to predict engine operation in both optical and metal engine configurations. The G-equation-based RANS simulation agreed well with the experimental data that changed fuel composition, spark timing, mixture equivalence ratio, engine speed, and combustion chamber geometry, using a unique set of combustion model tuning parameters. The validated motored and fired models were deemed accurate to reasonably predict in-cylinder turbulence and flame propagation behavior. 


\section{Chapter 4 Characteristics of Natural Gas Spark Ignition Combustion inside a Bowl-in-Piston Geometry}

Understanding the characteristics of natural gas spark ignition combustion inside a bowlin-piston geometry can help predict engine performance. This chapter describes how these characteristics were inferred using in-cylinder pressure-data from the metal engine experiments at baseline condition, FL measurements in the optical engine, and the results of the CFD simulations.

\subsection{In-Cylinder pressure analysis}

Experiments in both metal and optical engine configurations were performed at baseline condition (-10 CAD ATDC ST, medium load and 900rpm, see Tables 2.3 and 2.5 for details). As previously mentioned, the different residual gas composition and compression ratio resulted in a slight difference in equivalence ratio between the two engine configurations ( 0.66 for the optical engine compared to 0.73 for the metal engine). However, this difference did not influence the analysis of the NG flame propagation inside a bowl-in-piston geometry.

Figure 4.1 shows in-cylinder pressure, apparent heat release rate, pressure-rise rate, and mass fraction burned (MFB; calculated based on the cumulative heat release rate because, as it will be discussed in Chapter 6, the Wiebe function did not work for these experiments), 

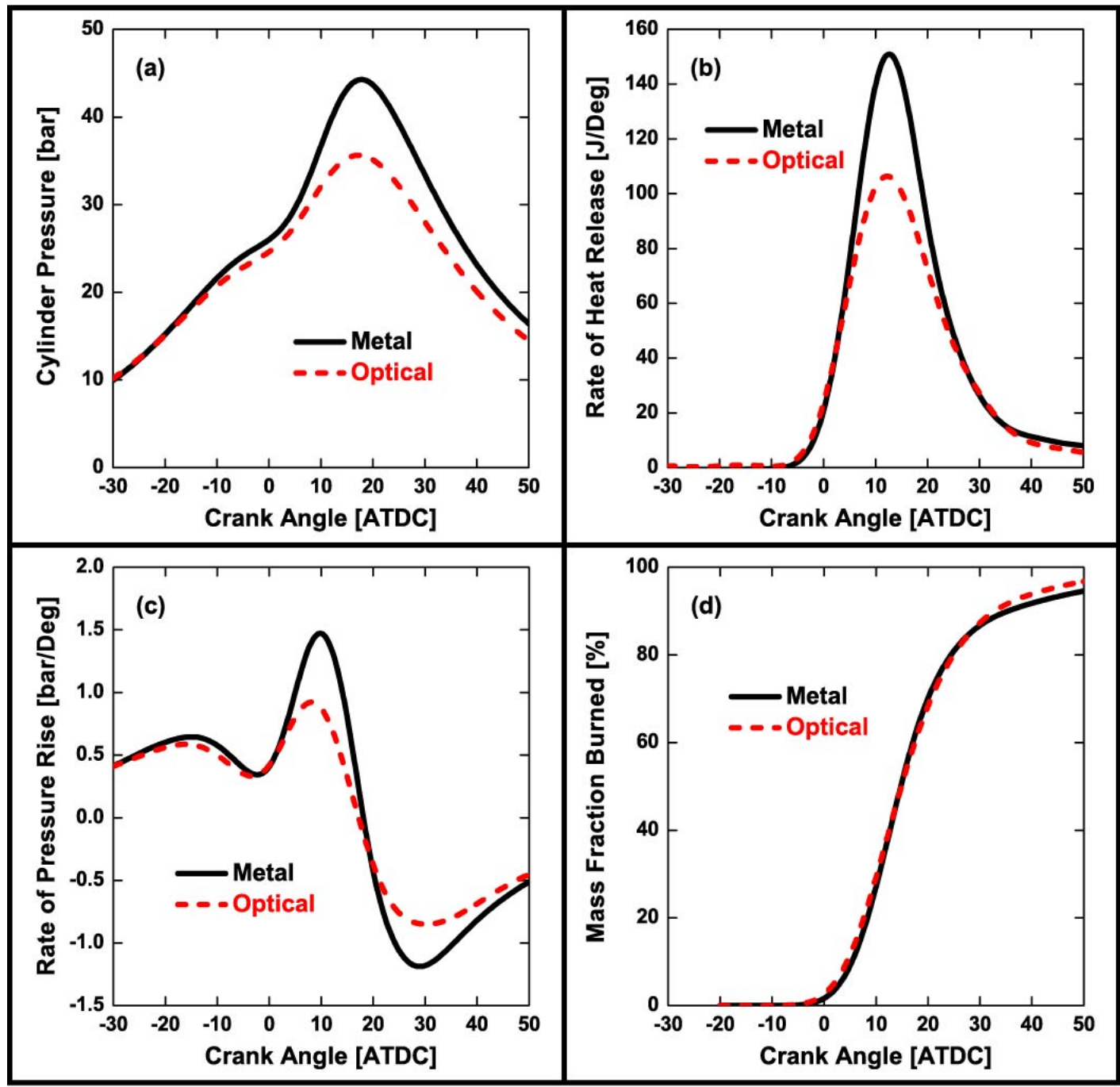

Figure 4.1 Pressure-based analysis for metal and optical engines at baseline condition: (a) in-cylinder pressure, (b) apparent heat release rate, (c) pressure-rise rate, and (d) mass fraction burned.

for both metal and optical engine configurations. There was no evidence of knocking in

Figure 4.1, which validated the choice of compression ratio, spark timing, engine speed, mixture equivalence ratio, and fuel type for these experiments. The maximum pressure rise rate $\left(\mathrm{PRR}_{\max }\right)$ was below $2 \mathrm{bar} / \mathrm{CAD}$ for both engine configurations, indicating that flame propagation dominated the combustion event. The coefficient of variation $(\mathrm{COV})$ of 
indicated mean effective pressure (IMEP), COV IMEP, was below $2 \%$ and $4 \%$ for metal and optical experiments respectively, indicating a stable combustion event. Furthermore, the COV and standard deviation (STD) of peak pressure (COV Pmax and STDPmax) were below $7 \%$ and $3.1 \mathrm{bar}$, and $6.3 \%$ and $2.3 \mathrm{bar} / \mathrm{CAD}$ for the metal and optical engine configurations, respectively. As a result, the average pressure data for both engine configurations were considered representative for the investigated condition and therefore used for the CFD model validation in Chapter 3. The lower pressure and heat release for the optical engine were probably due to the lower effective compression ratio, higher residual gas fraction (air for optical engine), and probably more unburned fuel trapped in the larger crevice. However, optical experiments had an advanced start of combustion (SOC), as shown in Figure 4.1b, suggesting that in-cylinder temperature for the optical engine configuration was higher than that of the metal configuration around the spark command. The higher temperature inside the optical engine suggested a lower heat transfer to the boundaries despite the skip-fire control strategy.

Figure 4.2 shows the ROHR for representative individual cycles. While not quite evident in the mean ROHR in Figure 4.1b, individual cycles in Figure 4.2 show evidence of substantial late burn (defined here as the second peak or "bump" in the ROHR after its main peak [69]) after 20 CAD ATDC, regardless of the engine configuration. This was probably due to the bowl-in-piston that "squeezed" an important mixture mass fraction in the squish volume when the piston was close to the TDC. It can be explained by the 


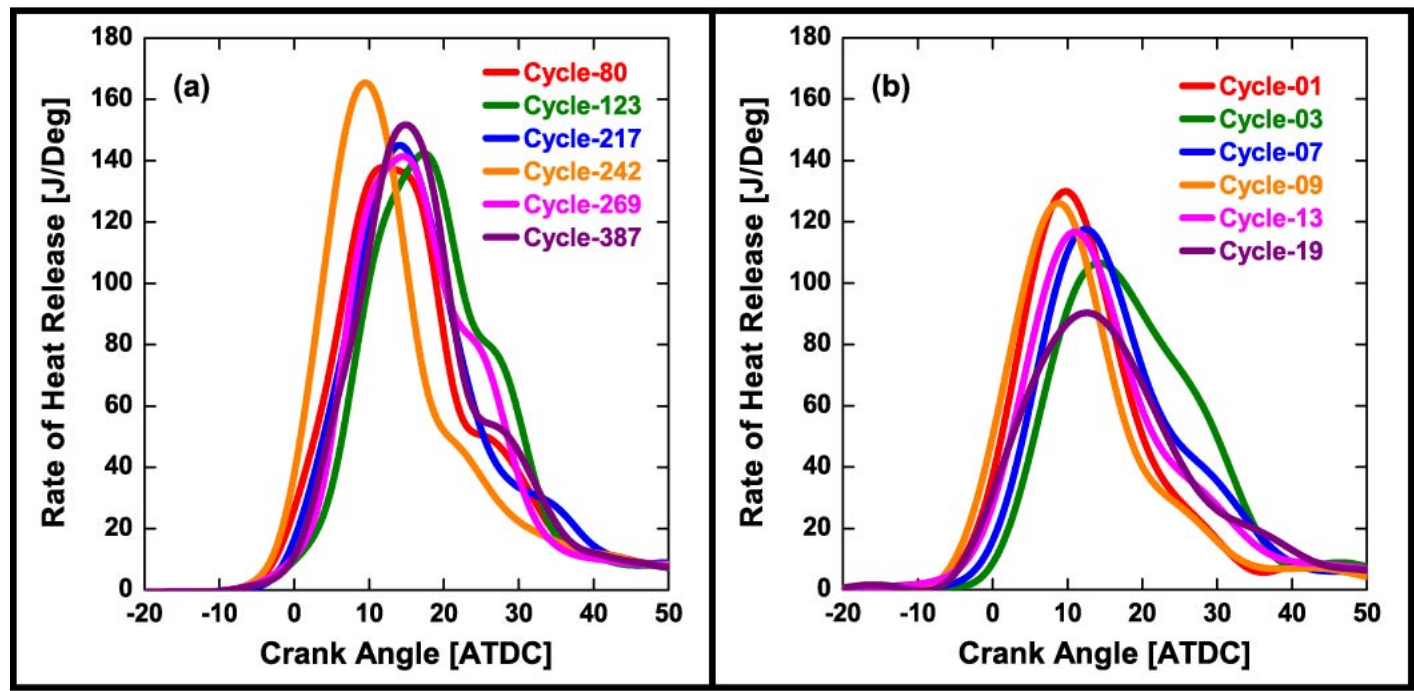

Figure 4.2 Apparent rate of heat release of several individual engine cycles for (a) metal and (b) optical engines at baseline condition.

relatively small height of the squish volume between the spark timing (-10 CAD ATDC) and 20 CAD ATDC. A smaller height in the squish region would increase the surface-tovolume ratio, which would then increase the heat transfer to the cylinder head and piston top. The result would be a lower temperature for the unburned mixture inside the squish volume, which, combined with the lower turbulence in this region, would greatly reduce flame speed. As the squish height increased during the power stroke, the surface-to-volume ratio reduced, which in turn increased the flame speed. This increased the rate at which the fuel was consumed, hence the increase in the heat release rate seen in individual cycles. More, as the late burn phenomenon was the same for both engine configurations, it suggests that the conclusions taken from the optical measurements can be also applied to the metal 
engine configuration.

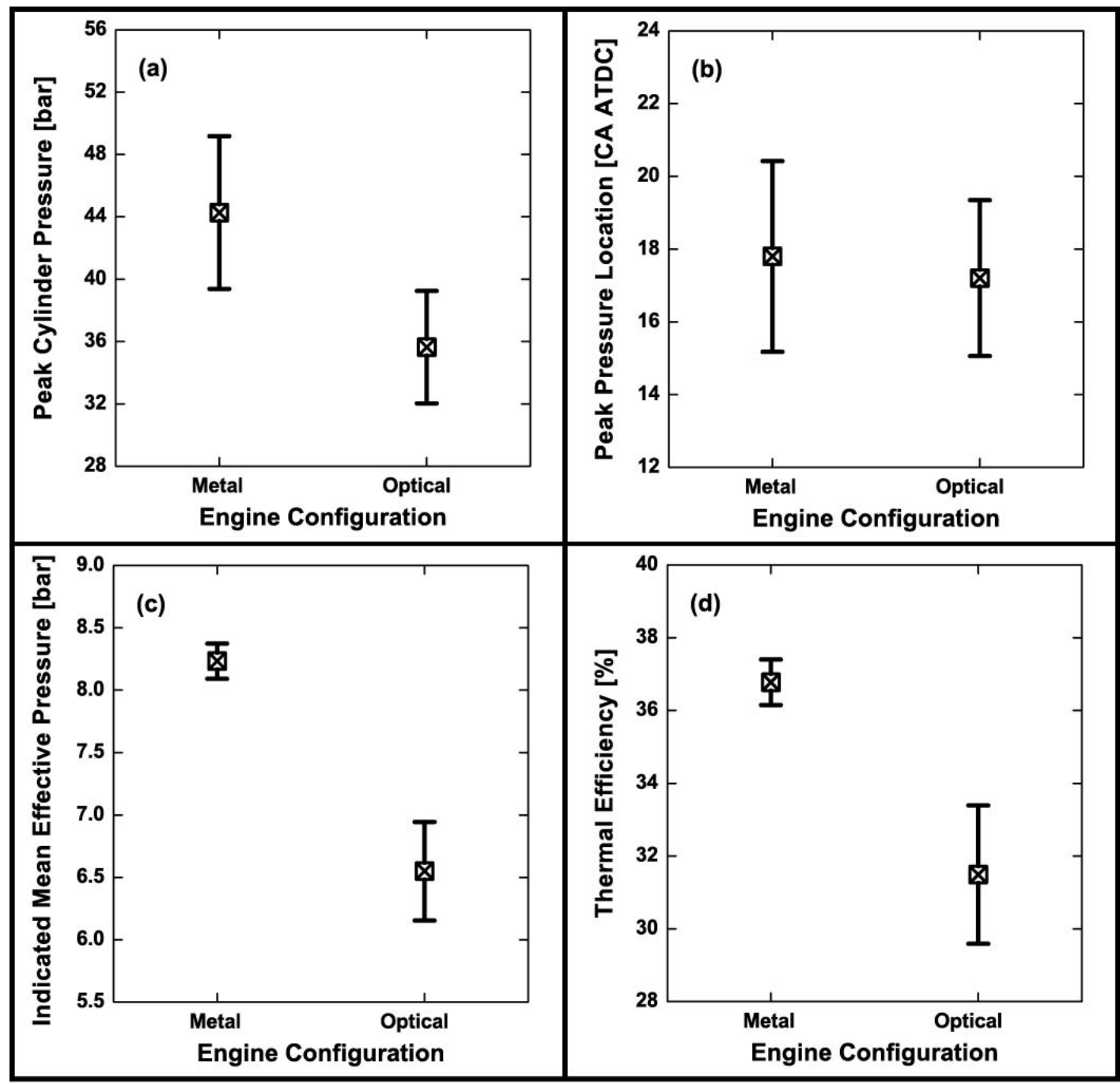

Figure 4.3 Engine performance for metal and optical engines at baseline condition: (a) peak cylinder pressure, (b) location of peak cylinder pressure, (c) indicated mean effective pressure, and (d) thermal efficiency. The error bars in the figures indicate the $95 \%$ confidence interval.

Figure 4.3 presents the engine performance for both engine configurations. The pressure trace in the metal engine experiments had a higher and slightly delayed maximum pressure 


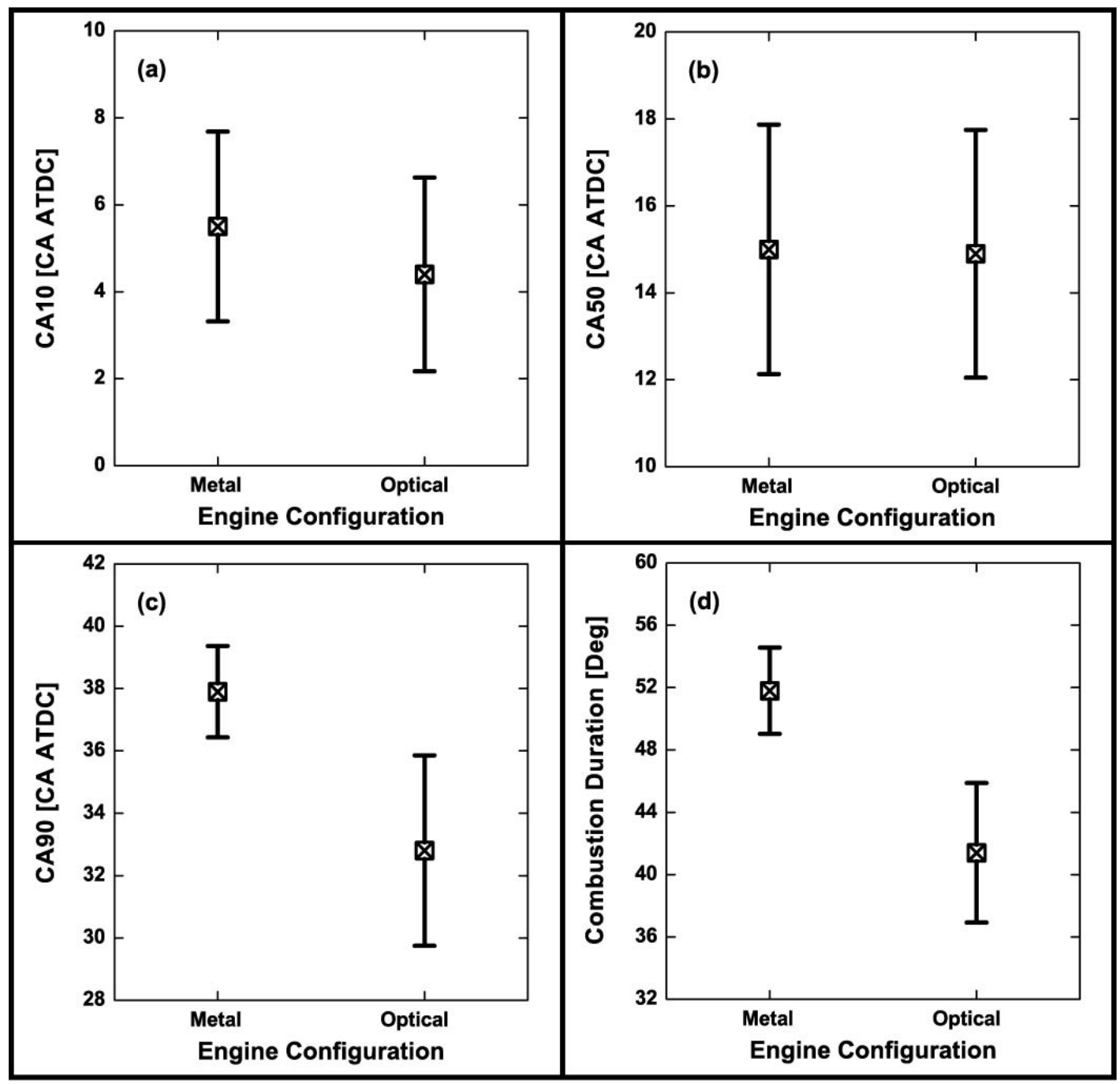

Figure 4.4 Combustion phasing for metal and optical engines at baseline condition:

(a) energy-release fraction of 10 percent, (b) energy-release fraction of 50 percent, (c) energy-release fraction of 90 percent, and (d) combustion duration (interval between energy-release fraction of 5 percent and energy-release fraction of 95 percent). The error bars in the figures indicate the $95 \%$ confidence interval.

compared to the optical engine data. In addition, the metal engine experiments produced a higher IMEP and thermal efficiency.

Figure 4.4 presents the combustion phasing calculated from the apparent heat release data. 
The CAx in this study was defined as the crank angle associated with $\mathrm{x} \%$ cumulative heat release. CA10, CA50, CA90 and combustion duration (DOC) are generally the main evaluating indexes [12]. CA10 is traditionally defined as the end of the kernel inception and therefore the time between ST and CA10 is regarded as the spark inception period [12]. CA50 is usually correlated with efficiency and emissions [12]. CA90 is the conventionally the start of the late combustion period [12]. The combustion duration was defined as the difference in CAD between CA5 and CA95. Optical engine data indicated an advanced CA10 compared with the metal engine, suggesting a faster flame inception, aligned with the faster SOC discussed before. However, both configurations had similar CA50, suggesting a faster flame propagation inside the metal engine after the flame inception period. This was probably due to the differences in the bowl geometry and CR, which would generate some differences in the squish-generated turbulence. The next section will discuss the early flame propagation inside the bowl region using the optical engine experiments. However, the analysis was representative for both engine setups.

\subsection{Flame luminosity analysis}

Figure 4.5 shows a sequence of FL images for the average cycle, using the processing methodology described in Chapter 2. Specifically, Figure 4.5 first presents the FL images from spark timing (-10 CAD ATDC) to $17 \mathrm{CAD}$ ATDC, every $1.8 \mathrm{CAD}$ (i.e., every other 


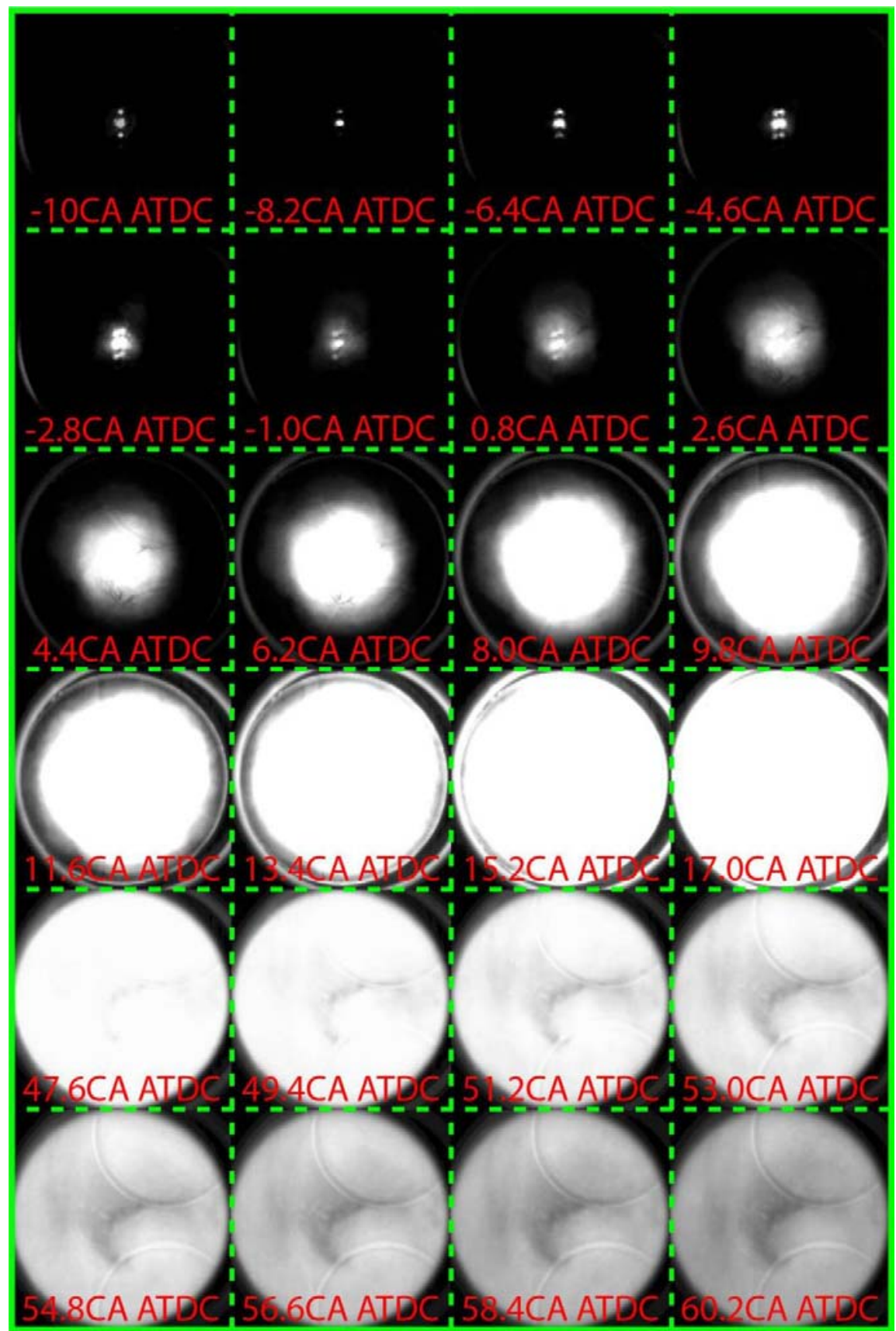

Figure 4.5 Cycle-averaged flame luminosity from the spark until the end of combustion.

fifth recorded frame). The images captured flame inception and propagation until the flame completely encompassed the field of view at 17 CAD ATDC. The FL images recorded after 
17 CAD ATDC were completely saturated (i.e., all the pixels inside the bowl were saturated), therefore this period is not shown here. More, Figure 4.5 also shows the FL images from 47.6 to 60.2 CAD ATDC every 1.8 CAD (i.e., every other fifth recorded frame), which captured the late combustion phenomena inside the bowl region. It is important to mention that FL for early stages was a subjective comparison as it also included the spark light reflected from the spark-plug electrodes and cylinder head. The cycle-averaged FL images indicate an almost circular flame propagation. A thick arc location shown in the first four images in Figure 4.5 was due to cycle-to-cycle variations in spark intensity and arc location. In addition, the cycle-averaged flame touched the bowl edge around 15.2 CAD ATDC, which was after the location of the maximum heat release rate (12.2 CAD ATDC). Therefore, it can be concluded that the fast burning period was associated to the burn inside the bowl region. More, the peak pressure location (17.2 CAD ATDC) was just two degrees after the flame reached the bowl edge, probably because the burning rate was still high at the entrance of the squish band. The short duration from the spark timing to the flame touching the edge of the bowl relative to the total combustion duration further supports the hypothesis of a fast burning inside the bowl region, compared to much longer burning inside the squish region. The FL images were also showing many high-intensity pixels and significant activity after the flame began to burn inside the squish and even after the end of combustion as inferred from the pressure data. As a result, it can be concluded that the cylindrical bowl of the engine optical configuration still contained some unburned mixture, most probably close to the bowl bottom corner as the rest of the 
unburned mixture was consumed inside the (not-visible) squish region. Further, while this unburned mass inside the bowl created a very intense FL signal, it was burning much slower compared to the initial fast burn, probably due to a higher heat loss to the nearby

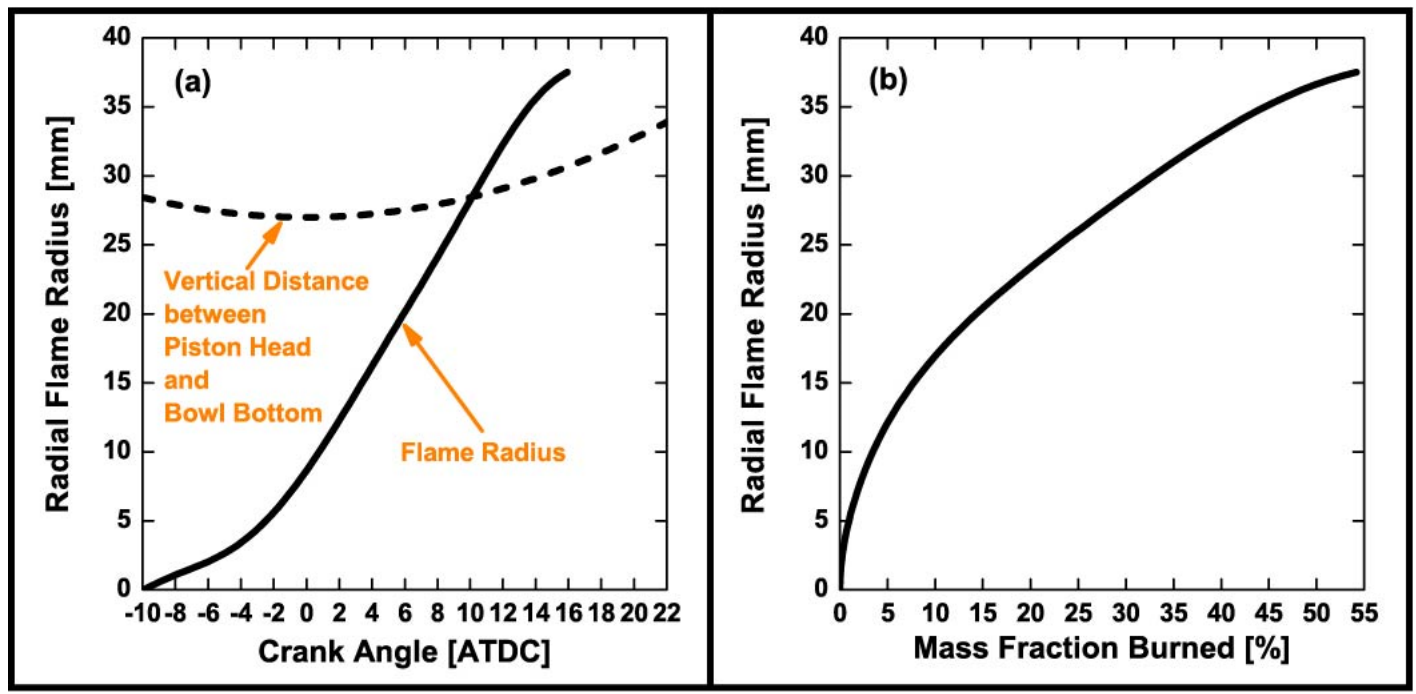

Figure 4.6 Mean-cycle radial flame radius for (a) crank angle degrees and (b) mass fraction burned.

bowl walls.

Figure 4.6 shows the equivalent flame radius for the average cycle, from spark timing to the time flame reached the edge of the bowl. The relatively slow increase in the equivalent flame radius at the beginning of the combustion process suggests that the flame speed during the early combustion stages was slower compared to that during the fast burning period. The comparison of the equivalent flame radius with the distance between the cylinder head and the bottom of the bowl shown in Figure 4.6a suggests that the piston compressed the enflamed region after 8 CAD ATDC. However, the FL images suggest that 
the radial flame propagation was not heavily affected by it. More, based on the CA5 and CA10 values in Figure 4.6b, the FL images showed that the enflamed region reached already an appreciable size at these two crank angles. This suggests that CA5 and CA10 cannot be used to define the SOC for NG SI inside bowl-in-piston combustion chamber. Further, the burned mass was only $\sim 50 \%$ when the flame reached the squish region. Consequently, the squish and crevice region were probably trapping an important mass of

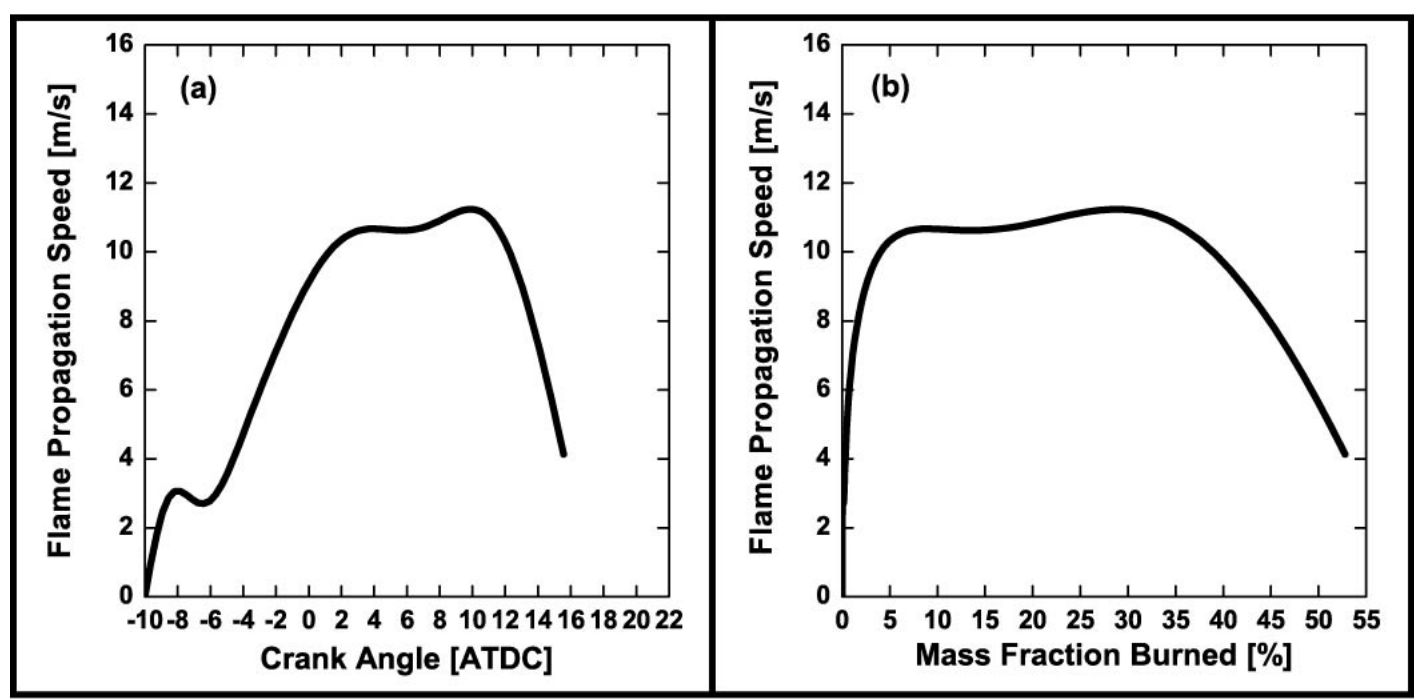

Figure 4.7 Mean-cycle radial flame expansion speed for (a) crank angle degrees and (b) mass fraction burned.

unburned mixture in the optical engine experiments.

Figure 4.7 shows the radial flame expansion speed, which is the derivative of the data shown in Figure 4.6. The fast increase and decrease of flame expansion speed during flame inception stages was due to the spark light interfering with FL. The spark duration was 1 ms (5.4 CAD at $900 \mathrm{rpm}$ ), which was similar to the duration of the flame speed 
increase/decrease seen in Figure 4.7a. After that, flame propagation speed increased during early flame development, then became relatively constant starting around 3 CAD ATDC. While the turbulence inside the bowl decreased when the piston was moving downward after TDC, the flame propagation speed was relatively constant, which was probably due to a combination of the expansion of the burned gas and the flame entering a region with a higher local turbulence, as the turbulence inside the bowl was not homogeneously distributed. In addition, the slight increase in the flame expansion speed shown in Figure 4.7a after 8 CAD ATDC was probably due to piston compression effects, as shown in Figure 4.6a. The radial flame expansion speed start decreasing once the flame front approached the bowl edge, probably due to the wall quenching near the narrow entrance of the squish region. More, the magnitude of the flame expansion speed suggests a very fast flame propagation inside the bowl region. However, Figure $4.7 \mathrm{~b}$ shows that just around $40 \%$ of fuel combusted when the flame speed started to decrease. As the volume of the bowl was large compared to the flame region, this suggests a very thick flame inside the piston bowl during the fast burn period.

Figure 4.8 shows the sum of all visible pixel intensities inside the piston bowl. The bowl contained only saturated pixels between 20 and 50 CAD ATDC, which was due to the larger camera exposure time used to detect the early flame stage. The flame intensity increased very fast with crank angle up to around 20 CAD ATDC (i.e., CA70). The longer period between CA70 and CA95 ( $37 \mathrm{CAD})$ compared to short period between $\mathrm{ST}$ and 


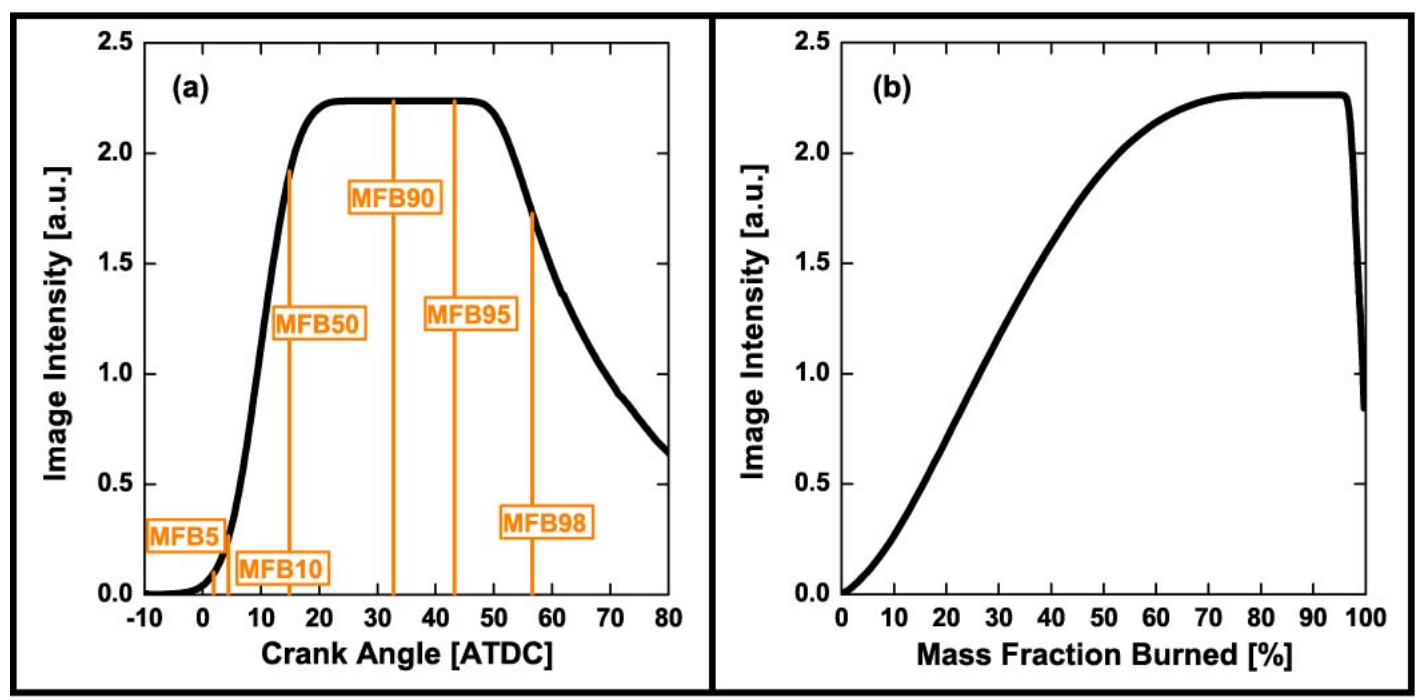

Figure 4.8 Flame intensity throughout the combustion process for the mean cycle: (a) total pixel intensity inside the piston bowl and (b) total pixel intensity function of the mass fraction burned. The plateau indicates complete pixel saturation inside the bowl.

CA70 ( 20 CAD) supports the separation of the overall combustion process inside this bowl-in-piston combustion chamber into two distinct events. Specifically, the bowl region can be considered as the fast-burn zone, while the squish volume and the bottom corner region of the bowl can be associated to the slow-burn zone. More, the slow-burn zone contained an important mass fraction of the unburned mixture, which contributed to the low slope of ROHR and even dual-peak towards the end of combustion shown in Figures 4.1b and 4.2. In addition, the high intensity of the visible light during the late combusting period was probably due to luminosity arising from small amount of unburned fuel and oxidation of active radicals/species inside the bowl region. 


\subsection{In-cylinder flow}

Pressure data for individual cycles showed the late burn phenomenon towards the end of combustion. FL data in the optical measurements showed fast flame propagation in the bowl region. CFD results can provide flame propagation details that cannot be inferred directly from experiments, especially the flame propagation outside the bowl region. This

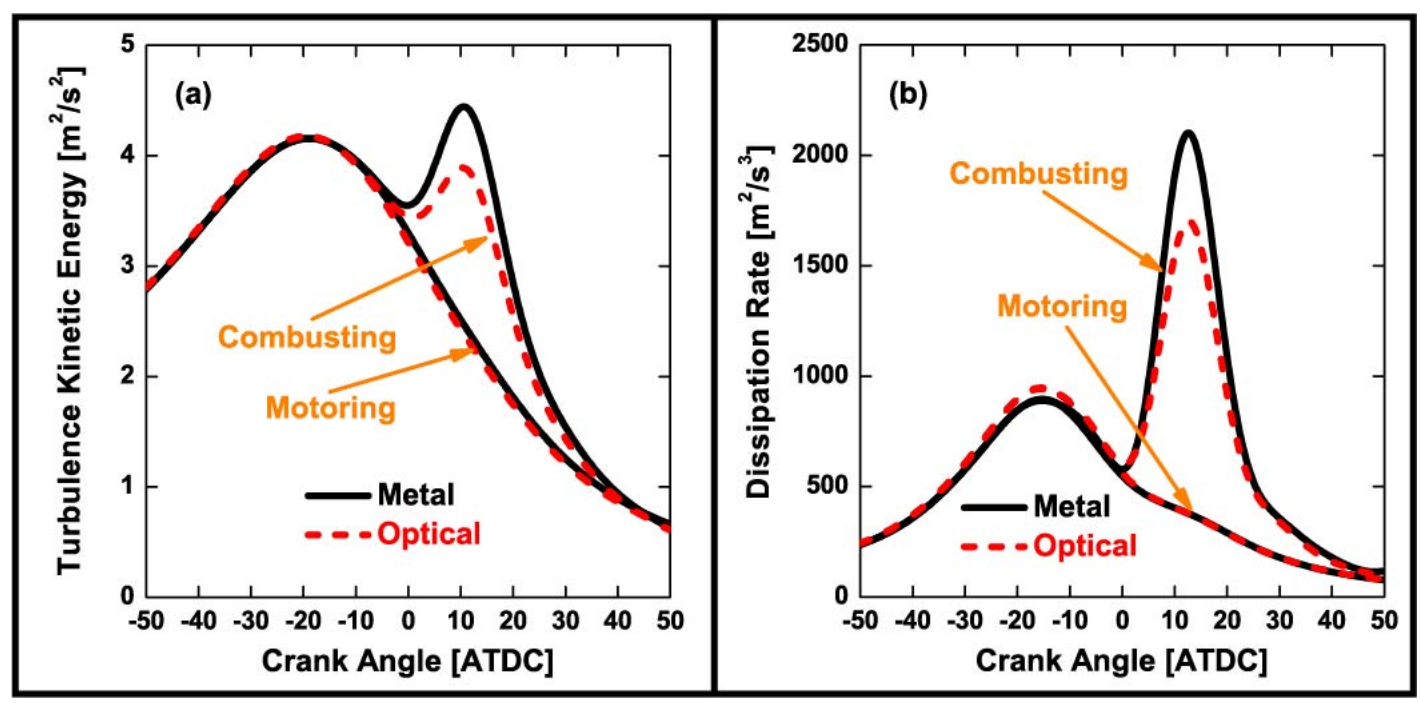

Figure 4.9 Spatially-averaged in-cylinder turbulence: (a) turbulent kinetic energy and (b) turbulent dissipation rate.

subsection will show how in-cylinder flow motion correlated with the flame behavior.

Simulations of both motoring and fired engine operations were used to evaluate in-cylinder turbulence. The 3D CFD model predicted how the interaction between the initial charge motion, piston movement, geometry, and combustion affected in-cylinder fluid motion. The motoring simulation predicted in-cylinder flow without the inclusion of combustion effects. Figure 4.9 presents in-cylinder mean turbulence kinetic energy (TKE) and 
turbulence dissipation rate. TKE is an indicator of in-cylinder gas motion intensity, while the turbulence dissipation rate is the rate at which TKE is converted into thermal internal energy. The motoring trace suggests a similar average turbulence for both engine configurations, with a peak TKE between -20 and -10 CAD ATDC. The peak TKE location supports the choice of spark timing at baseline condition in this study (-10 CAD ATDC) for fast flame propagation. In addition, the TKE had a second, higher peak in the fired cycle, probably the result of the combustion event. The combustion process increased the turbulence intensity more in the metal engine, probably due to more fuel being consumed during the fast combustion period. This hypothesis was supported by the corresponding higher ROHR in Figure 4.1b.

Figure 4.10 shows the predicted gas motion velocity for both optical and metal engine configurations during motoring and fired cycles. The squish region created a high turbulent flow in the radial direction as the piston approached TDC. Also, a tumble flow (see the arrows in Figures 4.11c and 4.11d) was generated by the interaction of squish and pistongenerated flow as the piston moved closer to TDC. The combination of tumble and intake swirl was effective in enhancing and stabilizing the combustion process, therefore increasing the burning rate [12]. For example, the radial inward motion during the compression stroke increased the burning rate as it moved the unburned mixture towards the flame front (see the arrows in Figures 4.11a and 4.11b). However, the flow motion reversed back towards the edge of the combustion chamber during the expansion stroke. 


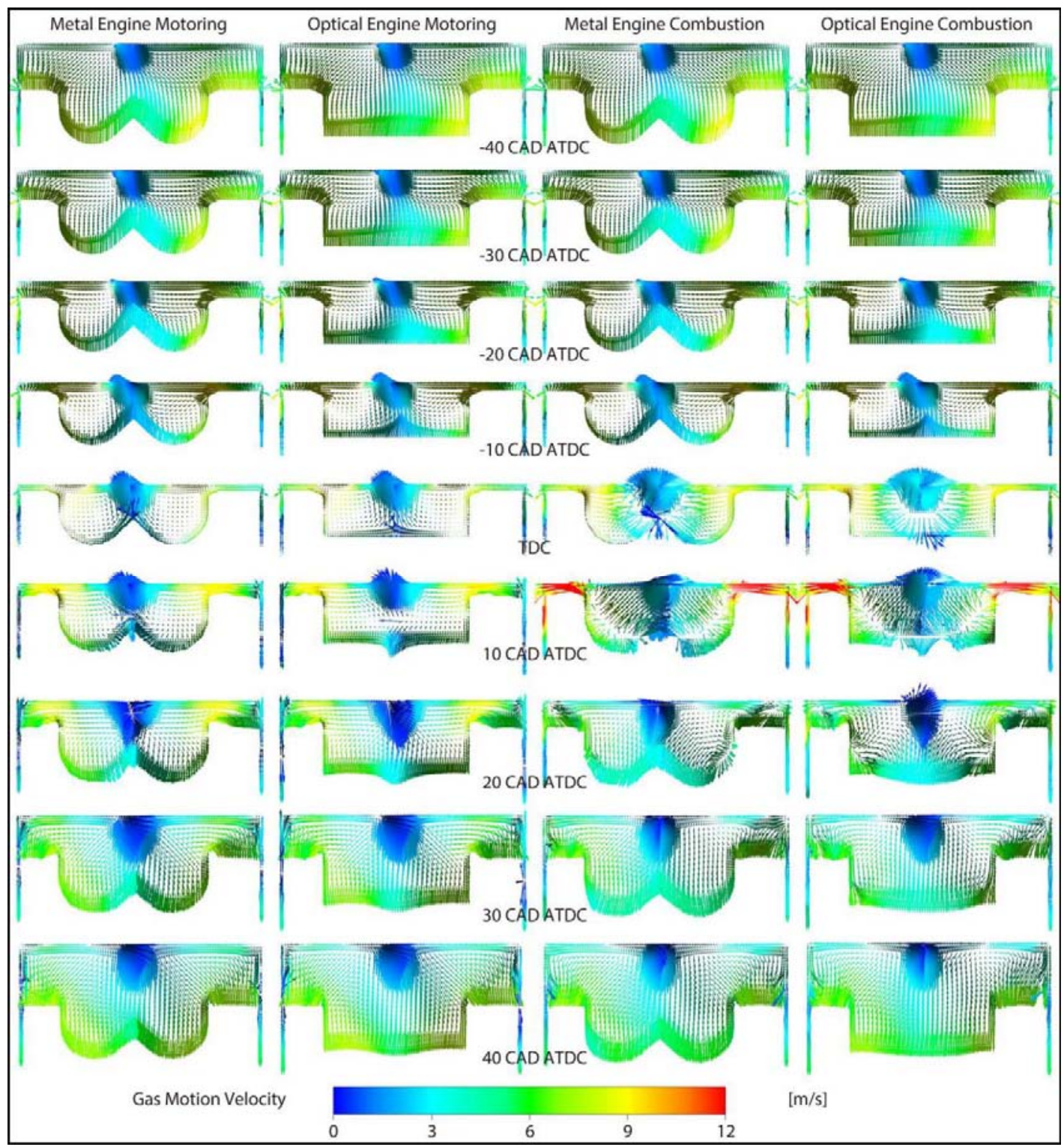

Figure 4.10 Spatially-resolved in-cylinder gas motion during compression and expansion strokes.

The reverse flow (see the arrows in Figures 4.11e and 4.11f) may help to keep a moderate flame speed at the entrance of the squish region, but this outward flow motion further decreased the burning rate towards the end of combustion. For example, the flow simulations from 20 to 35 CAD ATDC (see the arrows in Figures 4.11g and 4.11h) show 


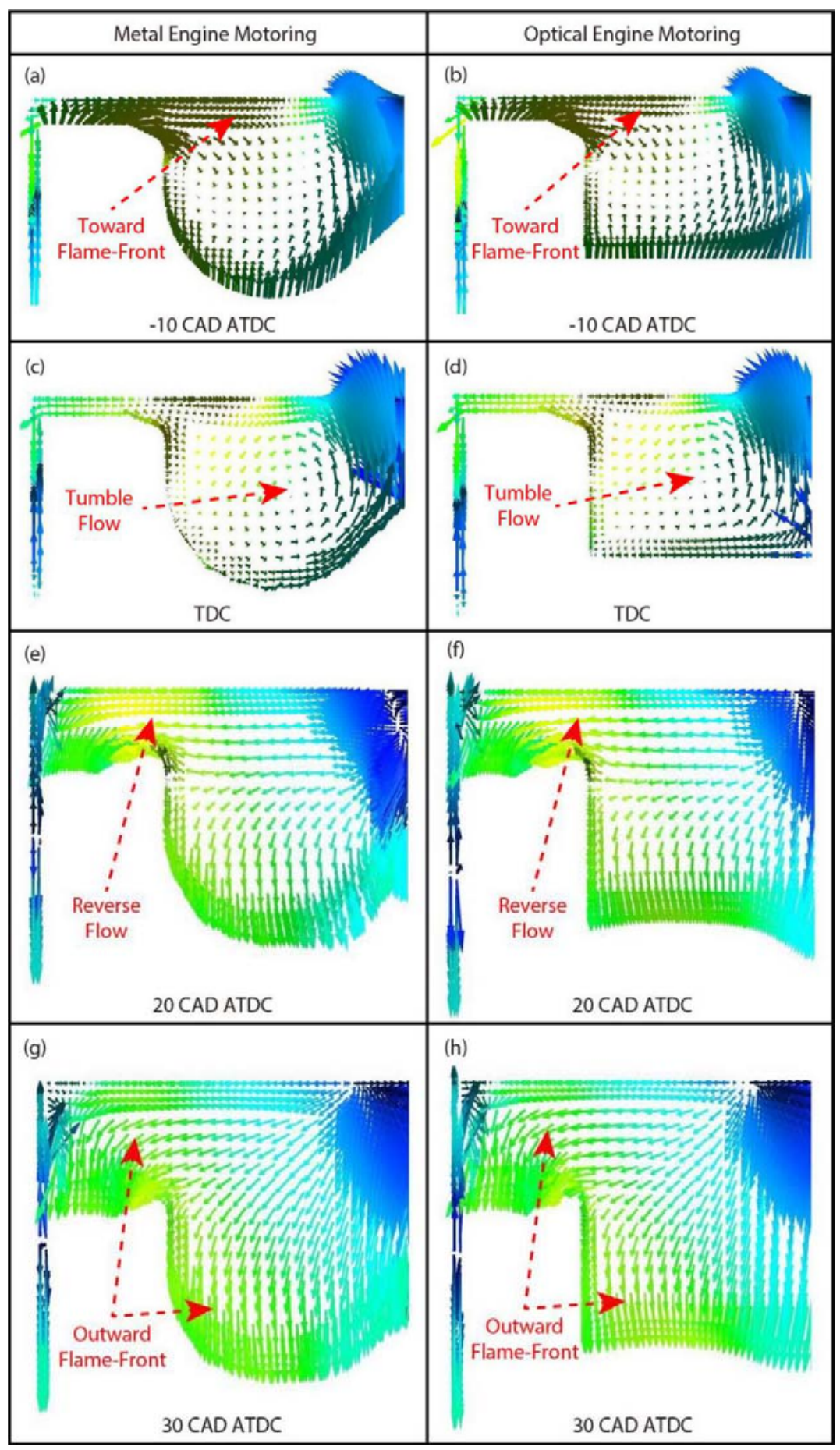

Figure 4.11 Enlarged spatially-resolved in-cylinder gas motion during motoring cycle at several CAD of interest.

that the flow motion in the squish band was towards the cylinder wall and downward during 
the expansion. As a result, it was expected that the burn inside the squish region would be slower and longer.

Further analysis of the motoring trace indicated that while the prominence in the middle of the bowl affected the local fluid motion, it did not significantly affect the flow in other

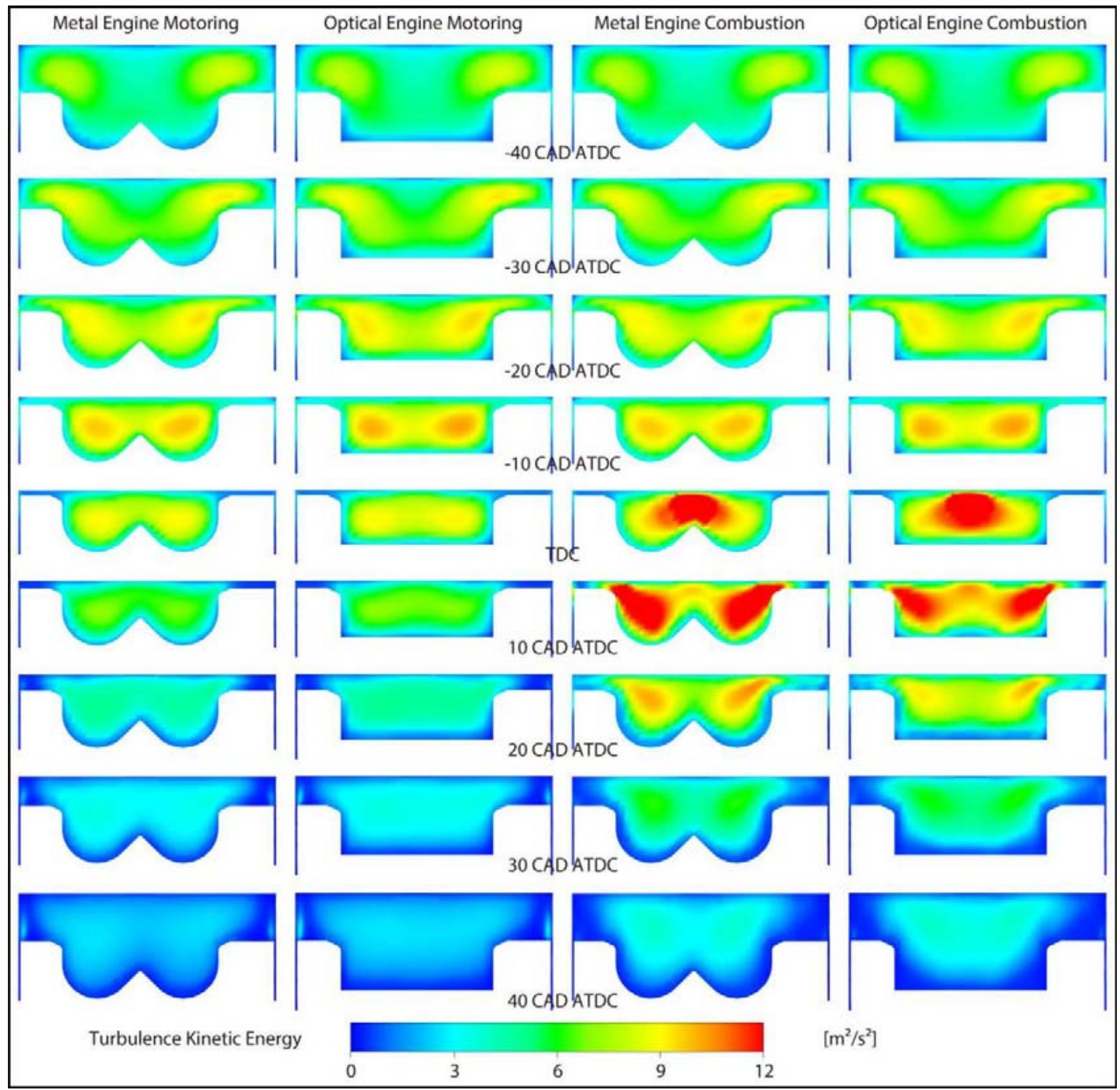

Figure 4.12 Spatially-resolved turbulent kinetic energy at several CAD of interest. 
areas. However, the piston geometry affected flame propagation for a fired cycle and thus influenced the local gas motion.

Figure 4.12 presents the TKE distribution inside the combustion chamber at various crank angle of interest during compression and expansion strokes. The motoring trace for both engine configurations indicated intensive motion during compression in the region between the straight-sided wall and the prominence in the middle of the bowl, which would promote flame propagation. However, as the region around the spark plug location experienced a moderate turbulence, it helped with the ignition process (i.e., avoided early-flame extinction). In-cylinder turbulence decreased as the piston moved downward during the expansion stroke. The squish region closer to the cylinder wall had a much lower turbulence intensity compared to the rest of the squish, which would reduce the local flame speed. In addition, the location and intensity of the high turbulence region were similar for both engine configurations, probably due to the similar clearance height. The slightly higher turbulence intensity inside the optical engine bowl can be explained by the lower mixture mass inside the bowl (because more mixture was trapped inside the larger crevice volume), which reduced the turbulence dissipation rate, hence higher velocity. Figure 4.12 also shows that the prominence in the middle of the bowl also affected the turbulence distribution, evidenced by the slight distortion of the high turbulence region. However, the most significant difference was located at the bottom edge of the cylindrical bowl in the optical engine, which experienced reduced turbulence throughout the whole investigated 
period. As a result, this volume can contain a significant percentage of the fuel, which will then experience a slow-burning process. Further, the reverse squish flow, together with the inertia of in-cylinder flow, probably generated a much higher turbulent flame propagation at the entrance of the squish compared to the rest of the region.

\subsection{Local and time separation of the combustion process}

The turbulence distribution inside the bowl-in-piston chamber separated the combustion phenomena into two separate events: a highly-turbulent and low-turbulence flame propagation. For the metal engine, the highly-turbulent flame propagation was restricted mainly inside the bowl region, while the low-turbulence flame propagation included the toroidal recess of the bowl and the squish band, especially the squish region close to the
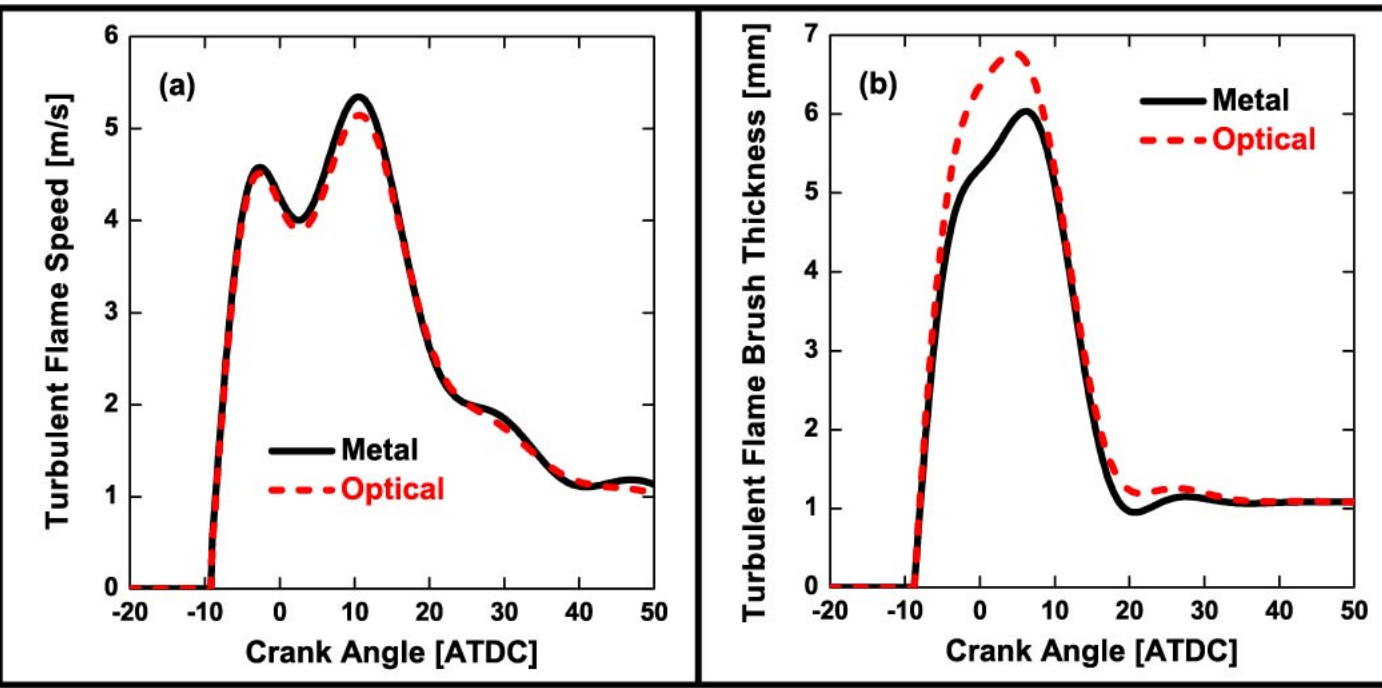

Figure 4.13 Spatially-averaged flame information for metal and optical engines: (a) turbulent flame speed and (b) flame brush thickness (i.e., the square root of the Favrevariance of $\mathrm{G})$. 
liner. For the optical engine, the highly-turbulent flame propagation was also inside the

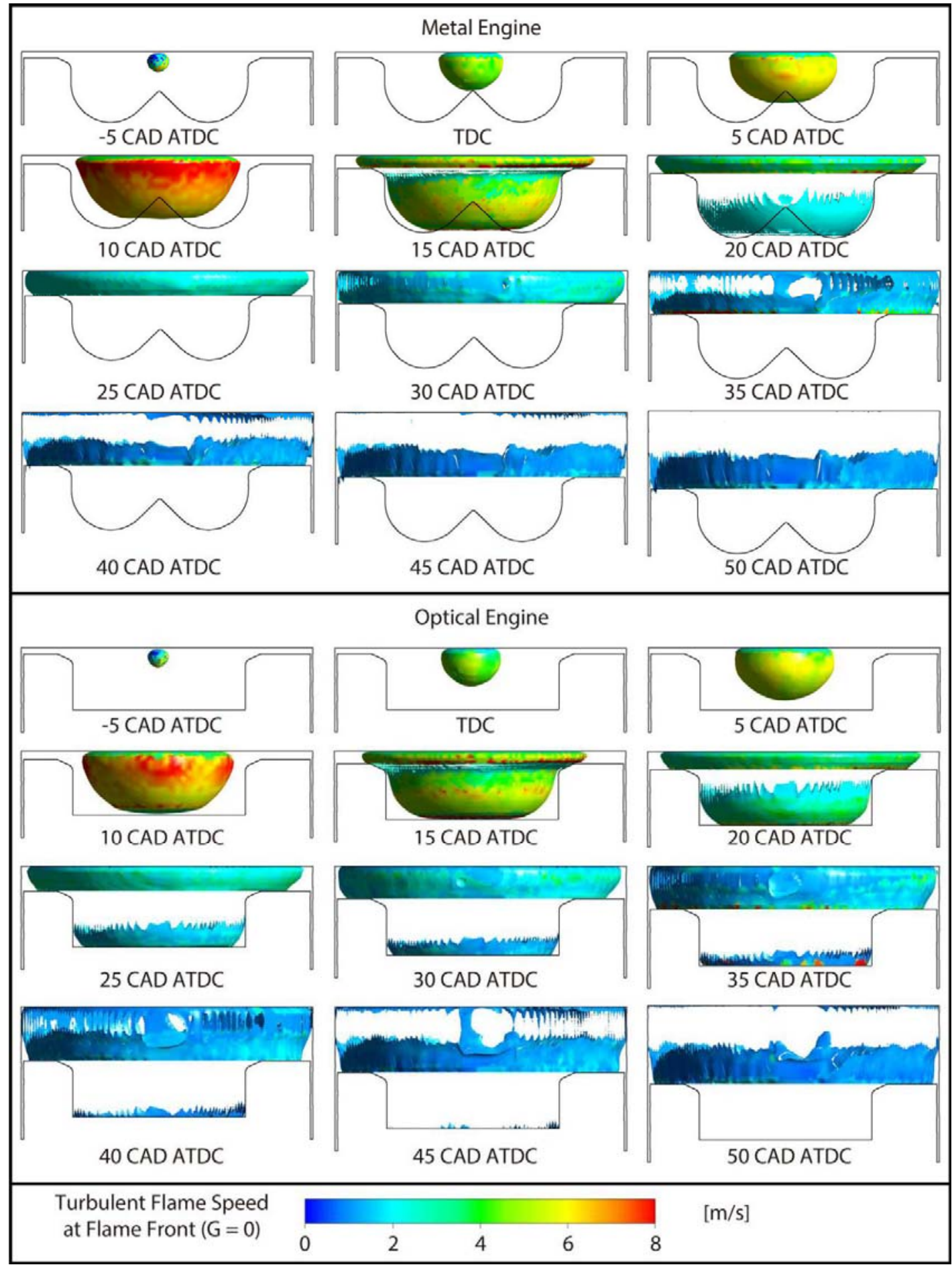

Figure 4.14 Spatially-distributed turbulent flame speed at the flame front (i.e., $G=0$ ) at several CAD of interest for metal and optical engines. 
bowl region, while the low-turbulence flame propagation included the $90^{\circ}$-shaped bottom corner of the bowl and the squish region. Therefore, this section describes the flame propagation process in the bowl-in-piston geometry using the main characteristics of the turbulence distribution inside the chamber.

Figures 4.13 and 4.14 provide additional information on the burning characteristics inside the bowl-in-piston combustion chamber. Figure 4.13 presents the spatially-averaged turbulent flame speed and flame brush thickness. The turbulent flame brush thickness is defined as the square root of the Favre variance of G [98]. Figure 4.14 shows the turbulent flame speed distribution at the $3 \mathrm{D}$ flame front surface. The flame front location $(\mathrm{G}=0)$ in Figure 4.14 shows that the flame entered the squish band around 15 CAD ATDC. Figure 4.13 shows that flame was fast and thick inside the bowl but slow and thin inside the squish, regardless of the engine configuration. The flame brush thickness decreased sharply when entering the squish band, probably due to the low-turbulence. The turbulent flame speed decreased much slower than the flame thickness, probably because the cylinder temperature and pressure decreased more gently compared to the turbulence. Overall, both metal and optical engine simulations predicted the combustion separation into two distinct events. The fast-burn zone coincided with the high-turbulence region, while the slow-burn zone coincided with the low-turbulence region.

It is also of interest to investigate the difference in the actual flame propagation between 
the optical and metal engine configurations. Figure 4.13 shows that both engine configurations had similar averaged turbulent flame speed, despite the leaner mixture and smaller CR for the optical engine configuration. The similar flame propagation supports the hypothesis of a similar in-cylinder flame development. However, the two configurations had a different average flame thickness, especially from TDC to $10 \mathrm{CAD}$ ATDC (i.e., during inside-the-bowl flame propagation), probably due to different local environments and bowl-crown effects. The spatially-resolved flame development process shown in Figure 4.14 was almost similar between optical and metal engine configurations. While flame propagated fast inside the bowl, the flame front masks the effects of the prominence in the middle of the bowl. However, the 3D flame front in Figure 4.14 suggests that the bowl dome did not influence the flame propagation in the rest of the bowl. After the fast flame slowed near the bowl edge in both engine configurations, the flame started to propagate inside the squish region, where the flame speed decreased continuously. The simulations predicted a faster burning inside the squish for the metal engine, evidenced by the flame front location at 35, 40, and 45 CAD ATDC in Figure 4.14. This was probably due to the lower equivalence ratio (0.66 compared with 0.73$)$ and lower local temperature for the optical engine at those crank angles, which reduced the flame speed in this lowturbulence region. The metal engine already completed the burning inside bowl at $25 \mathrm{CAD}$ ATDC. However, at this crank angle degree the optical engine still had an important fuel mass trapped at the bottom of the bowl. The result was that the fuel burning inside the bowl completed around $50 \mathrm{CAD}$ ATDC in the optical configuration. The fuel burning at the 
bottom of the bowl experienced a much slower flame speed, probably due to the lower

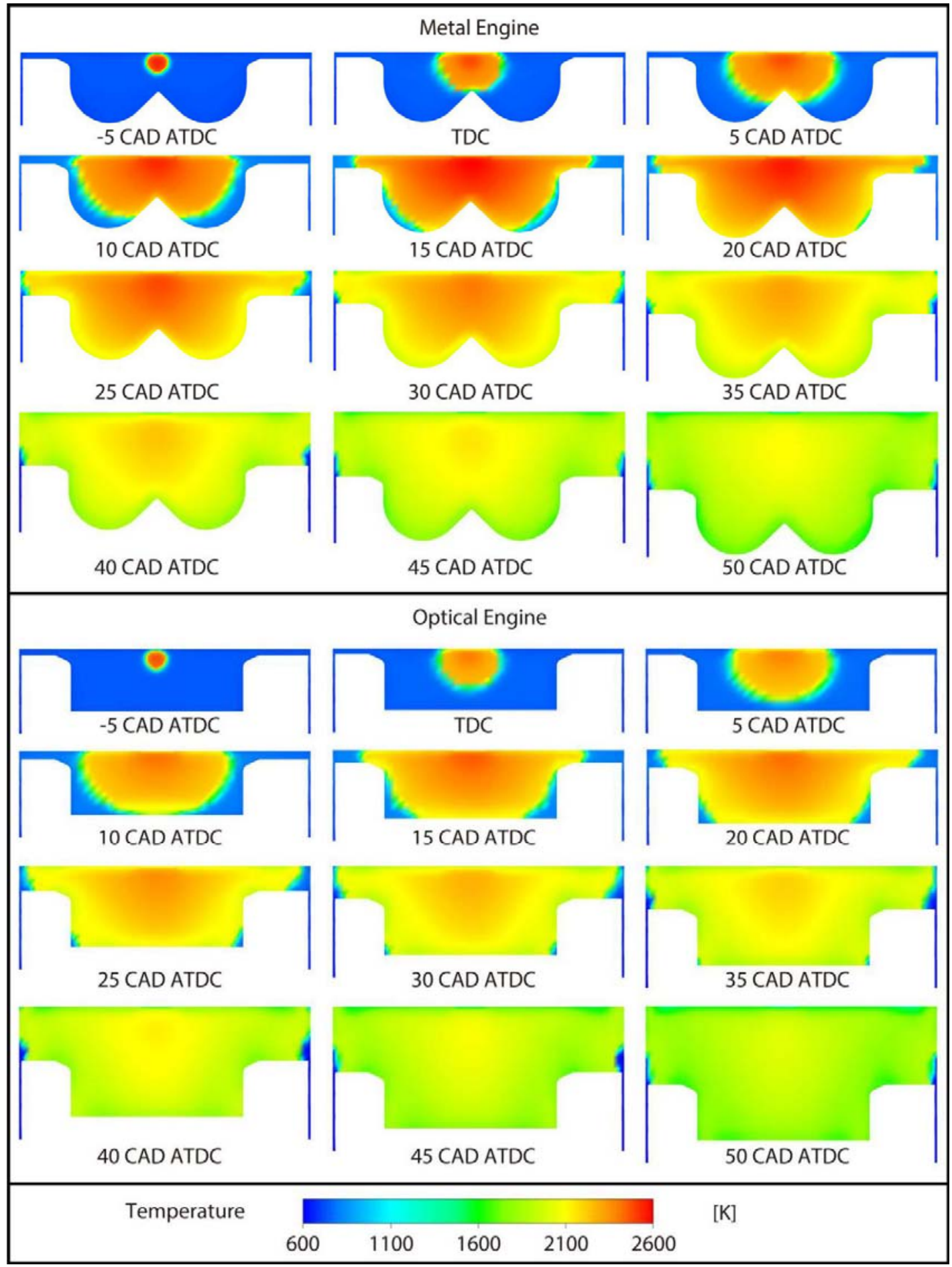

Figure 4.15 Spatially-distributed in-cylinder temperature at several CAD of interest for metal and optical engines. 
local turbulence and increased heat transfer to the boundaries. It was probably this fuel

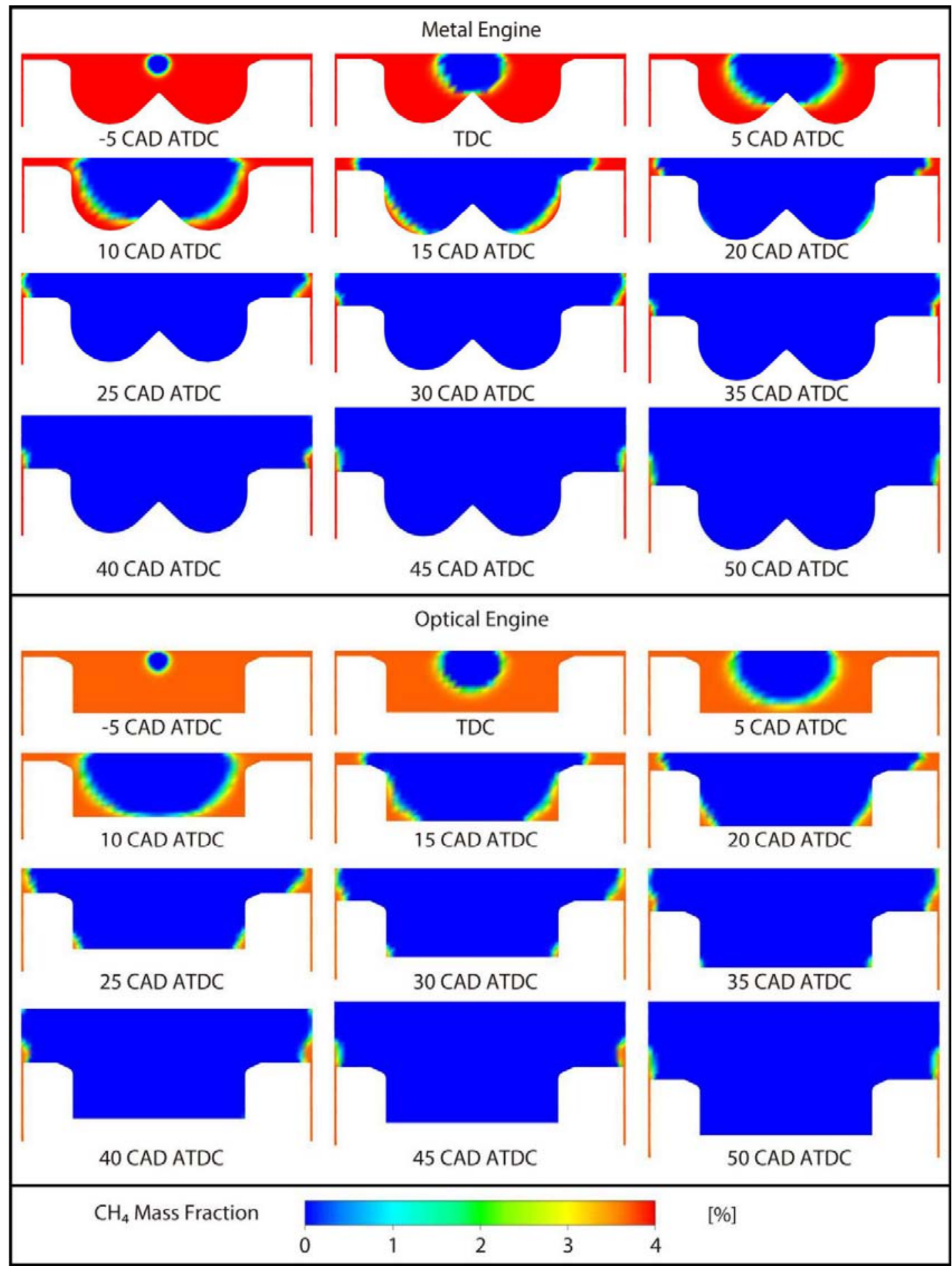

Figure 4.16 Spatially-distributed fuel mass fraction at several CAD of interest for metal and optical engines. 
trapped at the bottom of the bowl that produced the visible light captured by the CMOS camera in the optical experiments, hence the saturated pixels inside the bowl during the late combusting period and the FL seen even after end of combustion (see the FL images after 50 CAD ATDC in Figure 4.5). It can be concluded that the late oxidation seen in the optical engine experiments would not be representative for the metal engine. However, optical measurements using a Bowditch piston captured well the flame propagation characteristic of the metal configuration from the early flame development to the time when the flame touched the bowl edge.

Figure 4.15 presents in-cylinder temperature distribution at various crank angles during the combustion event. The temperature in the cylinder bowl was always higher than that in the squish region. Therefore, the preheat zone just before the flame front received more heat from the burned mixture inside the bowl region, which increased the chemical reaction rates. More, the bowl region was the high-temperature zone and the squish band was the low-temperature zone. The temperature distribution partially explains the combustion separation into two distinct events. Moreover, the temperature distribution was similar for both the metal and the optical engine configurations. The prominence in the middle of the bowl slightly changed the shape of the high temperature region near the center of the bowl. The slower combustion of the fuel trapped in the bottom corner of the cylindrical bowl in the optical engine delayed the peak temperature and the slower temperature decrease after the peak. 
Figures 4.16 and 4.17 show the fuel mass fraction distribution and the chemical heat release

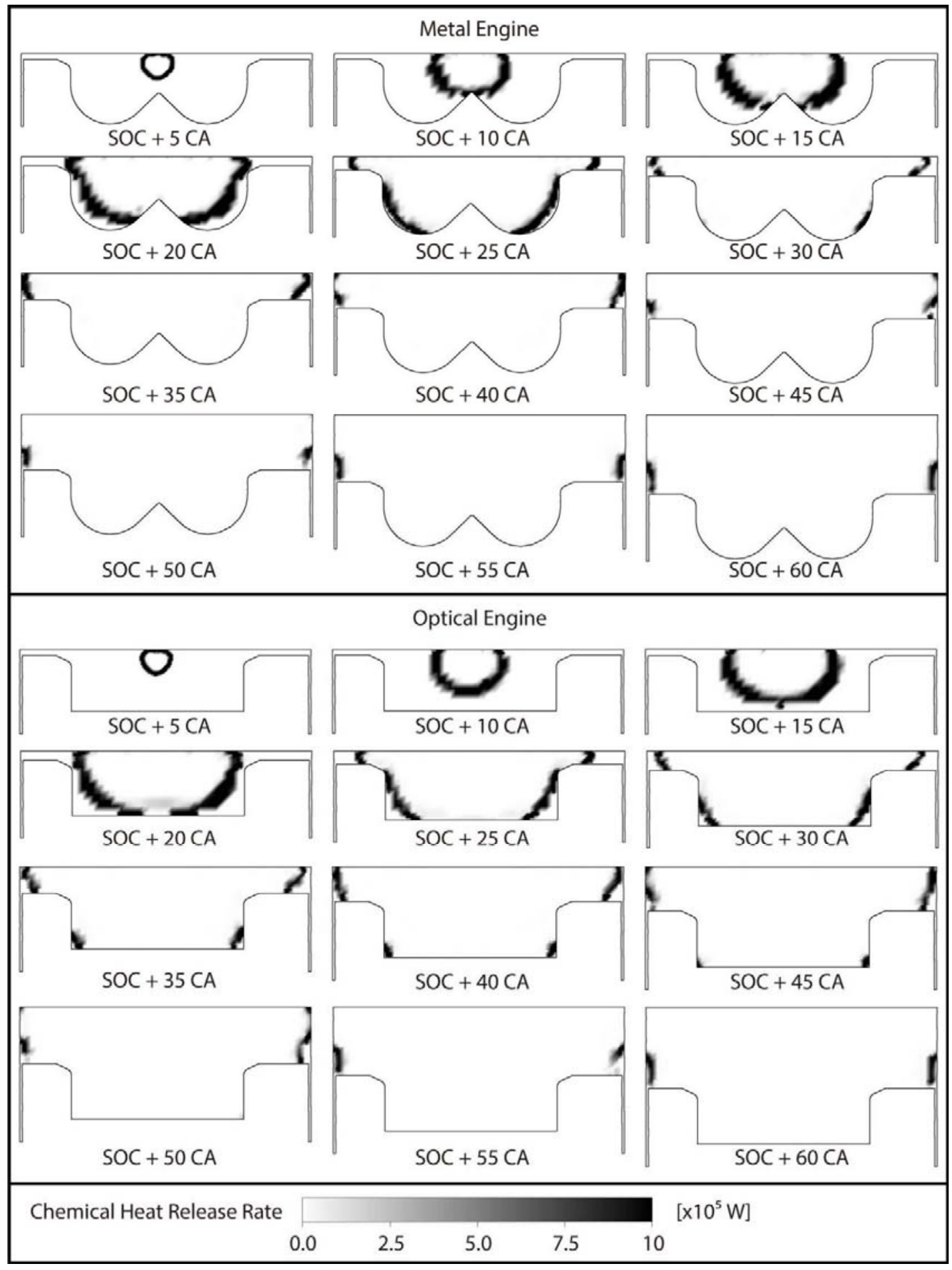

Figure 4.17 Spatially-distributed chemical heat release rate at several CAD of interest for metal and optical engines. 
rate during the combustion event, respectively, for both engines. As a reminder, the SOC in the simulation was defined as the crank angle in Figure 4.12 at which the turbulent flame speed increased from zero. The CFD results indicated that there was almost no unburned methane in the burned zone. Therefore, the heat was released only at the flame front. In addition, the burned region did not contain a lot of incomplete-burn products despite the thick flame, supported by the lack of heat release behind the flame front. As a result, the chemical heat release process took place at the flame front location.

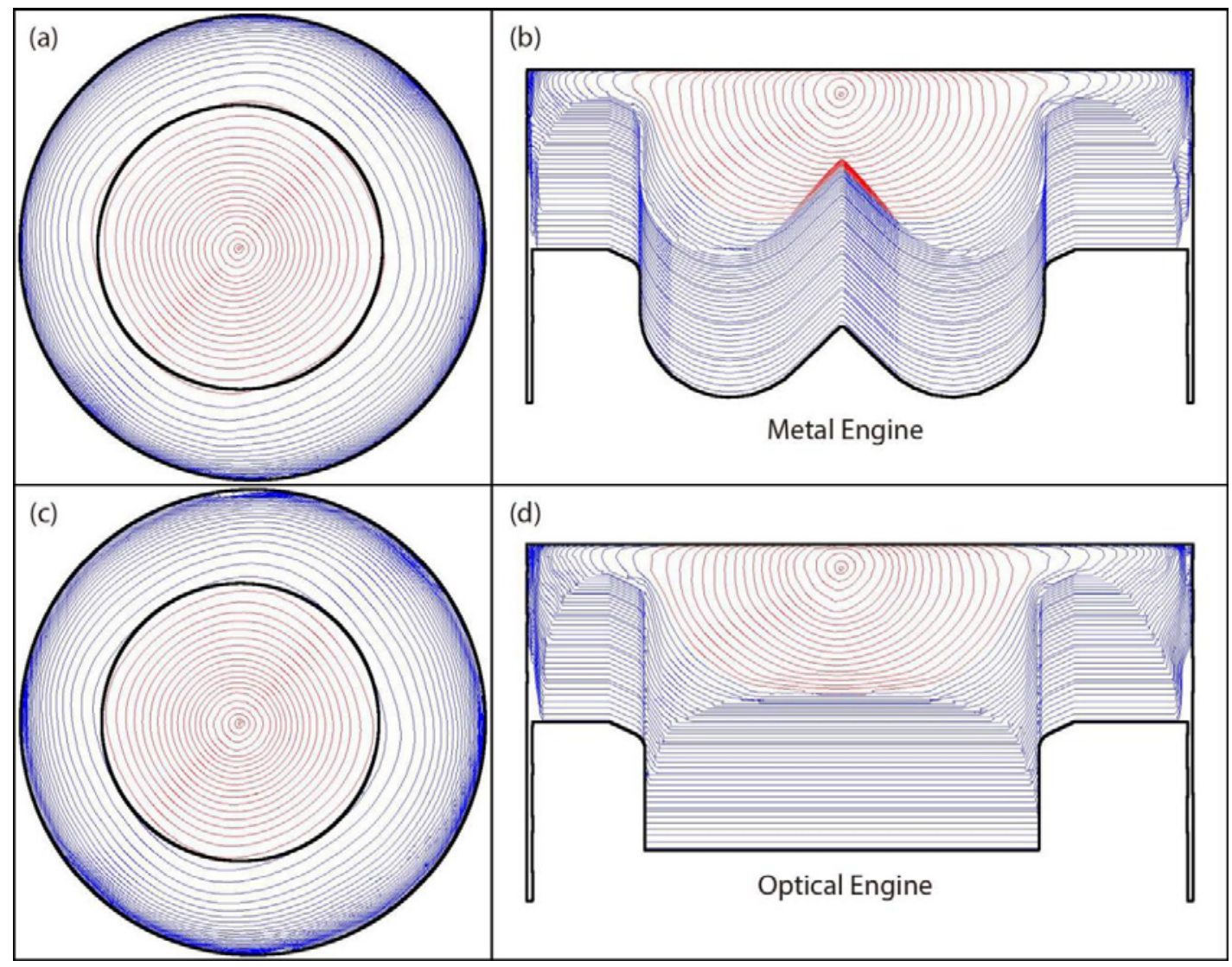

Figure 4.18 Flame propagation contour viewed from the piston bottom and side: $(a, b)$ metal engine and $(c, d)$ optical engine.

It is also of interest to compare the characteristics of flame propagation in a bowl-in-piston 
geometry in a two-dimensional reference frame. Figure 4.18 shows the flame front location at every CAD after ignition for both engine configurations. The inner and outer black circles in Figures 4.18a and 4.18c are the bowl and combustion chamber (liner) edges, respectively, as viewed through the piston bottom. The red and blue contours in Figures $4.18 \mathrm{~b}$ and $4.18 \mathrm{~d}$ show the flame propagation before and after reaching the squish region, respectively, as viewed from the side. Figure 4.18 shows that the flame propagation speed was higher inside the bowl region and when entering the squish region, despite the shorter vertical distance between the flat engine head and the piston top. This phenomenon can be explained by (i) a higher in-cylinder pressure and temperature, (ii) the inertia of the mixture motion, and (iii) the locally-strong turbulence caused by the combined effects of reverse squish flow and fast combustion. The flame propagated much slower in the squish region towards the cylinder wall because of the higher heat loss to the boundaries (high surfaceto-volume ratio), lower local turbulence, and lower temperature and pressure during the expansion stoke. Despite the fast burn inside the piston bowl, the slowly-moving flame front in the squish provided more time for unburned gas mixture to be exposed to high temperature and pressure situation. However, the high heat transfer in the slow-burn zone can help explain the knock-free operation even under the lean-burn conditions at the medium load and low speed in this study.

Figure 4.18 also shows that the radial flame propagation was almost identical for both optical and metal engine configurations. The flame front touched the entrance of the squish 
region at $11 \mathrm{CAD}$ ATDC for both engines. More, the prominence in the middle of the bowl did not significantly affect the flame front, even if it affected the local turbulence, flame speed, and flame thickness. The flame propagation in the vertical directions was almost identical for both engine configurations, except the region of the bottom of the bowl.

More, the numerical simulations suggest that the flame front was closer to the cylinder liner in the smaller squish region (the left side of the 2D slices shown above), as the piston bowl was positioned off-axis. Moreover, the results indicated that the bowl position relative to the cylinder axis was important, with the fuel being consumed faster in the toroidal recess than inside the smaller squish region (the left side of the 2D slices shown above). This was probably due to the way in which the asymmetrical squish region interacted with swirl when generating the turbulence. Further, the asymmetrical squish region also influenced the amount of fuel trapped inside the squish volume and the local temperature, heat transfer, turbulence, etc., which would affect the late combustion phenomena.

\subsection{Summary}

Premixed NG burn inside the bowl-in-piston combustion chamber can be separated into two distinct events. The inside the bowl experienced high turbulence, which increased the local turbulent flame speed, hence the high temperature of the combustion products behind the flame. More, the flame inside the bowl was thick. The squish region experienced a much lower turbulence, which, combined with the reduced temperature and pressure during 
the expansion stroke, and the higher surface/volume ratio, reduced the turbulent flame speed. In addition, the turbulence distribution inside the cylinder was not homogeneous, as discussed before. However, the high heat transfer in the squish can explain the knock-free operation despite the slow-burn inside the squish. 


\section{Chapter 5 Operating Condition Effects}

Previous chapters showed that the NG SI combustion inside a bowl-in-piston geometry can be described as a succession of two distinct combustion events. This chapter investigates the effect of the engine operating condition influences on the two distinct combustion events. The analysis was based on experiments performed in the metal engine configuration, which changed fuel composition, spark timing, equivalence ratio, and engine speed.

\subsection{Fuel composition effects}

The chemical and thermodynamic properties of each component in the NG composition affect the combustion process. For example, a larger fraction of heavier hydrocarbons or inert components in the NG can strongly influence engine performance and combustion characteristics such as ignition characteristics, durability of aftertreatment components, fuel economy, engine operability, power output, etc [109]. Figure 5.1 presents the pressure trace, ROHR, MFB, and burn rate from experiments performed in the metal engine configuration. The engine was operated at baseline condition (-10 CAD ATDC ST, 900 rpm, medium load; see Tables 2.2 and 2.3 for details), using $\mathrm{CH}_{4}$ and $\mathrm{NG}$ as fuels. As expected, the engine had a higher in-cylinder pressure when it was fueled with NG due to the higher $\mathrm{NG}$ energy content and better ignition quality compared to $\mathrm{CH}_{4}[110]$. NG had a higher peak rate of pressure rise than $\mathrm{CH}_{4}$, but it was below 2 bar/CA, suggesting that flame propagation was dominant throughout the combustion process. The low slope of 
ROHR during the late combusting period was due to the shape of the combustion chamber, as explained in Chapter 4. When the flame front entered the squish region atop the piston crown, the mixture burned much slower while more heat was transferred to the boundaries. The ROHR for NG had a faster decreasing slope than the one for $\mathrm{CH}_{4}$ during the latecombustion period, probably due to a faster flame propagation and an advanced start during this period. The burning rate of the turbulent flame inside the cylinder was defined as the

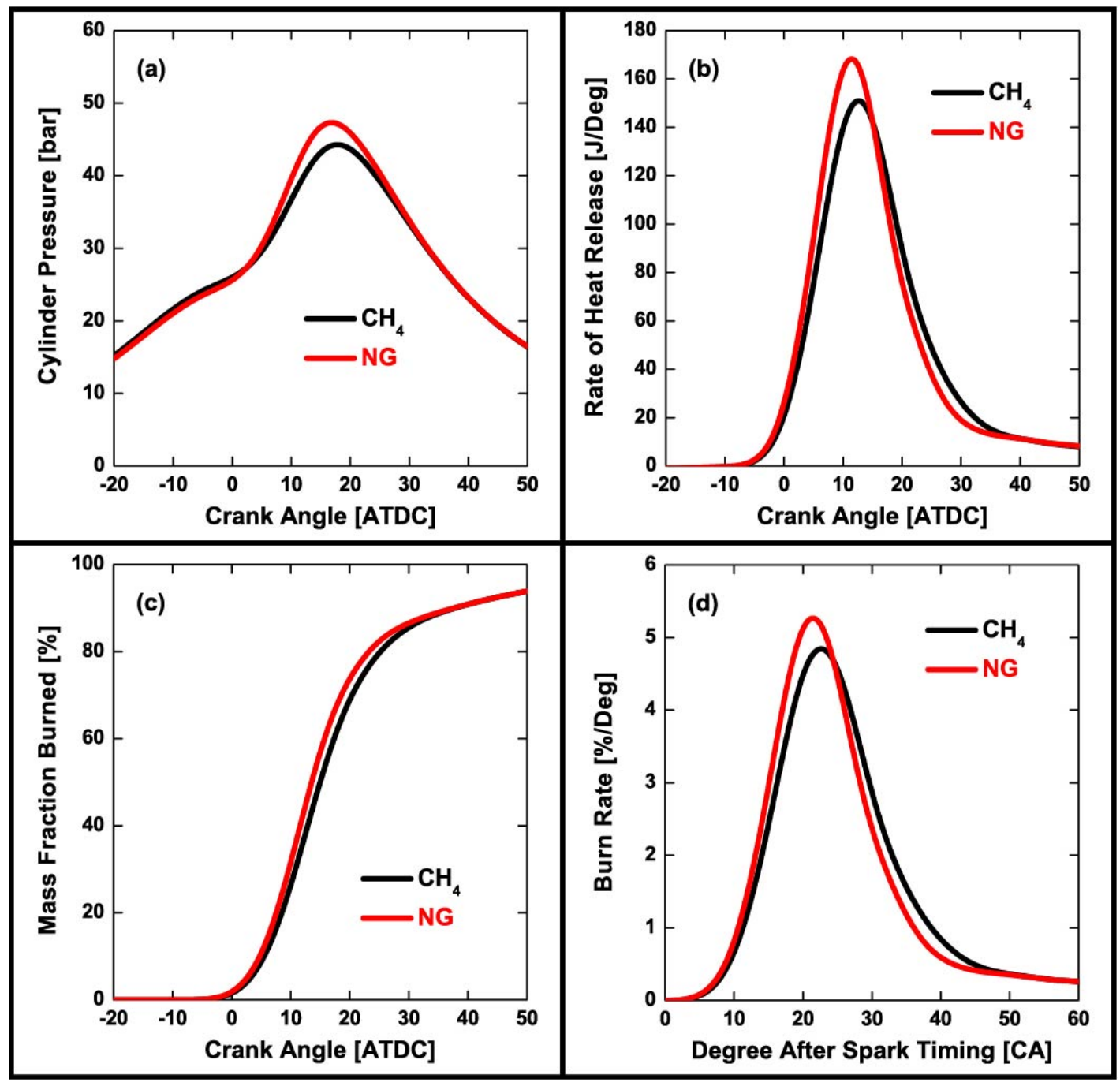

Figure 5.1 Effect of NG composition on (a) in-cylinder pressure, (b) apparent heat release rate, (c) mass fraction burned, and (d) burn rate. 


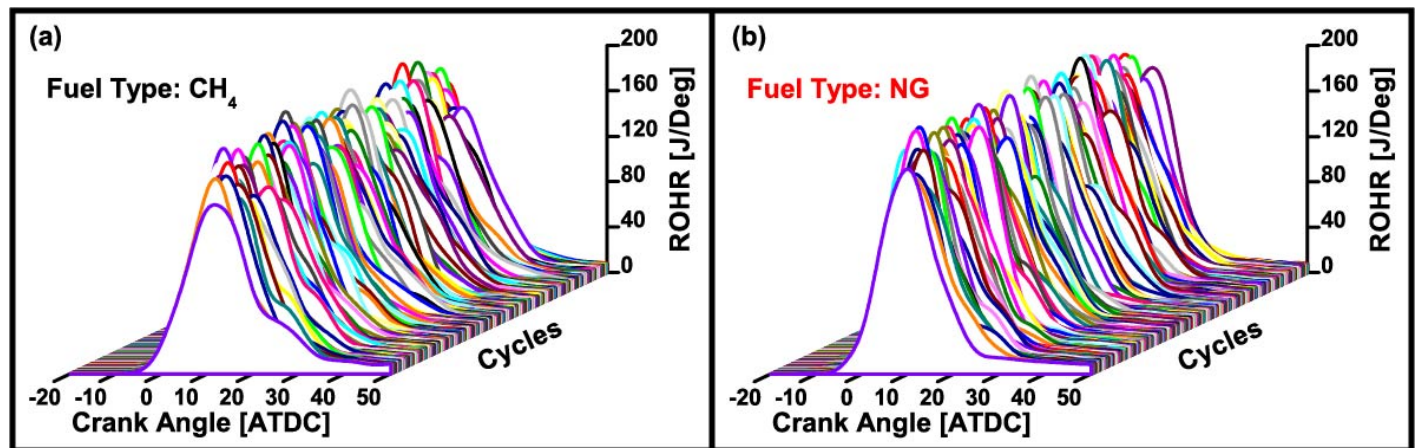

Figure 5.2 Effect of NG composition on the apparent rate of heat release of individual engine cycles.

derivative of mass fraction burned [111]. Figures 5.1c and 5.1d indicate that the flame development time (i.e., ignition delay or lag) was shorter for NG operation. This was due to the presence of higher hydrocarbon chains in the NG with better ignition properties compared to $\mathrm{CH}_{4}$, as the energy required to break a $\mathrm{C}-\mathrm{H}$ bond is higher than that required to break a $\mathrm{C}-\mathrm{C}$ bond [112]. As a result, the time required to initiate the combustion process for $\mathrm{CH}_{4}$ is longer than for other alkanes, which increases its ignition delay [113]. The comparison of MFB or burn rate between the two fuels also suggest that the addition of lower $\mathrm{H} / \mathrm{C}$ ratio compounds increased the burning velocity, probably due to formation of enhanced radicals that helped accelerate the combustion process [31].

Four hundred consecutive cycles were plotted in Figure 5.2 to investigate late combustion differences caused by different fuel blends. It is difficult to conclude which fuel increased the number of cycles with significant late burn. But it can be seen that NG shortened the late combustion duration, probably because its shorter $1^{\text {st }}$ combustion stage period 


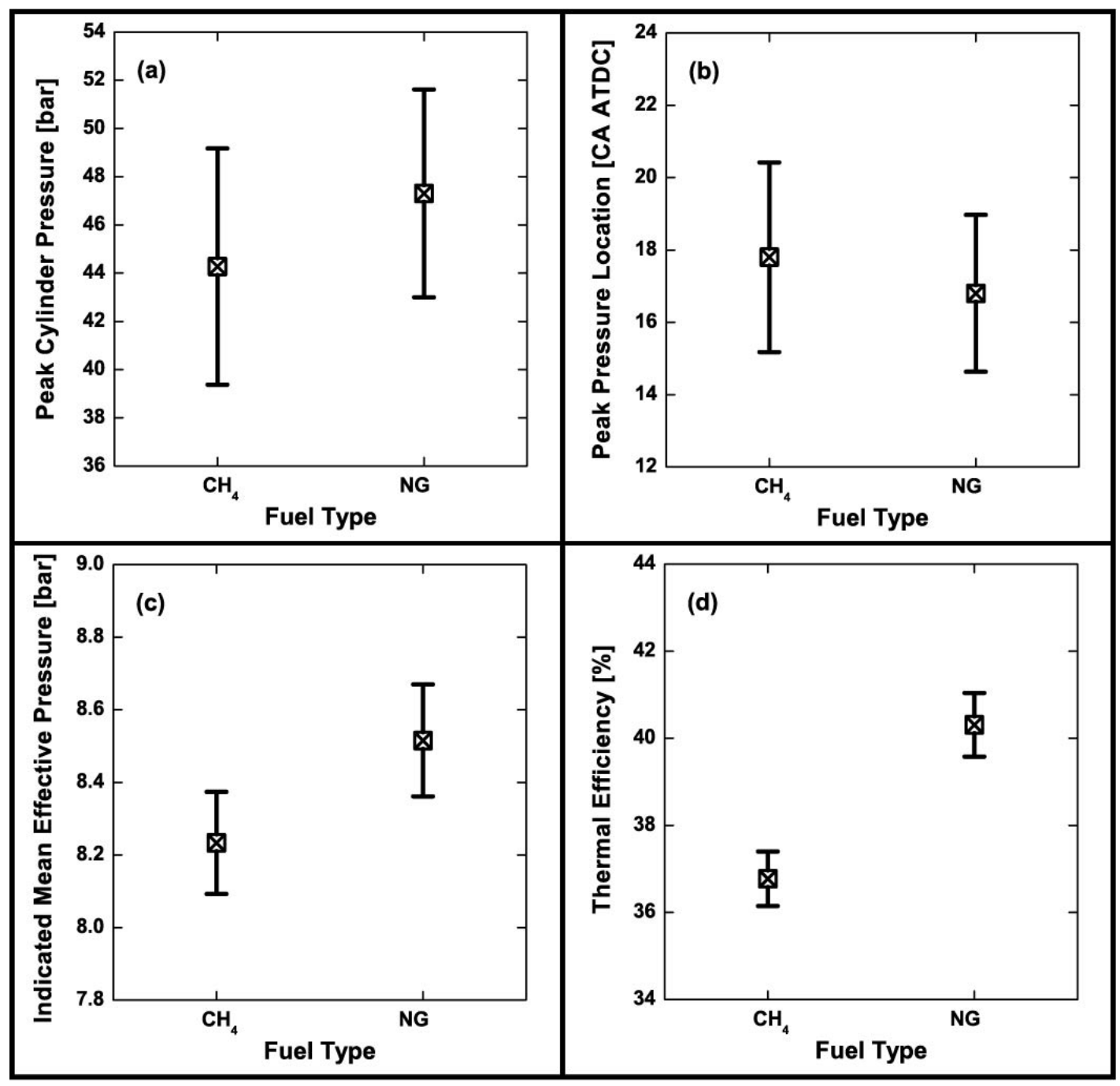

Figure 5.3 Effect of NG composition on the engine performance: (a) peak cylinder pressure, (b) location of peak cylinder pressure, (c) indicated mean effective pressure, and (d) thermal efficiency. The error bars in the figures indicate the 95\% confidence interval.

advanced the phasing of the $2^{\text {nd }}$ combustion stage. As a result, the $2^{\text {nd }}$ combustion stage for the NG operation took place at more optimal conditions (i.e., higher cylinder pressure and bulk temperature). This explains the faster decreasing slope of NG ROHR towards the end of combustion shown in Figure 5.1b. However, the experiments could not provide the details needed to better understand the fuel effect on the late burn phenomena. As a result, 
the numerical simulation will be used to further evaluate fuel effects.

Figure 5.3 shows that the average in-cylinder peak pressure was higher and advanced for NG compared with $\mathrm{CH}_{4}$, as the presence of higher carbon species enhanced flame speed

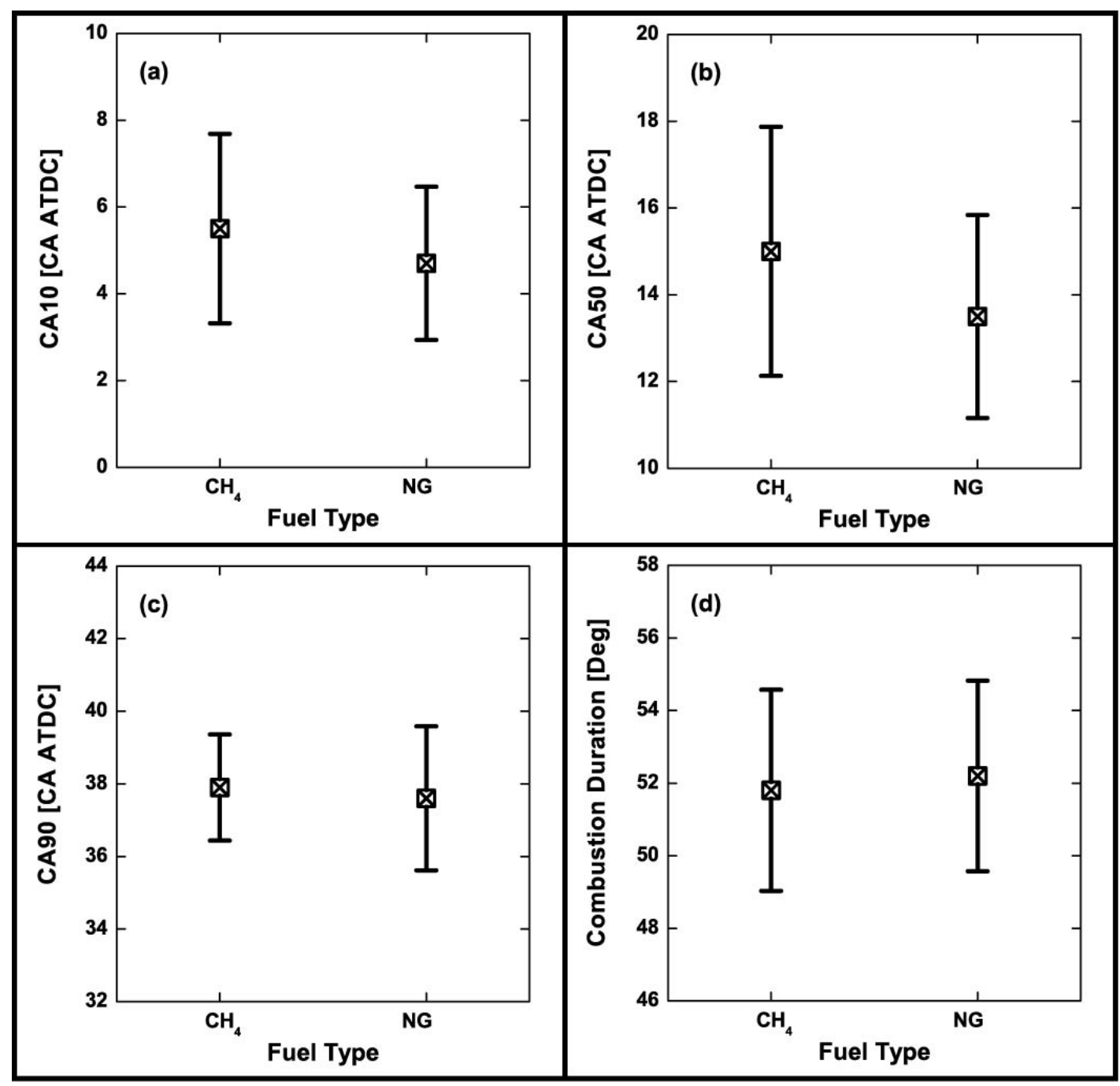

Figure 5.4 Effect of NG composition on the combustion phasing: (a) energy-release fraction of 10 percent, (b) energy-release fraction of 50 percent, (c) energy-release fraction of 90 percent, and (d) combustion duration (interval between energy-release fraction of 5 percent and energy-release fraction of 95 percent). The error bars in the figures indicate the $95 \%$ confidence interval. 
and the adiabatic flame temperature. More, $\mathrm{CH}_{4}$ had a $4 \%$ lower IMEP lower indicated thermal efficiency compared to NG because of (i) NG's higher flame propagation speed which resulted in a more complete combustion, (ii) NG's shorter fast-combustion duration (period before late combusting) overcame the higher heat transfer rate associated to the higher in-cylinder bulk temperature, and (iii) NG's higher low-heating value (LHV) and WI improved the engine performance compared to $\mathrm{CH}_{4}$.

Figure 5.4 shows that NG has an advanced CA10 and CA50 compared to $\mathrm{CH}_{4}$. $\mathrm{As}_{\mathrm{CH}}$ is less reactive than other alkanes, the addition of higher hydrocarbons to $\mathrm{CH}_{4}$ increased the flame speed [31]. The figure also shows that NG advanced CA90 much smaller than that of CA10 and CA50. As the addition of ethane and propane advanced the combustion phasing, one would expect it will also reduce the overall combustion duration. However, Figure 5.4 shows that the combustion duration was similar for $\mathrm{NG}$ and $\mathrm{CH}_{4}$ at the operating conditions investigated here, which can be explained by the diesel-like environment (i.e., part of the mixture burned much more slowly in the squish region, which contributed to much longer late combusting duration).

Figures 5.5 and 5.6 show the predicted flame behavior in the numerical simulation. Figure 5.5 indicates that $\mathrm{NG}$ had a slightly faster turbulent flame speed than $\mathrm{CH}_{4}$, but $\mathrm{NG}$ composition effects on the turbulent flame speed and thickness were not significant for the 


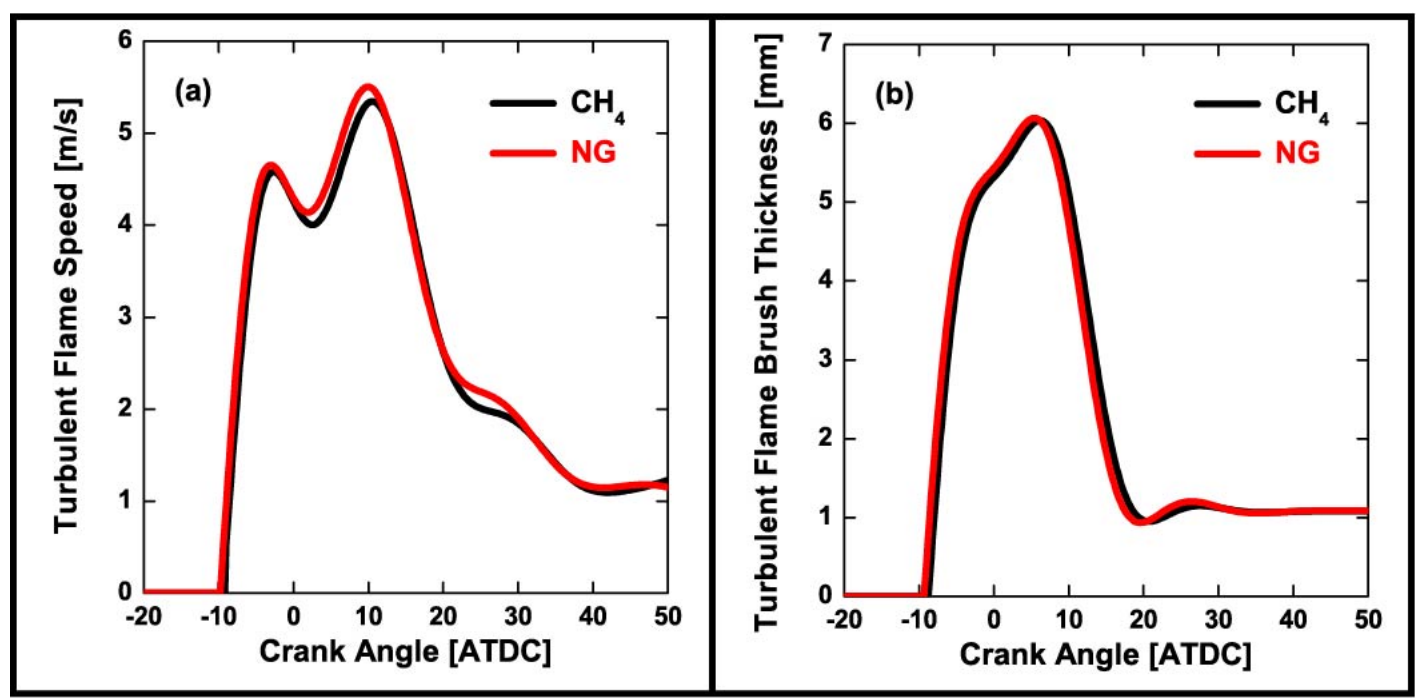

Figure 5.5 Effect of NG composition on spatially-averaged flame information: (a) turbulent flame speed and (b) flame brush thickness (i.e., the square root of the Favre-variance of $G)$.

conditions investigated here. Therefore, this suggests that the better engine performance for $\mathrm{NG}$ operation was due to the higher WI of the $\mathrm{NG}$, which increased the rate of heat release. In addition, the higher in-cylinder temperature during NG operation further increased the gas expansion speed. However, the simulation did not show an evident faster burning inside the squish region for the NG operation, compared to $\mathrm{CH}_{4}$.

It is important to note that more $\mathrm{CH}_{4}$ remained inside the bowl and burned a little slower after SOC $+25 \mathrm{CAD}$, according to Figure 5.6. It was more obvious at SOC $+30 \mathrm{CAD}$, $\mathrm{CH}_{4}$ was still burning inside the bowl but no more evidence of $\mathrm{NG}$ in the bowl. As the toroidal recess in the metal engine configuration is part of the slow-burn combustion, it can be concluded that NG burned a lower percentage of fuel inside the squish when the flame 


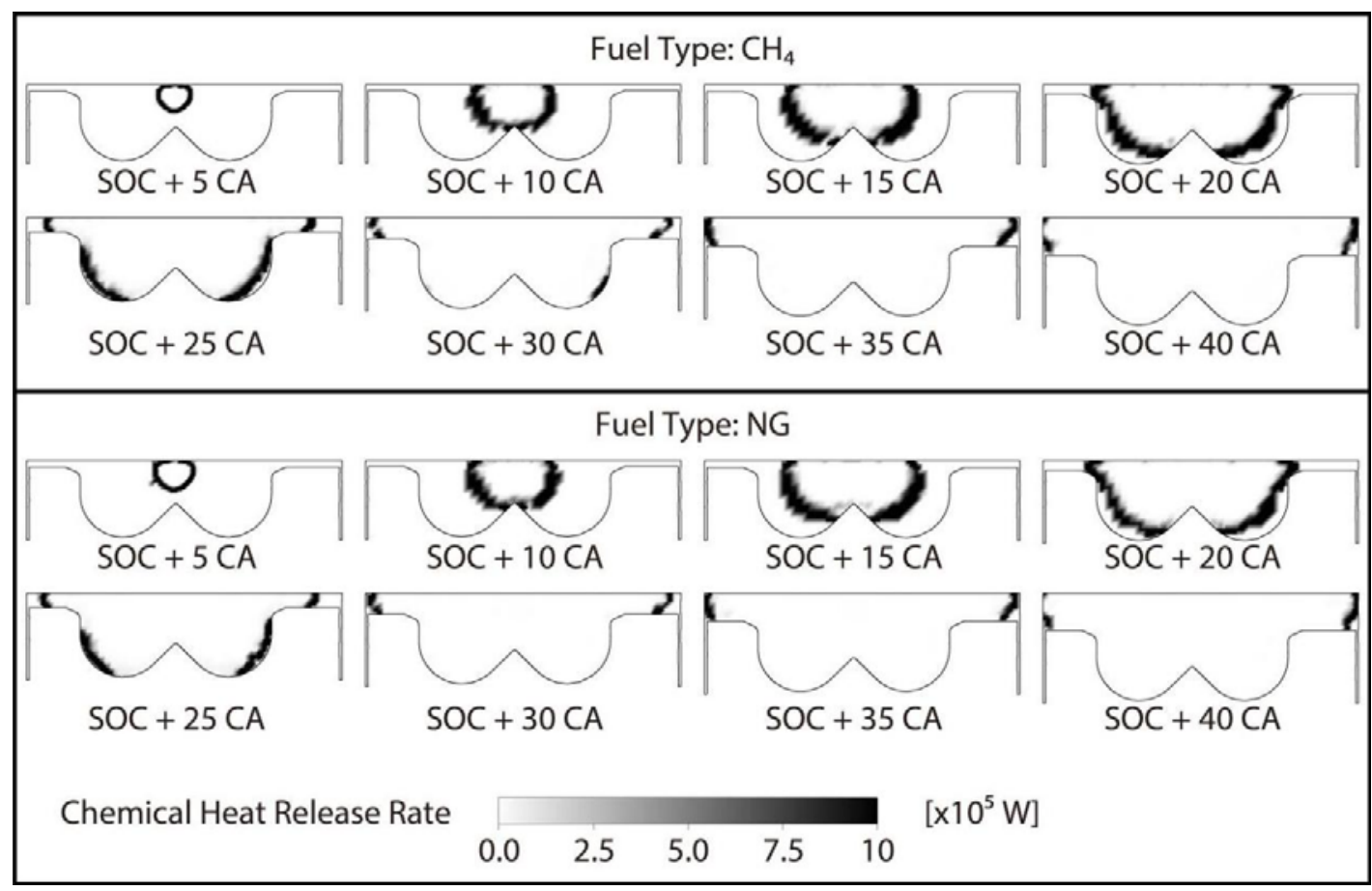

Figure 5.6 Effect of NG composition on spatially-distributed chemical heat release rate at several CAD of interest after SOC.

reached the bottom of the bowl (bowl recess). As a result, more NG will burn in the $2^{\text {nd }}$ combustion stage, hence a higher late burn. This suggests that the addition of heavier hydrocarbons increased the flame speed but did not benefit the burning inside the squish region. As a result, the fuel effects on the late burn was smaller than the effects of the low turbulence, increased heat transfer, and low temperature and pressure during the expansion stroke. Therefore, the addition of ethane and propane shortened the duration of the $1^{\text {st }}$ combustion stage and increased the phasing separation between the two combustion stages. However, it also advanced the $2^{\text {nd }}$ combustion stage which would be better for engine efficiency, considering that the spark timing at this condition was delayed compared to the maximum brake-torque spark timing (MBT). 


\subsection{Spark timing effects}

Spark timing affects combustion efficiency and stability through its effect on spark inception and flame propagation [12]. The experiment swept the ST from -30 CAD ATDC to $-10 \mathrm{CAD}$ ATDC at constant engine speed $(900 \mathrm{rpm})$ and $\mathrm{CH}_{4}$ equivalence ratio $(\phi=$ 0.73), as shown in Table 2.3. Figure 5.7 presents the ST effects of NG SI operation in a

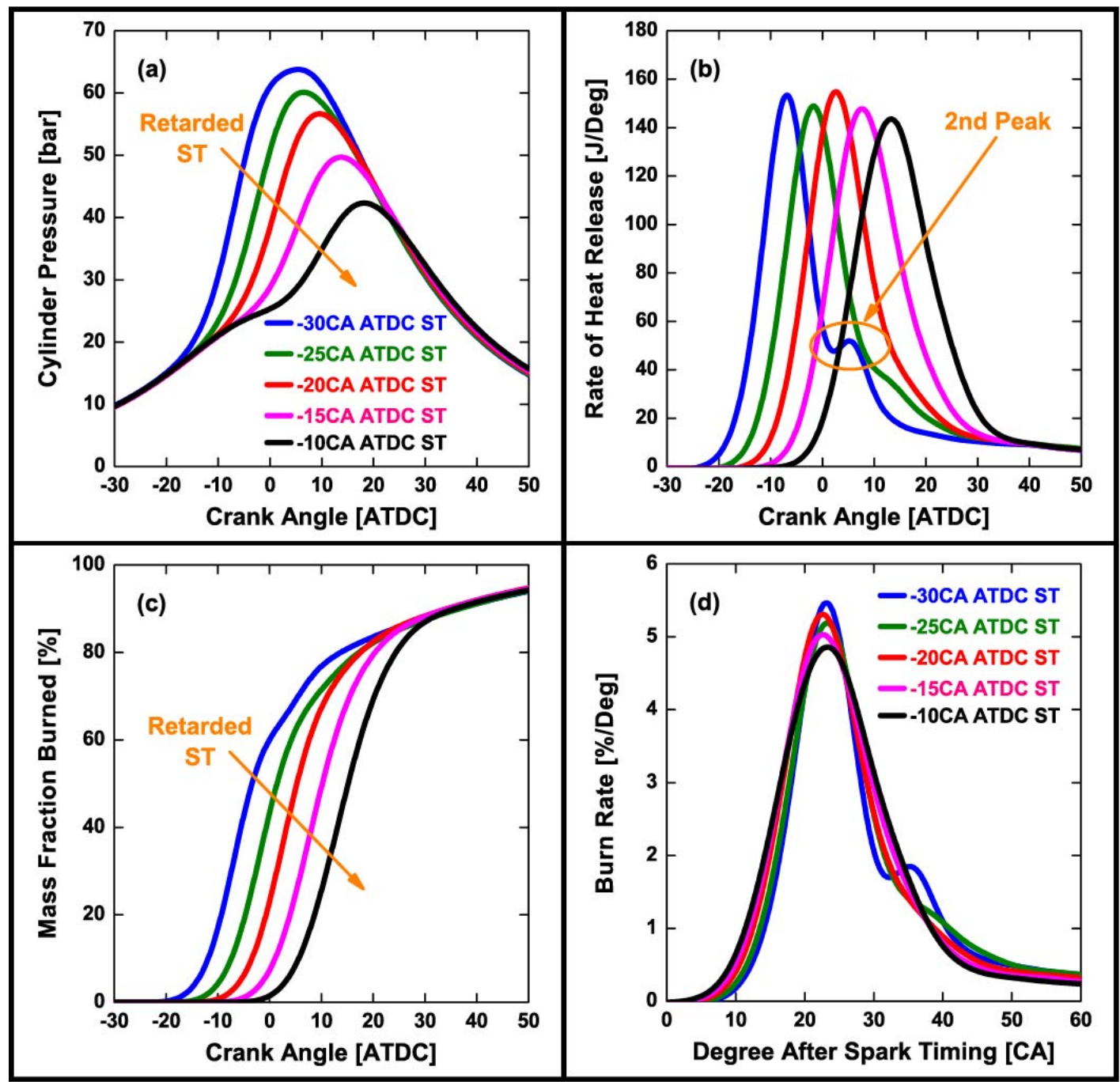

Figure 5.7 Effect of spark timing on (a) in-cylinder pressure, (b) apparent heat release rate, (c) mass fraction burned, and (d) burn rate. 
bowl-in-piston combustion chamber. As expected, advanced ST increased in-cylinder pressure and rate of pressure rise. However, the peak pressure rise rate (PRR) was always below 4 bar/CA, indicating flame propagation dominated during the combustion event.

Heat release analysis describes the efficiency of converting the thermal energy of the fuel into work done by the engine [12]. For a constant supply of chemical energy, more work is done by the system indicates the engine is more efficient. Figure $5.7 \mathrm{~b}$ shows that the heat release rate of $\mathrm{CH}_{4}$ at a -20 CAD ATDC ST was larger than at any another ST. The heat release analysis also shows a second peak on the heat release rate for -30 CAD ATDC ST. More, the ROHR for -25 CAD ATDC ST shows significant late burn, suggesting that an important fuel fraction was burned late in the cycle. Figure 5.7c, which shows the mass fraction burned for $\mathrm{CH}_{4}$ at various STs, suggests an almost similar end of combustion (EOC) for the five cases, despite the 20-CAD difference in ST. For a better visual comparison of combustion process, all the burn rates in Figure $5.7 \mathrm{~d}$ were shifted to have a similar start based on ST difference. Figure 5.7d shows that retarded ST shortened the ignition delay, probably due to the higher cylinder pressure and temperature at the time of the spark event. Delayed ST increased the initial burn rate, probably because retarded ST had a faster kernel inception. It resulted in a larger enflamed zone and a larger flame burning area at each observed crank angle compared with advanced ST. However, the differences disappeared at ST $+25 \mathrm{CAD}$, probably because of the much faster turbulent flame speed for advanced ST. 


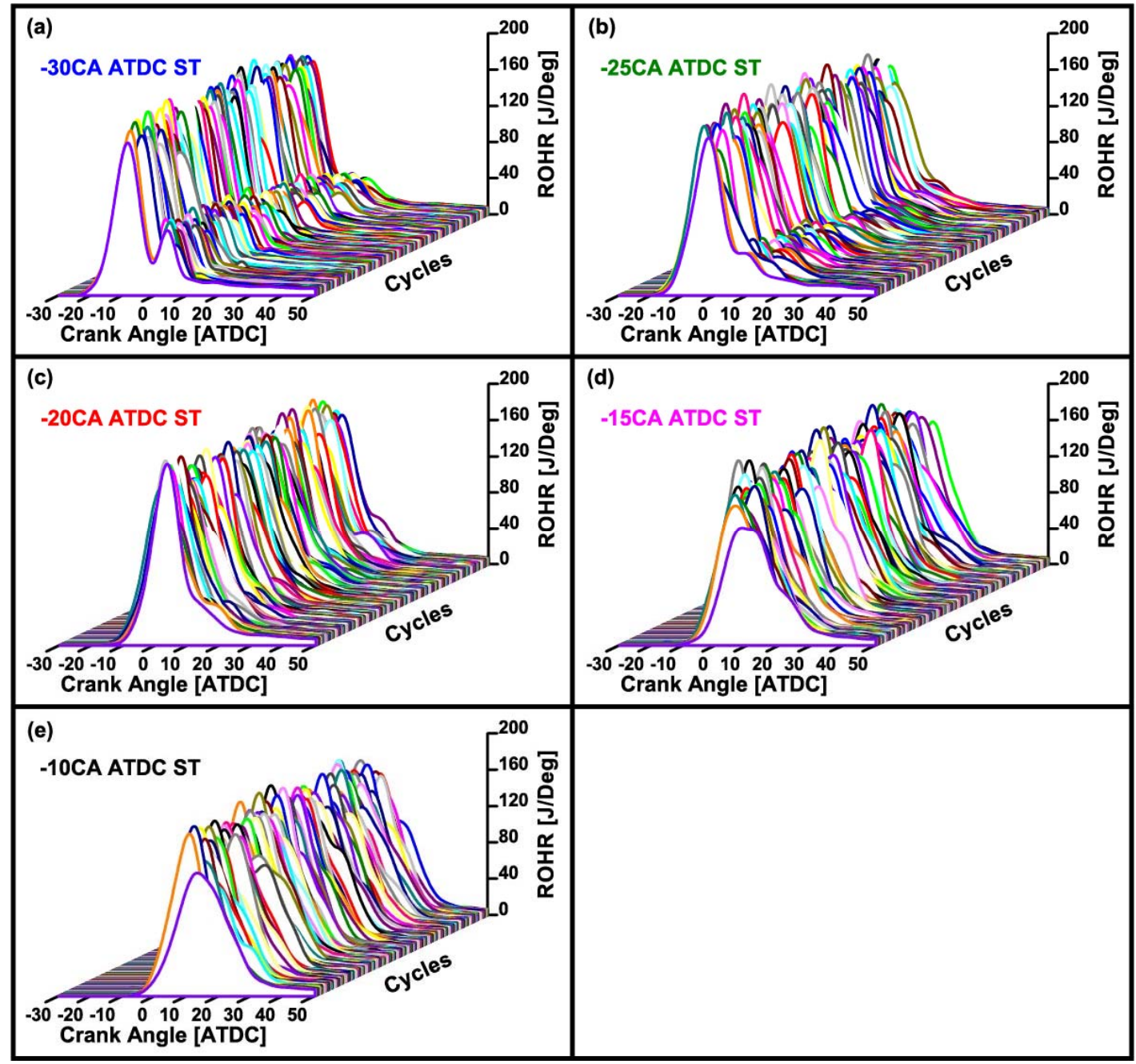

Figure 5.8 Effect of spark timing on the apparent rate of heat release of individual engine cycles.

To investigate the differences in late combustion, Figure 5.8 presents four hundred consecutive engine cycles for each ST. Figure 5.8 shows that several engine cycles had significant late combustion even at -10 CAD ATDC ST, which indicated that the averaged data can hide important characteristics of NG SI combustion in a bowl-in-piston chamber. More, the ROHR data at -15 CAD ATDC ST shows that the late burn appeared more 
frequent and had a higher intensity. The late burn was more visible at -20 CAD ATDC ST, and the double heat release peak started to be visible frequently in the ROHRs at -25 CAD ATDC ST. Finally, almost all the engine cycles at -30 CAD ATDC ST showed the second ROHR peak, but with different phasing and intensity. Overall, the late burn phenomenon was seen at all conditions irrespective of the ST.

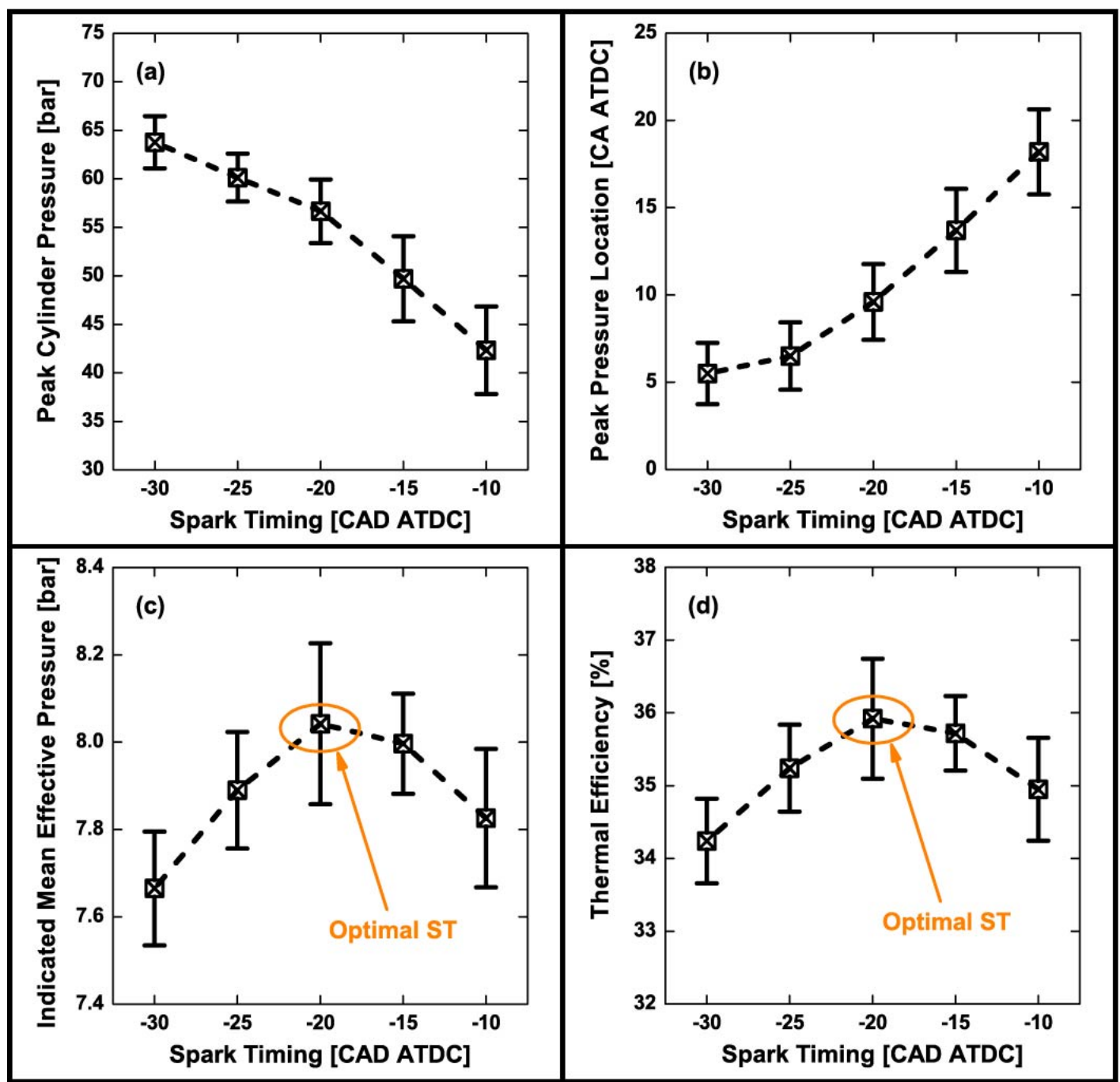

Figure 5.9 Effect of spark timing on the engine performance: (a) peak cylinder pressure, (b) location of peak cylinder pressure, (c) indicated mean effective pressure, and (d) thermal efficiency. The error bars in the figures indicate the 95\% confidence interval. 
Figure 5.9 shows the influence of ST on the engine performance. Advanced ST increased and advanced the location of maximum pressure. In addition, the error bars indicate that some cycles with advanced ST had similar combustion as cycles with delayed ST, evidenced by the overlapping of peak pressure and its location. This overlapping was probably due to variations in the spark intensity and location, which, together with variations in local turbulence and mixture equivalence ratio at the spark plug location, affected the early flame development.

Again, the higher IMEP and thermal efficiency in Figure 5.9 indicate that -20 CAD ATDC ST was the MBT for the load and equivalence ratio investigated here. Advancing the ST from the MBT advanced and increased cylinder pressure before TDC, which opposed the piston's upward movement. As a result, the amount of power delivered to the crankshaft reduced. Although retarding the ST can result in the peak cylinder pressure to occur later in the expansion stroke, this will lower peak pressure, hence decrease the work done on the piston. It is also important to note that even the optimal spark timing showed significant late burn.

Figure 5.10 presents the combusting phasing calculated based on the mass fraction burned. Both CA10 and CA50 were retarded with retarded ST. More, the differences in the actual CA10 and CA50 values between cases were similar to their difference in ST. However, the 


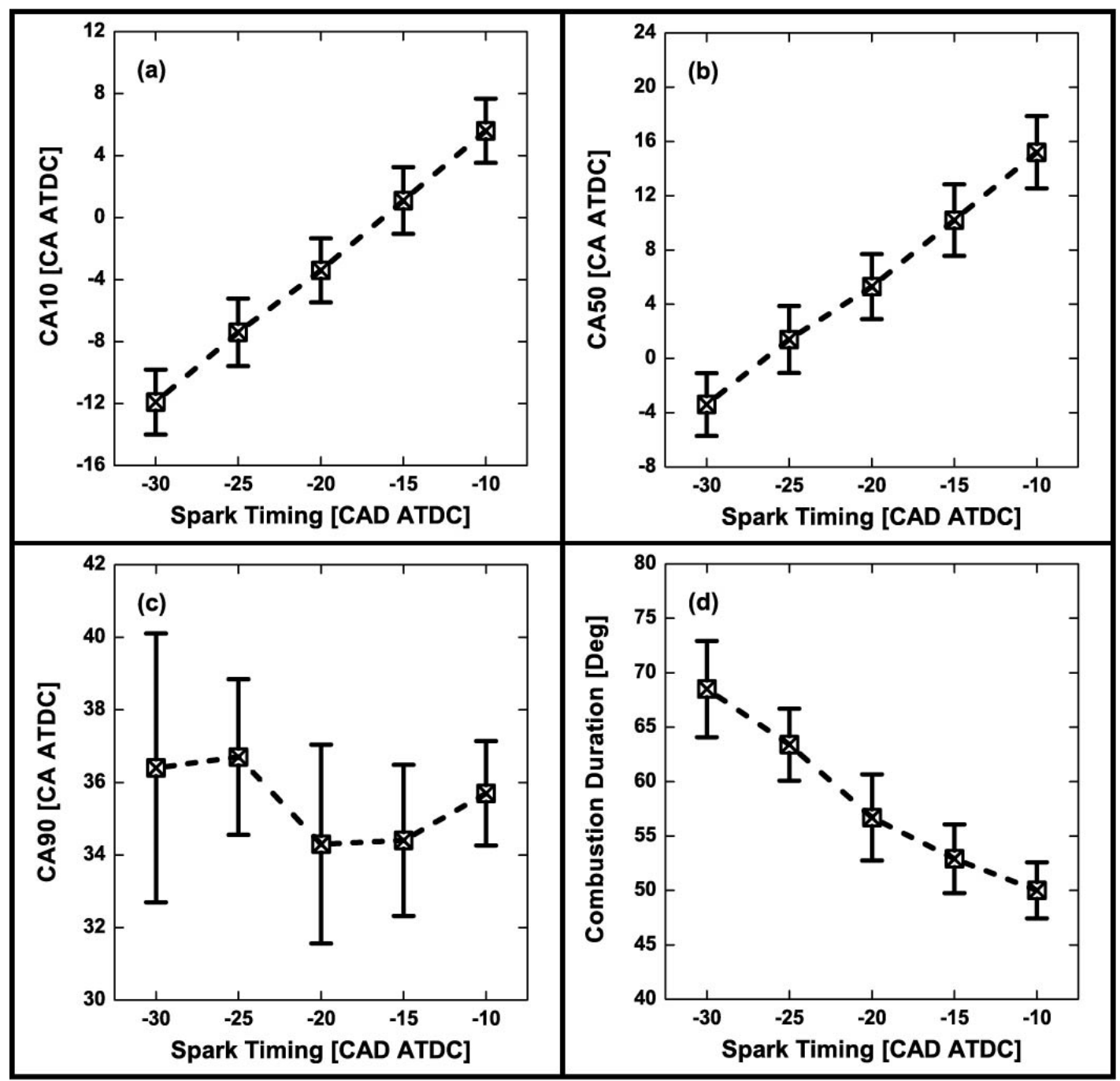

Figure 5.10 Effect of spark timing on the combustion phasing: (a) energy-release fraction of 10 percent, (b) energy-release fraction of 50 percent, (c) energy-release fraction of 90 percent, and (d) combustion duration (interval between energy-release fraction of 5 percent and energy-release fraction of 95 percent). The error bars in the figures indicate the $95 \%$ confidence interval.

CA90 was similar, which implies that delayed spark timing decreased the combustion duration, probably due to the different late burn mentioned earlier. 
As the experimental results indicated that advanced spark timing would result in significant late burn phenomenon and even double peak heat release rate, CFD simulations were used to further explain the ST effects on the combustion event separation.

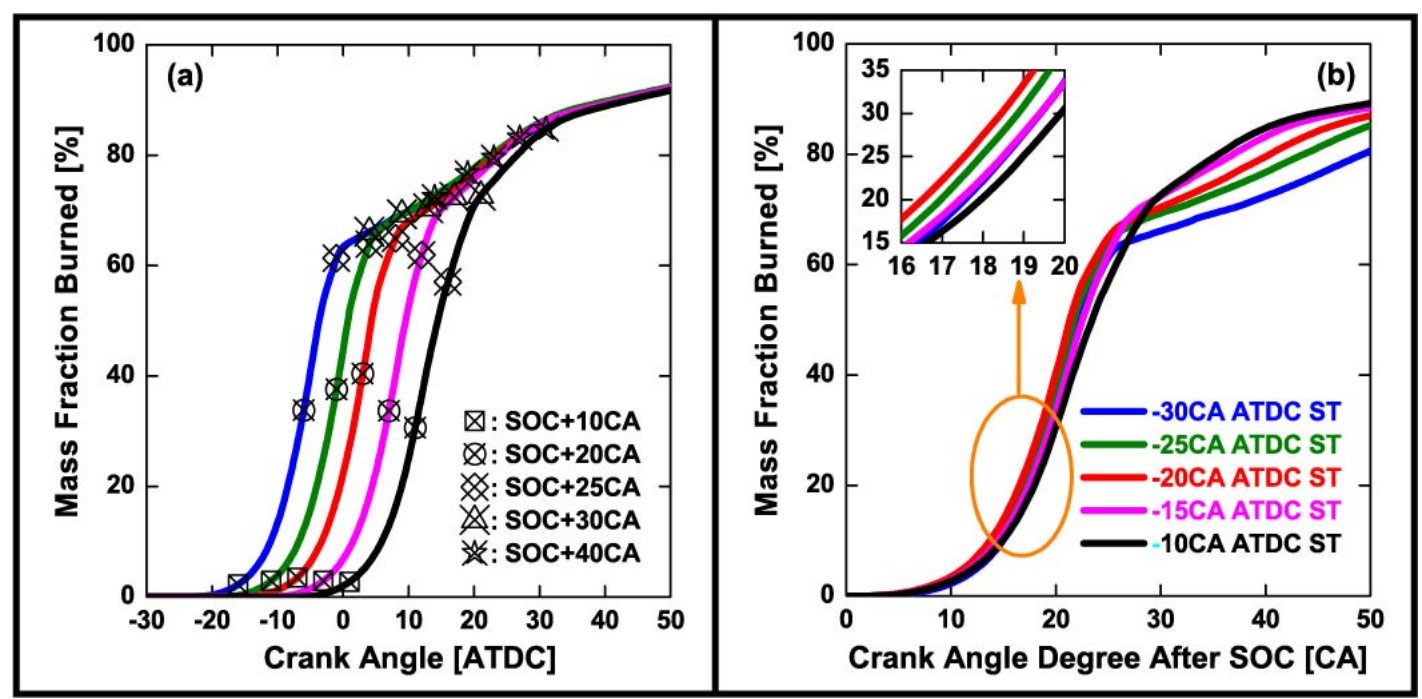

Figure 5.11 Effect of spark timing on the CFD predicted mass fraction burned.

The mass faction burned (Figure 5.11), spatially averaged flame information (Figure 5.12), and in-cylinder flame front location (Figure 5.13) provide additional information on the $2^{\text {nd }}$ peak of ROHR. The markers in Figure 5.11a show the MFB at several CAD of interest after SOC. Figure 5.13 indicates that flame was mostly burning inside the bowl in the first 20 CA degrees after SOC. The beginning of the second combustion event can be seen in Figure 5.12. Advanced ST had faster and thicker flame in the bowl region, due to the higher turbulence inside the bowl near TDC. More, delayed ST had a faster turbulent flame speed when burning in the squish region (i.e., the period between $\mathrm{SOC}+30 \mathrm{CAD}$ and $\mathrm{SOC}+40$ 
$\mathrm{CAD}$ ), which can be explained by the increased distance between the piston top and the cylinder head. The slower burning in the squish region for advanced ST was also evident in Figure 5.13. When the flame front of -10 CAD ATDC ST reached the cylinder liner at SOC + 40 CAD, the -30 CAD ATDC ST still had some unburned fuel inside the squish. It

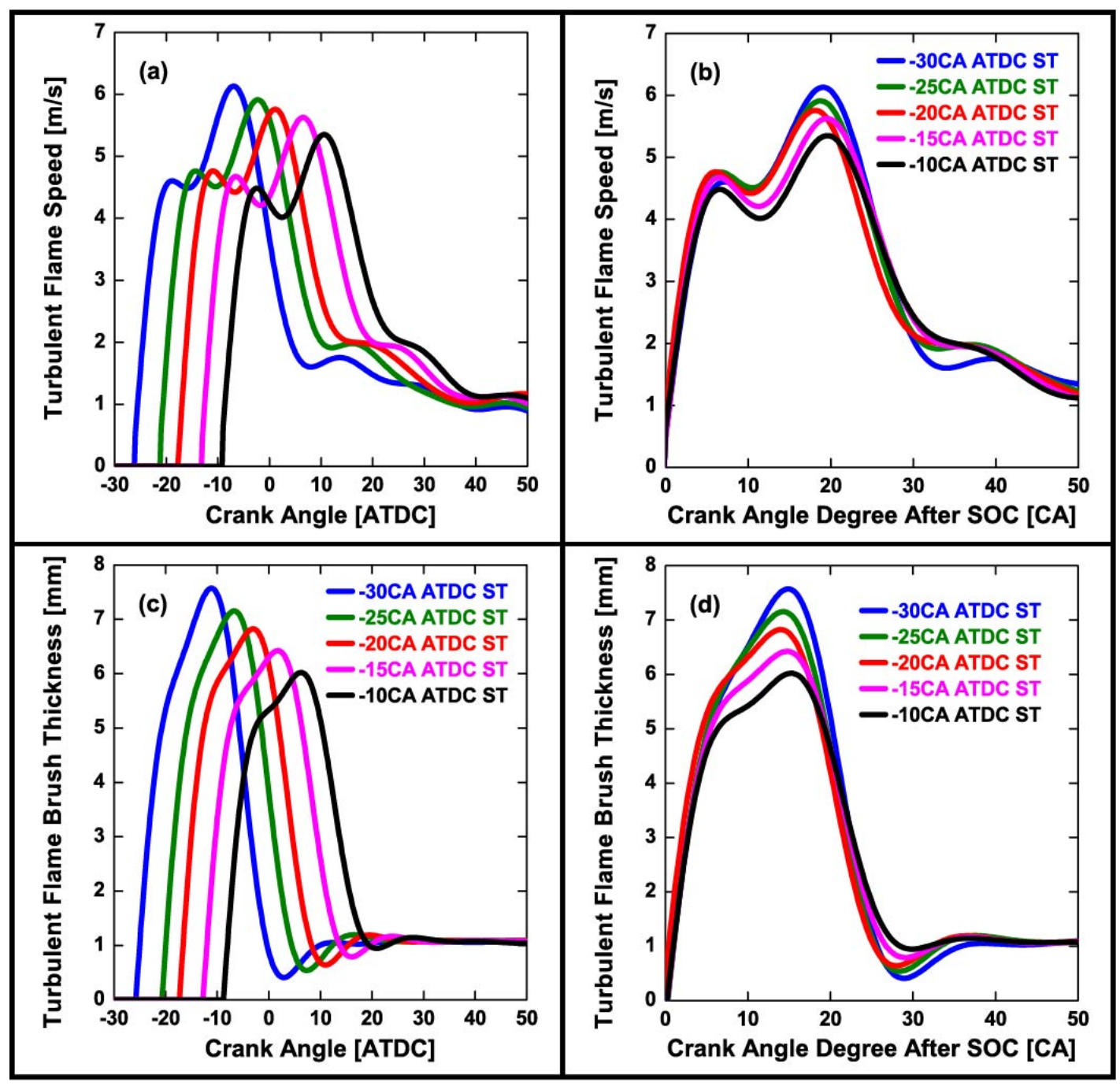

Figure 5.12 Effect of spark timing on the spatially-averaged flame information: $(a, b)$ spatially averaged turbulent flame speed and $(c, b)$ spatially averaged G-equationbased flame thickness. 


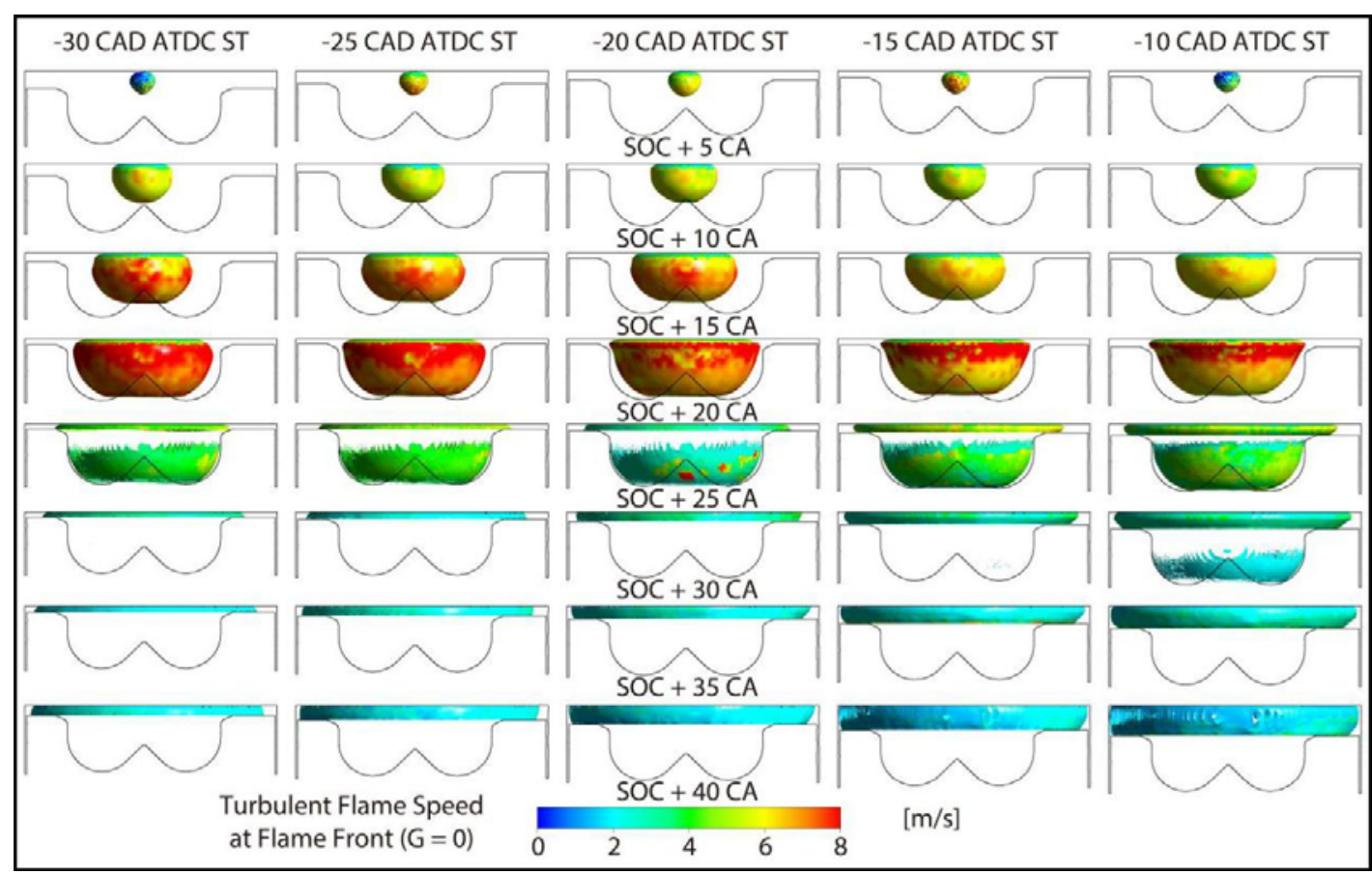

Figure 5.13 Effect of spark timing on the distribution of turbulent flame speed at the flame front (i.e., $G=0$ ) at several CAD of interest after SOC.

was probably the much slower burning in the squish for advanced ST that contributed to the almost identical EOC shown in Figure 5.7c, despite the difference between STs. Figure 5.13 also indicates that the differences in the phasing of the burning inside the bowl were similar to the differences in ST.

Figure 5.11a shows that at SOC +20 CAD the -20 CAD ATDC ST consumed the largest NG/air mixture (around $40 \%$ of the total burned fuel) compared to the rest of STs. This trend also kept the same till SOC $+25 \mathrm{CAD}$, which already burned $65 \%$ of the fuel mass for -20 CAD ATDC ST. The percentage of mass burning in the bowl region probably affected the IMEP because -20 CAD ATDC ST was the MBT ST. Figure 5.11b also proved 
that -20 CAD ATDC ST burned more fuel in the bowl region. However, the flame front at several location after SOC shown in Figure 5.13 was almost the same for all STs. It can be concluded that the combustion phasing determined the fuel ratio inside and outside the bowl.

The flame front reached the entrance of the squish at $\mathrm{SOC}+20 \mathrm{CAD}$, for all cases. However, the remaining unburned mass in the combustion chamber was large. For example, -20 CAD ATDC ST had the least fraction of remaining unburned fuel $(\sim 60 \%) .-10$ CAD ATDC ST had $\sim 70 \%$ of unburned fuel remaining in the chamber, shown in Figure 5.11a. At $\mathrm{SOC}+25 \mathrm{CAD}$, the flame front almost touched the toroidal recess region for all STs. The fuel in the bowl burned almost completely regardless of ST, except a smaller portion near the bowl bottom, indicating the end of the rapid burning period for all STs at $\sim \mathrm{SOC}+$ $25 \mathrm{CAD}$. At this time, $39 \%$ and $43 \%$ of unburned gas still existed in the combustion chamber for -30 CAD ATDC ST and -10 CAD ATDC ST respectively. At SOC + 30 CAD, $34 \%$ and $27 \%$ of unburned mixture were trapped in the combustion chamber for $-30 \mathrm{CAD}$ ATDC ST and -10 CAD ATDC ST respectively. It can be concluded that a significant mass of fuel was pushed into the late-burn zone during combustion. As a result, it was probably this large fraction of fuel/air mixture trapped in the squish volume that contributed to the evident late burn phenomenon. The case of -10 CAD ATDC ST did not show a significant late burn probably because the phasing of two combusting events (i.e., inside the bowl and inside the squish) was very close to each other. Specifically, the fuel in the bowl was burned 
completely at $\sim \mathrm{SOC}+35 \mathrm{CAD}$ for $-10 \mathrm{CAD}$ ATDC ST, while the flame front in the squish just reached the cylinder wall at this time. However, the separation of the combustion in two distinct events contributed to slow decreasing slop of ROHR towards the end of combustion for -10 CAD ATDC ST. For advanced spark timing, the phasing of these two events (fast-burn event and slow-burn event) was separated more. In addition, the much slower burning in the squish for advanced ST increased the duration of the $2^{\text {nd }}$ combustion stage, which made it more easily to separate the phasing of $1^{\text {st }}$ and $2^{\text {nd }}$ combustion stages. As a result, the more significant late burn created the second ROHR peak as more fuel trapped in the squish and burned slower. For example, -30 CAD ATDC ST completed the burning event in the bowl at $\sim \mathrm{SOC}+30 \mathrm{CAD}$, but the only a small fraction of fuel was already burned in the squish region. With the increase of squish height during the expansion stroke, the burning rate was increased and thus the second ROHR peak appeared for -30 CAD ATDC ST.

Figure 5.14 shows the instantaneous in-cylinder chemical heat release rate at several CAD of interest for all STs. The major chemical heat release was along the flame front. The crevice region (i.e., the narrow volume between the piston, piston rings, and cylinder wall) accumulated an important mixture mass fraction during compression and combustion due to increasing in-cylinder pressure and the lower local temperature [12]. The trapped mixture flew out of the crevice region at low velocity adjacent to the cylinder wall once 


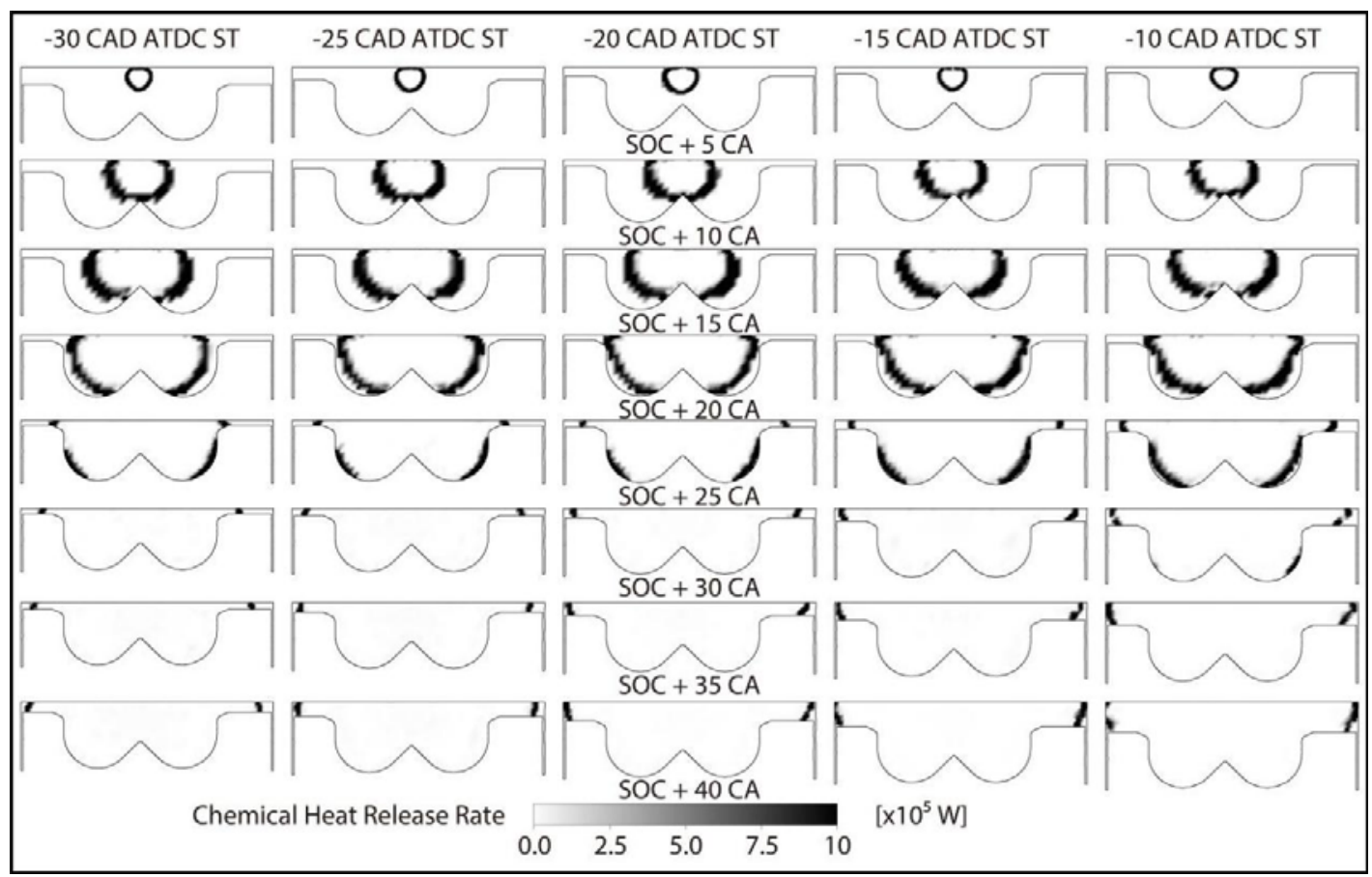

Figure 5.14 Effect of spark timing on spatially-distributed chemical heat release rate at several CAD of interest after SOC.

the pressure in crevice was higher than the decreasing in-cylinder pressure [12]. Therefore, the flame front location was always close to the crevice region during late combusting period. In addition, Figure 5.14 shows that it was mainly the reactions around the flame front zone that contributed to the dual-peak ROHR. Consequently, it can be concluded that the late burn phenomenon was not the result of some late oxidation inside the piston bowl region.

Overall, spark timing controlled the mixture distribution in the combustion chamber and also the phasing of the two combustion stages. As the squish height was larger during late combusting period at delayed ST, less fuel burned faster in the squish region, which helped 
alleviate the late burn phenomenon. Advanced ST trapped more mixture in the squish region and had less overlapping between fast- and slow-burn stages, which contributed to the second ROHR peak. In addition, the smaller squish height for advanced ST operation led to much slower burning speed inside the squish and thus a longer slow-burn stage. It is also important to note that the more significant late burn does not always decrease the thermal efficiency. For example, for spark timing that operated advanced from MBT ST, more fuel burned in the slow-burn stage can help increase the thermal efficiency as less energy was released during compression stroke against the upward-moving piston. By contrast, retarded spark timing compared to optimum would increase the engine efficiency if less fuel burned in the squish and had a more advanced slow-burn stage. However, more fuel trapped in the squish would contribute to incomplete combustion and eventually more unburned hydrocarbon emissions regardless of the combustion phasing. In order to better control $\mathrm{NO}_{\mathrm{x}}$ emission, $\mathrm{ST}$ is usually delayed from MBT [12]. Therefore, the optimization trend of NG combustion in such retrofitted engines is to reduce the fuel burned in the slowburning $2^{\text {nd }}$ stage and decrease the burning duration of the fuel combustion in the bowl region. This approach would increase thermal efficiency and decrease unburned HC emissions at the same time.

\subsection{Equivalence ratio effects}

Equivalence ratio $(\phi)$ is a fundamental engine operating variable [12]. Figure 5.15 shows 
the effect of $\phi$ at constant engine speed (900 rpm), spark timing (-10 CAD ATDC ST), and intake temperature and pressure. Figure 5.15a shows that a higher $\phi$ increased the cylinder pressure and pressure rise rate, but the maximum pressure rise rate was below 2.5 bar/CA. Figure $5.15 \mathrm{~b}$ indicates that the heat release rate increased with $\phi$ due to the increase in available chemical energy every cycle. More, the decrease in the ROHR magnitude during the late combusting period was larger at higher $\phi$. Higher $\phi$ increased the laminar flame

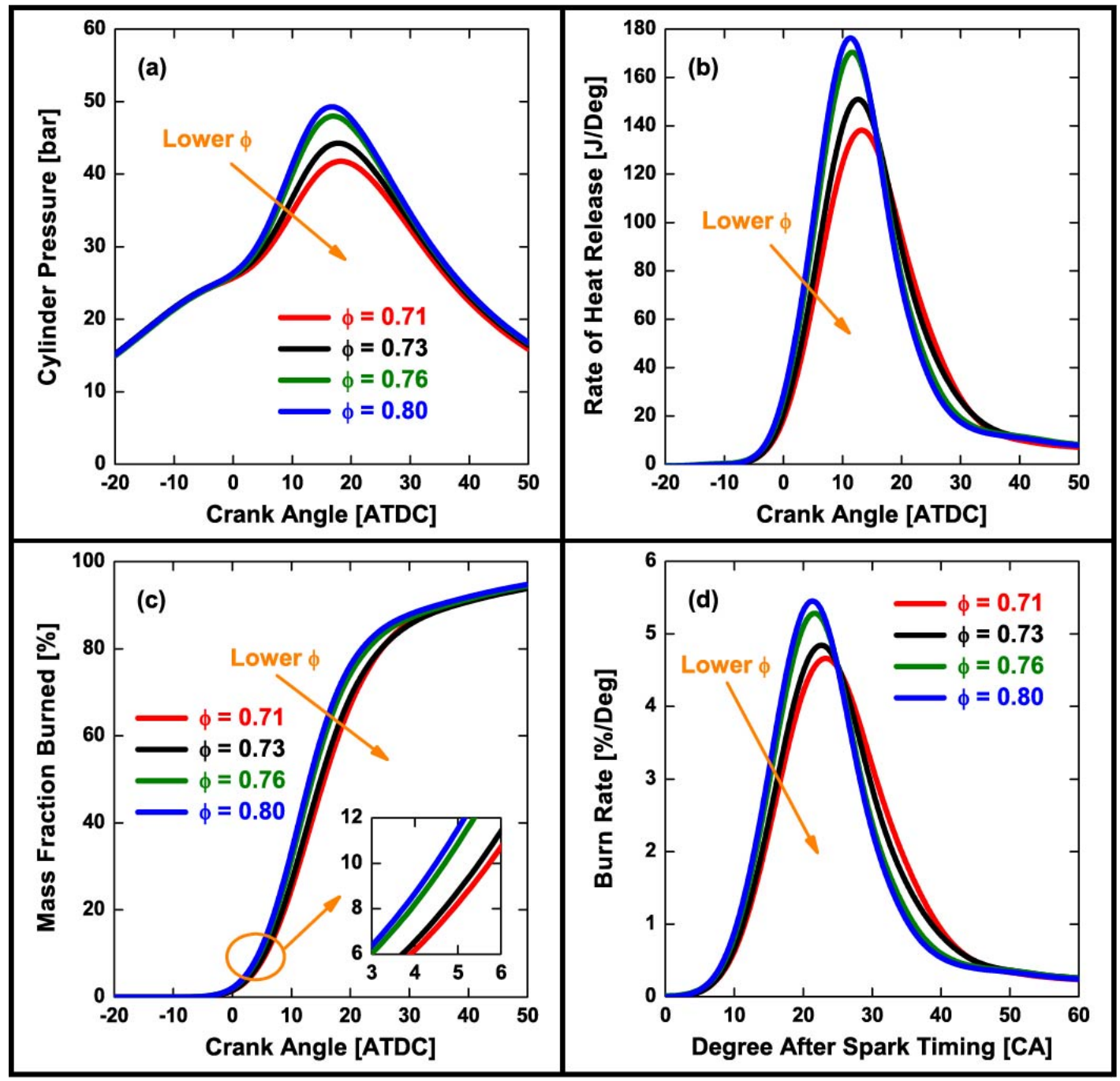

Figure 5.15 Effect of equivalence ratio on (a) in-cylinder pressure, (b) apparent heat release rate, (c) mass fraction burned, and (d) burn rate. 
speed and therefore the ignition delay was shorter, as shown in Figure 5.15d. A faster spark inception and flame propagation advanced the combustion event. However, Figure 5.15c indicates that the end of combustion was similar regardless of $\phi$, which can be explained by the late combustion phenomenon.

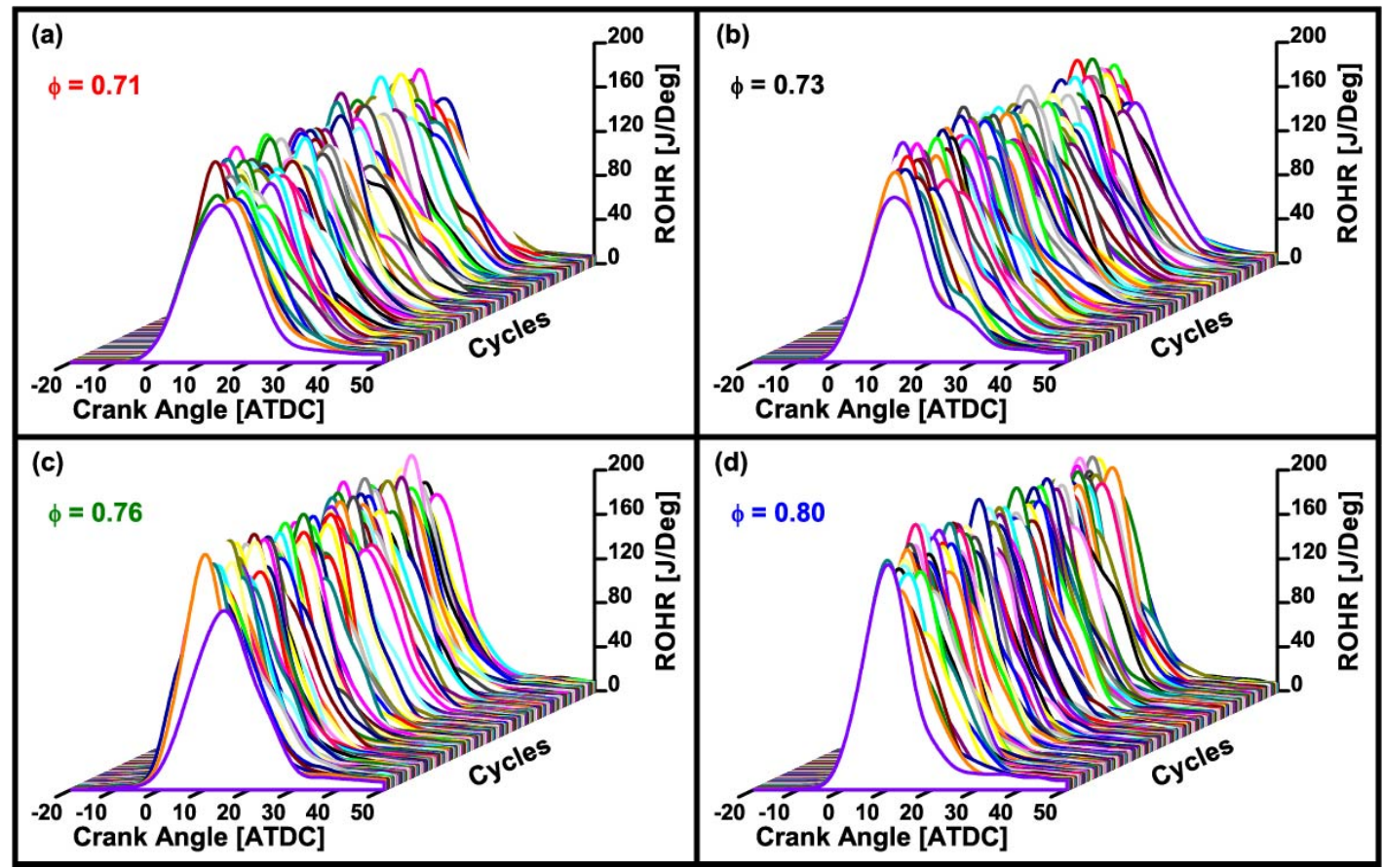

Figure 5.16 Effect of equivalence ratio on the apparent rate of heat release of individual engine cycles.

Based on the ROHR of four hundred consecutive cycles plotted in Figure 5.16, the leaner mixture $(\phi=0.71$ and 0.73$)$ had a more frequent and significant late burn. However, significant late burn is not seen in most of individual cycles with higher $\phi(\phi=0.76$ and $0.80)$. It can be concluded that increasing $\phi$ would decrease the late burn. 


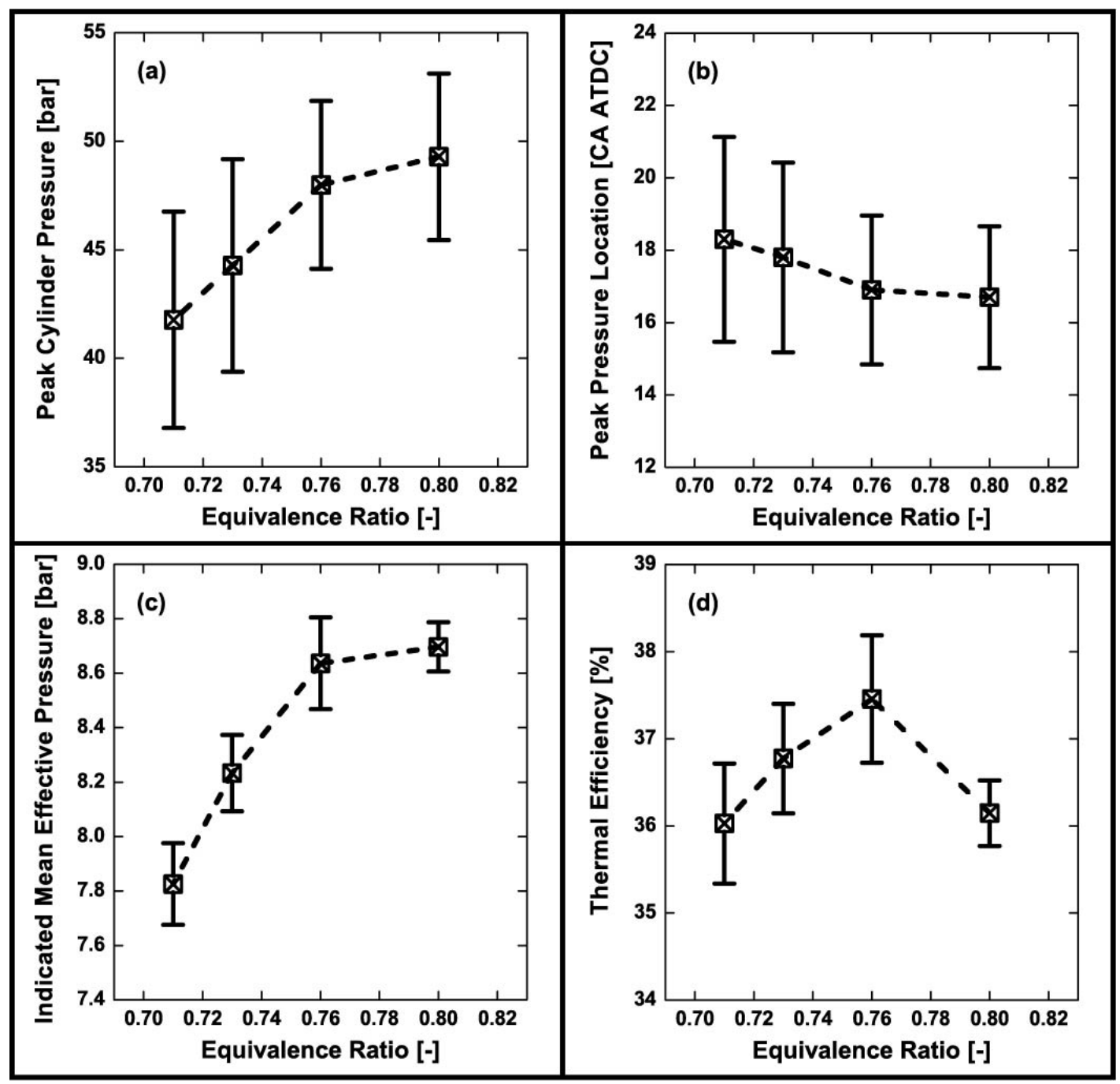

Figure 5.17 Effect of equivalence ratio on the engine performance: (a) peak cylinder pressure, (b) location of peak cylinder pressure, (c) indicated mean effective pressure, and (d) thermal efficiency. The error bars in the figures indicate the 95\% confidence interval.

Figure 5.17 indicate that a higher $\phi$ advanced and increased peak in-cylinder pressure. A higher amount of fuel accelerated the flame development and propagation under lean conditions, resulting in higher power output (i.e., IMEP) from the engine, as seen in Figure $5.17 \mathrm{c}$. Higher $\phi$ at constant speed usually increased the burning speed, which increased 
combustion efficiency. However, leaner combustion also has the potential to increase the fuel conversion efficiency, according to Equation 1.1. This trade-off explained the decrease in engine thermal efficiency at the highest $\phi$ shown in Figure $5.17 \mathrm{~d}$.
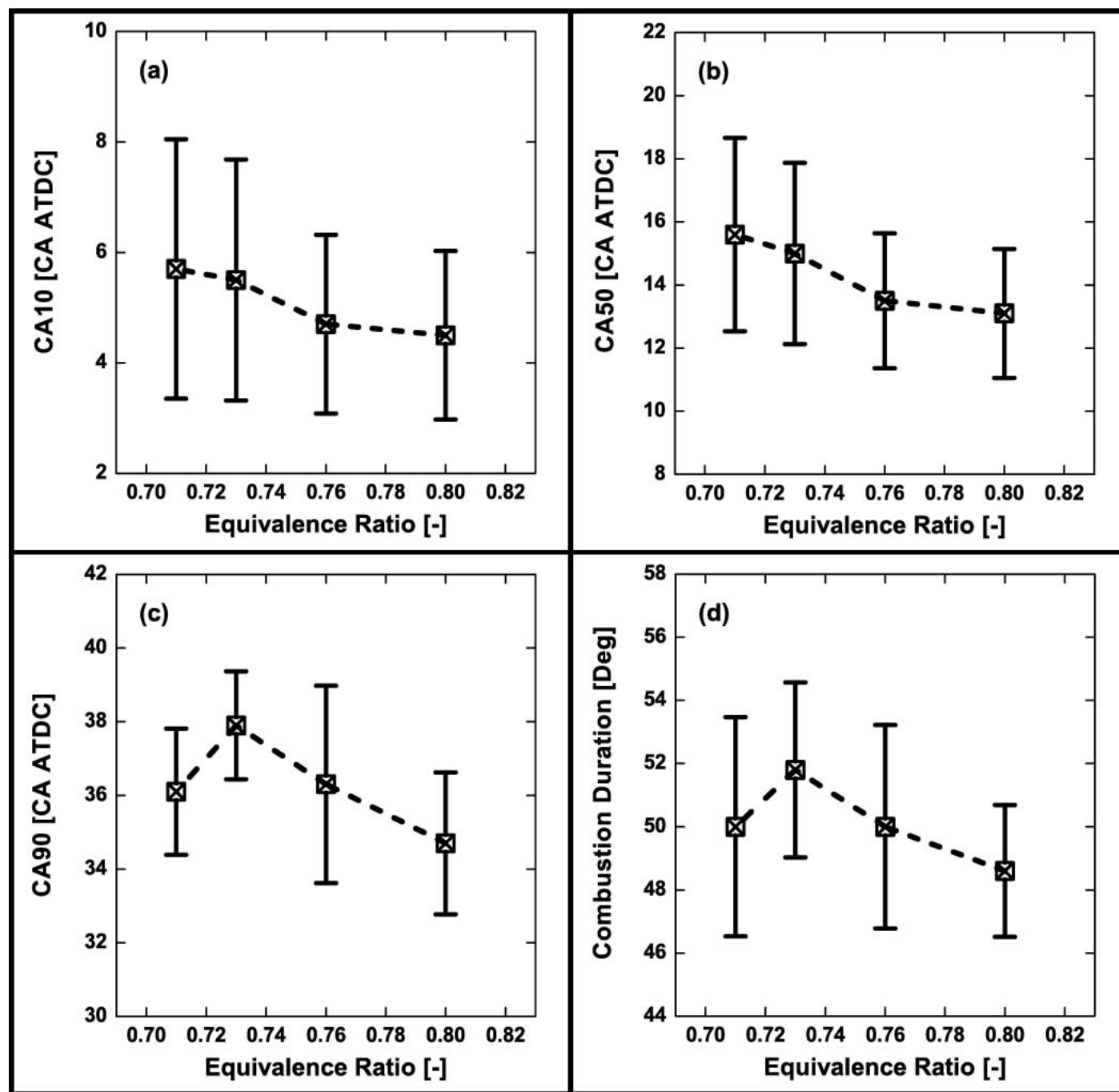

Figure 5.18 Effect of equivalence ratio on the combustion phasing: (a) energyrelease fraction of 10 percent, (b) energy-release fraction of 50 percent, (c) energyrelease fraction of 90 percent, and (d) combustion duration (interval between energyrelease fraction of 5 percent and energy-release fraction of 95 percent). The error bars in the figures indicate the $95 \%$ confidence interval. 
The combustion phasing plots shown in Figure 5.18 indicate that CA10 and CA50 advanced with higher $\phi$, which can be explained by the higher laminar flame speed. However, there was no correlation for the DOC or CA90, probably due to the two-stage combustion.

The numerical simulation results shown in Figures 5.19 and 5.20 provide additional information on in-cylinder flame propagation. Figure 5.19a shows that higher $\phi$ increased the turbulent flame speed between TDC and 10 CAD ATDC, probably due to the associated increase in the laminar flame speed. However, the flame thickness was similar except from 10 to 18 CAD ATDC where the flame thickness was larger for the lower $\phi$ cases. Overall, the spatially-averaged flame information suggests that the equivalence ratio had little effect
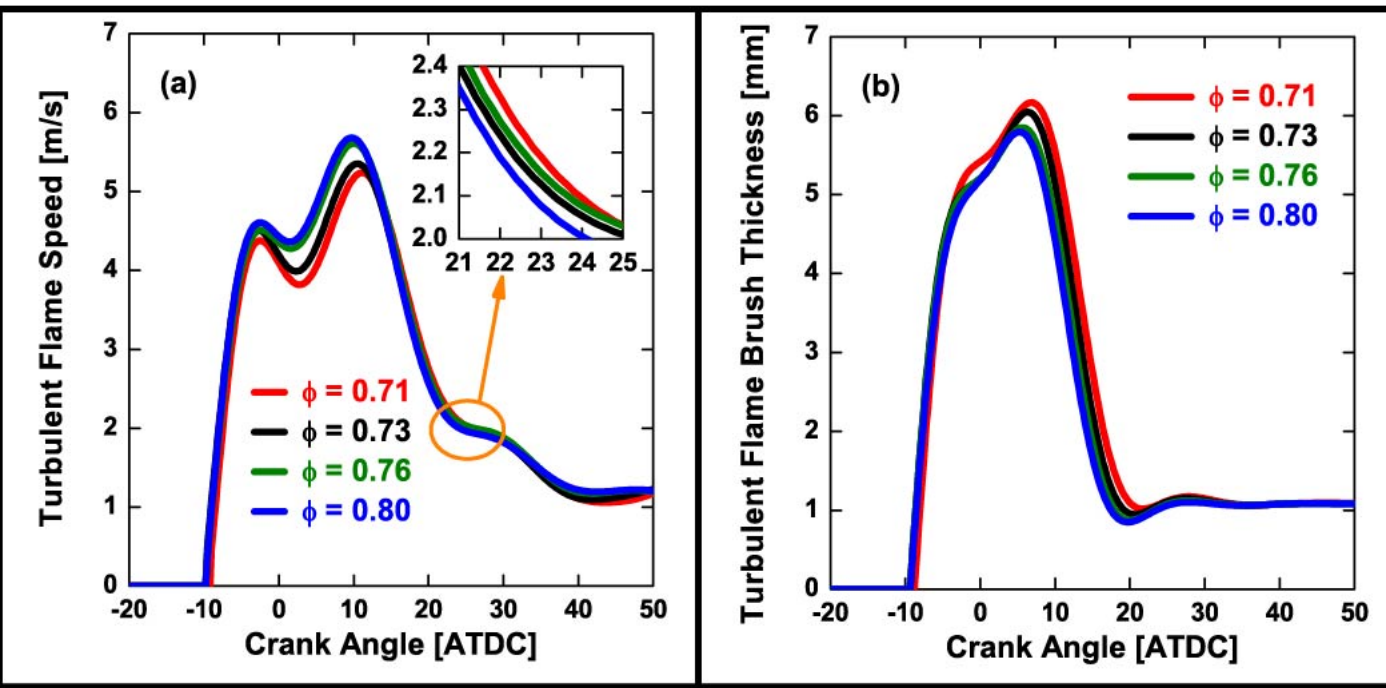

Figure 5.19 Effect of equivalence ratio on spatially-averaged flame information: (a) turbulent flame speed and (b) flame brush thickness (i.e., the square root of the Favre-variance of $\mathrm{G}$ ). 
on the slow-burn stage. However, $\phi$ will affect the flame behavior inside the bowl region.

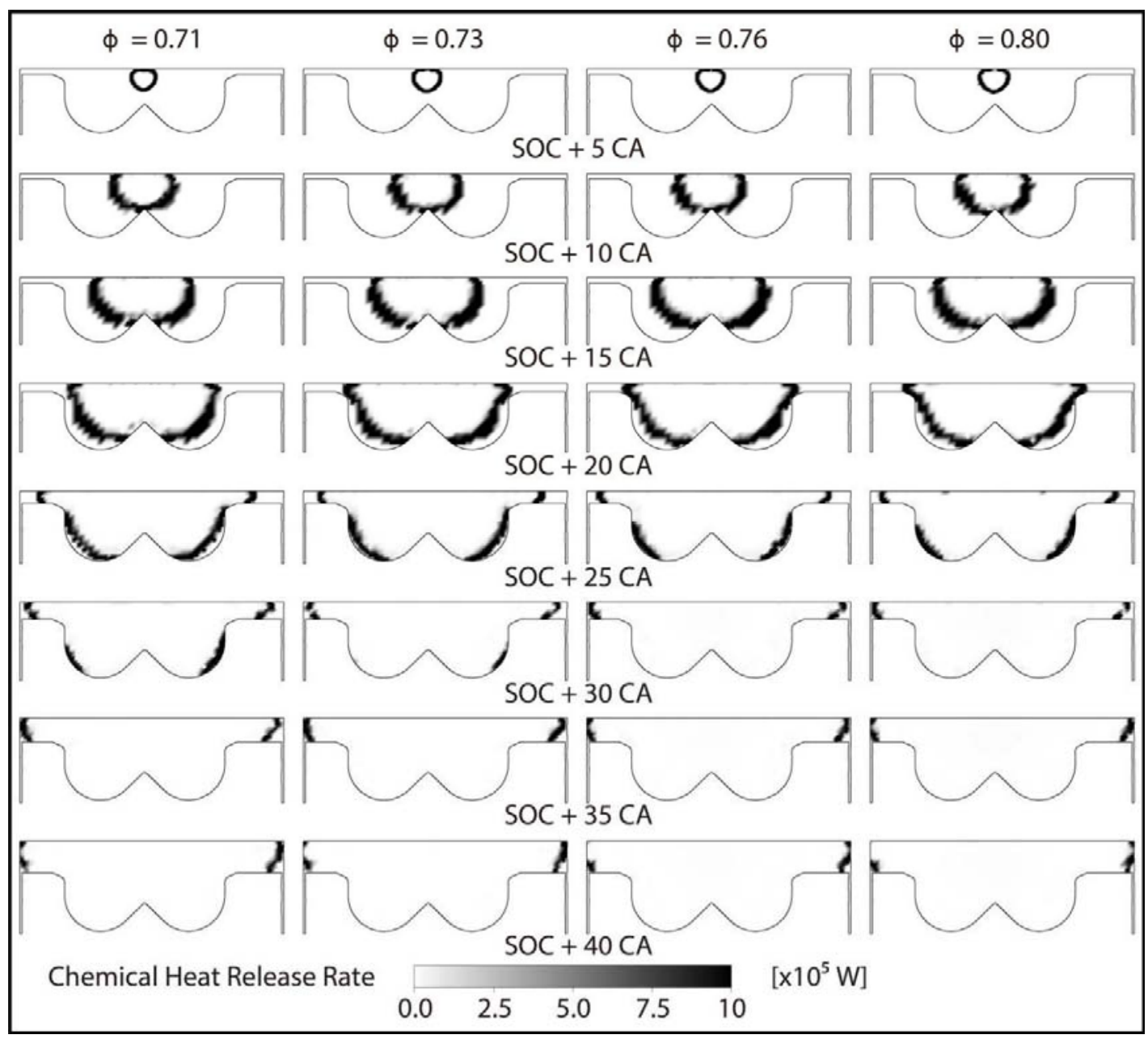

Figure 5.20 Effect of equivalence ratio on spatially-distributed chemical heat release rate at several CAD of interest after SOC.

The flame front shown in Figure 5.20 also suggests a faster flame propagation inside the piston bowl for higher equivalence ratio cases. For example, the flame front of $\phi=0.71$ did not reach the squish entrance around SOC $+20 \mathrm{CAD}$, while the fuel started to burn inside the squish at this time at a higher $\phi$. More, combustion completed the inside-the- 
bowl around SOC $+30 \mathrm{CAD}$ for $\phi=0.76$ and $\phi=0.80$, both more advanced than the corresponding timing for the baseline $(\phi=0.73)$ and leaner-than-baseline $(\phi=0.71)$ conditions. Further, the flame front position with CA inside the squish region showed a similar flame propagation regardless of $\phi$, especially flame propagation close to the cylinder liner, which explains their similar EOC. The results suggest that $\phi$ had a minor effect on the flame propagation deeply inside the squish region compared to local turbulence, heat transfer, pressure, and unburned gas temperature, at least for the operating conditions investigated here.

It is important to note that faster flame propagation inside bowl accelerated the burning speed at the bottom of the bowl and in the region near the squish's entrance. Therefore, some parts inside the slow-burn zone for the lower- $\phi$ operation can be parts of the fast-burn zone for higher- $\phi$ operation. As a result, higher- $\phi$ decreased the size of the slow-burn zone (crater and squish). In other words, a larger fraction of the fuel inside the slow-burn region burned at the higher- $\phi$ operation before the fast-burn event was completed, which decreased the fraction of the fuel burning in the late-combustion stage. In addition, higher$\phi$ operation completed the bowl burning faster and advanced the squish burning event, which moved the slow-burning stage inside a more optimal environment. These effects helped alleviate the late burn phenomenon for higher $\phi$ cases $(\phi=0.76$ and 0.80$)$ compared to baseline $(\phi=0.73)$, as shown in Figure 5.16. However, leaner combustion had additional effects. As the leaner mixture (i.e., $\phi=0.71$ ) decreased the flame propagation speed, lower- 
$\phi$ operation burned more fuel inside the squish band. More, the larger squish height, together with similar radial flame propagation speed, contributed to more volume to be burned per radial distance. As a result, lower- $\phi$ operation burned more fuel in the squish region before the end of the fast-burn stage, which increased the overlapping of the twostage combustion. Therefore, $\phi=0.71$ decreased the combustion event separation compared to baseline $(\phi=0.73)$. Overall, the magnitude of late burn phenomenon was affected by the equivalence ratio's trade-off effects discussed above.

\subsection{Engine speed effects}

Engine speed affects in-cylinder gas motion, friction work, residual gas fraction, volumetric efficiency, flame propagation speed, the time available to complete combustion, and the heat transfer rates [12]. For example, higher engine speed increases the frictional loss to a magnitude comparable to the combustion heat loss. Although the higher turbulence associated to the increased engine speed accelerated flame propagation, the overall combustion process will be also affected by the reduced residence time, hence a higher probability of lower combustion efficiency. Therefore, mid-range engine speeds are preferred, where high in-cylinder pressure compensates the frictional loss hence more optimum operating conditions. More, the ST is usually advanced with increased engine speed to provide more time for completing the combustion event. In this study, the engine speed was increased from $900 \mathrm{rpm}$ to $1300 \mathrm{rpm}$ in $100 \mathrm{rpm}$ increments, at constant spark timing (-10 CAD ATDC) and equivalence ratio $(\phi=0.73)$. The ST was not optimized for 
the higher speed.

Figure 5.21 shows the pressure-based analysis for the investigated engine speeds. Higher engine speed decreased PRR, which was always below 2 bar/CA. Therefore, there was no evidence of knock, supporting the hypothesis that flame propagation dominated the combustion event. In-cylinder pressure decreased with engine speed due to the lower

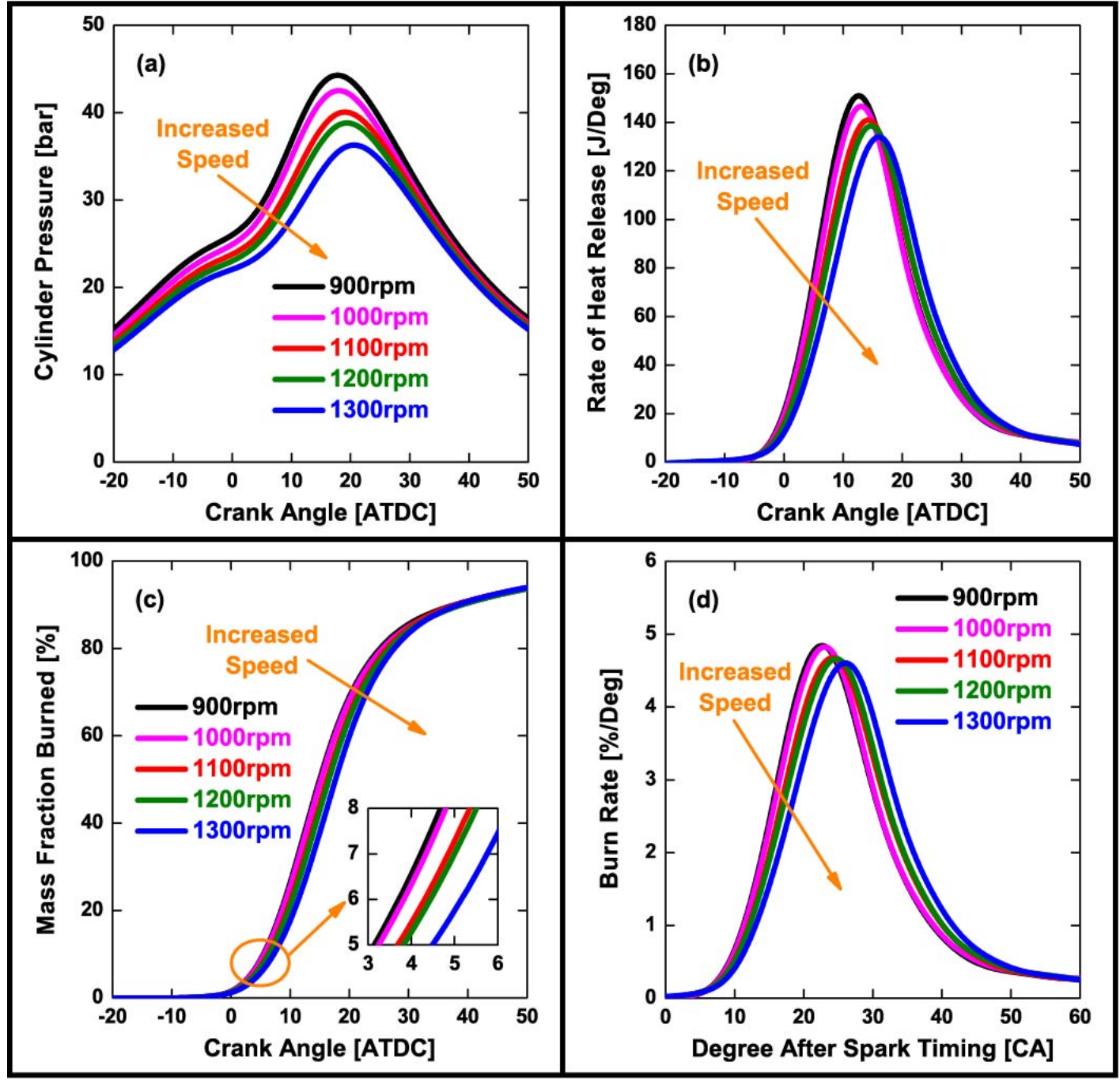

Figure 5.21 Effect of engine speed on (a) in-cylinder pressure, (b) apparent heat release rate, (c) mass fraction burned, and (d) burn rate. 
volumetric efficiency (see the decrease in pressure at the beginning of the compression stroke for the higher-speed conditions) and the non-optimized ST. The ROHR and burn rate indicate that flame burning speed decreased when engine speed increased. However, the mass fraction burn showed similar EOCs regardless of the engine speed, which can be explained by the two-stage combustion event.

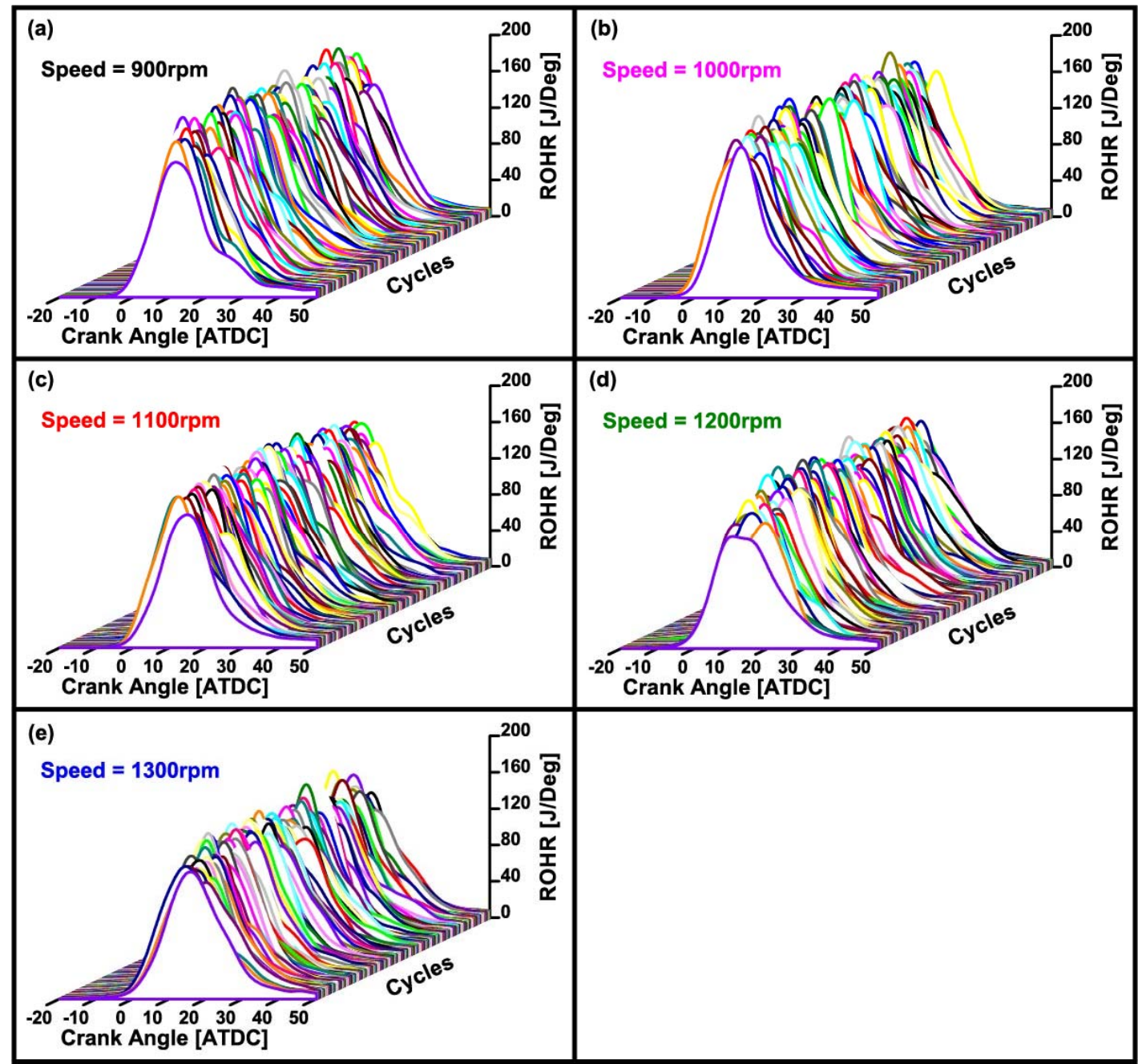

Figure 5.22 Effect of engine speed on the apparent rate of heat release of individual engine cycles. 
Figure 5.22 shows that the late burn was evident at all engine speeds. In addition, the late burn phenomenon was relieved for higher speed operation. Even though individual cycles shown in Figure 5.22 cannot show it very clearly, the average ROHR shown in Figure $5.21 \mathrm{~b}$ proved this conclusion.
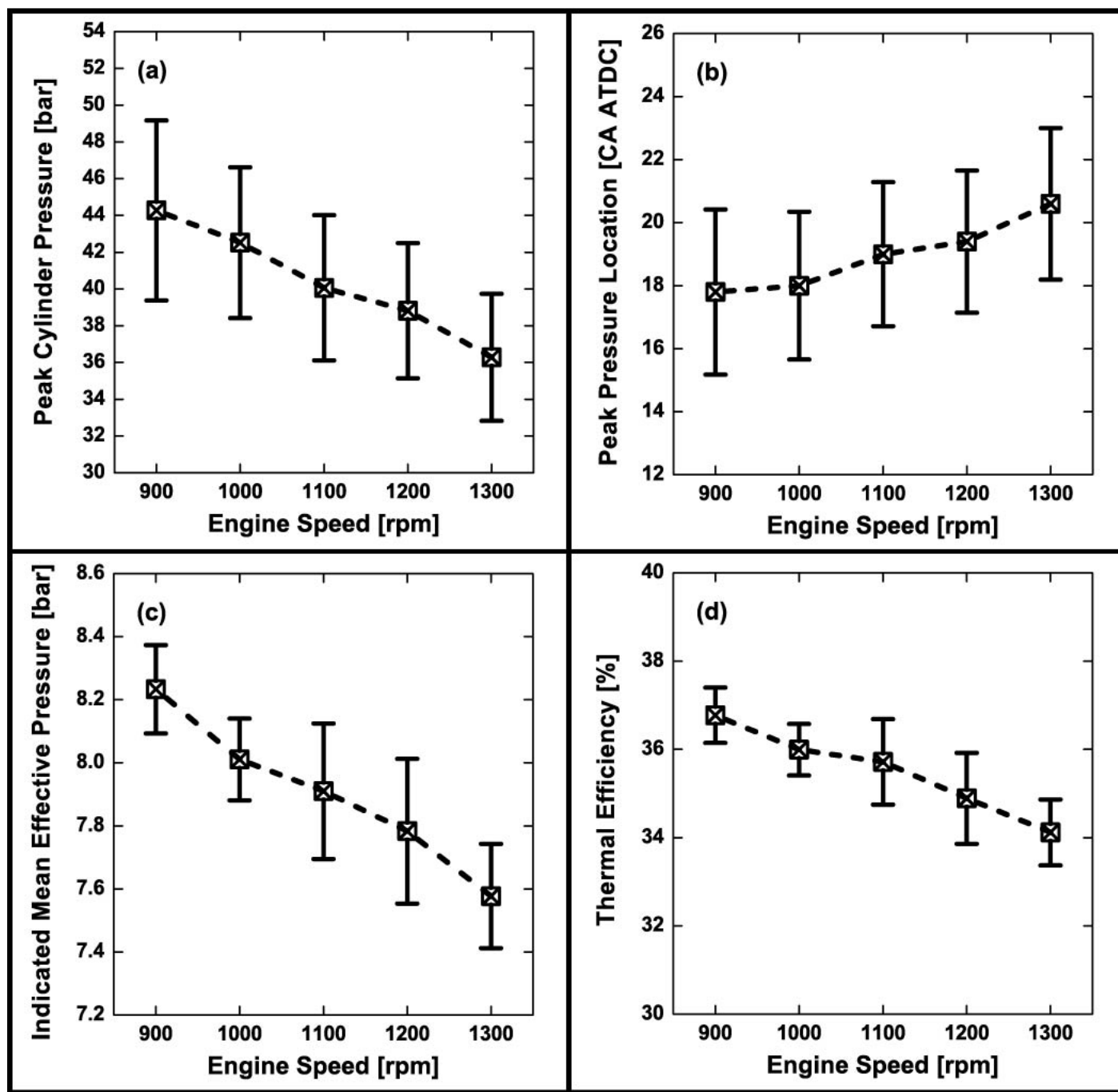

Figure 5.23 Effect of engine speed on the engine performance: (a) peak cylinder pressure, (b) location of peak cylinder pressure, (c) indicated mean effective pressure, and (d) thermal efficiency. The error bars in the figures indicate the 95\% confidence interval. 
Engine performance shown in Figure 5.23 suggests that increased engine speed decreased and delayed the maximum pressure, probably due to less time available to complete combustion at constant ST settings. There was a large overlapping of 95\% confidence interval despite the different engine speed. Figure 5.21 shows the highest heat release was

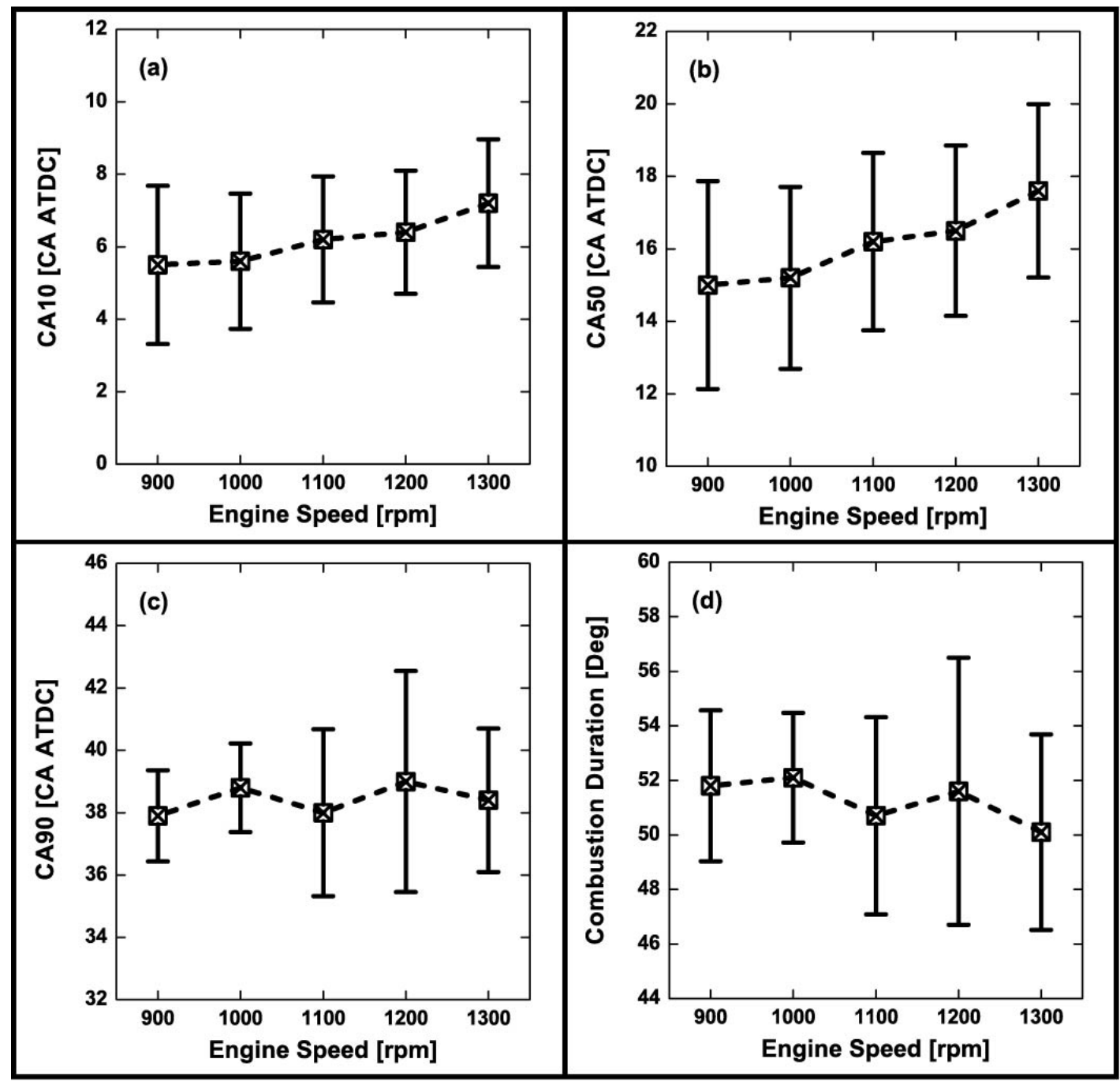

Figure 5.24 Effect of engine speed on the combustion phasing: (a) energy-release fraction of 10 percent, (b) energy-release fraction of 50 percent, (c) energy-release fraction of 90 percent, and (d) combustion duration (interval between energy-release fraction of 5 percent and energy-release fraction of 95 percent). The error bars in the figures indicate the $95 \%$ confidence interval. 
at $900 \mathrm{rpm}$, which also had the maximum thermal efficiency for this speed sweep. The lower peak pressure and heat release rate in Figure 5.21 suggest less work per cycle, which affected the engine power output. Hence, the IMEP and thermal efficiency decreased linearly with increasing speed.

The combustion phasing shown in Figure 5.24 indicates that a higher engine speed delayed CA10 and CA50. However, engine speed had negligible effects on CA90 and DOC, which again can be explained by the combustion characteristics in such converted engines.

Figures 5.25 and 5.26 show some additional details of engine-speed effects on the flame behavior throughout the combustion event as predicted by the CFD simulations. Figure 5.25 indicates that the turbulent flame speed increased with engine speed, as the higher

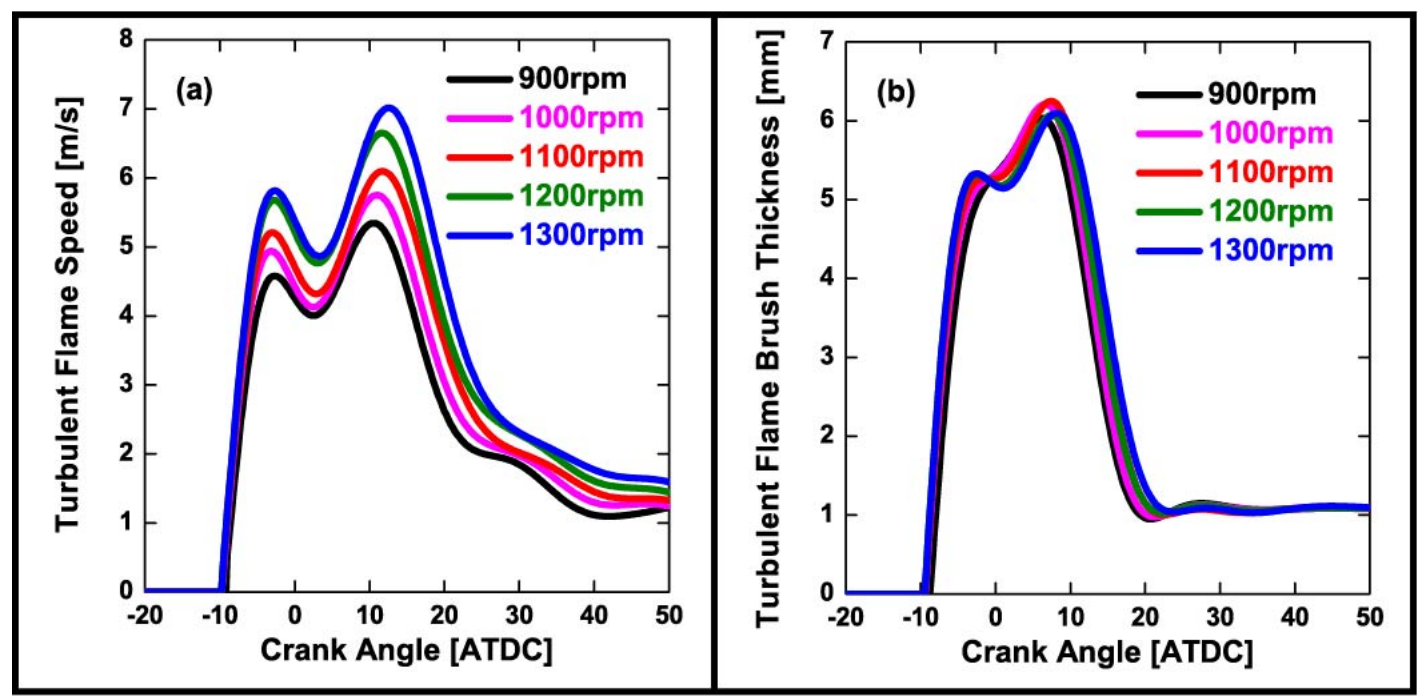

Figure 5.25 Effect of engine speed on spatially-averaged flame information: (a) turbulent flame speed and (b) flame brush thickness (i.e., the square root of the Favre-variance of $G$ ). 


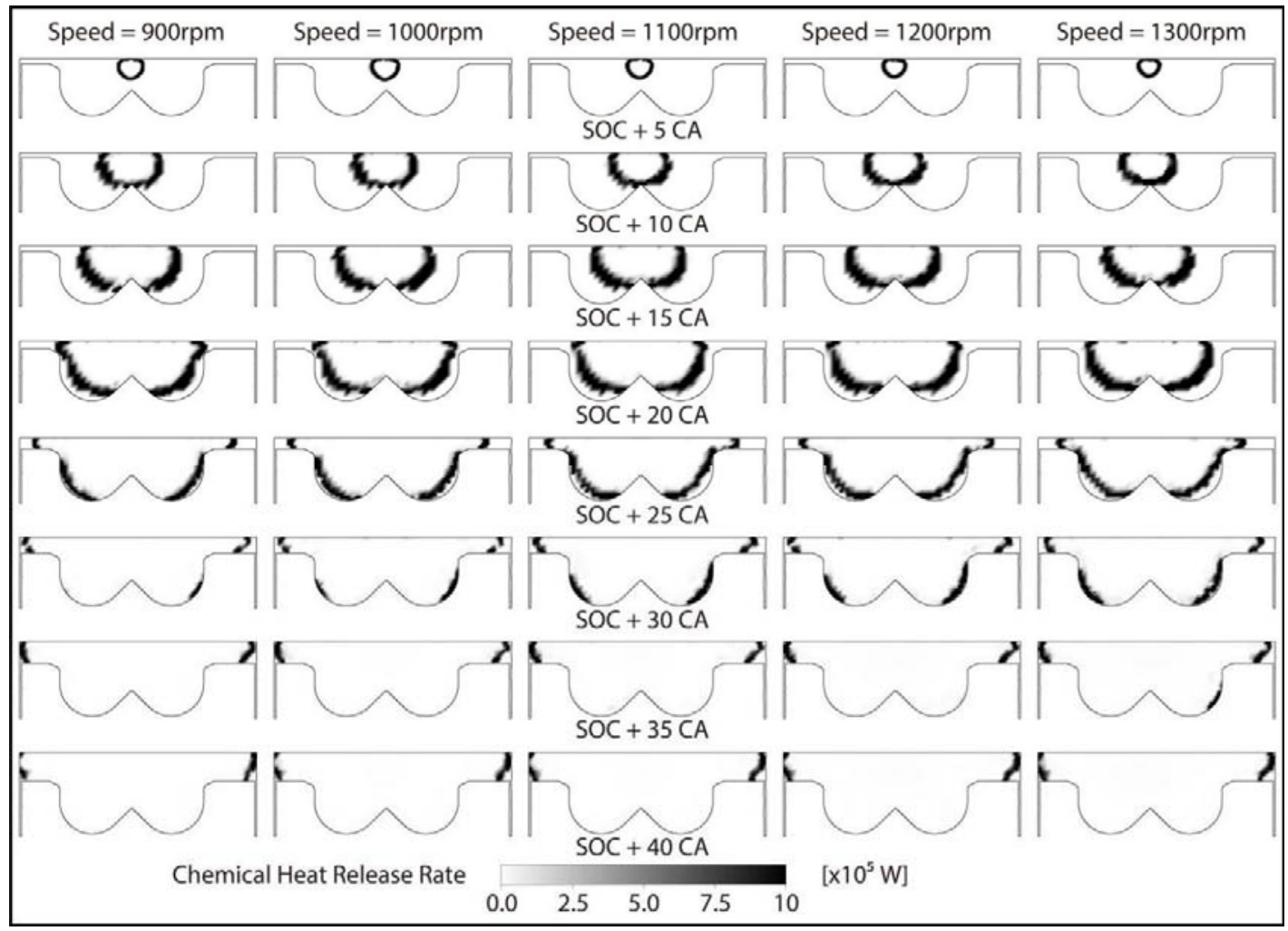

Figure 5.26 Effect of engine speed on spatially-distributed chemical heat release rate at several CAD of interest after SOC.

piston speed increased in-cylinder turbulence. However, Figure 5.26 show that a higher speed retarded the flame front position, probably due to less time available for chemical reactions despite the larger turbulent flame speed. In addition, the changes in engine speed had a negligible effect on the flame thickness inside the bowl or inside the squish volume, at least for the range of engine speeds investigated here.

It is also important to note that the slower flame propagation at higher engine speeds affected the separation between the fast-burn and the slow-burn stages. Specifically, the squish height was higher when the flame entered the squish region at the higher engine 
speed, which helped the burning inside the squish. Therefore, a larger portion of the squish region (i.e., the slow-burn zone) combusted before the fast-burn event finished for higherspeed operation, which increased the overlapping of the two combustion stages. This probably explains why there was a less-evident late burn at higher engine speeds. For example, Figure 5.26 shows that 1300-rpm case at SOC + 30 CAD had a similar burning rate inside the bowl region as the $900 \mathrm{rpm}$ case at SOC $+25 \mathrm{CAD}$. However, more fuel burned inside the squish for the 1300-rpm case compared to the 900-rpm case. The results indicate that a higher engine speed decreased the phasing separation of two combustion stages.

\subsection{Summary}

Engine operating conditions influenced the two-stage combustion event. A higher percentage of heavier hydrocarbons in NG increased the flame propagation speed in the bowl region and the phasing separation between the two combustion events. However, a faster burn inside the bowl advanced the combustion event inside the squish region, which then took place at higher pressure and temperature conditions.

Spark timing controlled the mass fraction burned and the phasing of the two combustion stages. There was no obvious late burn phenomenon for delayed ST because the phasing of the inside- and outside-the-bowl combustion was very close. For advanced ST, the phasing of these two combusting events was more separated and, as a result, significant 
late burn (or even double ROHR peak) was visible.

The equivalence ratio had combined effects on the late burn under NG lean-burn operation. For example, a higher equivalence ratio accelerated the flame burning speed in the bowl region and can help relief the late-burn phenomenon. The mechanism is that a faster combustion inside the bowl advanced the start of the outside-the-bowl burning, which provided more optimal conditions (higher pressure and bulk temperature) for the $2^{\text {nd }}$ combustion stage. These effects may hid the "bump" towards the end of combustion. By contrast, the leaner mixture delayed the $1^{\text {st }}$ stage combustion and increased the superposition period between the two combustion stages, therefore also making the lateburn less visible in the ROHR.

A higher engine speed reduced the late-burn phenomenon at constant ST. The delayed combustion phasing of higher engine speed operation increased the squish height when outside-the-bowl burn took place, which reduced the local flame quenching. More, the delayed combustion phasing increased the overlapping of the two combustion stages.

It is important to note that reducing the late burn was not the major goal of investigating the two-stage combustion. The analysis presented in this chapter shows that lean mixture operated at retarded ST and high engine speed would make the late burn less evident. But it will also lower the thermal efficiency, increased knocking tendency, and increase the CO 
and $\mathrm{HC}$ emissions. As a result, the optimization of the two-stage combustion at retarded spark timing should focus on shortening the $1^{\text {st }}$ stage combustion and moving the $2^{\text {nd }}$ stage combustion to a more optimal phasing. 


\section{Chapter 6 Characterization of Energy Released Throughout the Combustion Period}

The turbulence distribution inside the combustion chamber separated the combustion phenomena into two distinct events: a highly-turbulent and a low turbulence flame propagation. More, the operating conditions decided the phasing and magnitude of these two distinct combustion events. This chapter presents the methodology used to identify the fast-burning combustion period. In addition, CFD simulations were applied to evaluate this method at various operating conditions. Further, combustion characteristics such as the mass fraction burned, combustion phasing, and burn rate were analyzed during early flame development, fast-burning period, and late-burning period.

\subsection{The separation of the combustion phenomena}

The profile of mass fraction burned as a function of crank angle describes the chemical energy or gross heat release. This profile has a characteristic symmetrical shape in conventional SI engine [12]. The rate at which the fuel-air mixture burns increases from a low value immediately following the spark discharge to a maximum about halfway through the burning process and then decreases close to zero as the combustion process ends [12]. It is convenient to use the mass fraction burned to characterize the different stages of the SI combustion process based on their duration in crank angels. 


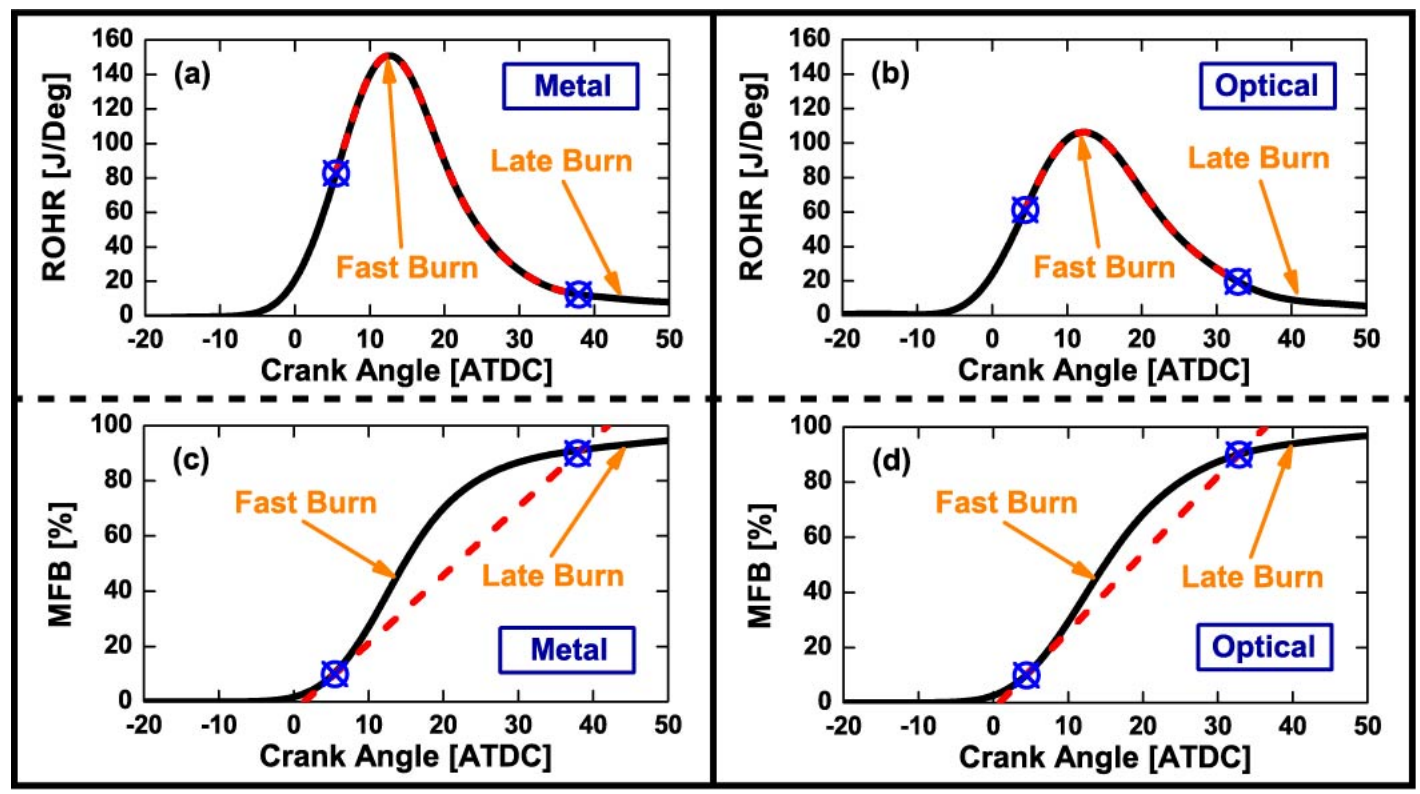

Figure 6.1 Rapid-burning period characterized by the duration between CA10 and CA90 on the rate of heat release and mass fraction burned for both metal and optical engines at baseline condition.

Traditional methodology that describes the different combustion stages in conventional SI engines defines the flame development process as the duration from the spark discharge to the point where a small but measurable fuel fraction has burned (usually the duration between ST and CA10). This stage is primarily influenced by the mixture state and composition, and the motion in the vicinity of the spark plug. The fast-burning stage is the crank angle interval required to burn the major portion of the charge, which is defined as the interval between the end of the flame-development stage (usually CA10) and the end of the fast flame-propagation process (usually CA90). This stage is influenced by incylinder conditions. The final stage (i.e., the late combusting period) is defined as the time from CA90 to EOC, when the remainder of the charge burns to completion. It is not easy to quantify the final stage because the energy-release rates are comparable to the other 
energy-transfer processes that are occurring at the same time (such as the heat loss to the boundary and heat released from late oxidation) [12]. It is important to note that the selection of the 10 and 90 percent points is arbitrary [12]. CA10 and CA90 are selected to avoid the difficulties involved in determining accurately the shape of the curve at the start and end of combustion [12].

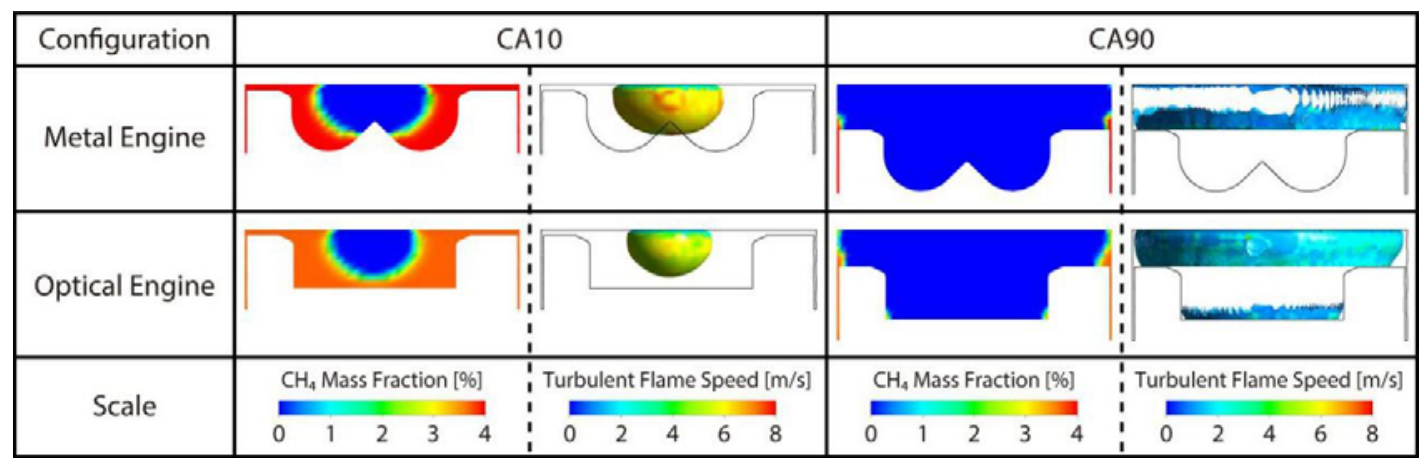

Figure 6.2 CAD simulation predicted flame front location at CA10 and CA90 for both metal and optical engines at baseline condition.

Figures 6.1 and 6.2 show the rapid-burning period defined by the traditional approach described above for experiments at baseline condition in both engine configurations. Figure 6.1 shows that the straight line connecting CA10 and CA90 was far away from the MFB curve for both engine configurations. Figure 6.2 shows that CA90 was close to the end of combustion. More, the duration between CA10 and CA90 included both the fast-burn (inside the bowl) and the slow-burn (inside the squish) events discussed in the previous chapters. Therefore, the traditional defined rapid burning period (i.e., the duration between CA10 and CA90) was not appropriate for NG SI in bowl-in-piston combustion chamber. This is understandable because combustion chamber had a substantial impact on the 10-to- 
90-percent burn time [12].

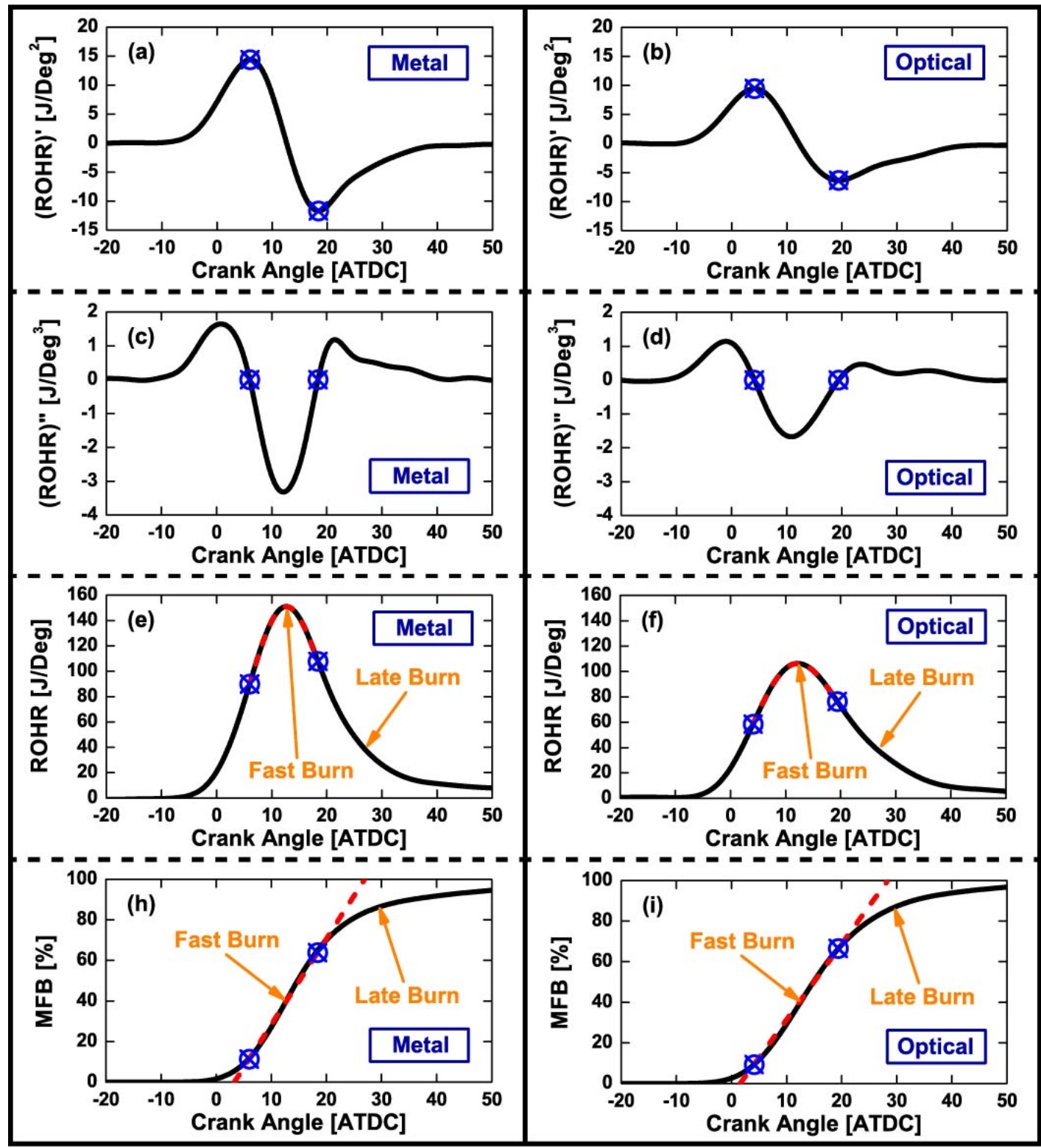

Figure 6.3 Rapid-burning period characterized by the duration between ROHR inflection points on the rate of heat release and mass fraction burned for both metal and optical engines at baseline condition: $(a, b)$ peak points on first derivative of ROHR, (c,d) zero points on second derivative of ROHR, $(e, f)$ inflection points on $\mathrm{ROHR}$ trace, and $(\mathrm{h}, \mathrm{i})$ fast-burn duration defined on mass fraction burned. 
This study proposes a novel methodology to separate the fast burning event in the bowl region from the slow combustion in the squish volume, as shown in Figure 6.3. The methodology is based on identifying the inflection points in the ROHR, which are the peak points or the critical/stationary points of the $1^{\text {st }}$ derivative of ROHR. The zero/root of the ROHR's $2^{\text {nd }}$ derivative is also an inflection point of ROHR. Based on this methodology, the early flame development stage was defined as the duration between ST and the $1^{\text {st }}$ inflection point of ROHR. The fast-burn stage was defined as the period between the $1^{\text {st }}$ and $2^{\text {nd }}$ inflection points of ROHR. Finally, the late combustion was defined as the crank angle interval between ROHR's $2^{\text {nd }}$ inflection point and EOC (CA90 was used in this chapter).

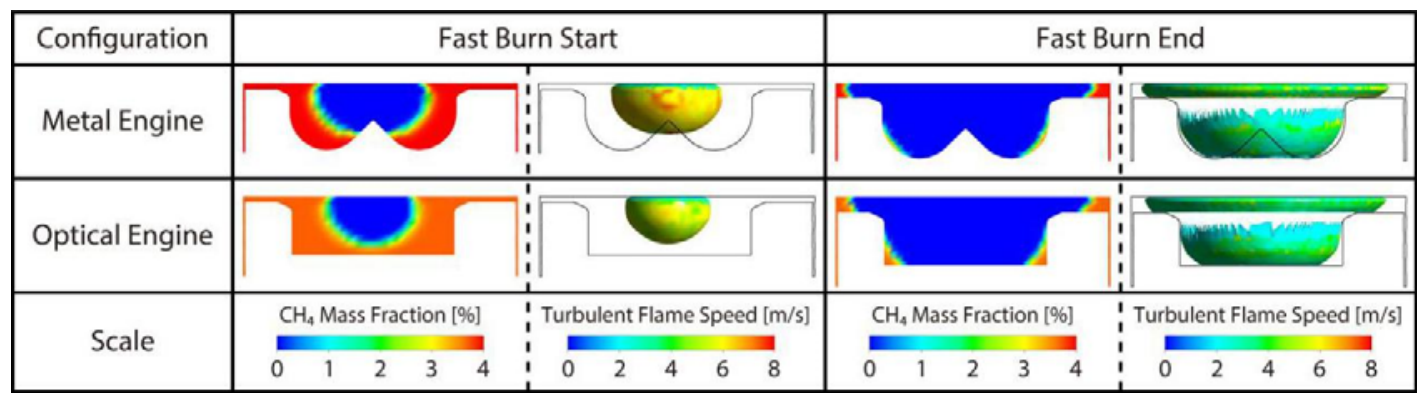

Figure 6.4 CAD simulation predicted flame front location at ROHR inflection points for both metal and optical engines at baseline condition.

The ROHR in Figure 6.3 shows that the fast-burn duration using the ROHR inflection point method was shorter than the period between CA10 and CA90. As expected, Figures $6.3 \mathrm{~h}$ and 6.3i show that the lines between the inflection points were tangent to the MFB curve regardless of engine configuration, which were the appropriate for fast burning. The 
predictions of the flame front shown in Figure 6.4 shows that the flame front location was similar to CA10 at the beginning of the fast-burning period. This is logical because the chamber geometry's effects on 0-to-10 MFB were relatively small [12]. However, both metal and optical engine configurations almost completed the burning event inside the bowl region at the second inflection point, except near the bottom of the bowl (which was included in the slow-burn region). Therefore, the second inflection point successfully separated the fast burning period, albeit the overlapping between the fast-burn and the slow-burn could not be separated. In addition, the values of the turbulent flame speed at the flame front confirm the effectiveness of this novel methodology. Specifically, the turbulent flame speed increased from the $1^{\text {st }}$ inflection point (i.e., the end of flame development stage) due to the higher turbulence intensity created by the squish and piston motion during compression. The slower turbulent flame speed at the $2^{\text {nd }}$ inflection point supports the end of the rapid-burning stage. More, Figures $6.3 \mathrm{e}$ and $6.3 \mathrm{f}$ show that the heat release rate at these two inflections points were at the same order, albeit the different turbulent flame speed. This was probably due to the smaller flame surface but fastermoving flame at the $1^{\text {st }}$ inflection point and the larger flame surface but slower-moving flame at the $2^{\text {nd }}$ inflection point, which resulted in similar heat release rates.

The inside-the-bowl burning stage included both early flame development and fast burning. It is also important to note that the fast-burning stage defined in analysis also included 
some fuel burning in the slow-burn region because of the overlap between the fast- and the

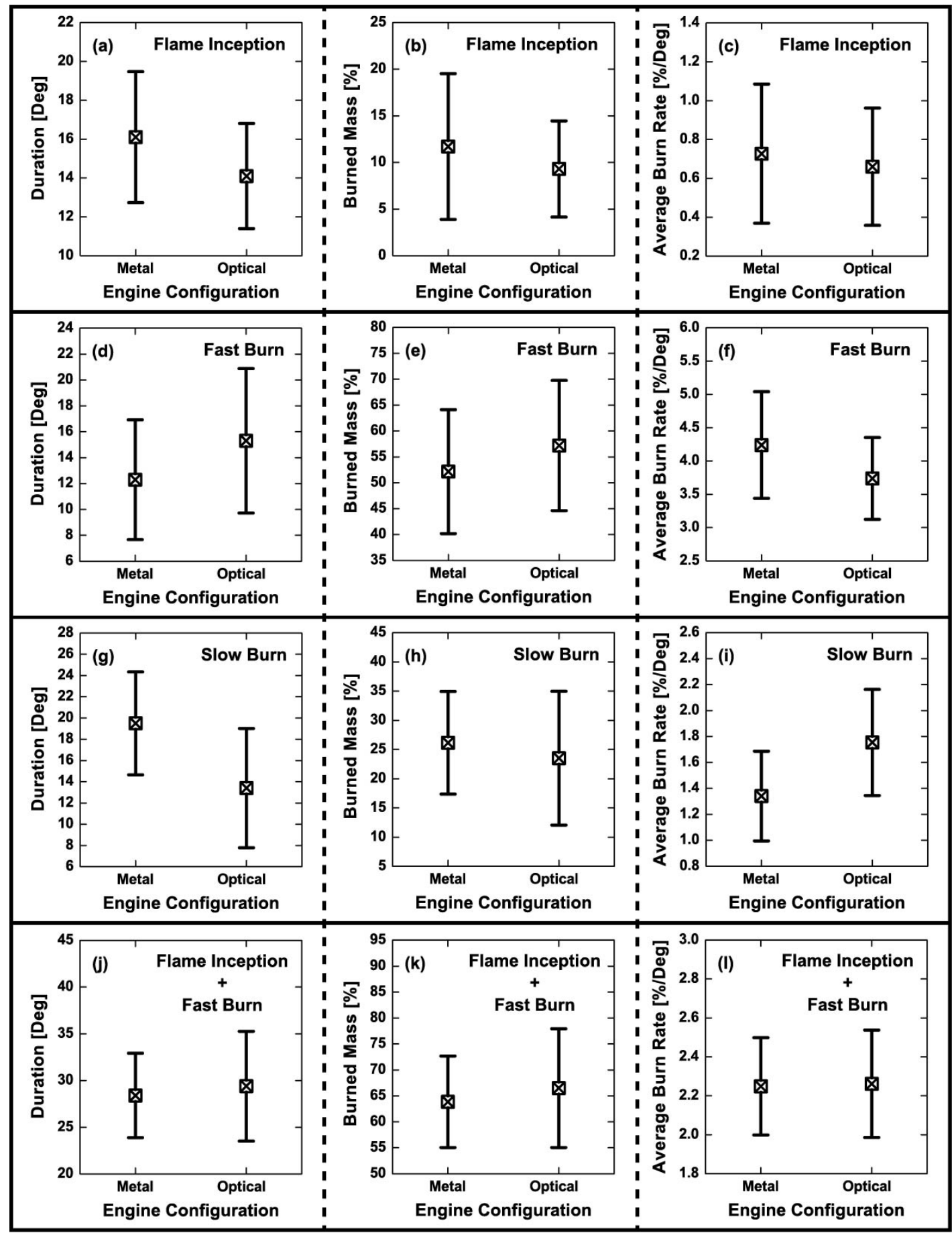

Figure 6.5 Burning duration, mass fraction burned, and average burning rate of early flame development, fast-burn, late-burn, and inside-the-bowl burn stages, for both metal and optical engines at baseline condition. 
slow-burning periods.

Figure 6.5 shows the burning duration, mass fraction burned, and average burning rate during the combustion stages separated based on the ROHR inflections points. The data shows that the flame inception period burned $\sim 10 \%$ of the fuel mass, despite the large size of the enflamed zone shown in Figure 6.4. The gap between ST and SOC was included in flame inception period, which contributed to its duration and the low burning rate. The fastburning duration burned more than $50 \%$ of fuel due to the high turbulence inside the bowl region. In addition, an important fuel mass $(\sim 25 \%)$ was burned in the slow-burn period, which increased the burning duration compared to the fast-burning period. The average burn rate for the fast-burning period was the highest of these three stages, which validates the methodology used to detect it. The average burn rate of late burn period was not very low compared to that during spark inception, probably because of the transition period between the fast and slow burning in that region.

Overall, the use of the ROHR's inflection points to separate the fast-burning period in a bowl-in-piston combustion chamber was better than the conventional method used in the literature (i.e., CA10-CA90). The following subsections would estimate if this method is effective regardless of changes in operating conditions (i.e., changes in fuel composition, spark timing, mixture equivalence ratio, and engine speed). 


\subsection{Fuel composition effects on combustion stages}

The method described above was implemented to experimental data from the metal engine experiments that used methane and natural gas (see Table 2.2) at baseline condition (-10 CAD ATDC ST, medium load, $900 \mathrm{rpm}, \phi=0.73$ for methane and $\phi=0.71$ for $\mathrm{NG}$, see Table 2.3).

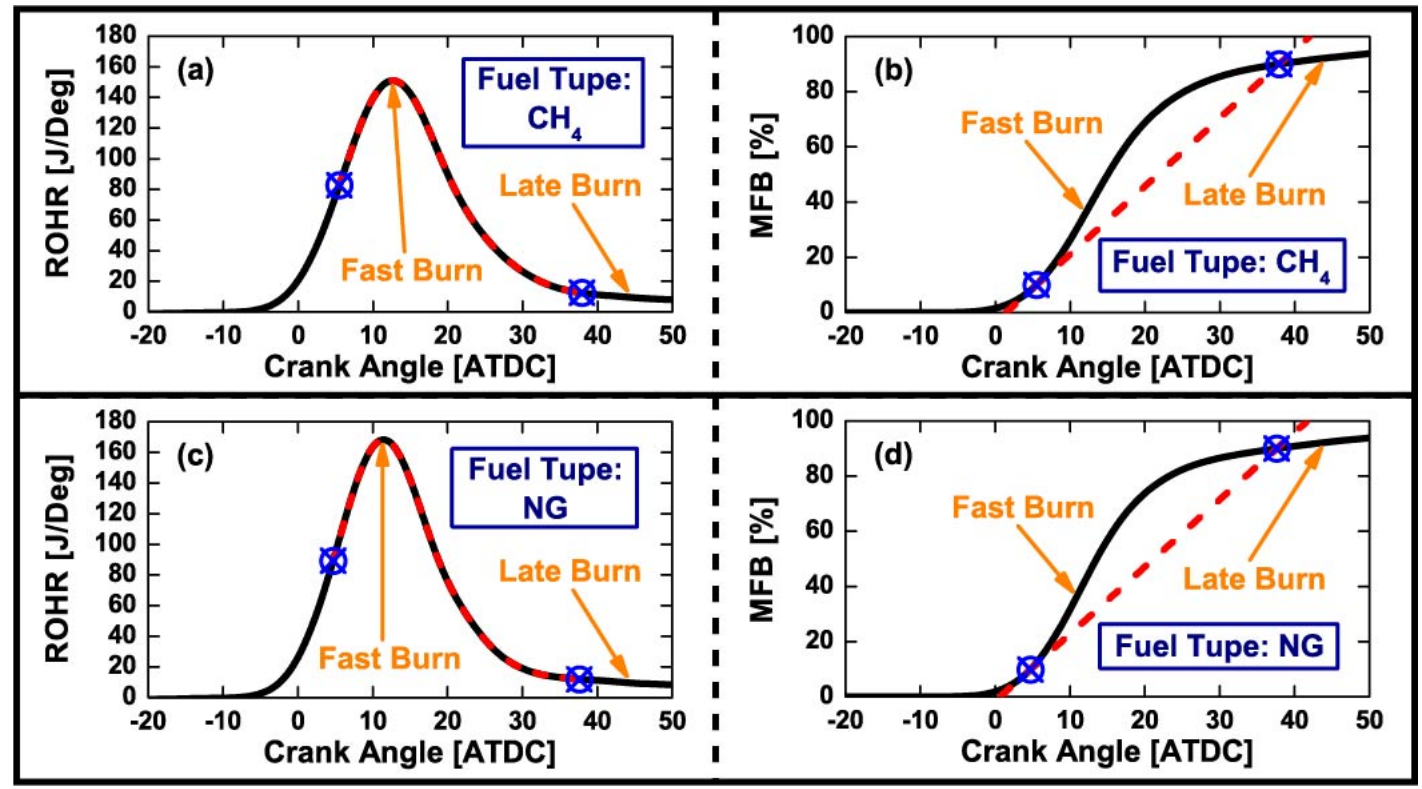

Figure 6.6 Rapid-burning period characterized by the duration between CA10 and CA90 on the rate of heat release and mass fraction burned for different gas composition operations.

Figure 6.6 shows the CA10 and CA90 points on the ROHR and MFB. It is evident that the period between CA10 and CA90 cannot be defined as the fast-burning period regardless of the fuel composition. However, the ROHR's inflection points shown in Figure 6.7 successfully identified the fast-burning period. In addition, the CFD simulation results 


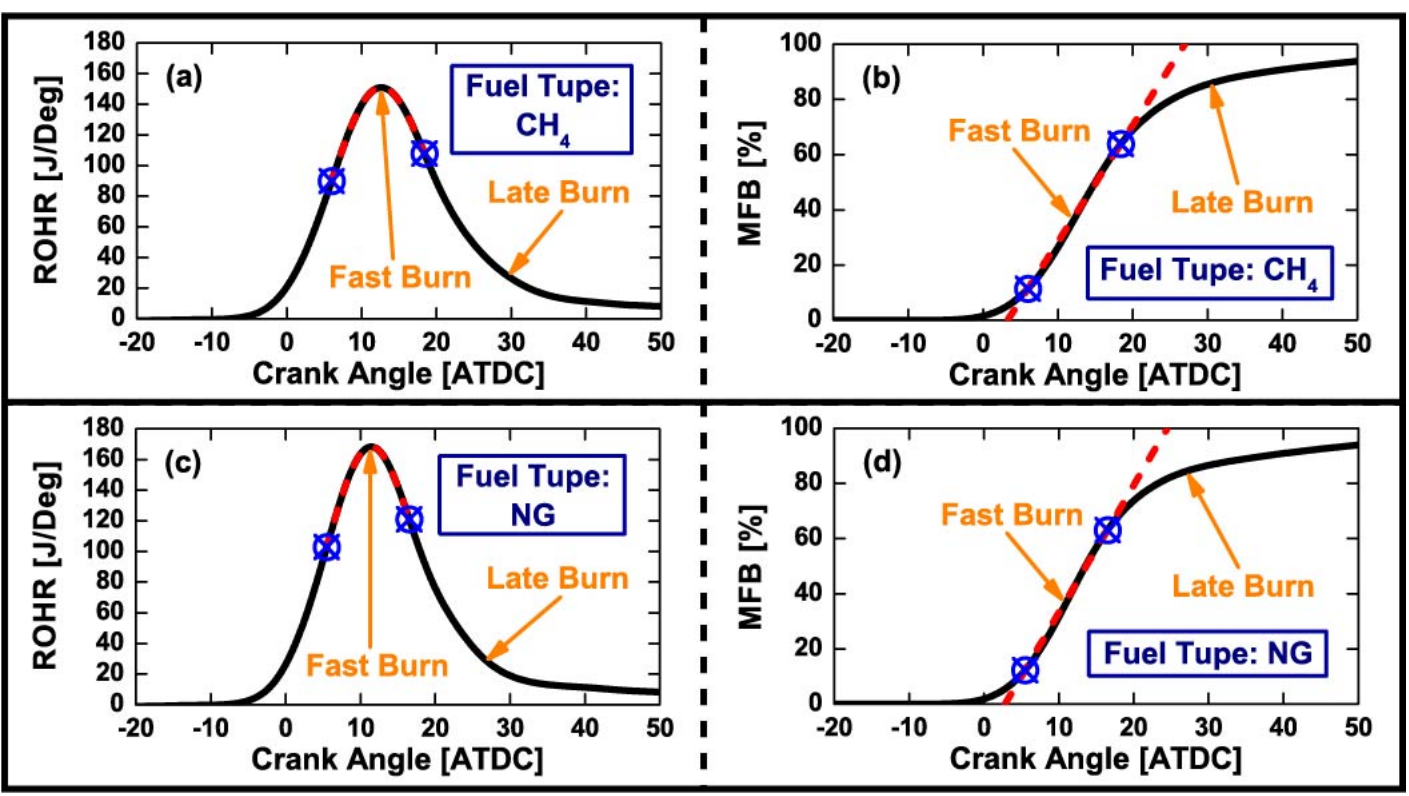

Figure 6.7 Rapid-burning period characterized by the duration between ROHR inflection points on the rate of heat release and mass fraction burned for different gas composition operations.

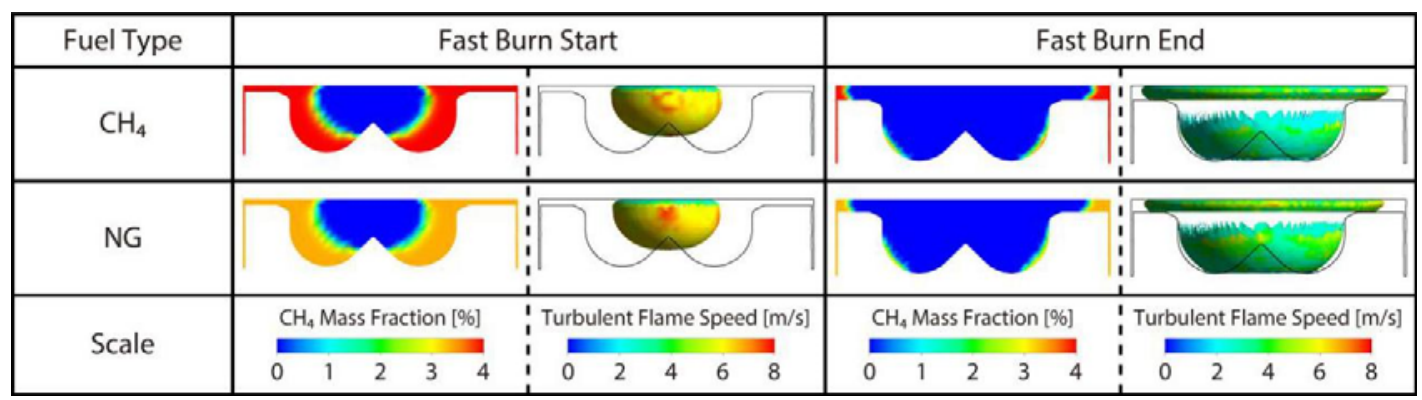

Figure 6.8 CAD simulation predicted flame front location at ROHR inflection points for different gas composition operations.

shown in Figure 6.8 indicated that the end of the fast-burning period was the time when the flame front just touched the bowl's toroidal recess. Therefore, this novel approach can help determine the fast-burn period regardless of the fuel composition.

Figure 6.9 shows the combustion analysis for both methane and NG operation. NG's higher 


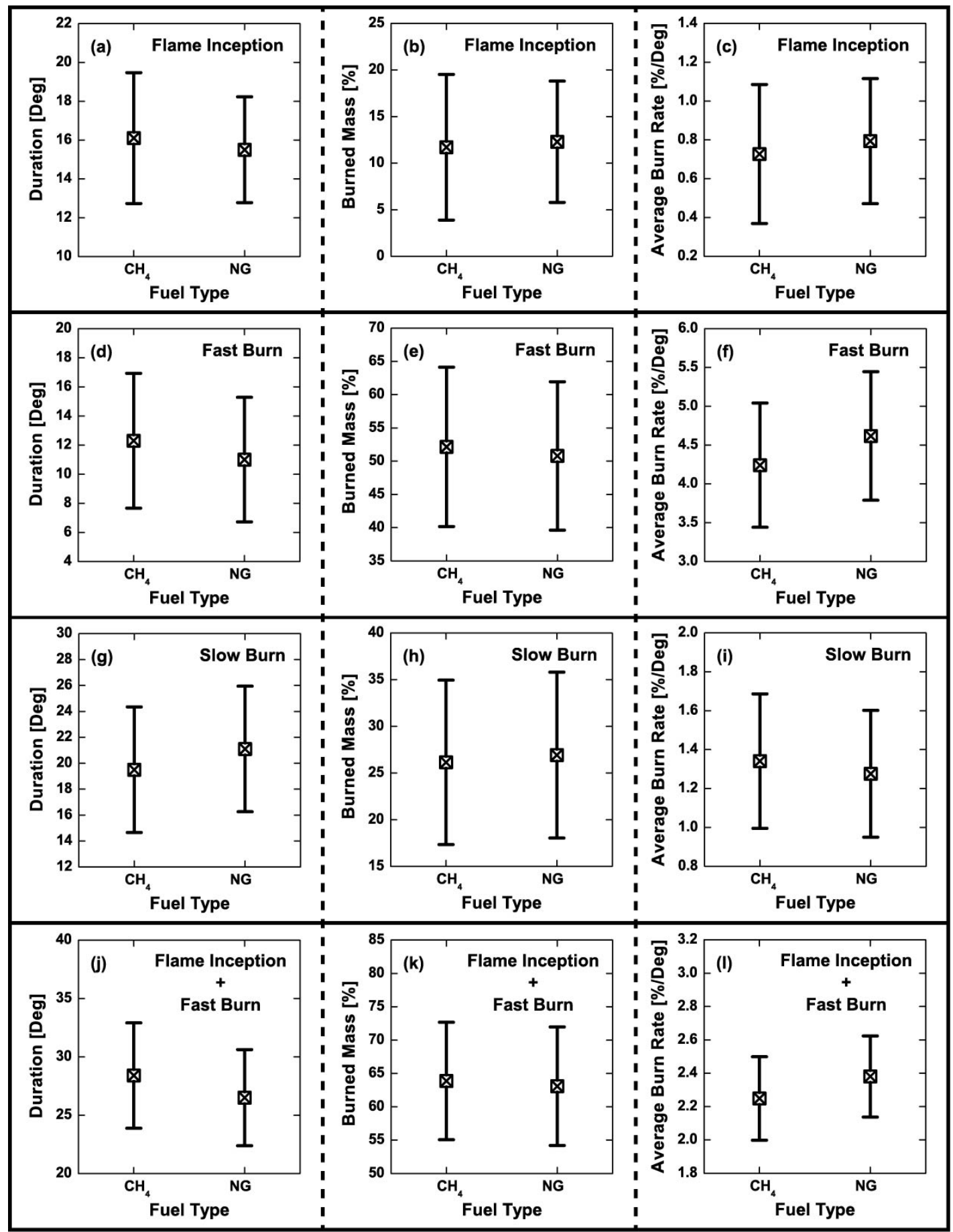

Figure 6.9 Burning duration, mass fraction burned, and average burning rate of early flame development, fast-burn, late-burn, and inside-the-bowl burn stages, for different gas composition operations.

flame speed and better ignition quality decreased the spark inception period and increased 
the burn rate compared to methane operation. In addition, NG operation needed less time to reach the toroidal recess and therefore shortened the fast-burning period. The higher burn rate during fast burn can be explained by NG's higher laminar flame speed. NG's better performance (shorter burning duration and faster burn rate) was also shown in the inside-the-bowl combustion period. Meanwhile, a shorter fast-burning period for the NG operation resulted in less NG burning in the squish region during the overlapping between the fast- and the slow-burning stages. The NG operation showed a lower burning speed in late-burn period probably because of the relative smaller squish height at the same crank angle.

\subsection{Spark timing effects on combustion stages}

Chapter 5 described experiments in the metal engine configuration at different spark timings, from -30 CAD ATDC to -10 CAD ATDC in 5 CAD increments. The engine was fueled with methane and operated at medium load, $900 \mathrm{rpm}, \phi=0.73$ (see Table 2.3 for details). As the spark timing significantly change the phasing of both fast- and slowburning stages, it is of interest to investigate if the ROHR inflection points can help identity the fast-burning period when ST changed.

Figure 6.10 shows that CA90 was almost identical for all operations, despite the $20 \mathrm{CAD}$ differences in ST. In addition, the duration between CA10 and CA90 included some of the late combustion period. Therefore, the traditional definition was not appropriate here. 
However, the novel method shown in Figure 6.11 successfully separated the fast-burning

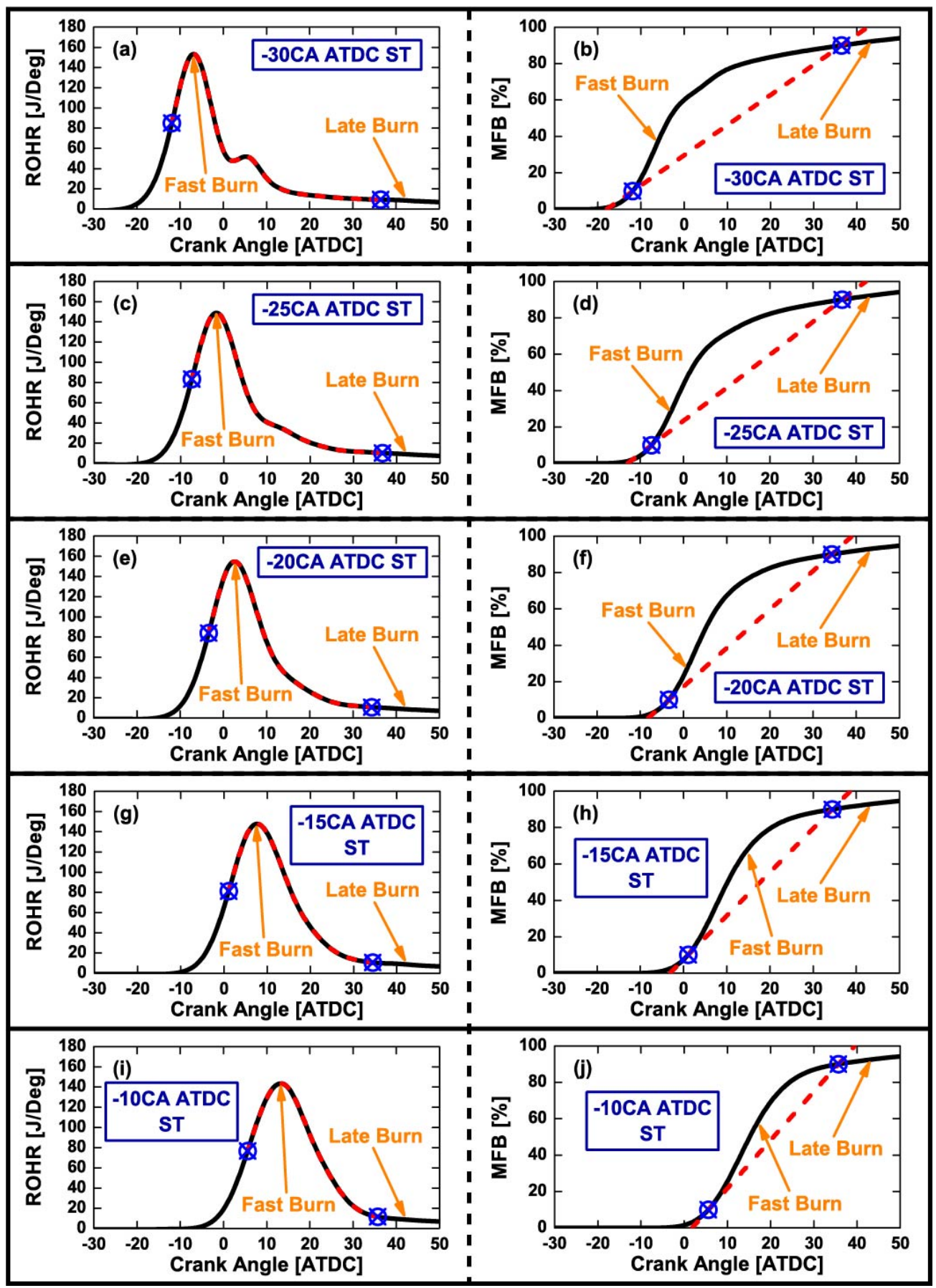

Figure 6.10 Rapid-burning period characterized by the duration between CA10 and CA90 on the rate of heat release and mass fraction burned for different spark timing operations. 
stage from the late combustion or the $2^{\text {nd }}$ peak in the ROHR. The CFD results shown in

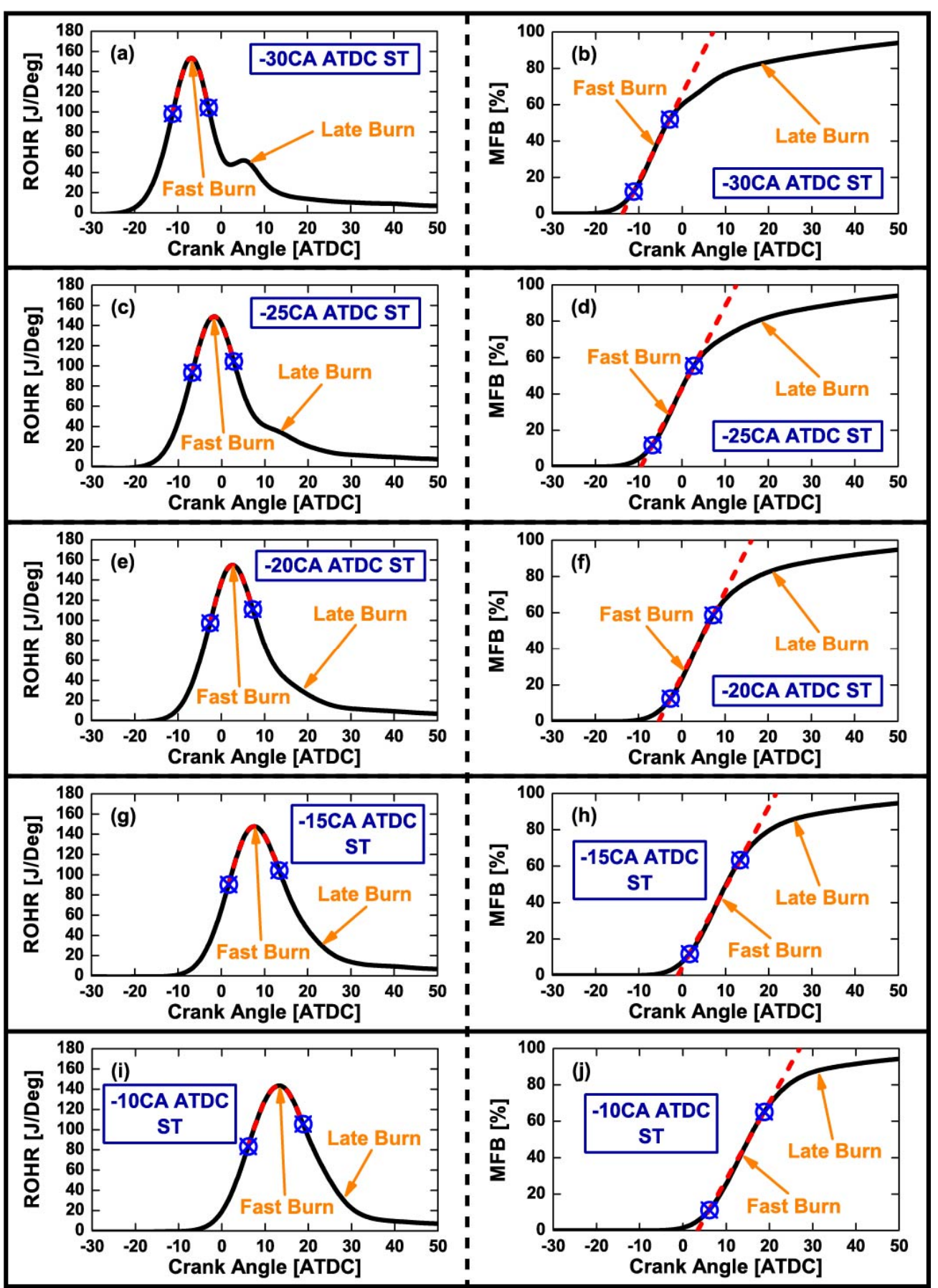

Figure 6.11 Rapid-burning period characterized by the duration between ROHR inflection points on the rate of heat release and mass fraction burned for different spark timing operations. 
Figure 6.12 suggest that the flame front already touched the bowl center, with high turbulent flame speeds for all of the five STs investigated here. All these cases show that the flame reached the toroidal recess inside the bowl at the second inflection point, where was included in the slow-burn zone. However, the burning conditions inside the squish were different. Advanced ST had less fuel burning inside the squish region, which indicates that ST controlled the phasing or overlapping between the fast- and slow-burning stages. Overall, the ROHR's inflection points identified better the fast-burning period during the spark timing sweep.

Figure 6.13 presents the effects of spark timing on combustion parameters during different combustion stages. The duration of the flame inception decreased with delayed spark timing, which can be explained by the decrease in the ignition delay due to the higher

\begin{tabular}{|c|c|c|}
\hline Spark Timing & Fast Burn Start & Fast Burn End \\
\hline-30 CAD ATDC & & : \\
\hline-25 CAD ATDC & & ! \\
\hline-20 CAD ATDC & & 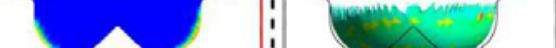 \\
\hline-15 CAD ATDC & & ! \\
\hline-10 CAD ATDC & & : \\
\hline Scale & $\mathrm{CH}_{4}$ Mass Fraction [\%] $\quad$ Turbulent Flame Speed [m/s] & $\begin{array}{lll}\mathrm{CH}_{4} \text { Mass Fraction [\%] } & \text { Turbulent Flame Speed [m/s] }\end{array}$ \\
\hline & $\begin{array}{lllll:lllll}0 & 1 & 2 & 3 & 4 & 0 & 2 & 4 & 6 & 8\end{array}$ & $\begin{array}{llllll} & 0 & 2 & 4 & 6 & 8\end{array}$ \\
\hline
\end{tabular}

Figure 6.12 CAD simulation predicted flame front location at ROHR inflection points for different spark timing operations. 
temperature and pressure closer to TDC. The different mass fraction burned in the flame

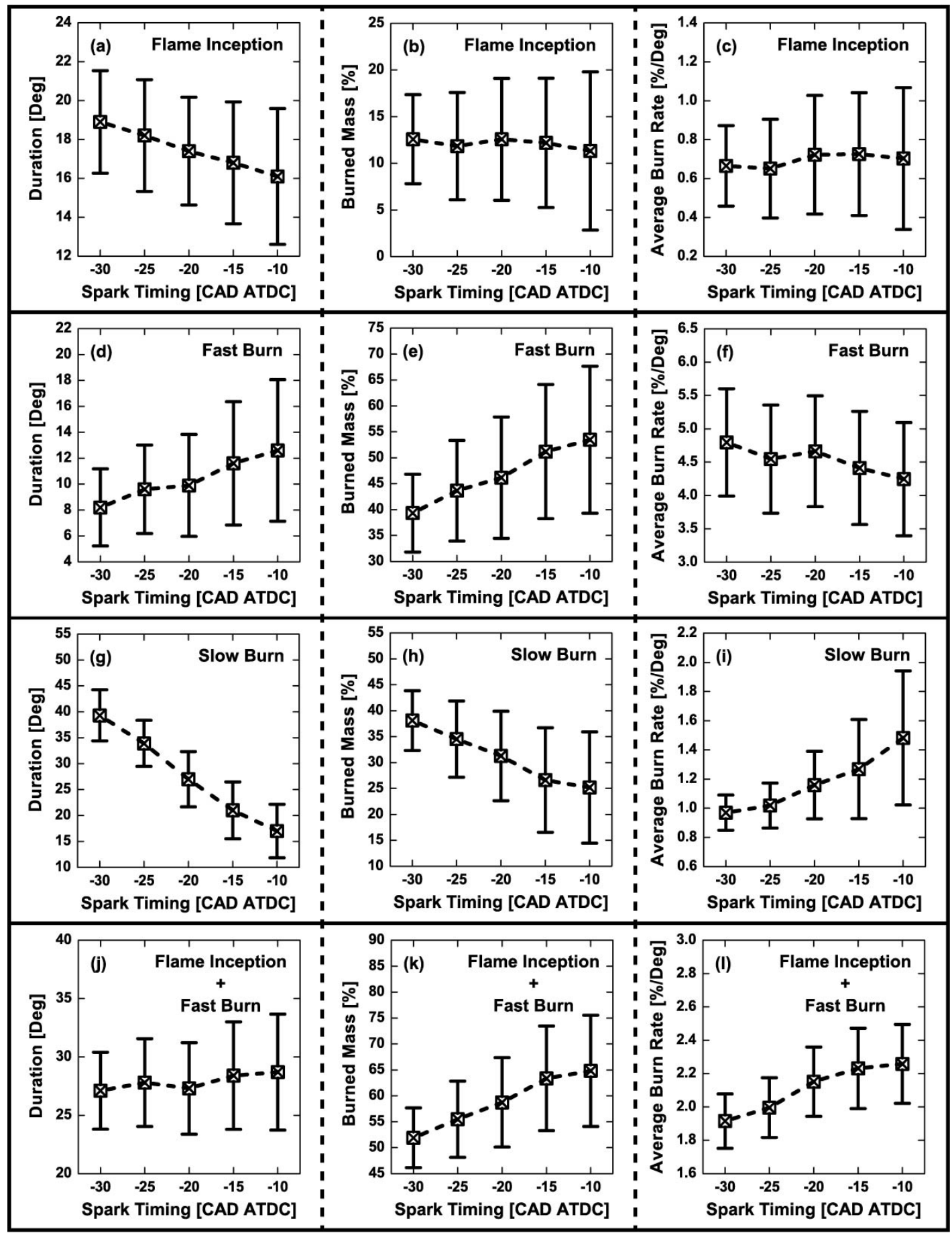

Figure 6.13 Burning duration, mass fraction burned, and average burning rate of early flame development, fast-burn, late-burn, and inside-the-bowl burn stages, for different spark timing operations. 
inception period suggests that the spark timing also controlled the mass distribution inside the combustion chamber. The optimal ST (-20 CAD ATDC) showed the largest burned mass and burn rate during spark inception. Delayed ST had the longest fast-burn duration probably because it took more time for the flame front to reach the bowl's toroidal recess. However, delayed ST had more fuel burning during the fast-burning duration due to more stage overlapping. Delayed ST needed less time to complete the burning during the late combusting period, probably because of the lower remaining fuel fraction and also less heat transfer from the flame front as the squish height was larger. The duration of burning inside the bowl increased with delayed ST except at -25 CAD ATDC ST. Moreover, the burn rate inside bowl was faster for delayed ST probably because the spark inception stage dominated the overall effects as the ignition delay was too long for advanced ST.

\subsection{Equivalence ratio effects on combustion stages}

Experimental data at several operating conditions that varied the equivalence ratio (methane, -10 CAD ATDC ST, medium load, $900 \mathrm{rpm}$; see Table 2.3 for details) was used to investigate if the ROHR's inflection points can help identity the fast-burning period.

Figure 6.14 shows that the traditional definition of the fast-burning period (i.e., the duration between CA10 and CA90) was not appropriate because it included the late burn phenomenon. However, the duration between the $1^{\text {st }}$ and $2^{\text {nd }}$ inflection points of ROHR, shown in Figure 6.15, can successfully distinguish the combustion stages, which was also 
supported by the CFD predictions shown in Figure 6.16. The burning period between the two ROHR's inflection points were tangent to the MFB curve. In addition, the start of the rapid-burning period was always the time when flame front touched the bottom center of
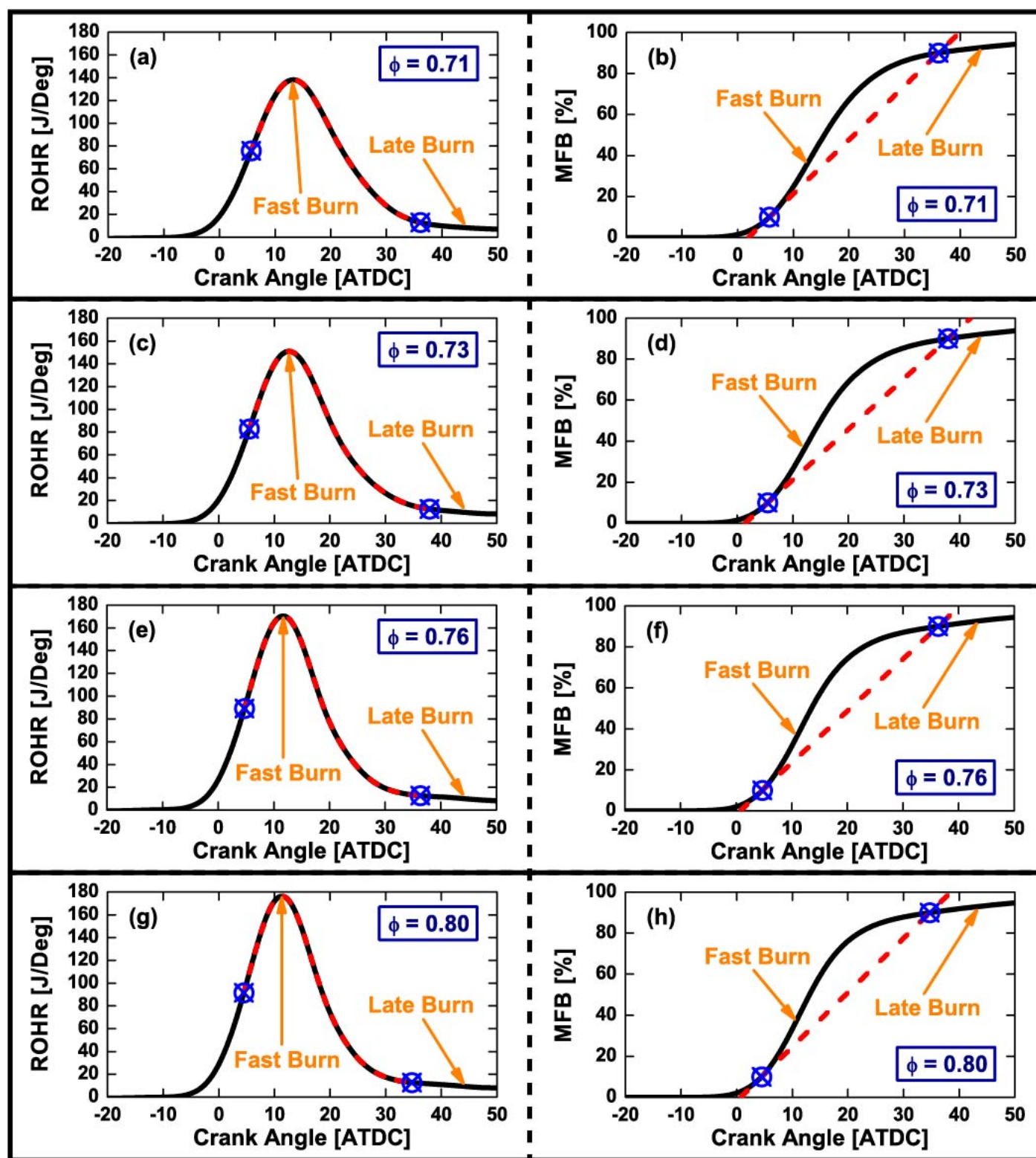

Figure 6.14 Rapid-burning period characterized by the duration between CA10 and CA90 on the rate of heat release and mass fraction burned for different equivalence ratio operations. 


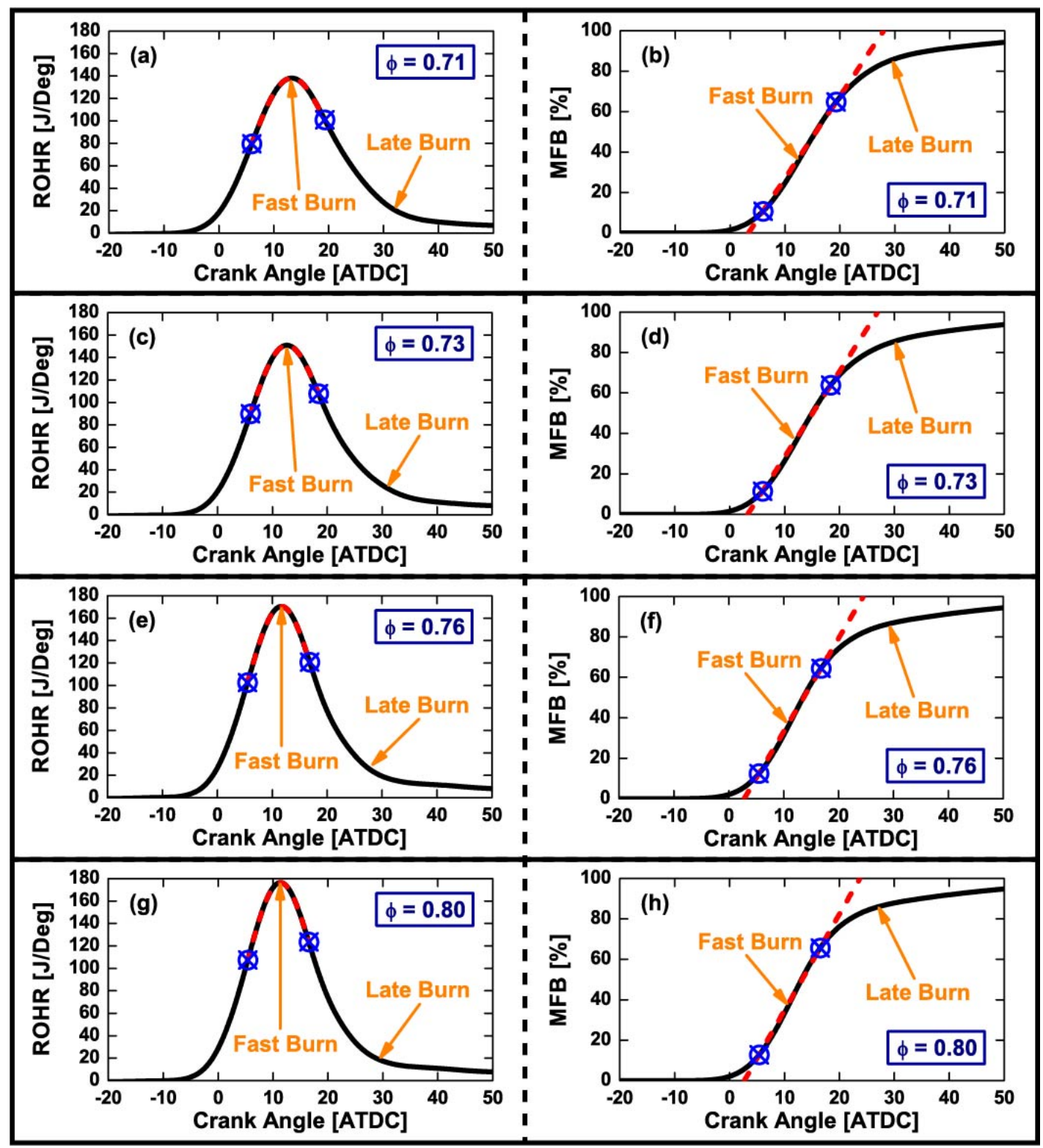

Figure 6.15 Rapid-burning period characterized by the duration between ROHR inflection points on the rate of heat release and mass fraction burned for different equivalence ratio operations.

the bowl. More, the end of the fast-burning stage was always the CAD when the flame front reached the toroidal recess. Consequently, the method introduced in this study was effective to determine the rapid burning stage regardless of the mixture equivalence ratios. 


\begin{tabular}{|c|c|c|}
\hline Equivalence Ratio & Fast Burn Start & Fast Burn End \\
\hline \multicolumn{3}{|l|}{0.71} \\
\hline \multicolumn{3}{|l|}{0.73} \\
\hline \multicolumn{3}{|l|}{0.76} \\
\hline \multicolumn{3}{|l|}{0.80} \\
\hline \multirow{2}{*}{ Scale } & $\mathrm{CH}_{4}$ Mass Fraction [\%] $\quad$ Turbulent Flame Speed $[\mathrm{m} / \mathrm{s}]$ & $\mathrm{CH}_{4}$ Mass Fraction [\%] $\quad$ Turbulent Flame Speed $[\mathrm{m} / \mathrm{s}]$ \\
\hline & $\begin{array}{lllll:lllll}0 & 1 & 2 & 3 & 4 & 0 & 2 & 4 & 6 & 8\end{array}$ & $\begin{array}{lllllllllll}0 & 1 & 2 & 3 & 4 & 0 & 2 & 4 & 6 & 8\end{array}$ \\
\hline
\end{tabular}

Figure 6.16 CAD simulation predicted flame front location at ROHR inflection points for different equivalence ratio operations.

Figure 6.17 shows combustion characteristics in each heat-release stage. The flame inception period decreased with increasing equivalence ratio despite more fuel burning in this period, probably due to the increase in the burning rate. Therefore, the fast-burn stage for the higher- $\phi$ operation had a lower duration. This conclusion also fitted for the stage of burning inside the bowl region. However, the fuel mass that burned during this stage did not show a similar trend. The lower flame speed at the lower $\phi$ operation $(\phi=0.71)$ delayed the completion of the fast-burning period, compared to baseline condition $(\phi=0.73)$. As a result, more fuel in the squish region burned during the fast-burning period for lower- $\phi$ operation because of more overlapping period of the two combustion events. However, for higher- $\phi$ operation $(\phi=0.76$ and 0.80$)$, the increased flame speed helped to burn more mass when the flame front touched the toroidal recess. The faster flame front changed the fuel/air mixture distribution during combustion event and also the flow motion, which helped to 
burn a higher fraction of the fuel inside the bowl region or originally trapped in the slow-

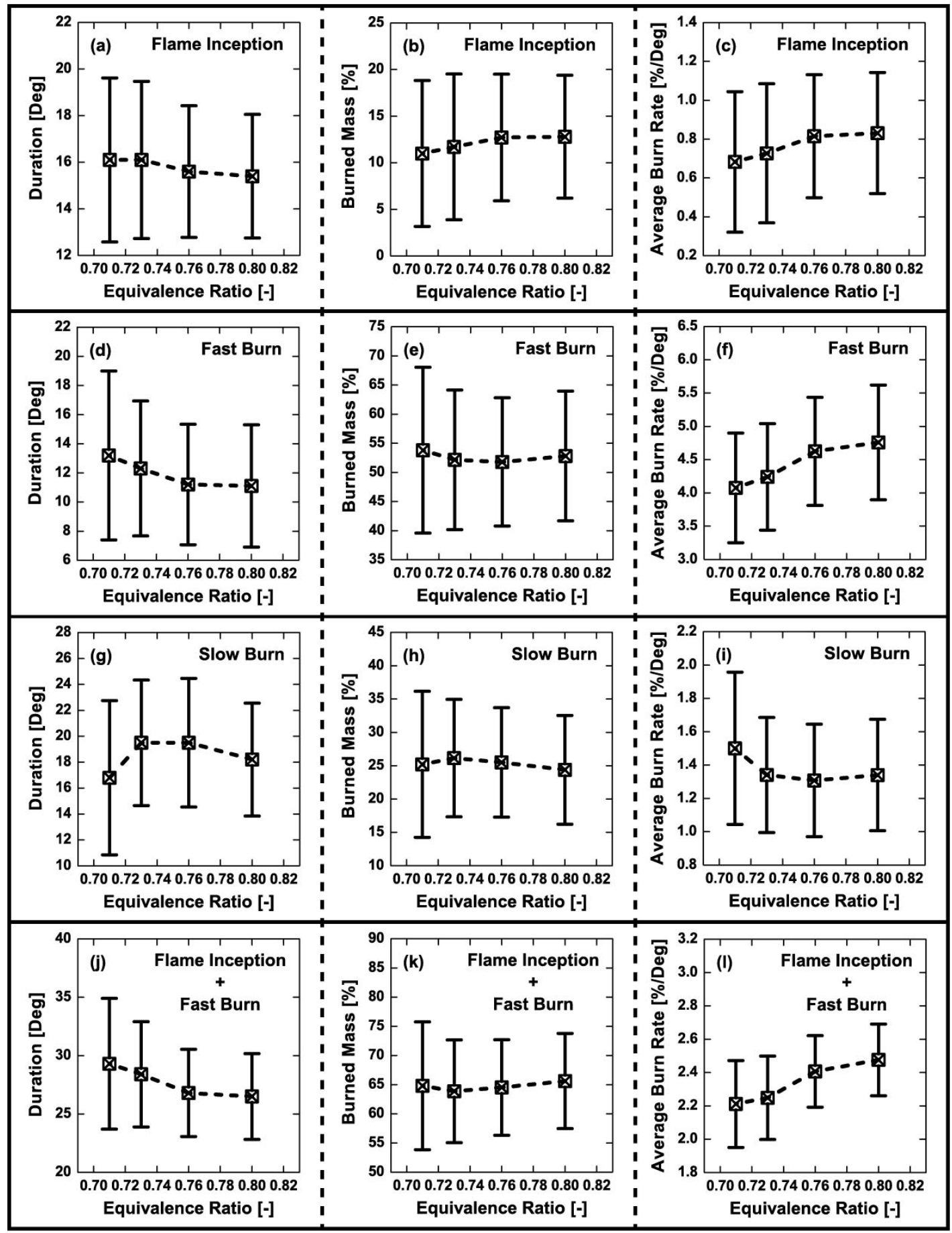

Figure 6.17 Burning duration, mass fraction burned, and average burning rate of early flame development, fast-burn, late-burn, and inside-the-bowl burn stages, for different equivalence ratio operations. 
burn zone at the end of fast-burning period. These complicated the effect of the equivalence ratio on the late combustion, hence the lack of a clear trend for this duration.

\subsection{Engine speed effects on combustion stages}

Experimental data from an engine speed sweep $(900 \mathrm{rpm}$ to $1300 \mathrm{rpm}$, in $100 \mathrm{rpm}$ increments) at constant spark timing (-10 CAD ATDC) and mixture equivalence ratio $(\phi=$ 0.73) compared the traditional and novel method in determining fast-burning period.

Figure 6.18 shows that the period between CA10 and CA90 was not applicable to the presented data. However, Figure 6.19 shows that the use of the ROHR's inflection points can determine the fast burning period. The CFD simulations shown in Figure 6.20 further proved the effectiveness of the novel segmentation method. Therefore, the novel approach was more effective in determining the rapid burning stage compared to traditional method, regardless of the engine speeds.

Figure 6.21 shows the combustion characteristics in each heat-release stage during the engine speed sweep. Obviously, as the spark timing was kept constant, higher speed delayed the flame inception and thus the longer period for this stage. Although high-speed operation had higher turbulence that increased the turbulent flame speed, the faster moving piston decreased the time available for chemical reactions and thus the slower flame propagation speed. This also delayed the time when the flame front reached the toroidal 
recess at high-speed operation. Therefore, the duration of the fast-burning period was

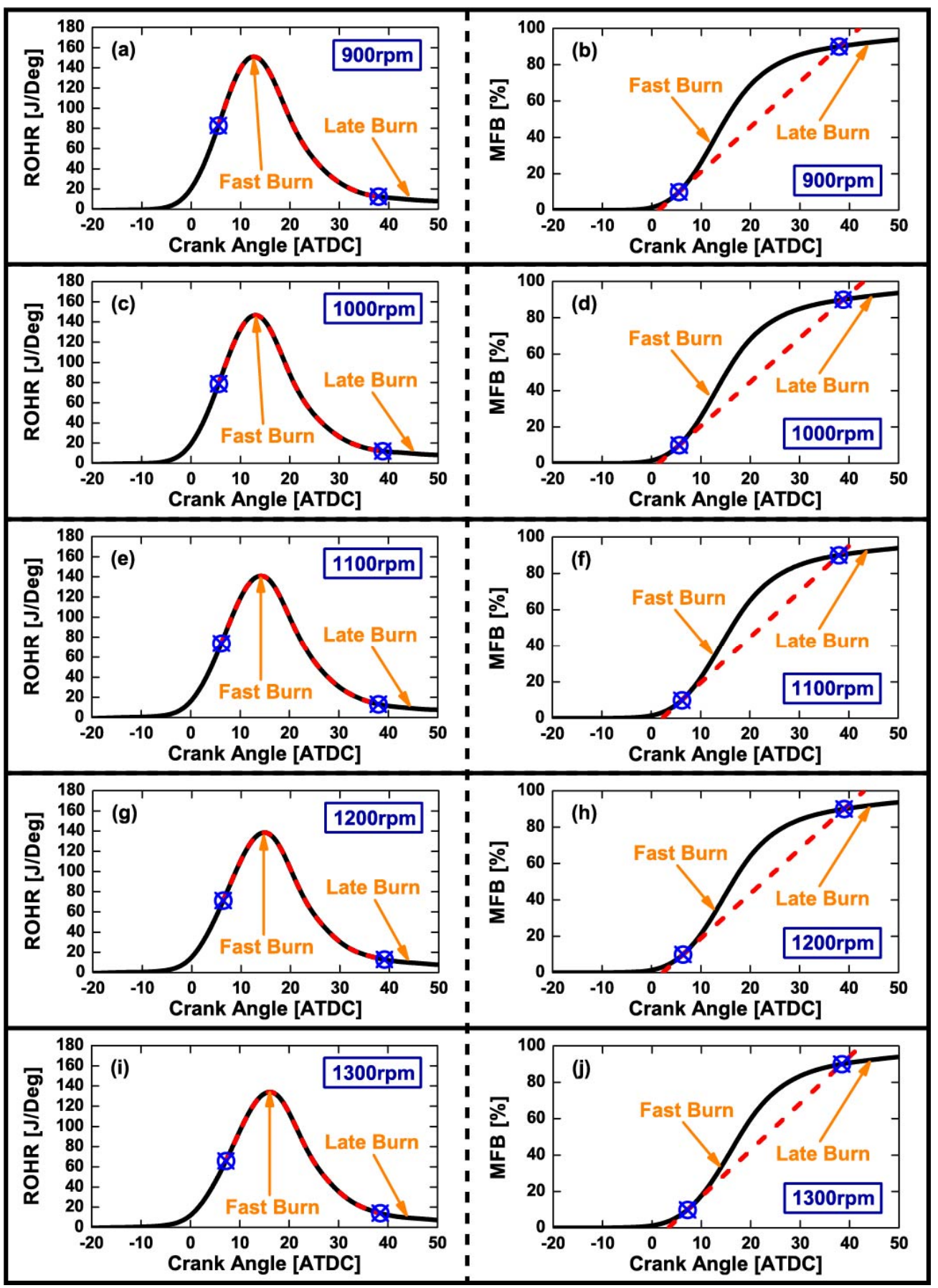

Figure 6.18 Rapid-burning period characterized by the duration between CA10 and CA90 on the rate of heat release and mass fraction burned for different engine speed operations. 
longer and the burn rate was smaller for high-speed operation. In addition, the delayed

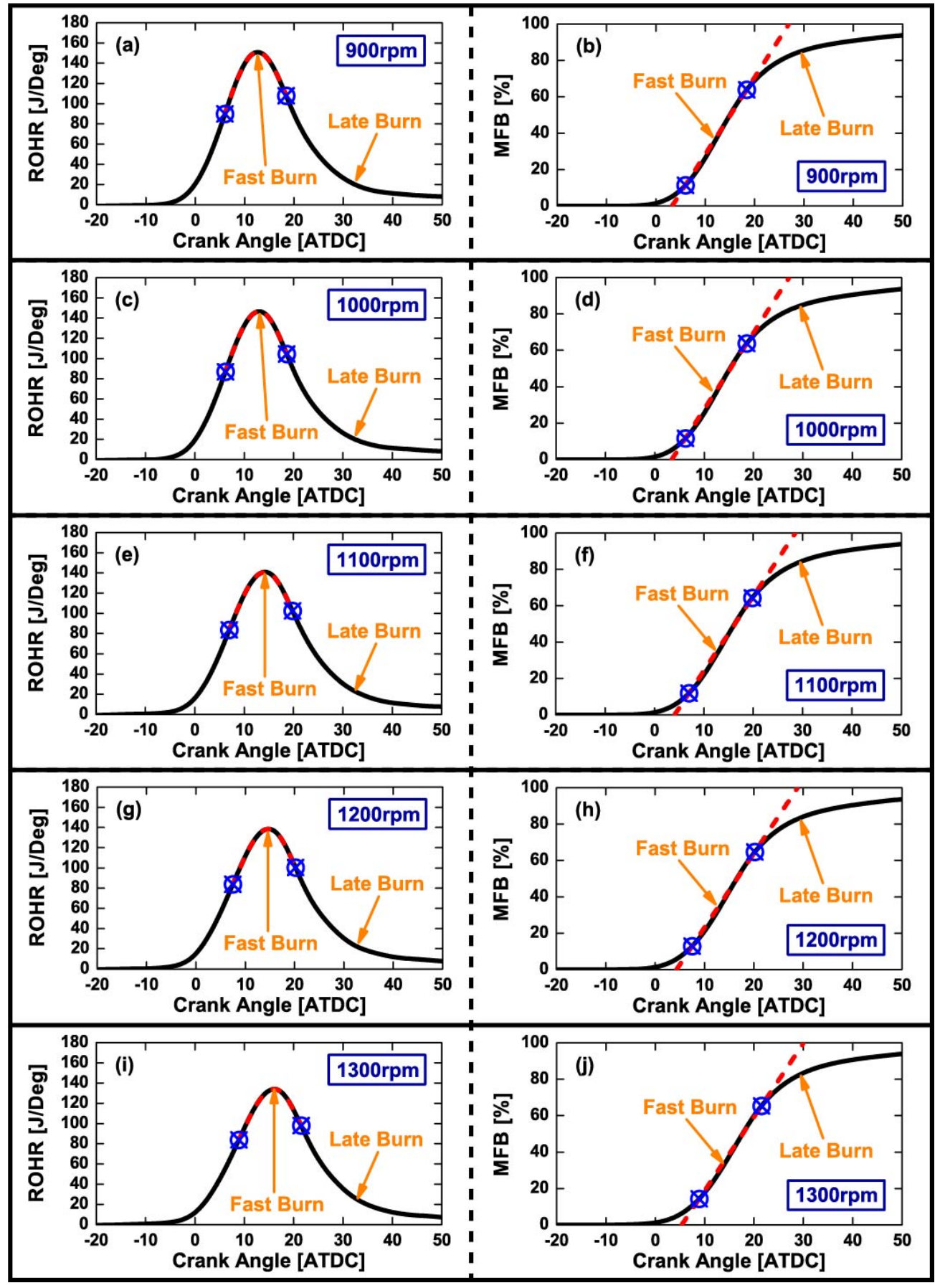

Figure 6.19 Rapid-burning period characterized by the duration between ROHR inflection points on the rate of heat release and mass fraction burned for different engine speed operations. 


\begin{tabular}{|c|c|c|}
\hline Engine Speed & Fast Burn Start & Fast Burn End \\
\hline \multicolumn{3}{|l|}{ 900rpm } \\
\hline \multicolumn{3}{|l|}{ 1000rpm } \\
\hline \multicolumn{3}{|l|}{ 1100rpm } \\
\hline \multicolumn{3}{|l|}{ 1200rpm } \\
\hline \multicolumn{3}{|l|}{$1300 \mathrm{rpm}$} \\
\hline \multirow{2}{*}{ Scale } & $\begin{array}{l:l}\mathrm{CH}_{4} \text { Mass Fraction [\%] } & \text { Turbulent Flame Speed [m/s] }\end{array}$ & $\begin{array}{l:l}\mathrm{CH}_{4} \text { Mass Fraction [\%] } & \text { Turbulent Flame Speed [m/s] }\end{array}$ \\
\hline & $\begin{array}{lllll:lllll}0 & 1 & 2 & 3 & 4 & 0 & 2 & 4 & 6 & 8\end{array}$ & $\begin{array}{lllll}0 & 1 & 2 & 3 & 4\end{array}$ \\
\hline
\end{tabular}

Figure 6.20 CAD simulation predicted flame front location at ROHR inflection points for different engine speed operations.

phasing meant a larger squish height when the flame front was at the same location in the combustion chamber for the high-speed operation. As the flame speed in the squish was similar, a larger vertical distance in the squish region contributed to more mass to be burned per CAD. Therefore, more of the fuel inside the squish region was burned before the flame front touched the toroidal recess region. This more overlapping explained the larger mass fraction that burned in the fast-burning period at high engine speeds. As a result, there was less fuel to burn in the slow-burning stage at higher engine speeds due to the lower separation between the two combustion events and the higher burn rate due to the larger squish height. Despite Figure 6.21 showing this trend, $900 \mathrm{rpm}$ and $1100 \mathrm{rpm}$ were a little off this trend, probably caused by complex interactions between increased turbulence and 


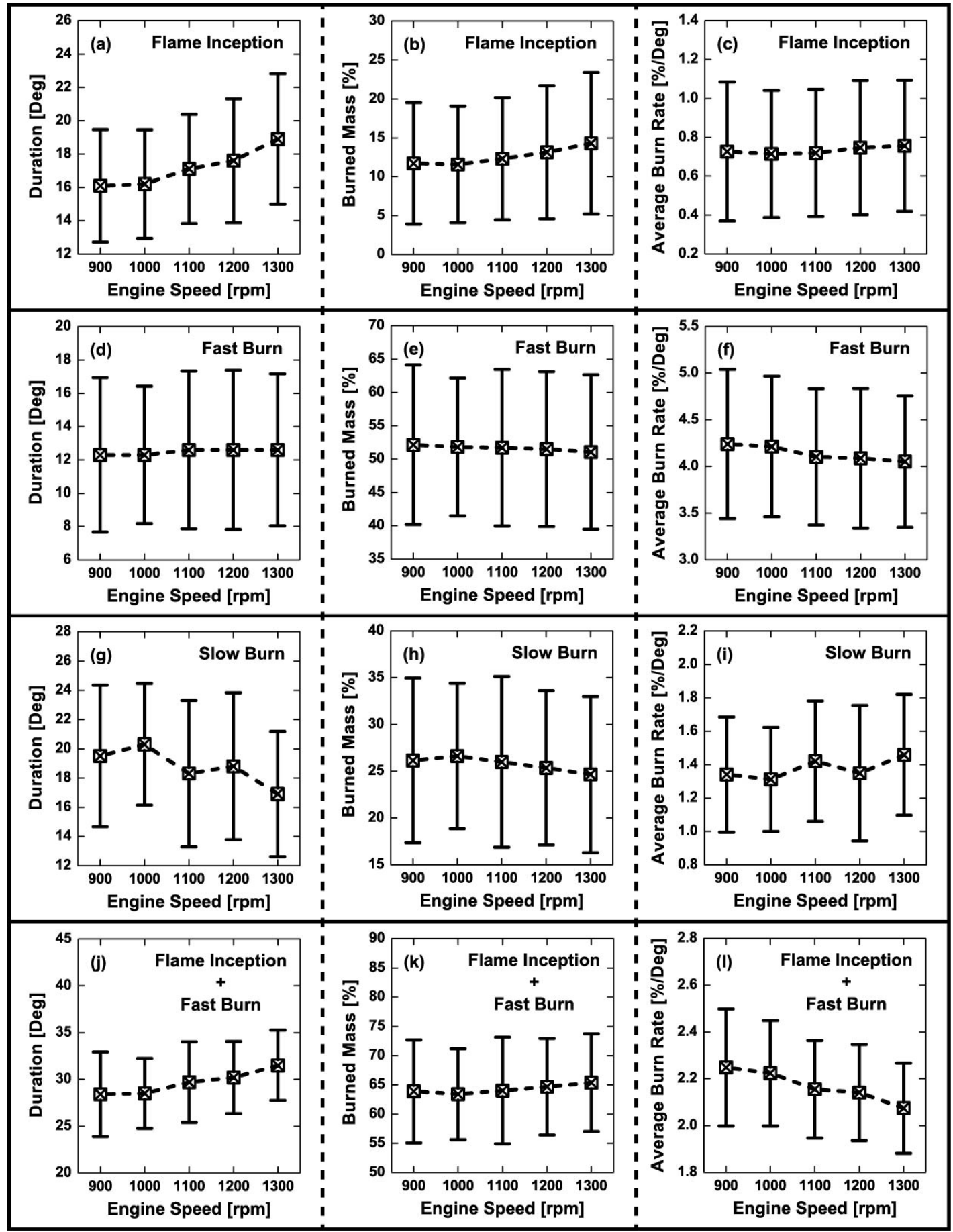

Figure 6.21 Burning duration, mass fraction burned, and average burning rate of early flame development, fast-burn, late-burn, and inside-the-bowl burn stages, for different engine speed operations.

a different combustion phasing. 


\subsection{Summary}

The traditional segmentation method for the combustion process in conventional SI engines was not applicable to NG SI combustion inside a bowl-in-piston combustion chamber. As a result, ROHR's inflection points were used to separate the most important heat release stages. This approach can successively separate the fast-burning stage, regardless of changes in fuel composition, spark timing, mixture equivalence ratio, and engine speed.

The early flame development stage was defined as the duration between spark timing and $1^{\text {st }}$ ROHR inflection. The period between $1^{\text {st }}$ and $2^{\text {nd }}$ ROHR inflection points was defined as the fast-burning stage. The late burn stage was defined as the duration between the $2^{\text {nd }}$ ROHR inflection point to EOC. The burning duration, burned mass fraction, and burning rate were investigated during these three stages. The results indicated that NG operation, delayed spark timing, higher equivalence ratio, and lower engine speed (at constant ST) shortened the flame inception period. In addition, NG operation, advanced spark timing, higher equivalence ratio, and lower engine speed (at constant ST) reduced the completion of the fast-burning stage. However, it was more complicated for the fuel that burned before the start of the late burn. For example, methane operation at retarded spark timing, higher equivalence ratio (compared to baseline), and higher engine speed (at constant ST) burned a higher mass fraction before the end of the fast-burn stage. However, a lower equivalence ratio (compared to baseline) may also contributed to more fuel burned before the beginning 
of the late combusting stage. Overall, operating conditions controlled the fuel distribution inside the combustion chamber and also the interactions between turbulence and combustion, which complicated the analysis of the two distinct combustion events. 


\section{Chapter 7 Effect of Diesel Geometry on Cycle-to-Cycle Variation}

Cycle-to-cycle variations due to variations in the spark event or combustion instabilities can be of concern for diesel engines retrofitted to lean-burn NG SI operation. Flame visualization provided information about the reliability and robustness of the ignition event, flame propagation stability, and late combustion in individual engine cycles. More, it is of interest to investigate how changes in operating conditions such as different fuel composition, spark timing, mixture equivalence ratio, and engine speed affected the cycleto-cycle variation.

\subsection{Sources of cycle-to-cycle variation}

The magnitude of cycle-to-cycle variations is of particular importance in lean-burn NG SI engines, as NG's laminar flame speed is lower than that of gasoline and the difference is more significant under lean conditions [11]. However, the cycle-to-cycle variations (CCV) must be maintained within acceptable limits $\left(\mathrm{COV}_{\text {IMEP }}<5 \%\right)[114]$ for the successful conversion of existing diesel engines to NG operation.

$\mathrm{CCV}$ was investigated in this study using the data recorded during experiments in the optical engine configuration. The engine was run at -10 CAD ATDC ST, medium load, 900 rpm engine speed, and low equivalence ratio $(\phi=0.66)$. Results showed that the COV IMEP 


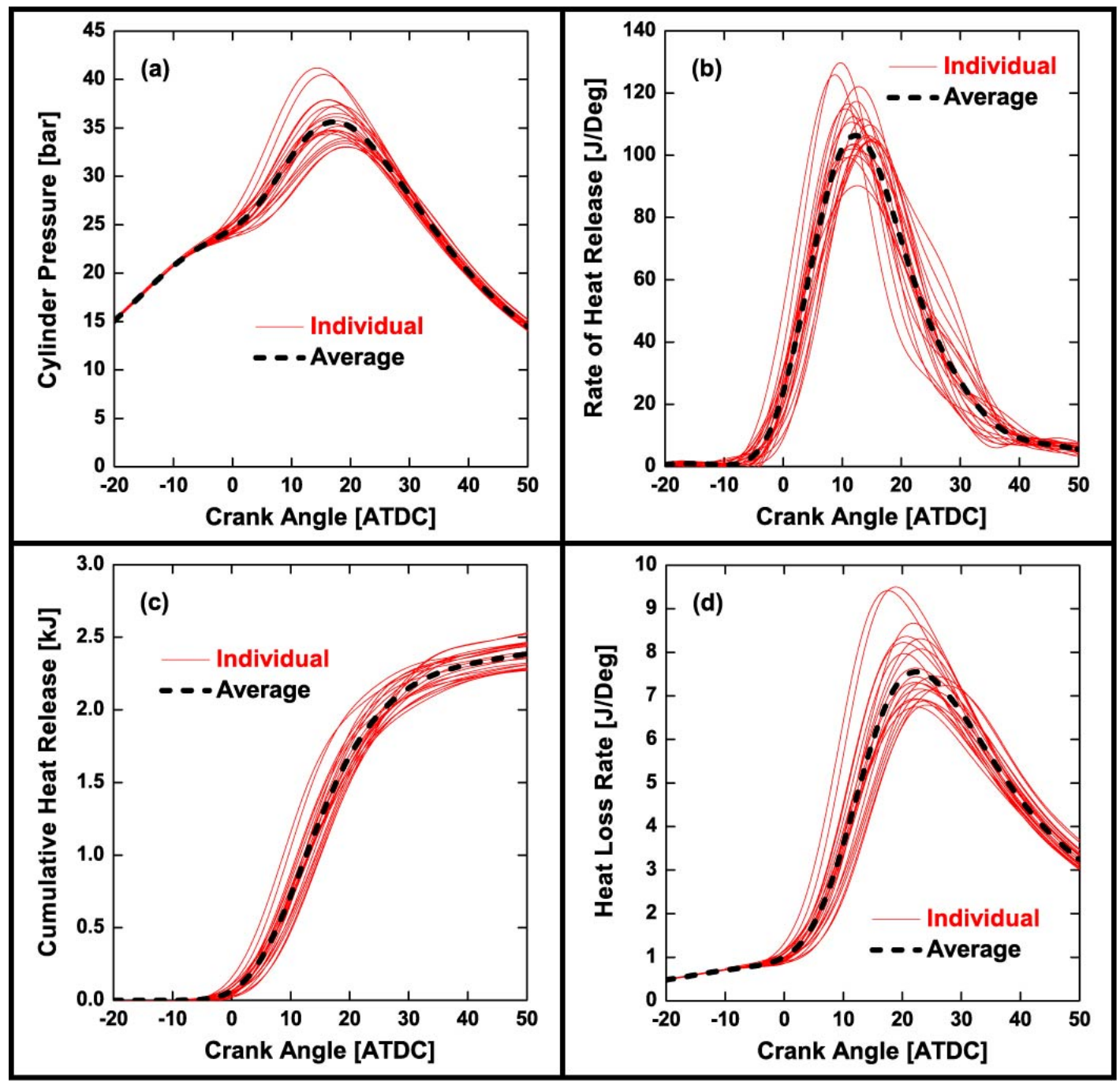

Figure 7.1 Pressure-based data from optical engine experiments at baseline condition: (a) in-cylinder pressure, (b) apparent heat release rate, (c) cumulative heat release, and (d) heat loss rate. Thin red and thick dash black lines indicate individual cycles and their mean, respectively.

was below 4\%, indicating a good combustion stability. Figure 7.1 shows the pressure-based data for the individual and the average cycles. In addition to the CCV in start of combustion and early flame development, the heat release rate indicated a larger variation in the latecombustion period (after 20 CAD ATDC), which can be explained by the different mass fraction inside the squish region for each cycle. Also, the cumulative heat release indicated 


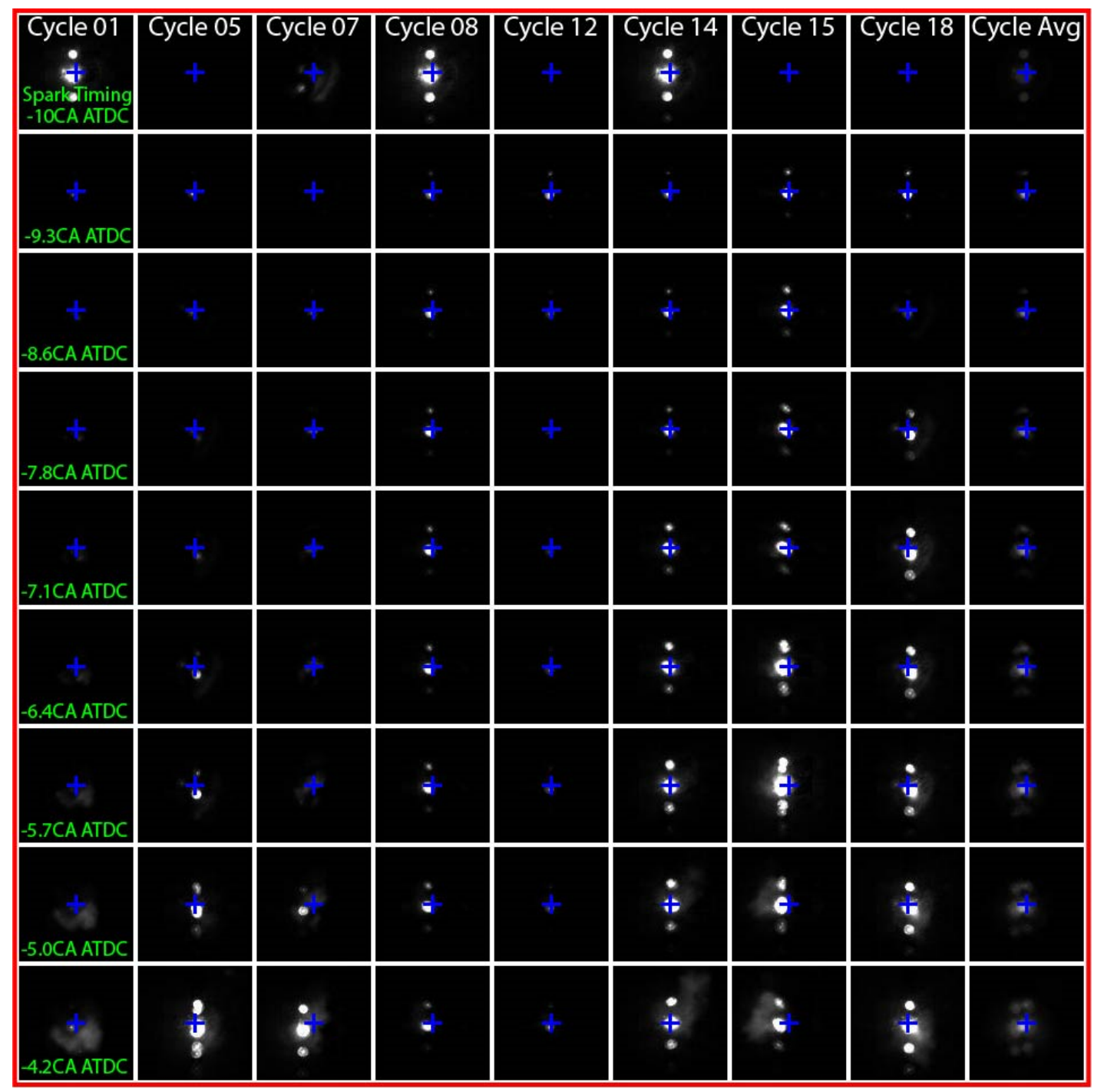

Figure 7.2 Spark intensity and arc location variations during spark inception period. The blue small cross indicates the spark plug location.

that total mass burned in each cycle was different, which also explains the CCV. More, differences in turbulence, in-cylinder temperature, and burned zone region size with crank angle affected the heat loss of individual cycles, hence the CCV.

Flame visualization captured the spark event and the early flame development. It is 
important to note that luminosity around the spark region included the spark light reflected from the spark-plug electrodes and cylinder head. The spark duration was $1 \mathrm{~ms}$, which corresponded to $5.4 \mathrm{CA}$ at $900 \mathrm{rpm}$. Consequently, the first 15 frames captured the spark event (i.e., from ST until -4.6 CAD ATDC). Figure 7.2 shows in-cylinder luminosity from the spark timing until the end of the spark event for eight different individual cycles and for the average cycle. Some individual cycles (such as cycle 01, 08 and 14) had a stronger spark than the rest, which shows the importance of a robust spark event for such engines. Also, cycles 15 and 18 had a constant spark luminosity, while cycle 01 showed a strong spark only in the first image. A similar observation was for cycle 14, which also had a strong spark intensity at first, but a weaker spark intensity later, even though the spark light was continuous. In addition to the spark intensity variations, arc location also changed cycle-by-cycle. For example, the arc location of cycle 14 was always close to the center of the spark plug, but cycle 5 and cycle 7 generated the arc to the right side and to the left side of the electrode, respectively. Interestingly, the arc location also moved during the spark event, such as cycle 15 which initially had the arc in the center and later it moved to the left side. More, Figure 7.2 shows the effect of the spark event on flame inception. Flame inception was faster for cycles that showed a continuous spark event such as cycles 15 and 18. More, the different arc location determined the enflamed position (e.g., to the left in cycle 15 and to the right in cycle 18). In contrast, the low spark intensities in cycle 12 resulted in a weaker flame inception. Consequently, spark quality correlated with flame inception, hence the cycle-to-cycle variations. However, the phenomena was much more 
complex. For example, while cycle 01 had a strong initial spark but a weaker spark later, it still had a better and earlier flame development, probably due to a successful ignition of the fuel/air mixture. Cycle 05 and cycle 07 had a strong spark arc later in the spark event, but a good flame inception, which can be explained by a higher equivalence ratio at the spark location. Cycle 08 had a good spark quality in all images but a not-so-good flame inception, probably due to a leaner equivalence ratio at the spark location. Turbulence effects were evident in cycle 14: even though the energy released was always near the center of the spark plug, the flame ignited and propagated to the right and up in the images. Overall, the spark intensity, arc location, local turbulence, equivalence ratio, temperature, and heat transfer all affected the ignition event, which in turn affected the start of combustion, the direction in which flame developed, and flame intensity.

Figure 7.3, which shows a typical sequence of flame images inside the bowl, after the spark events and for the same cycles shown in Figure 7.2, indicates that spark inception would determine the subsequent flame propagation. For example, the low intensity flame inception was followed by a delayed flame development in cycles 08 and 12 . The other individual cycles had acceptable flame propagations inside the piston bowl, although the spark quality was different, indicating that the fast flame propagation period also played an important role in the cycle-to-cycle variation. For example, cycles 15 and 18 had better flame inception than cycles 01,05 and 07 , but they all had similar flame propagation, showing the importance of turbulence and mixture homogeneity. Cycle 14 had the fastest 


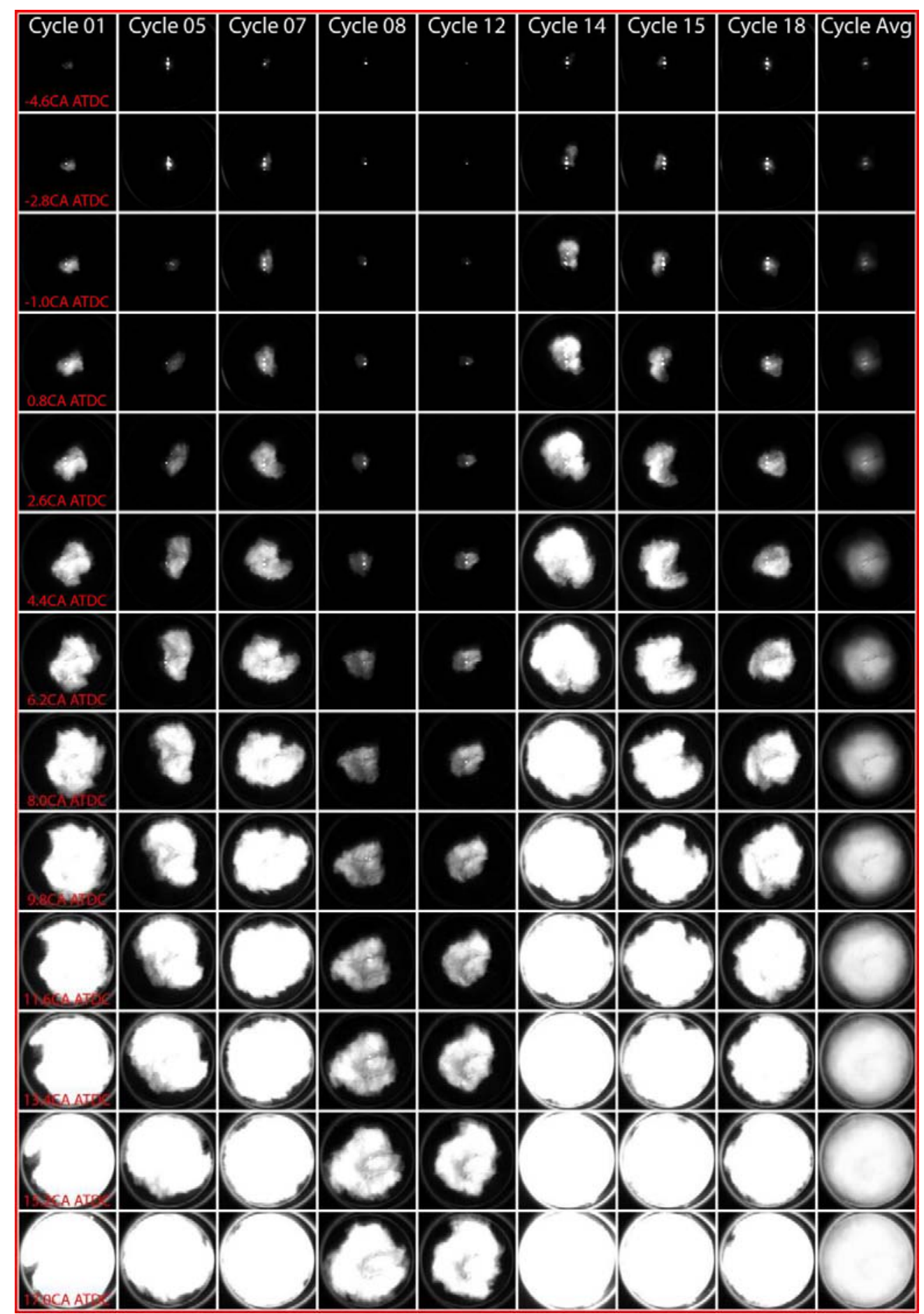

Figure 7.3 Flame propagation variations during fast burning period. The right column shows the average image.

flame propagation among all the cycles shown in Figure 7.3. Further, FL images also 
indicated the flame propagation directions for individual cycles. Flame propagated in different directions, which was expected as the turbulence would suffer changes cycle-tocycle. Changes in the direction in which the flame developed affected the mass fraction trapped inside the squish and its following combustion. In addition, the fuel/air mixing homogeneity and turbulence-flame interactions determined the flame propagation path. The mean cycle images indicated that flame propagated isotropically towards the squish region.

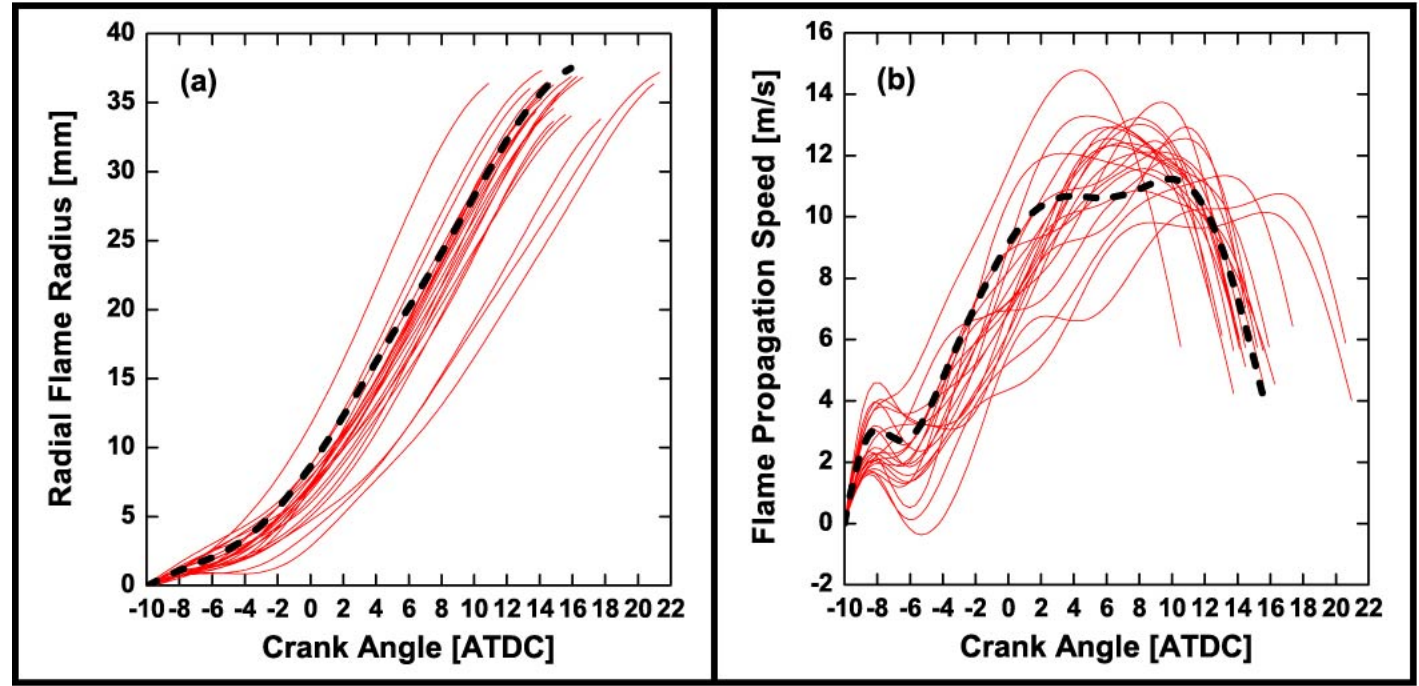

Figure 7.4 Flame development variations during flame development in piston bowl: (a) radial flame radius and (b) flame propagation speed. Thin red and thick dashed black lines indicate individual cycles and their mean cycle, respectively..

Figure 7.4 shows the radial flame from spark timing to the time when flame touched the edge of the piston bowl. Again, it is important to mention that the spark intensity influenced the analysis during the flame inception period, which caused the negative flame expansion speed for certain individual cycles shown in Figure 7.4b. However, data such as the one in 
Figure 7.4 helped analyzing the CCV. Irrespective of the spark luminosity effects, the flame radius showed that SOC varied with the engine cycle, probably due to variations in the mixture equivalence ratio and turbulence around the spark plug, in the heat transfer from the spark plug to the engine head, and in the energy released by the spark plug. Additional analysis of the flame radius progress in individual cycles suggested that flame propagation inside bowl further amplified the CCV. For example, cycles with advanced spark inception always had a higher flame propagation speed, evidenced by the higher magnitude of flame radius in Figure 7.4a. This was probably due to the higher in-cylinder pressure and/or unburned temperature at the same crank angle. In addition, the changes in flame speed at a particular crank angle shown in Figure $7.4 \mathrm{~b}$ also affected CCV.

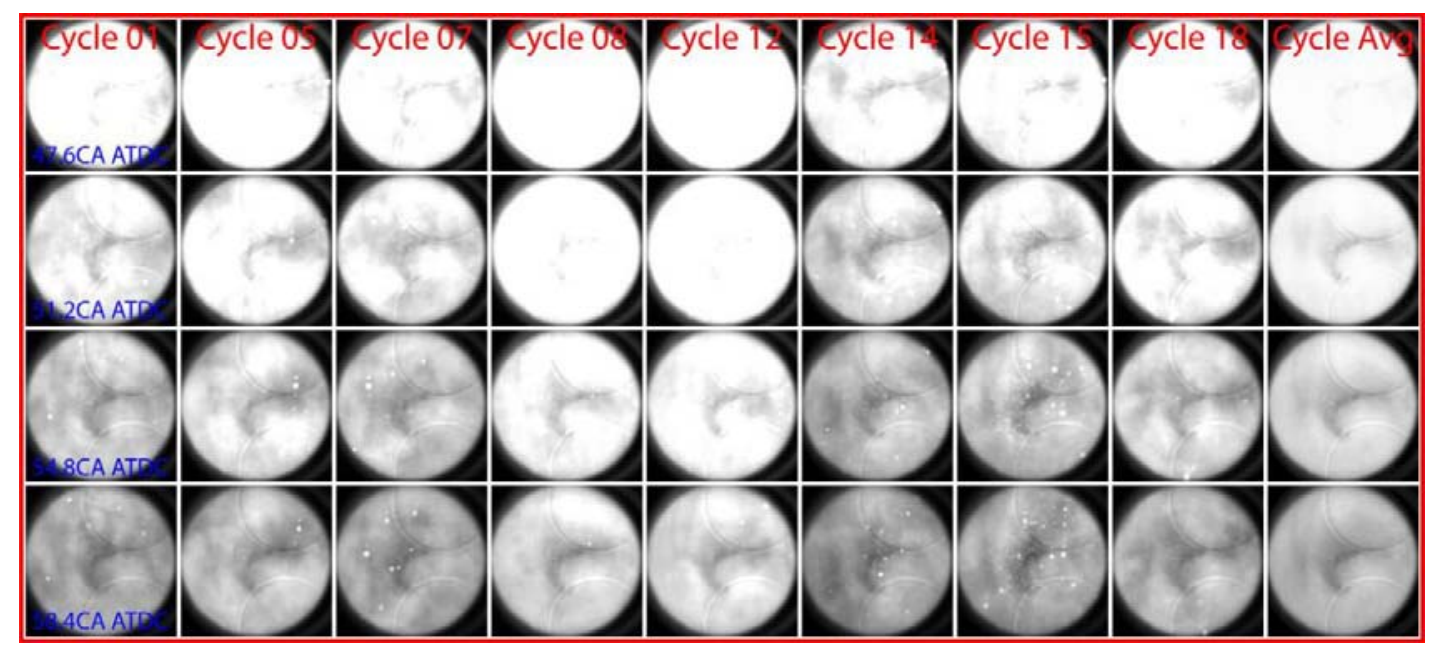

Figure 7.5 Late combustion and oxidation variations during late combusting period. The right column shows the average image.

Figure 7.5 shows flame activities of the fuel trapped in the bottom corner regions of the flat bowl specific to the optical engine configuration. As the bottom region of the flat bowl 


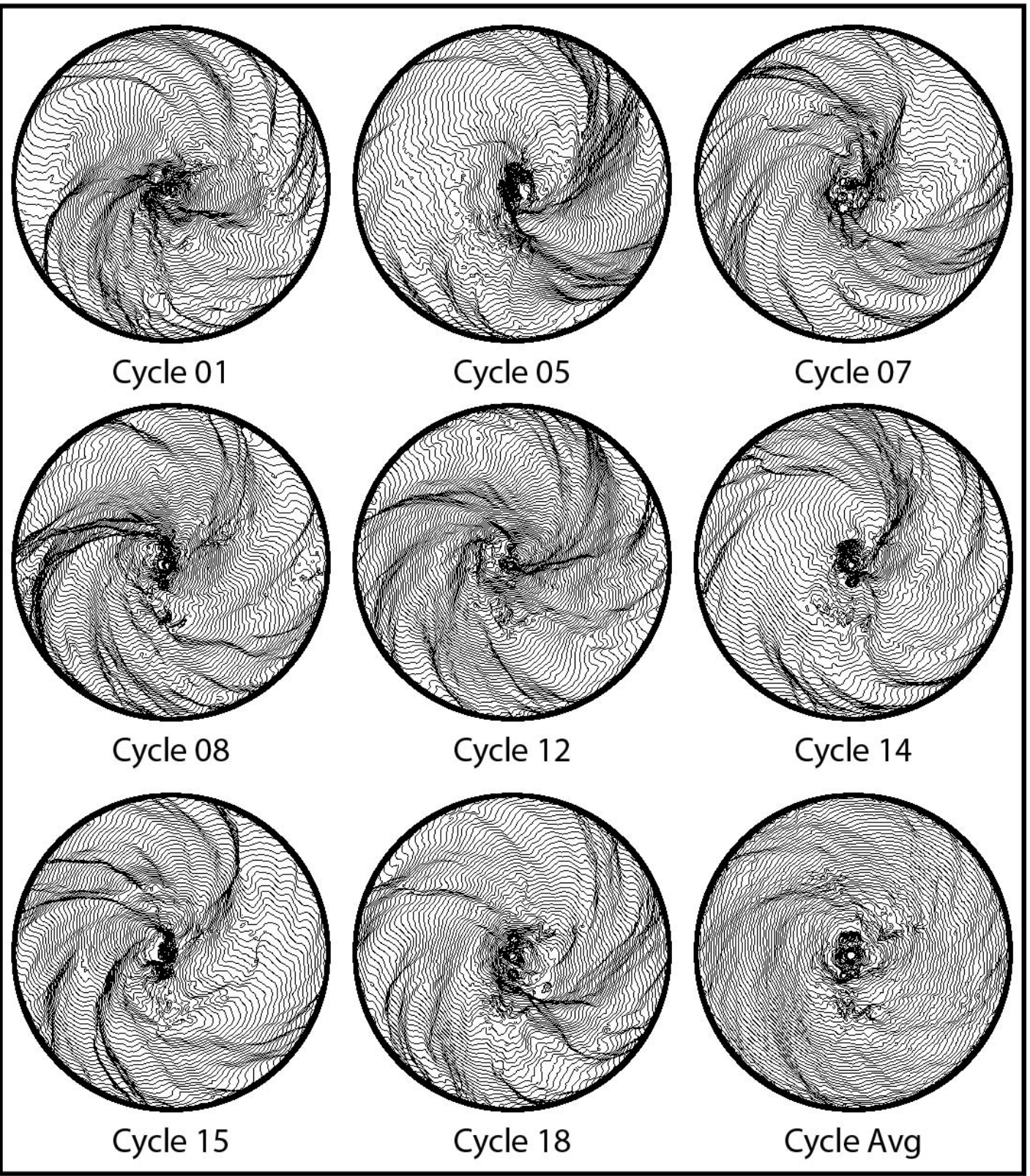

Figure 7.6 Radial flame front propagation contours in piston bowl for selected individual and average cycles.

had a higher surface-to-volume ratio which lowered the local temperature, it probably also trapped an important unburned fuel mass, which then burned slowly throughout the late combusting period. The light intensity inside the bowl for cycles 08 and 12 in Figure 7.5 
suggest a delayed combustion event. Comparisons of high luminosity locations for individual cycles indicated the trapped mass inside the bowl varied with engine cycle, which can be explained by the different flame propagation directions shown in Figure 7.3. In addition, it seems that the unburned fuel was not always distributed in the corner, suggesting that variations in the location of the unburned mixture at the bottom of the bowl also contributed to different late combustions phenomena.

Also, of interest is to visualize the turbulence variations. Figure 7.6 shows the flame front location from spark timing to the time the flame was out of sight. The strong wrinkling of the turbulent flame for individual cycles suggests a strong variation in turbulence distribution with the engine cycle. In addition, the strong flame curvature and/or rotation indicate the swirl-turbulence interactions were also evident. The cycle-averaged flame edge shown in Figure 7.6 was relatively circular throughout the visualization period. Moreover, the cycle-averaged flame had a counter-clock rotation due to the intake-generated swirl.

Figure 7.7 presents the flame contours based on the equivalent flame radius in Figure 7.6. The closer contours around the spark plug location were representative of the slower flame speed during flame inception, also shown in Figure 7.4. The almost-constant spacing between flame contours after flame inception supports the stable flame propagation hypothesis. The spacing between flame contours became smaller near the edge of the bowl, supporting the flame quenching hypothesis. Figure 7.7 also suggests that for some 


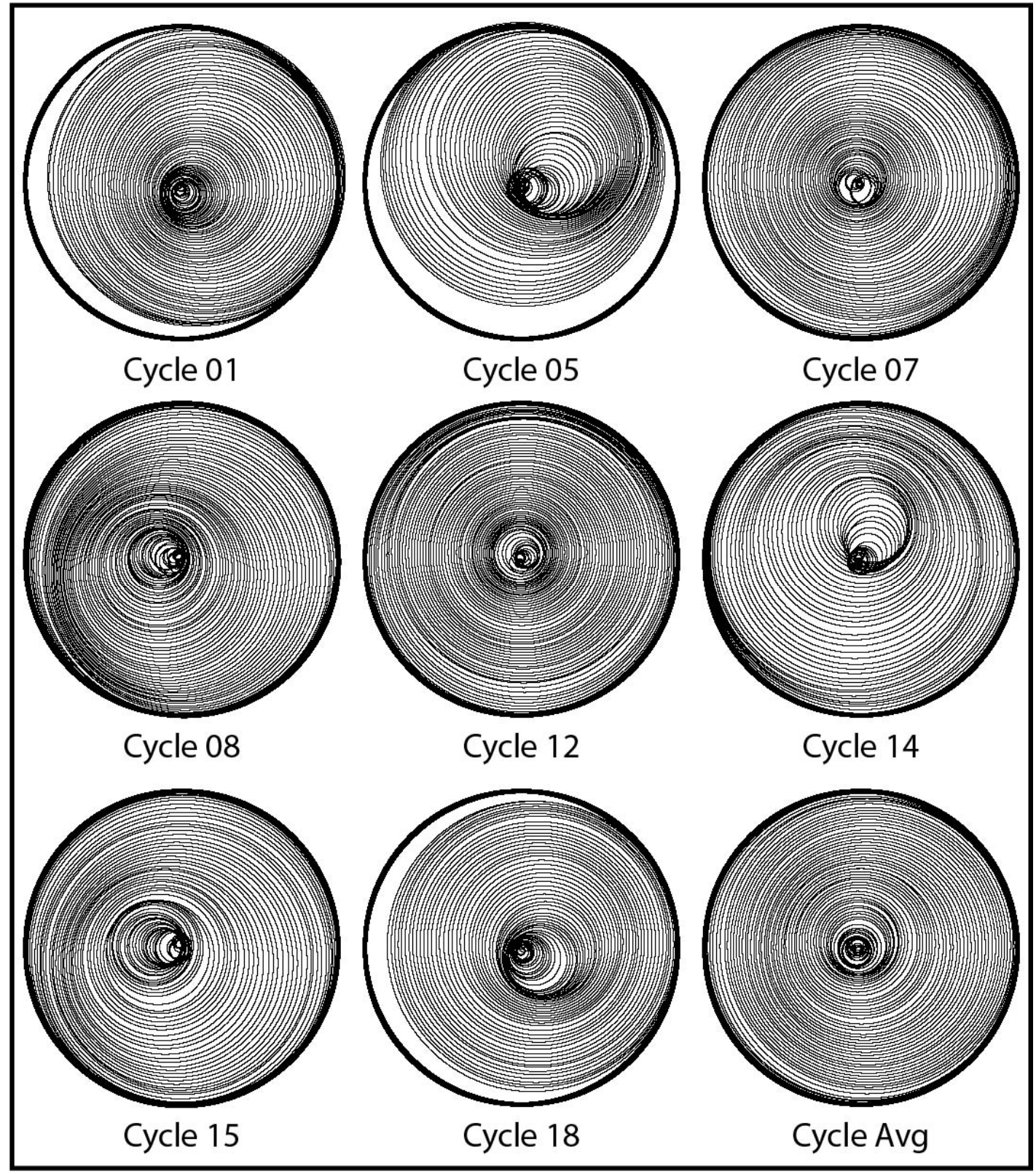

Figure 7.7 Radial flame development based on the equivalent flame radius in piston bowl for selected individual and average cycles.

individual cycles the flame initially propagated fast in one direction, then the whole enflamed region began to develop isotropically. As mentioned before, this was probably due to the variations of the mixture equivalence ratio, arc location and energy-release 
intensity, and turbulence around the spark plug. In addition, it also suggests that variations in the spark inception could play an important role in cycle-to-cycle variations. More, the circular flame propagation seen for the average cycle suggests that flame front would touch first the right edge of the bowl from the viewpoint in the figure. This observation can be

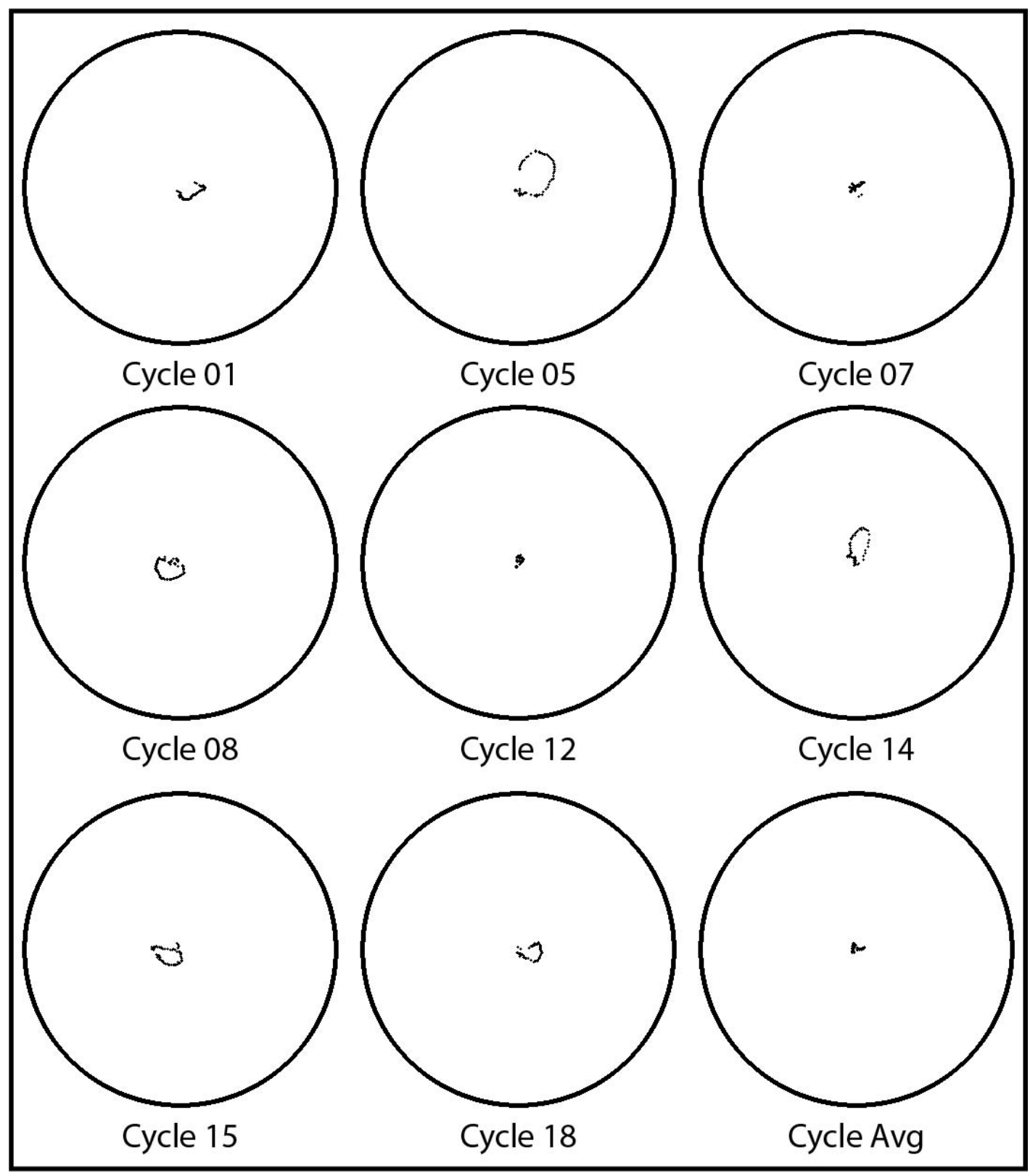

Figure 7.8 Flame center displacement for selected individual and average cycles. 
explained by the tilted-to-the-left position of the spark plug relative to the cylinder axis. This will theoretically increase the heat transfer to the cylinder head to the left of the image, which will favor initial flame propagation to the right.

Figure 7.8 shows the movement of the flame center with crank angle relative to the spark plug position, for selected individual cycles and the average cycle. The flame center movement added to the counter-clock flame rotation seen in Figure 7.6, which was probably due to the intake-generated swirl. The flame center movement was stochastic, due to the stochastic nature of the interaction between the in-cylinder turbulence (i.e., swirl, squish and tumble) and combustion process. Further, while the flame centers in the average cycle also had a similar counterclockwise movement, the magnitude was much smaller. These observations are also important when related to the usual discussions in the CFD modeling community of RANS versus LES simulations to predict in-cylinder combustion phenomena.

In conclusion, the sources of cycle-to-cycle variations in this retrofitted engines were the variations in (i) spark intensity, arc location, and energy released, (ii) local mixture equivalence ratio, turbulence, pressure, and temperature, (iii) the interaction between intake swirl and flow motion caused by piston movement and the combustion chamber which determines the flame propagation direction, (iv) the mass burned per cycle and heat transfer. However, the COV of IMEP was less than 4\%, suggesting the promise for heavy- 
duty CI engines converted to NG SI operation. This acceptable cycle-to-cycle variation at lean-burn operation was the effect of the combustion chamber used in this study. Specifically, the high turbulence in the bowl region guaranteed a fast combustion event which help to stabilize the flame propagation.

\subsection{Effect of operating condition on cycle-to-cycle variation}

Four hundred consecutive cycles were collected from experiments in the metal engine configuration that changed the fuel composition, spark timing, mixture equivalence ratio, and engine speed. This section evaluated the effects of the operating condition on the cycleto-cycle variations.

Four parameters were used to investigate the CCV. A traditional estimator of the CCV was the COV of IMEP. The second estimator used here was the COV of combustion duration $(\mathrm{DOC}=\mathrm{CA} 95-\mathrm{CA} 5)$. Similar to its previous use in the literature to evaluate $\mathrm{CCV}$, the statistical processing of the peak cylinder pressure (PCP) has also been used in this work. Therefore, the standard deviation (STD) and COV of PCP were the other two parameters used in this work to investigate CCV. IMEP measures engine's capacity to do work and is independent of engine displacement [12]. IMEP can be considered as the mean pressure acting on a piston during compression and expansion strokes. In other words, IMEP is a parameter that characterizes the whole combustion event. Consequently, COV of IMEP is a coefficient related to the whole combustion event [70]. Similarly, COV of DOC can be 
regarded as a qualitative cycle-integrated parameter [70]. In contrast, peak pressure was affected by the history of spark inception and the subsequent fully-developed turbulent flame propagation, but not affected by the late combusting period. Therefore, COV and

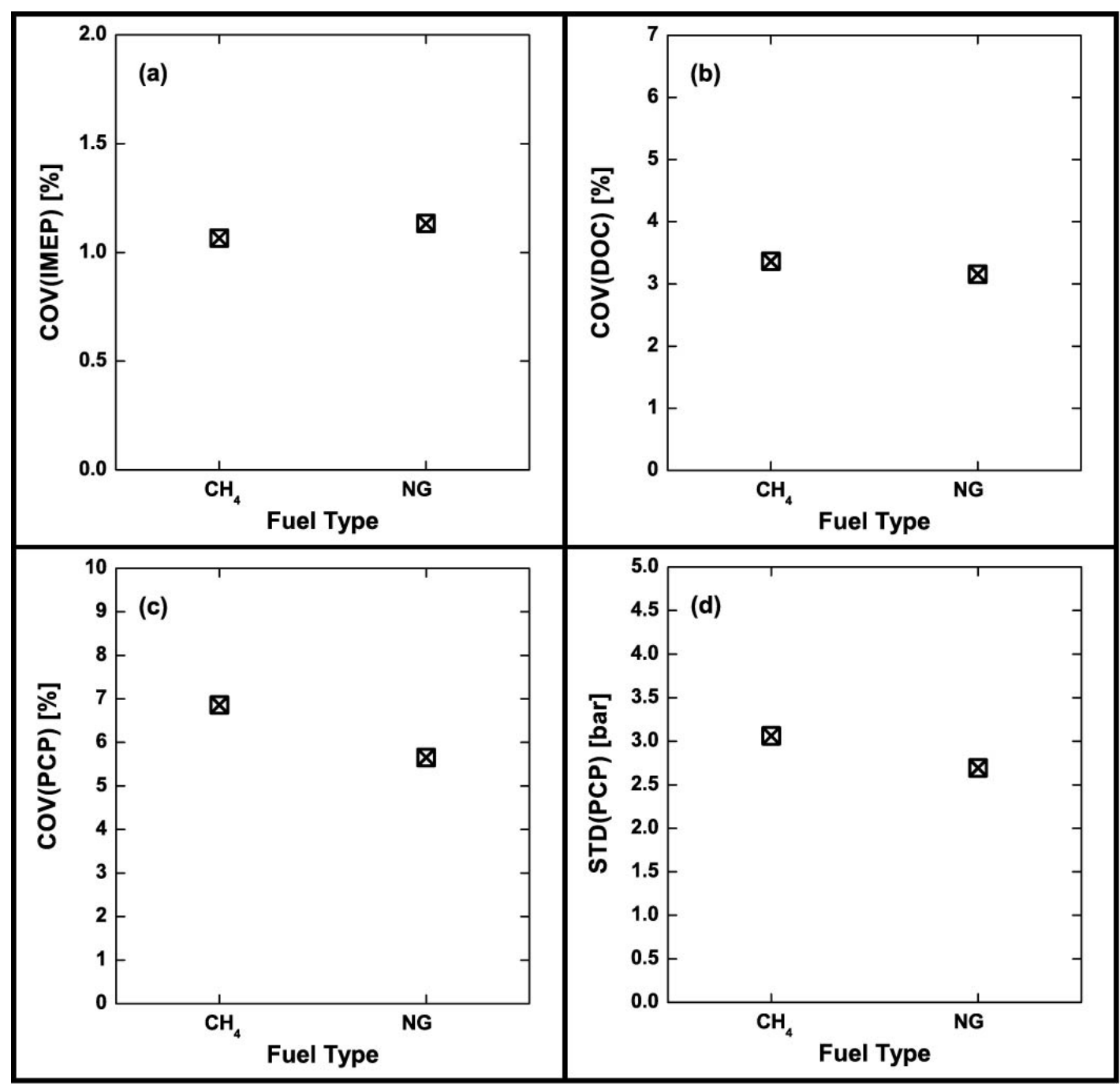

Figure 7.9 Effect of gas composition on cycle-to-cycle variation: (a) COV IMEP, (b) $\mathrm{COV}_{\mathrm{DOC}}$, (c) COV $\mathrm{PCP}$, and (d) STDPCP.

STD of peak pressure only partial characterized the combustion event.

Experiments were performed at baseline condition (-10 CAD ATDC ST, medium load, 
900rpm, $\phi=0.73$ for methane and $\phi=0.71$ for NG, see Table 2.3). Figure 7.9 shows the $\mathrm{COV}_{\text {IMEP }}$ for both fuels was lower than $2 \%$, indicating stable lean-burn operation. More, the $\mathrm{COV}_{\mathrm{PCP}}$ was under $7 \%$, hence the flame propagation was stable. To be specific, NG shows lower coefficient of variation and standard deviation of peak cylinder pressure, suggesting a lower cycle-to-cycle variation compared with $\mathrm{CH}_{4}$. This can be explained by the addition of heavier hydrocarbons to $\mathrm{CH}_{4}$, which improved the ignition process and
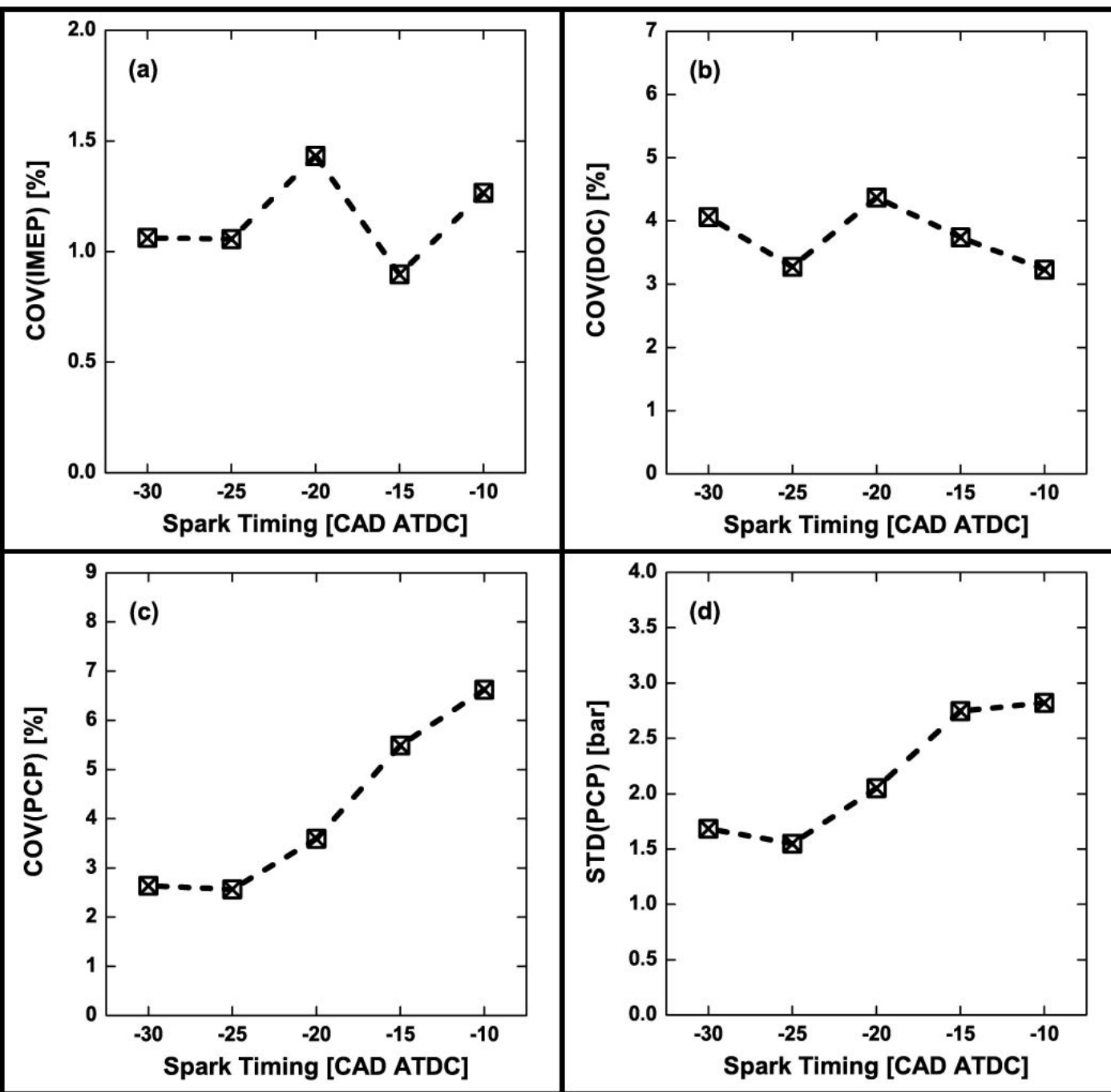

Figure 7.10 Effect of spark timing on cycle-to-cycle variation: (a) COV IMEP, (b) $\mathrm{COV}_{\mathrm{DOC}}$, (c) COV $\mathrm{PCP}$, and (d) STDPCP. 
increased the flame propagation speed, in turn helping to decrease the cycle-to-cycle variation [115]. Considering the small percentage of higher hydrocarbons for NG shown in Table 2.3, it seems that even small amounts of higher species of hydrocarbon additives produced a more stable combustion process compared to $\mathrm{CH}_{4}$ only. However, the traditional estimator $\mathrm{COV}_{\text {IMEP }}$ indicates $\mathrm{NG}$ operation had a higher $\mathrm{CCV}$, which was different from the conclusion from COVPCP. The work variation in the second stage of combustion (i.e., during the slow-burn) probably varied more for NG operation, which affected the overall IMEP. In addition, a smaller of $\mathrm{COV}_{\mathrm{DOC}}$ for NG operation further suggests a more stable combustion event than engine fueled with pure $\mathrm{CH}_{4}$.

Figure 7.10 shows the effect of spark timing (see Table 2.3 for operation conditions) on cycle-to-cycle variations. The lack of knocking and small $\mathrm{COV}_{\text {IMEP }}$ and $\mathrm{COV}_{\text {DOC }}$ values suggest stable combustion at all investigated STs. Advanced ST decreased the cycle-tocycle variation because it shifted the flame propagation at more favorable in-cylinder conditions for the flame development. This was true for COVPCP and STDPCP except at -30 CAD ATDC ST (as shown in Figure 7.10c), which can be explained by the late combustion effects. Specifically, Figure 5.7 indicates that, for the average pressure trace, the maximum pressure location was close to the position of the second peak of heat release rate located (also evidenced by reduced peak-growth trend at -30 CAD ATDC ST compared to delayed ST), which was also true for individual cycles. It can be concluded that the different phasing and intensity of the second heat release peak (shown in Figure 5.8) during the late 
burning period largely increased the variations in the peak cylinder pressure for $-30 \mathrm{CAD}$ ATDC ST. As to $\mathrm{COV}_{\text {IMEP }}$ and $\mathrm{COV}_{\mathrm{DOC}}$, they did not show the expected trend (i.e., advanced ST decreased the cycle-to-cycle variation, similar to the trend of COVPCP and STDPCP), which indicates that $\mathrm{COV}_{\mathrm{IMEP}}$ was not enough to properly evaluate the CCV for NG SI burning in a diesel-like environment, at least under the conditions investigated here.

This was probably due to the $\mathrm{COV}_{\text {IMEP }}$ being affected by the late combustion event, in

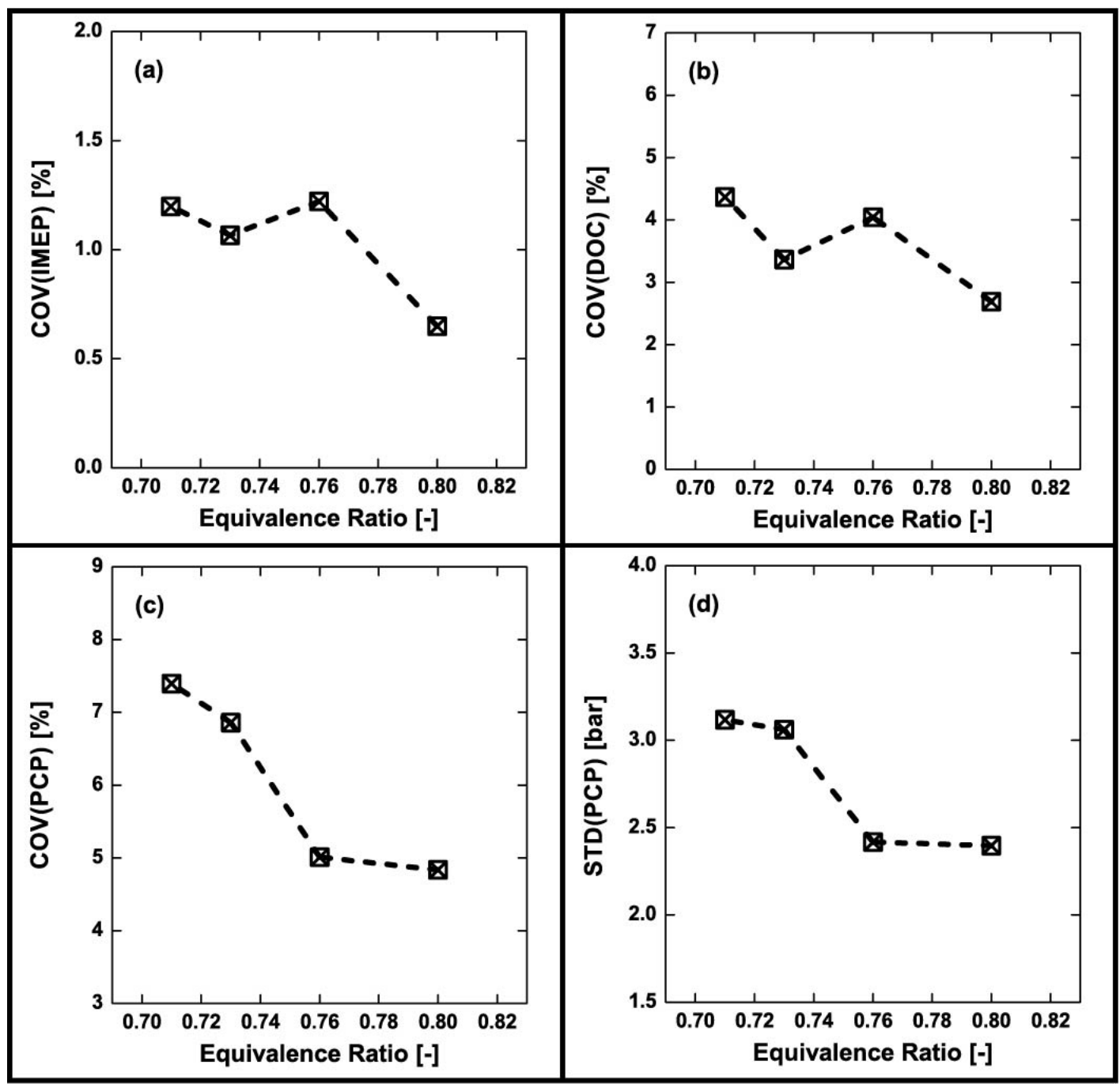

Figure 7.11 Effect of equivalence ratio on cycle-to-cycle variation: (a) COV IMEP $_{\text {, (b) }}$ $\mathrm{COV}_{\mathrm{DOC}}$, (c) COV $\mathrm{PCP}$, and (d) STDPCP. 
addition to many other factors such as the spark intensity and location, turbulence around spark and in the main combustion chamber, piston geometry, residual gas composition, operating conditions (spark timing, load, speed, and mixture equivalence ratio), etc.

Figure 7.11 presents several different lean burn mixtures (see Table 2.3 for operation conditions) influence on cycle-to-cycle variations. As $\phi$ decreased, the air to fuel ratio

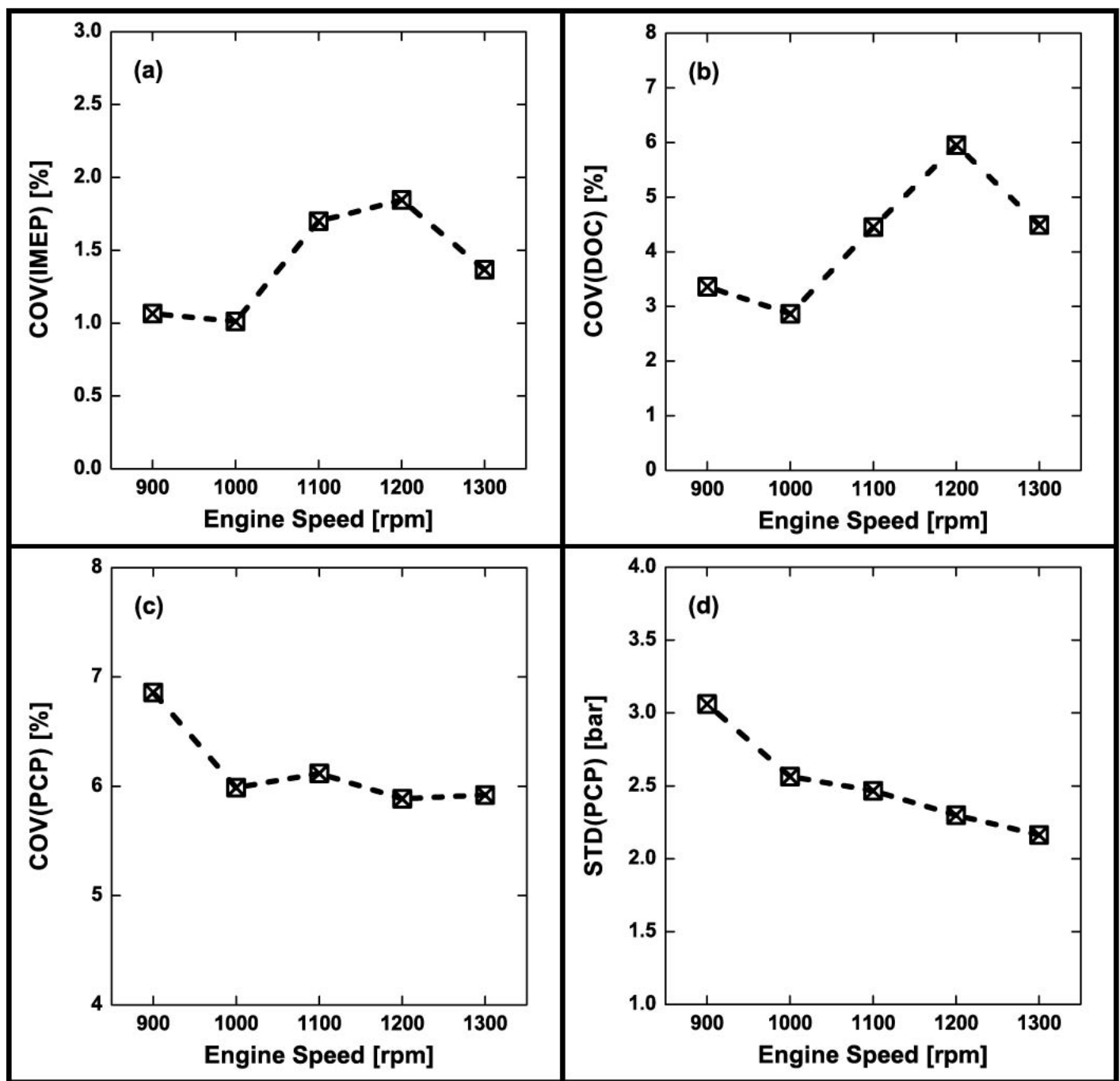

Figure 7.12 Effect of engine speed on cycle-to-cycle variation: (a) $\operatorname{COV}_{\text {IMEP }}$, (b) $\mathrm{COV}_{\mathrm{DOC}}$, (c) COV $\mathrm{PCP}$, and (d) STDPCP. 
increased, resulting in a lower adiabatic flame speed and occasional flame quenching and/or misfiring [12], especially when compared to stoichiometric operation. But the relative small values for $\mathrm{COV}_{\mathrm{IMEP}}$ and $\mathrm{COV}_{\mathrm{DOC}}$ shown in Figure 7.11 help alleviate this concern. A faster flame propagation can generally compensate for the differences in flame inception, hence the decreasing $\mathrm{CCV}$. This can be achieved by increasing the equivalence ratio or using a faster-burning fuel. The COVPCP and STDPCP, shown in Figure 7.11, agreed well with this hypothesis. However, the COVIMEP and COVDOC were not correlated with $\phi$, probably due to the late burn effects, which suggests that more parameters (such as COVPCP and STDPCP) are needed to correlate the cycle-to-cycle variations.

Figure 7.12 shows the cycle-to-cycle variation results for the engine speed sweep (see Table 2.3 for details). A low $\mathrm{COV}_{\text {IMEP }}$ irrespective of engine speed and fuel suggests no misfire cycles existed even under higher speed. It is also interesting that the STDPCP decreased with engine speed, probably due to the less time available for fuel to burn and the faster flame speed that decreased the differences in peak pressure under the premise of a good spark ignition event and no misfiring. However, COV IMEP and COV DOC shown in Figure 7.12 did not show any correlation with speed. This suggests that COVPCP and STDPCP would be better to evaluate the cycle-to-cycle variation for two-zone combustion, while $\mathrm{COV}_{\mathrm{IMEP}}$ that recorded the whole history of combustion would be good to evaluate power output variations that may affect vehicle drivability. 


\subsection{Summary}

Spark quality, fluid motion, and mixture composition varied with engine cycle, and therefore contributed to combustion variability. Cyclic differences in gas motion in the vicinity of the spark plug resulted in differences in motion of the flame kernel during its early stages of development. Differences in turbulence resulted in differences in the rates at which the initially smooth surface of the flame kernel became wrinkled and convoluted by the flow. Differences in the amount of fuel and air which enter each cylinder cycle-bycycle, the nonuniformity in composition of the entering charge, and any incomplete mixing of that entering charge with the residual gases in the cylinder also contributed to combustion variability. However, all these factors were within the direct control of this fast-burn combustion chamber, evidenced by the acceptable COVIMEP.

In addition, NG operation, advanced spark timing, higher equivalence ratio and higher engine speed seemed help to decrease the cycle-by-cycle variations for the conditions investigated here. Different initial flame development changed the interaction of the flame front with the squish later in the flame propagation process. Therefore, COVPCP and STDPCP were better for evaluating the cycle-to-cycle variation for the combustion event investigated here compared to the $\mathrm{COV}_{\mathrm{IMEP}}$ and $\mathrm{COV}_{\mathrm{DOC}}$ because they were less affected by the late burn phenomenon. 


\section{Chapter 8 Conclusions}

The increase of natural gas utilization for on- and off-road power applications can reduce U.S. dependence on imported oil and enhance national energy security. In a cost-oriented market like U.S., the conversion of existing diesel engines to natural gas spark-ignition operation with the least amount of engine and control modifications is an economical and promising approach for heavy-duty applications, which can be achieved by the addition of a gas injector in the intake manifold for fuel delivery and of a spark plug in place of the diesel injector to initiate and control combustion.

Existing studies indicate a slow and delayed late combusting period for natural gas burning in the original diesel bowl-in-piston combustion chamber, which is not representative of conventional spark ignited engines. It supports the hypothesis that natural gas premixed combustion inside a bowl-in-piston-and-flat-head geometry has substantial differences compared to the typical spark ignition regime. Consequently, the main objective of this dissertation was to improve the available information on natural gas flame propagation characteristics inside a bowl-in-piston combustion chamber, under lean burn conditions. Steady-state experiments, that changed gas composition, spark timing, mixture equivalence ratio, and engine speed, were performed to provide high-quality data for the $3 \mathrm{D}$ numerical models. In addition, the base engine was modified to an optical accessible configuration to obtain information that conventional measurements in all-metal engines cannot provide. 
Specifically, optical measurements of flame luminosity inside the piston's bowl were used to investigate flame inception and propagation, and the cycle-to-cycle variation. CFD simulations provided additional information on the turbulence distribution inside the combustion chamber, which would explain the flame propagation characteristics including flame propagation inside the (not-visualized) squish region, for all operating conditions investigated here. Based on both experimental and numerical studies conducted in this research, the following conclusions can be drawn:

- The G-equation-based RANS simulation agreed well with experimental data using a unique set of model tuning parameters, regardless of combustion chamber shape, fuel composition, spark timing, mixture equivalence, and engine speed. In addition, RANS simulation successfully captured physical quantities such as the geometric features.

- Optical measurements using a Bowditch piston provided valuable flame development characteristic of the metal configuration, from the early flame development to the time when flame touched the bowl edge. The cylindrical bowl provided better optical access and avoided image distortion issues. However, the cylindrical bowl bottom trapped an important mass of fuel that burned slowly, a phenomenon that would not seem to exist in the toroidal bowl. As a result, it was difficult to assess with certitude that the late combustion phenomena captured by 
the CMOS camera was representative of the metal engine operation.

- As the optical and metal engine configuration generated similar in-cylinder flow motion despite the different piston geometry, the optical engine can be used to investigate turbulence characteristics, such as the interaction between pistoninduced motion and swirl. Cold-flow measurements would be preferred because the combustion-induced motion seemed affected by the different bowl geometry.

- The squish created a strong radial inward movement into the bowl during compression. In addition, tumble was generated inside the bowl due to the interaction between the squish-generated flow and the flow generated by the upward piston movement. This resulted in a strong turbulence inside the bowl near top dead center compared to the low turbulence intensity inside the squish region. However, there was a moderate turbulence near the spark plug location, which both helped with flame inception and avoided flame extinction in its early stages. Moreover, in-cylinder motion moved the unburned mixture towards and away the flame front during compression and expansion, respectively.

- The differences in turbulence between the inside- and outside-the-bowl regions partitioned the lean burn natural gas combustion into two distinct events in terms of timing and location: a fast, thick flame inside the bowl and a slow, thinner, and 
delayed flame inside the squish region. Specifically, the inside the bowl experienced high turbulence, which increased the local turbulent flame speed, hence the high temperature of the combustion products behind the flame. The squish and bowl recess region experienced a much lower turbulence, which, combined with the reduced temperature and pressure during the expansion stroke, and the higher surface/volume ratio, reduced the turbulent flame speed. The slow burning event in the squish region can help explain the low slope of the heat release rate towards the end of combustion in existing studies. In addition, the lessfavorable conditions for the combustion in the squish region explained the increased carbon monoxide and unburned hydrocarbon emissions in such retrofitted engines.

- The fast combustion in the bowl region and high heat transfer in the squish region explained the lack of knocking in this 13.3 compression ratio natural gas spark ignition engine under lean-burn, medium-load, and low-speed conditions investigated here.

- The timing the flame front touched the bowl recess inside the bowl can be used to separate the $1^{\text {st }}$ and $2^{\text {nd }}$ combustion stages. An important fuel fraction burning in the late combustion stage can create a secondary peak in the apparent heat release rate towards the end of combustion. The operating conditions influenced the fuel fraction burning in the $2^{\text {nd }}$ combustion stage and also the overlapping/phasing of 
the fast- and slow-burn stages. For example, the addition of high hydrocarbons in the fuel gas decreased the burning duration of the $1^{\text {st }}$ stage combustion and therefore advanced the start of the $2^{\text {nd }}$ stage combustion to a more optimum condition, despite more evident late burn phenomenon (defined as the second peak or "bump" in the heat release rate after its main peak). Combined with a higher heating value, it increased the engine efficiency when the spark timing was retarded compared to the optimum. More, advanced spark timing increased the phasing difference between the fast- and slow-burn regions and the mass of fuel burning in the $2^{\text {nd }}$ combustion stage, which made the secondary peak in the apparent heat release rate more evident in both the individual and average engine cycles. Therefore, advanced spark timing resulted in a more frequent and higher intensity late burn phenomenon. Interestingly, the late burn phenomenon was also evident at optimal spark timing. The mixture equivalence ratio also controlled the magnitude of the late burn event, albeit in a more complex way. Higher equivalence ratio can advance the start of the burning event inside the squish region, which can reduce the late burn. However, a leaner mixture retarded the phasing of $1^{\text {st }}$ combustion stage and therefore burned more fuel in the squish region due to a larger vertical distance of the clearance height before the end of the fast-burn event, which also helped to alleviate the late burn. For increased engine speed at constant spark timing, the phasing of the $1^{\text {st }}$ combustion stage was retarded, which resulted in more overlapping of the two combustion stages and therefore less visible late burn phenomenon. 
- Peak cylinder pressure and its location, IMEP, thermal efficiency, CA10, and CA50 were correlated to changes in the fuel composition, spark timing, equivalence ratio, and engine speed. Specifically, the addition of ethane and propane increased flame propagation and the power output probably due to the higher heating value, better ignition quality, and higher flame propagation speed. Delayed spark timing, lower equivalence ratio, and higher engine speed would decrease the peak pressure, IMEP and retard the CA10, CA50, and peak pressure location. However, CA90 and combustion duration did not show any strong correlations, probably due to the late-combustion effects.

- The end of combustion and CA90 was not heavily affected by the operating conditions. Therefore, the traditional definition of rapid burning period (duration between CA10 and CA90) was not applicable to such retrofitted engines. However, the period between the inflection points in the apparent heat release rate can be used to define the fast-burn event in this study. CFD simulation results indicated that this simple method was effective. The trends of combustion duration, mass of fuel burned, and burn rate for each combustion stage were reasonable and echoed the effects of operating conditions summarized before.

- Optical measurements indicated that the spark event, flame inception, and flame propagation contributed to cycle-to-cycle variations. Specifically, spark intensity and arc location, in-cylinder motion, and mixture equivalence ratio around the spark plug influenced the flame propagation process. As a result, the flame initiated faster in one direction for several cycles and then propagated isotropically. 
Turbulence and mixture homogeneity inside the bowl, together with the intake swirl, determined the flame propagation such as its speed and direction. But a more successful kernel inception can generally advance the phasing of the $1^{\text {st }}$ combustion event and the start of $2^{\text {nd }}$ combustion stage. Variations in the mass of fuel that burned in the late combusting period also contributed to cycle-to-cycle variations. More, different combustion phasing, flame-turbulence interactions, heat loss rate also played important roles in the cycle-by-cycle variations. Despite the strong evidence of turbulent flame wrinkling seen in the movies of individual cycles, the cycle-averaged flame edge in the $2 \mathrm{D}$ images was relatively circular throughout the visualization period. This phenomenon validated the time-filtered RANS simulation approach that only resolved large-scale eddies and modeled the remaining scales.

- The addition of heavier hydrocarbons, advanced spark timing, higher equivalence ratio and higher engine speed decreased the cycle-by-cycle variations for the conditions investigated here. Variations in the initial flame development affected the interaction of the flame front with the squish later in the flame propagation process. Therefore, the coefficient of variation and standard deviation of peak cylinder pressure were needed to evaluate the cycle-to-cycle variation for the combustion event investigated here in addition to the coefficient of variation of IMEP and the combustion duration, because they were less affected by the late burn phenomenon. More, the coefficient of variation of IMEP would be efficient in evaluating power output variations that may affect vehicle drivability. 
- The low cycle-to-cycle variation (COV IEMP lower than $4 \%$ and $2 \%$ for optical and metal engine experiments, respectively), moderate pressure rise rate, and lack of knocking showed promise for heavy-duty compression ignited engines converted to natural gas lean-burn spark ignited operation.

- The slow-burning stage cannot be avoided in such retrofitted engines. As a result, optimum design and control should reduce the fuel fraction contained in the squish region at the end of the fast burn inside the bowl and/or advance the phasing of the second combustion stage. This can be achieved by optimizing the combustion chamber geometry and also tailoring the gas composition. 


\section{References}

[1] Liu, J., and C. E. Dumitrescu. "Combustion Visualization in a Single-Cylinder Heavy-Duty CI Engine Converted to Natural Gas SI Operation.” Proc. Eastern States Section of the Combustion Institute's Spring Technical Meeting, March 4-7, 2018. State College, PA, US, 2018.

[2] Varde, K. S., J. C. Cherng, C. J. Bailey, and W. A. Majewski. "Emissions and Their Control in Natural Gas Fueled Engines.” SAE Technical Paper, 922250, 1992.

[3] Li, H., G. A. Karim, and A. Sohrabi. "The Lean Mixture Operational Limits of a Spark Ignition Engine When Operated on Fuel Mixtures.” Journal of Engineering for Gas Turbines and Power 131, no. 1 (2009): 012801.

[4] Li, H., S. Liu, C. Liew, T. Gatts, S. Wayne, N. Clark, and J. Nuszkowski. “An Investigation of the Combustion Process of a Heavy-Duty Dual Fuel Engine Supplemented with Natural Gas or Hydrogen.” International Journal of Hydrogen Energy 42, no. 5 (2017): 3352-3362.

[5] Li, H., S. Liu, C. Liew, T. Gatts, S. Wayne, N. Clark, and J. Nuszkowski. “An Investigation of the Combustion Process of a Heavy-Duty Natural Gas-Diesel Dual Fuel Engine.” Journal of Engineering for Gas Turbines and Power 140, no. 9 (2018): 091502.

[6] Li, H., and G. A. Karim. "Modeling the Performance of a Turbo-Charged Spark Ignition Natural Gas Engine With Cooled Exhaust Gas Recirculation.” Journal of Engineering for Gas Turbines and Power 130, no. 3 (2008): 032804.

[7] Beck, N. J., R. L. Barkhimer, W. P. Johnson, H. C. Wong, and K. Gebert. "Evolution of Heavy Duty Natural Gas Engines - Stoichiometric, Carbureted and Spark Ignited to Lean Burn, Fuel Injected and Micro-Pilot.” SAE Technical Paper, 972665, 1997. 
[8] Cho, H. M., and B. Q. He. "Combustion and Emission Characteristics of a Lean Burn Natural Gas Engine." International Journal of Automotive Technology 9, no. 4 (2008): 415-422.

[9] Li, Y., H. Li, H. Guo, Y. Li, and M. Yao. "A Numerical Investigation on Methane Combustion and Emissions from a Natural Gas-Diesel Dual Fuel Engine Using CFD Model." Applied Energy 205 (2017): 153-162.

[10] Boretti, A., P. Lappas, B. Zhang, and S. K. Mazlan. "CNG Fueling Strategies for Commercial Vehicles Engines - A Literature Review.” SAE Technical Paper, 201301-2812, 2013.

[11] Weaver, C. S. "Natural Gas Vehicle - A Review of the State of the Art." SAE Transactions 98 (1989): 1190-1210.

[12] Heywood, J. B. "Internal Combustion Engine Fundamentals.” (1988).

[13] Golomb, D., and J. A. Fay. "The Role of Methane in Tropospheric Chemistry." (1989).

[14] DeLuchi, M. A., R. A. Johnston, and D. Sperling. "Transportation Fuels and the Greenhouse Effect.” Transportation Research Record 1175 (1988): 33-44.

[15] Bommisetty, H., J. Liu, R. Kooragayala, and C. E. Dumitrescu. "Fuel Composition Effects in a CI Engine Converted to SI Natural Gas Operation.” SAE Technical Paper, 2018-01-1137, 2018.

[16] McTaggart-Cowan, G. P., C. C. O. Reynolds, and W. K. Bushe. "Natural Gas Fuelling for Heavy-Duty On-Road Use: Current Trends and Future Direction." International Journal of Environmental Studies 63, no. 4 (2006): 421-440.

[17] Bolt, J. A., and D. H. Holkeboer. "Lean Fuel/Air Mixtures for High-Compression Spark-Ignited Engines.” SAE Technical Paper, 620524, 1962. 
[18] Jones, K., and D. M. Heaton. "Nebula Combustion System for Lean Burn Spark Ignited Gas Engines.” SAE Technical Paper, 890211, 1989.

[19] Karim, G. A., and I. Wierzba. "Experimental and Analytical Studies of the Lean Operational Limits in Methane Fuelled Spark Ignition and Compression Ignition Engines.” SAE Technical Paper, 891637, 1989.

[20] Klimstra, J.. "Performance of Lean-Burn Natural-Gas-Fueled Engines - On Specific Fuel Consumption, Power Capacity and Emissions.” SAE Transactions (1990): 460-472.

[21] Germane, G. J., C. G. Wood, and C. C. Hess. "Lean Combustion in Spark-Ignited Internal Combustion Engines - A Review.” SAE Technical Paper, 831694, 1983.

[22] Gupta, M., S. R. Bell, and S. T. Tillman. "An Investigation of Lean Combustion in a Natural Gas-Fueled Spark-Ignited Engine.” Journal of Energy Resources Technology 118, no. 2 (1996): 145-151.

[23] Li, H., G. A. Karim, and A. Sohrabi. "Knock and Combustion Characteristics of $\mathrm{CH}_{4}, \mathrm{CO}, \mathrm{H}_{2}$ and Their Binary Mixtures." SAE Technical Paper, 2003-01-3088, 2003.

[24] Johansson, B., and K. Olsson. "Combustion Chambers for Natural Gas SI Engines Part I: Fluid Flow and Combustion.” SAE Transactions (1995): 374-385.

[25] Chiu, J. P., J. Wegrzyn, and K. E. Murphy. "Low Emissions Class 8 Heavy-Duty On-Highway Natural Gas and Gasoline Engine.” SAE Technical Paper, 2004-012982, 2004.

[26] Eghbali, B.. "Natural Gas as a Vehicular Fuel.” SAE Technical Paper, 841159, 1984. 
[27] Li, H., and G. A. Karim. "Exhaust Emissions from an SI Engine Operating on Gaseous Fuel Mixtures Containing Hydrogen.” International Journal of Hydrogen Energy 30, no. 13-14 (2005): 1491-1499.

[28] Karim, G. A., and I. Wierzba. "Experimental and Analytical Studies of the Lean Operational Limits in Methane Fuelled Spark Ignition and Compression Ignition Engines.” SAE Technical Paper, 891637, 1989.

[29] Naber, J. D., D. L. Siebers, S. S. Di Julio, and C. K. Westbrook. "Effects of Natural Gas Composition on Ignition Delay under Diesel Conditions." Combustion and Flame 99, no. 2 (1994): 192-200.

[30] Amirante, R., E. Distaso, S. Di Iorio, P. Sementa, P. Tamburrano, B. M. Vaglieco, and R. D. Reitz. "Effects of Natural Gas Composition on Performance and Regulated, Greenhouse Gas and Particulate Emissions in Spark-Ignition Engines.” Energy Conversion and Management 143 (2017): 338-347.

[31] McTaggart-Cowan, G. P., S. N. Rogak, S. R. Munshi, P. G. Hill, and W. K. Bushe. "The Influence of Fuel Composition on a Heavy-Duty, Natural-Gas DirectInjection Engine.” Fuel 89, no. 3 (2010): 752-759.

[32] Malenshek, M., and D. B. Olsen. "Methane Number Testing of Alternative Gaseous Fuels.” Fuel 88, no. 4 (2009): 650-656.

[33] Ryan, T. W., T. J. Callahan, and Steve R. King. "Engine Knock Rating of Natural Gases - Methane Number.” Journal of Engineering for Gas Turbines and Power 115, no. 4 (1993): 769-776.

[34] Klimstra, J.. "Interchangeability of Gaseous Fuels - the Importance of the WobbeIndex.” SAE Technical Paper, 861578, 1986.

[35] Li, H., and G. A. Karim. “An Experimental Investigation of SI Engine Operation on Gaseous Fuels Lean Mixtures.” SAE Technical Paper, 2005-01-3765, 2005. 
[36] Feist, M. D., M. Landau, and E. Harte. "The Effect of Fuel Composition on Performance and Emissions of a Variety of Natural Gas Engines." SAE International Journal of Fuels and Lubricants 3, no. 2 (2010): 100-117.

[37] Clark, N. N., G. E. Mott, C. M. Atkinson, R. J. Atkinson, T. Latvakosky, and M. L. Traver. "Effect of Fuel Composition on the Operation of a Lean Burn Natural Gas Engine.” SAE Technical Paper, 952560, 1995.

[38] Liu, J., and C. E. Dumitrescu. "Flame Development Analysis in a Diesel Optical Engine Converted to Spark Ignition Natural Gas Operation.” Applied Energy 230 (2018): 1205-1217.

[39] Unich, A., R. M. Bata, and D. W. Lyons. "Natural Gas: A Promising Fuel for IC Engines.” SAE Technical Paper, 930929, 1993.

[40] Tahir, M. M., M. S. Ali, M. A. Salim, R. A. Bakar, A. M. Fudhail, M. Z. Hassan, and M. A. Muhaimin. "Performance Analysis of a Spark Ignition Engine Using Compressed Natural Gas (CNG) as Fuel.” Energy Procedia 68 (2015): 355-362.

[41] Bell, S. R., G. A. Loper, and Manishi Gupta. "Combustion Characteristics of a Natural Gas Fueled Spark Ignited Engine.” In Energy-Sources Technology Conference and Exhibition, Houston, TX, USA, 1993.

[42] Ramasamy, D., M. M. Noor, K. Kadirgama, and M. M. Rahman. "Analysis of Modifications on a Spark Ignition Engine for Operation with Natural Gas." In MATEC Web of Conferences, vol. 74, p. 00031. EDP Sciences, 2016.

[43] Fleming, R. D., and J. R. Allsup. "Emission Characteristics of Natural Gas as an Automotive Fuel.” SAE Technical Paper, 710833, 1971.

[44] Polcyn, N., M. Lai, and P. Lee. "Investigation of Ignition Energy with Visualization on a Spark Ignited Engine Powered by CNG.” SAE Technical Paper, 2014-01-1331, 2014. 
[45] Beck, N. J.. "Natural Gas - A Rational Approach to Clean Air." SAE Technical Paper, 902228, 1990.

[46] Liu, J., and C. E. Dumitrescu. "Lean-Burn Characteristics of a Heavy-Duty Diesel Engine Retrofitted to Natural Gas Spark Ignition.” ASME 2018 International Mechanical Engineering Congress and Exposition, American Society of Mechanical Engineers, IMECE2018-87761, 2018.

[47] Liu, J., H. Bommisetty, and C. E. Dumitrescu. "Experimental Investigation of a Heavy-Duty CI Engine Retrofitted to Natural Gas SI Operation.” ASME 2018 Internal Combustion Engine Division Fall Technical Conference, American Society of Mechanical Engineers, ICEF2018-9611, 2018.

[48] Li, H., G. A. Karim, and A. Sohrabi. "An Experimental and Numerical Investigation of Spark Ignition Engine Operation on $\mathrm{H}_{2}, \mathrm{CO}, \mathrm{CH}_{4}$, and Their Mixtures.” Journal of Engineering for Gas Turbines and Power 132, no. 3 (2010): 032804.

[49] Li, H., and G. A. Karim. "Experimental Investigation of the Knock and Combustion Characteristics of $\mathrm{CH}_{4}, \mathrm{H}_{2}, \mathrm{CO}$, and Some of Their Mixtures." Proceedings of the Institution of Mechanical Engineers, Part A: Journal of Power and Energy 220, no. 5 (2006): 459-471.

[50] Hofeldt, D. L. "Alternative Fuel Technologies for Heavy Duty Vehicles: Performance, Emissions, Economics, Safety, and Development Status." SAE Technical Paper, 930731, 1993.

[51] Stocchi, I., J. Liu, Dumitrescu, and C. E. Dumitrescu. "Effect of Piston Crevices on 3D Simulation of a Heavy-Duty Diesel Engine Retrofitted to Natural Gas Spark Ignition." ASME 2018 International Mechanical Engineering Congress and Exposition, American Society of Mechanical Engineers, IMECE2018- 87783, 2018. 
[52] Chown, D., C. Habbaky, and J. S. Wallace. "An Experimental Investigation of Combustion Chamber Design Parameters for Hot Surface Ignition." ASME 2014 Internal Combustion Engine Division Fall Technical Conference, American Society of Mechanical Engineers, ICEF2014-5646, 2014.

[53] Fabbroni, M., and J. S. Wallace. "Flame Propagation in Natural Gas Fueled Direct Injection Engines.” ASME 2010 Internal Combustion Engine Division Fall Technical Conference, American Society of Mechanical Engineers, ICEF2010$35182,2010$.

[54] Snyder, W. E., and S. G. Dexter. "Looking into a Lean Burn Spark Ignited Gas Engine." In The Thirteenth Annual Energy-Sources Technology Conference and Exhibition, New Orleans, Luisiana, January, pp. 14-18. 1989.

[55] Snyder, W. E., M. R. Wright, and S. G. Dexter. "A Natural Gas Engine Combustion Rig with High-Speed Photography.” Journal of Engineering for Gas Turbines and Power 110, no. 3 (1988): 334-342.

[56] Li, Y., H. Li, and H. Guo. "A Numerical Investigation on $\mathrm{NO}_{2}$ Formation Reaction Pathway in a Natural Gas-Diesel Dual Fuel Engine.” Combustion and Flame 190 (2018): 337-348.

[57] Li, Y., H. Li, H. Guo, H. Wang, and M. Yao. "A Numerical Study on the Chemical Kinetics Process during Auto-Ignition of N-Heptane in a Direct Injection Compression Ignition Engine.” Applied Energy 212 (2018): 909-918.

[58] Dumitrescu, C. E., V. Padmanaban, and J. Liu. "An Experimental Investigation of Early Flame Development in an Optical Spark Ignition Engine Fueled With Natural Gas.” Journal of Engineering for Gas Turbines and Power 140, no. 8 (2018): 082802 . 
[59] Clarke, D. P., C. H. Such, M. T. Overington, and P. K. Das. "A Lean Burn Turbocharged, Natural Gas Engine for the US Medium Duty Automotive Market." SAE Technical Paper, 921552, 1992.

[60] Donateo, T., F. Tornese, and D. Laforgia. "Computer-Aided Conversion of an Engine from Diesel to Methane." Applied Energy 108 (2013): 8-23.

[61] Zheng, J., Z. Huang, J. Wang, B. Wang, D. Ning, and Y. Zhang. "Effect of Compression Ratio on Cycle-by-Cycle Variations in a Natural Gas Direct Injection Engine.” Energy \& Fuels 23, no. 11 (2009): 5357-5366.

[62] Zheng, J., X. Chen, T. Hu, and Z. Zhan. "The Research Development in Direct Injection Spark-Ignition Natural Gas Engine.” In Proceedings of the FISITA 2012 World Automotive Congress, pp. 51-63. Springer, Berlin, Heidelberg, 2013.

[63] Liu, J., and C. E. Dumitrescu. "Numerical Simulation of Re-Entrant Bowl Effects on Natural Gas SI Operation.” ASME 2018 Internal Combustion Engine Division Fall Technical Conference, American Society of Mechanical Engineers, ICEF20189609, 2018.

[64] Elgin, R. C., C. W. Turner, and C. L. Hagen. "Combustion Chamber Design Considerations for a Compression Ignition Engine to Spark Ignited Natural Gas Engine Conversion." In Western States Section of the Combustion Institute, Fall Technical Meeting, Fort Collins, CO. 2013.

[65] McMillian, M., S. Richardson, S. D. Woodruff, and D. McIntyre. "Laser-Spark Ignition Testing in a Natural Gas-Fueled Single-Cylinder Engine.” SAE Technical Paper, 2004-01-0980, 2004.

[66] McIntyre, D. L., S. D. Woodruff, and J. S. Ontko. "Lean-Burn Stationary Natural Gas Engine Operation with a Prototype Laser Spark Plug.” Journal of Engineering for Gas Turbines and Power 132, no. 7 (2010): 072804. 
[67] Kakaee, A., A. Paykani, and M. Ghajar. "The Influence of Fuel Composition on the Combustion and Emission Characteristics of Natural Gas Fueled Engines." Renewable and Sustainable Energy Reviews 38 (2014): 64-78.

[68] Zuo, C., and J. Zhao. "Development of Diesel Engines Fuelled with Natural Gas." SAE Technical Paper, 2001-01-3505, 2001.

[69] Liu, J., and C. E. Dumitrescu. "3D CFD Simulation of a CI Engine Converted to SI Natural Gas Operation Using the G-Equation.” Fuel 232 (2018): 833-844.

[70] Reyes, M., F. V. Tinaut, B. Giménez, and A. Pérez. "Characterization of Cycle-toCycle Variations in a Natural Gas Spark Ignition Engine.” Fuel 140 (2015): 752761.

[71] Olsson, K., and B. Johansson. "Combustion Chambers for Natural Gas SI Engines Part 2: Combustion and Emissions." SAE Transactions (1995): 499-511.

[72] Yan, B., H. Wang, Z. Zheng, Y. Qin, and M. Yao. "The Effect of Combustion Chamber Geometry on In-Cylinder Flow and Combustion Process in a Stoichiometric Operation Natural Gas Engine with EGR.” Applied Thermal Engineering 129 (2018): 199-211.

[73] Poulos, S. G., and J. B. Heywood. "The Effect of Chamber Geometry on SparkIgnition Engine Combustion.” SAE Transactions (1983): 1106-1129.

[74] Raine, R. R., J. Stephenson, and S. T. Elder. "Characteristics of Diesel Engines Converted to Spark Ignition Operation Fuelled with Natural Gas.” SAE Technical Paper, 880149, 1988.

[75] Meyer, R., D. Meyers, S. M. Shahed, and V. K. Duggal. "Development of a Heavy Duty On-Highway Natural Gas-Fueled Engine.” SAE Technical Paper, 922362, 1992. 
[76] U.S. Energy Information Administration. "Annual Energy Outlook 2016 (AEO 2016).” No. DOE/EIA-0383, 2016.

[77] G Cussons LTD. "Proteus Single Cylinder Research Engine Instruction Manual."

[78] Woschni, G.. "A Universally Applicable Equation for the Instantaneous Heat Transfer Coefficient in the Internal Combustion Engine." SAE Technical paper, 670931, 1967.

[79] Kashdan, J. T., and B. Thirouard. "A Comparison of Combustion and Emissions Behaviour in Optical and Metal Single-Cylinder Diesel Engines." SAE International Journal of Engines 2, no. 1 (2009): 1857-1872.

[80] Colban, Will F., D. Kim, P. C. Miles, S. Oh, R. Opat, R. Krieger, D. Foster, R. P. Durrett, and M. A. Gonzalez D. "A Detailed Comparison of Emissions and Combustion Performance Between Optical and Metal Single-Cylinder Diesel Engines at Low Temperature Combustion Conditions.” SAE International Journal of Fuels and Lubricants 1, no. 1 (2009): 505-519.

[81] Aronsson, U., C. Chartier, U. Horn, Ö. Andersson, B. Johansson, and R. Egnell. "Heat Release Comparison between Optical and All-Metal HSDI Diesel Engines." SAE Technical Paper, 2008-01-1062, 2008.

[82] Jain, A. K. "Fundamentals of Digital Image Processing." Englewood Cliffs, NJ: Prentice Hall, 1989.

[83] Otsu, N.. "A Threshold Selection Method from Gray-Level Histograms.” IEEE Transactions on Systems, Man, and Cybernetics 9, no. 1 (1979): 62-66.

[84] Duda, R. O., and P. E. Hart. "Pattern Classification and Scene Analysis." A WileyInterscience Publication, New York: Wiley, 1973 (1973). 
[85] Levenberg, K.. "A Method for the Solution of Certain Non-Linear Problems in Least Squares.” Quarterly of Applied Mathematics 2, no. 2 (1944): 164-168.

[86] Huang, Q., W. Gao, and W. Cai. "Thresholding Technique with Adaptive Window Selection for Uneven Lighting Image.” Pattern Recognition Letters 26, no. 6 (2005): 801-808.

[87] Steeper, R. R., and E. J. Stevens. "Characterization of Combustion, Piston Temperatures, Fuel Sprays, and Fuel-Air Mixing in a DISI Optical Engine.” SAE Technical Paper, 2000-01-2900, 2000.

[88] ANSYS ${ }^{\circledR}$ Forte. “User Guide.” Ansys, Inc, Release 17.2.

[89] Peters, N.. “Turbulent combustion.” Cambridge University Press, 2000.

[90] Tan, Z., and R. D. Reitz. "Modeling Ignition and Combustion in Spark-Ignition Engines using a Level Set Method.” SAE Transactions (2003): 1028-1040.

[91] Tan, Z., and R.D. Reitz. "An Ignition and Combustion Model based on the LevelSet Method for Spark Ignition Engine Multidimensional Modeling." Combustion and Flame 145, no. 1-2 (2006): 1-15.

[92] Herweg, R., and R. R. Maly. “A Fundamental Model for Flame Kernel Formation in SI Engines." SAE Transactions (1992): 1947-1976.

[93] Liang, L., R. D. Reitz, J. Yi, and C. O. Iyer. "A G-Equation Combustion Model Incorporating Detailed Chemical Kinetics for PFI/DI SI Engine Simulations.” In SAE Congress April, vol. 2. 2006.

[94] Tan, Z., S. Kong, and R. D. Reitz. "Modeling Premixed and Direct Injection SI Engine Combustion using the G-Equation Model." SAE Transactions (2003): 12981309.

[95] ANSYS® Chemkin. “Chemkin-Pro Theory Manual.” Ansys, Inc, Release 17.2. 
[96] Guest, P. G. "Numerical Methods of Curve Fitting." Cambridge University Press, 2012.

[97] Gülder, Ö. L. "Correlations of Laminar Combustion Data for Alternative SI Engine Fuels.” SAE Technical Paper, 841000, 1984.

[98] ANSYS ${ }^{\circledR}$ Forte. “Forte Theory.” Ansys, Inc, Release 17.2.

[99] Han, Z., and R. D. Reitz. "Turbulence Modeling of Internal Combustion Engines

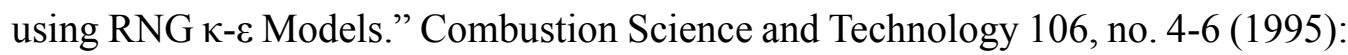
267-295.

[100] Yakhot, V., and S. A. Orszag. "Renormalization Group Analysis of Turbulence. I. Basic Theory.” Journal of Scientific Computing 1, no. 1 (1986): 3-51.

[101] Fröhlich, J., and D. V. Terzi. "Hybrid LES/RANS Methods for the Simulation of Turbulent Flows.” Progress in Aerospace Sciences 44, no. 5 (2008): 349-377.

[102] Heywood, J. B. “Combustion and its Modeling in Spark-Ignition Engines.” In International symposium COMODIA, vol. 94, pp. 1-15. 1994.

[103] Verma, I., E. Bish, M. Kuntz, E. Meeks, K. Puduppakkam, C. Naik, and L. Liang. "CFD Modeling of Spark Ignited Gasoline Engines-Part 1: Modeling the Engine under Motored and Premixed-Charge Combustion Mode." SAE Technical Paper, 2016-01-0591, 2016.

[104] Verma, I., E. Bish, M. Kuntz, E. Meeks, K. Puduppakkam, C. Naik, and L. Liang. "CFD Modeling of Spark Ignited Gasoline Engines-Part 2: Modeling the Engine in Direct Injection Mode along with Spray Validation.” SAE Technical Paper, 201601-0579, 2016.

[105] Yang, S., R. D. Reitz, C. O. Iyer, and J. Yi. "Improvements to Combustion Models for Modeling Spark-Ignition Engines using the G-Equation and Detailed Chemical 
Kinetics.” SAE International Journal of Fuels and Lubricants 1, no. 1 (2009): 10091025.

[106] Reitz, R. D. “Assessment of Wall Heat Transfer Models for Premixed-Charge Engine Combustion Computations.” SAE Transactions (1991): 397-413.

[107] Han, Z., and R. D. Reitz. "A Temperature Wall Function Formulation for VariableDensity Turbulent Flows with Application to Engine Convective Heat Transfer Modeling.” International Journal of Heat and Mass Transfer 40, no. 3 (1997): 613625.

[108] Liu, J., J. P. Szybist, and C. E. Dumitrescu. "Choice of Tuning Parameters on 3D IC Engine Simulations Using G-Equation.” SAE Technical Paper, 2018-01-0183, 2018.

[109] Langness, C., and C. Depcik. "Statistical Analyses of CNG Constituents on DualFuel Compression Ignition Combustion.” SAE Technical Paper, 2016-01-0802, 2016.

[110] Kim, K., H. Kim, B. Kim, and K. Lee. "Effect of Natural Gas Composition on the Performance of a CNG Engine.” Oil \& Gas Science and Technology-Rev. IFP 64, no. 2 (2009): 199-206.

[111] Li, H., T. Gatts, S. Liu, S. Wayne, N. Clark, and D. Mather. "An Experimental Investigation on the Combustion Process of a Simulated Turbocharged Spark Ignition Natural Gas Engine Operated on Stoichiometric Mixture.” Journal of Engineering for Gas Turbines and Power 140, no. 9 (2018): 091504.

[112] Burcat, A., K. Scheller, and A. Lifshitz. "Shock-Tube Investigation of Comparative Ignition Delay Times for C1-C5 Alkanes.” Combustion and Flame 16, no. 1 (1971): 29-33. 
[113] Spadaccini, L. J., and M. B. Colket Iii. "Ignition Delay Characteristics of Methane Fuels.” Progress in Energy and Combustion Science 20, no. 5 (1994): 431-460.

[114] Cartellieri, W., F. G. Chmela, P. E. Kapus, and R. M. Tatschl. "Mechanisms Leading to Stable and Efficient Combustion in Lean Burn Gas Engines.” In Proceedings of International Symposium COMODIA, 1994.

[115] Kreutzer, C. J., D. B. Olsen, and R. J. Bremmer. "Evaluation of a Lean-Burn Natural Gas Engine Operating on Variable Methane Number Fuel.” ASME 2011 Internal Combustion Engine Division Fall Technical Conference, American Society of Mechanical Engineers, ICEF2011-60071, 2011. 